\title{
Child Injury Prevention
}

\author{
Edited by \\ David C. Schwebel
}

Printed Edition of the Special Issue Published in IJERPH 
David C. Schwebel (Ed.)

\section{Child Injury Prevention}


This book is a reprint of the special issue that appeared in the online open access journal International Journal of Environmental Research and Public Health (ISSN 1660-4601) in 2013 (available at: http://www.mdpi.com/journal/ijerph/special_issues/child-injuryprevention).

Guest Editor

David C. Schwebel

Department of Psychology, University of Alabama at Birmingham,

Birmingham, AL, USA

\section{Editorial Office}

MDPI AG

Klybeckstrasse 64

Basel, Switzerland

Publisher

Shu-Kun Lin

Production Editor

Martyn Rittman

\section{Edition 2014}

MDPI • Basel, Switzerland

ISBN 978-3-906980-49-2

(C) 2014 by the authors; licensee MDPI, Basel, Switzerland. All articles in this volume are Open Access distributed under the Creative Commons Attribution 3.0 license (http://creativecommons.org/licenses/by/3.0/), which allows users to download, copy and build upon published articles even for commercial purposes, as long as the author and publisher are properly credited, which ensures maximum dissemination and a wider impact of our publications. However, the dissemination and distribution of copies of this book as a whole is restricted to MDPI, Basel, Switzerland. 


\section{Table of Contents}

Preface vi

\section{Karl Peltzer and Supa Pengpid}

Injury and Social Correlates among in-School Adolescents in Four Southeast

Asian Countries 1

Reprinted from Int. J. Environ. Res. Public Health 2012, 9(8), 2851-2862;

doi:10.3390/ijerph9082851; http://www.mdpi.com/1660-4601/9/8/2851

\section{Aaron L. Davis, David C. Schwebel, Barbara A. Morrongiello, Julia Stewart and Melissa Bell}

Dog Bite Risk: An Assessment of Child Temperament and Child-Dog Interactions

Reprinted from Int. J. Environ. Res. Public Health 2012, 9(8), 3002-3013;

doi:10.3390/ijerph9083002; http://www.mdpi.com/1660-4601/9/8/3002

\section{Mariana Brussoni, Lise L. Olsen, Ian Pike and David A. Sleet}

Risky Play and Children's Safety: Balancing Priorities for Optimal

Child Development

Reprinted from Int. J. Environ. Res. Public Health 2012, 9(9), 3134-3148;

doi:10.3390/ijerph9093134; http://www.mdpi.com/1660-4601/9/9/3134

\section{Silvia Snidero, Nicola Soriani, Ileana Baldi, Federica Zobec, Paola Berchialla and Dario Gregori}

Scale-Up Approach in CATI Surveys for Estimating the Number of Foreign

Body Injuries in the Aero-digestive Tract in Children

Reprinted from Int. J. Environ. Res. Public Health 2012, 9(11), 4056-4067;

doi:10.3390/ijerph9114056; http://www.mdpi.com/1660-4601/9/11/4056

\section{Michael L. Wilson, Andrea C. Dunlavy, Bharathi Viswanathan and Pascal Bovet}

Suicidal Expression among School-Attending Adolescents in a Middle-Income

Sub-Saharan Country....

Reprinted from Int. J. Environ. Res. Public Health 2012, 9(11), 4122-4134;

doi:10.3390/ijerph9114122; http://www.mdpi.com/1660-4601/9/11/4122 
Xin Xia, Joe Xiang, Jianbo Shao, Gary A. Smith, Chuanhua Yu, Huiping Zhu and Huiyun Xiang

Characteristics and Trends of Hospitalized Pediatric Abuse Head Trauma in Wuhan,

China: 2002-2011 65

Reprinted from Int. J. Environ. Res. Public Health 2012, 9(11), 4187-4196;

doi:10.3390/ijerph9114187; http://www.mdpi.com/1660-4601/9/11/4187

Mirjam E. J. van Beelen, Eduard F. van Beeck, Paul den Hertog,

Tinneke M. J. Beirens and Hein Raat

Correlates of Unsupervised Bathing of Infants: A Cross-Sectional Study .76

Reprinted from Int. J. Environ. Res. Public Health 2013, 10(3), 856-866; doi:10.3390/ijerph10030856; http://www.mdpi.com/1660-4601/10/3/856

\section{Jiabin Shen, Shaohua Li, Huiyun Xiang, Shulan Pang, Guozhang Xu} and David C. Schwebel

A Multi-Site Study on Knowledge, Attitudes, Beliefs and Practice of Child-Dog Interactions in Rural China 87

Reprinted from Int. J. Environ. Res. Public Health 2013, 10(3), 950-962; doi:10.3390/ijerph10030950; http://www.mdpi.com/1660-4601/10/3/950

\section{Aruna Chandran, Uzma Rahim Khan, Nukhba Zia, Asher Feroze, Sarah Stewart} de Ramirez, Cheng-Ming Huang, Junaid A. Razzak and Adnan A. Hyder

Disseminating Childhood Home Injury Risk Reduction Information in Pakistan:

Results from a Community-Based Pilot Study. 100

Reprinted from Int. J. Environ. Res. Public Health 2013, 10(3), 1113-1124;

doi:10.3390/ijerph10031113; http://www.mdpi.com/1660-4601/10/3/1113

\section{Phaedra S. Corso, Justin B. Ingels and M. Isabel Roldos}

A Comparison of Willingness to Pay to Prevent Child Maltreatment Deaths

in Ecuador and the United States

Reprinted from Int. J. Environ. Res. Public Health 2013, 10(4), 1342-1355;

doi:10.3390/ijerph10041342; http://www.mdpi.com/1660-4601/10/4/1342

\section{Jean Simpson, Geoff Fougere and Rob McGee}

A Wicked Problem: Early Childhood Safety in the Dynamic, Interactive Environment of Home 126

Reprinted from Int. J. Environ. Res. Public Health 2013, 10(5), 1647-1664; doi:10.3390/ijerph10051647; http://www.mdpi.com/1660-4601/10/5/1647 


\section{Preface}

Injuries are among the leading causes of child morbidity and mortality worldwide [1]. Because injuries typically are incurred by healthy children engaging in daily activities, they can be particularly devastating to the injured child and his or her family, disrupting otherwise mentally and physically healthy lives with tragic short- and long-term consequences.

Despite the implication of the lay term "accident", injuries are preventable. The global community of scholars and practitioners is slowly creating, discovering, and implementing programs to reduce the burden of injury on the world's youth. This volume contributes to those objectives.

\section{The Need for Diverse Perspectives}

Each injury to a child is caused by a complex intersection of multiple behavioral, environmental, and contextual factors. Unlike communicable diseases, which are normally caused by a single pathogen that can be countered with an appropriate pharmaceutical treatment, injuries are caused by multiple factors that coincide to create a negative outcome without an obvious treatment or prevention strategy. Prevention might occur via blockage of any number of pathways to injury. To offer an example, consider a child pedestrian struck by a motorist while crossing an urban street in Manila. A multitude of factors may have prevented that injury. The driver might have driven more slowly, without distraction, or with sunglasses to reduce glare. The child may have made a better judgment about the vehicle's speed or the driver's ability to stop quickly. A parent may have accompanied the child walking to school. Traffic engineers may have reduced the road's speed limit, installed speed bumps, or painted a crosswalk on the road. Filipino authorities might encourage children under age 10 to ride buses to school rather than walking. And so on.

Because injuries are caused — and prevented — by a wide range of factors, scholarly work in injury prevention must be multi-disciplinary and multifaceted. This special issue volume reflects that need. Study populations reported in the 11 articles were recruited from 13 nations - Canada, China, Ecuador, Indonesia, Italy, Myanmar, Netherlands, New Zealand, Pakistan, Seychelles, Sri Lanka, Thailand, and the United States - on six continents. Study authors include psychologists, epidemiologists, physicians, and other professionals. Methodological strategies include economic cost-benefit analyses, mathematical modeling, randomized intervention trials, epidemiological work at the population level, experimental work in a laboratory, and hospital medical records review. Together, this geographic and scholarly diversity represents beautifully the many approaches required to reduce the burden of child injury.

This volume also offers a glimpse of the work needed to improve global child public health, but it is just a glimpse into a broad and gaping aperture. The authors are to be commended for their efforts, as they inspire us to collaborate and move together toward reducing the tremendous burden of injury on the children of the world. 
Eleven articles are included in this volume. Two sets of authors present probing and insightful review and commentary papers. Simpson and colleagues address cultural aspects of one form of child injury, injuries to young children in the home, with a focus on their native country of New Zealand [2]. They specifically discuss the need to examine the complex dynamic issues that create injury situations in that context. Brussoni and colleagues offer a different and novel perspective to the child injury prevention field: we must encourage child development and risky outdoor play within the confines of keeping children safe from serious injury [3]. Through a provocative discussion, the authors offer persuasive evidence that play is necessary for healthy child development and growth.

Several of the included manuscripts examine large-scale, population-level injury data. Shen and colleagues offer epidemiological and behavioral data concerning dog bite risk from a sample of over 1,500 children living in three regions of rural China [4]. They found over $30 \%$ of the sample had a history of dog bites, and various demographic, cognitive and behavioral factors were related to risk of bites. Van Beelen and colleagues used a similar strategy to survey over 1,400 Dutch parents with an infant and evaluate parent supervision strategies during bathing [5]. Over $6 \%$ of parents admitted to leaving their infants unsupervised in the bathtub, and various demographic and cognitive factors were associated with this tendency.

Wilson and colleagues report data from adolescents in the African island nation of the Seychelles [6]. They found that an alarming $16 \%$ of adolescents in the sample reported suicidal expression, with $10 \%$ describing a specific plan for suicide. Correlates of suicide expression are outlined. Peltzer and Pengpid examined epidemiological data from over 9,000 adolescents in Indonesia, Myanmar, Sri Lanka, and Thailand [7]. They report on epidemiology of serious injuries among those adolescents and examine demographic and psychosocial correlates of injury prevalence. Rather than surveying individuals, Xia and colleagues conducted a review of hospital records at a large pediatric medical center in China, studying all traumatic brain injury cases for patients $0-4$ years old to identify and describe suspected child abuse cases [8].

Two other papers examine population-level data, but do so via alternative methodological strategies. Corso and colleagues conducted an economic cost-benefit analysis of strategies to reduce child maltreatment deaths both in the United States and Ecuador, and concluded that estimating benefits in one culture may not transfer to another culture [9]. Snidero and colleagues present mathematical modeling designed to estimate the number of foreign body choking injuries among children in Italy [10]. Using sophisticated modeling to overcome missing data for self-resolved child injuries, they conclude that a large number of Italian children likely suffer from non-medically-treated choking injuries each year.

Finally, two studies utilize smaller samples to study child injury risks. Davis and colleagues present data from a structured laboratory study examining the role of child temperament on risk-taking with dogs and risk of dog bite injuries [11]. They report shyness is associated with safer behavior with a dog, even after controlling for relevant child and dog characteristics. Chandran and colleagues describe a randomized trial designed to reduce hazards in the homes of low-income neighborhoods in Pakistan [12]. They found that families receiving an in-home tutorial on safety 
were more likely to protect their children from drowning and burn risks compared to families receiving only a pamphlet about safety.

\section{Conclusions}

This volume offers eleven manuscripts dedicated to understanding and preventing injuries to children worldwide. They offer diverse scholarly perspectives, methodological approaches, and geographic targets, but together they form a collection of ideas and programs that will chip away at the public health burden of child injuries. Thanks to the authors for their persistence in studying a challenging health topic and their continued dedication to achieve healthier and happier lives for the youth of our world.

David C. Schwebel, Ph.D.

Guest Editor

\section{References}

1. World report on Child Injury Prevention. World Health Organization: Geneva, Switzerland, 2008.

2. Simpson, J.; Fougere, G.; McGee, R. A Wicked Problem: Early Childhood Safety in the Dynamic, Interactive Environment of Home. Int. J. Environ. Res. Public Health 2013, 10, 1647-1664.

3. Brussoni, M.; Olsen, L.L.; Pike, I.; Sleet, D.A. Risky Play and Children's Safety: Balancing Priorities for Optimal Child Development. Int. J. Environ. Res. Public Health 2012, 9, 3134-3148.

4. Shen, J.; Li, S.; Xiang, H.; Pang, S.; Xu, G.; Schwebel, D.C. A Multi-Site Study on Knowledge, Attitudes, Beliefs and Practice of Child-Dog Interactions in Rural China. Int. J. Environ. Res. Public Health 2013, 10, 950-962.

5. Van Beelen, M.E.J.; van Beeck, E.F.; den Hertog, P.; Beirens, T.M.J.; Raat, H. Correlates of Unsupervised Bathing of Infants: A Cross-Sectional Study. Int. J. Environ. Res. Public Health 2013, 10, 856-866.

6. Wilson, M.L.; Dunlavy, A.C.; Viswanathan, B.; Bovet, P. Suicidal Expression among School-Attending Adolescents in a Middle-Income Sub-Saharan Country. Int. J. Environ. Res. Public Health 2012, 9, 4122-4134.

7. Peltzer, K.; Pengpid, S. Injury and Social Correlates among in-School Adolescents in Four Southeast Asian Countries. Int. J. Environ. Res. Public Health 2012, 9, 2851-2862.

8. Xia, X.; Xiang, J.; Shao, J.; Smith, G.A.; Yu, C.; Zhu, H.; Xiang, H. Characteristics and Trends of Hospitalized Pediatric Abuse Head Trauma in Wuhan, China: 2002-2011. Int. J. Environ. Res. Public Health 2012, 9, 4187-4196.

9. Corso, P.S.; Ingels, J.B.; Roldos, M.I. A Comparison of Willingness to Pay to Prevent Child Maltreatment Deaths in Ecuador and the United States. Int. J. Environ. Res. Public Health 2013, 10, 1342-1355. 
viii

10. Snidero, S.; Soriani, N.; Baldi, I.; Zobec, F.; Berchialla, P.; Gregori, D. Scale-Up Approach in CATI Surveys for Estimating the Number of Foreign Body Injuries in the Aero-Digestive Tract in Children. Int. J. Environ. Res. Public Health 2012, 9, 4056-4067.

11. Davis, A.L.; Schwebel, D.C.; Morrongiello, B.A.; Stewart, J.; Bell, M.; Dog Bite Risk: An Assessment of Child Temperament and Child-Dog Interactions. Int. J. Environ. Res. Public Health 2012, 9, 3002-3013.

12. Chandran, A.; Khan, U.R.; Zia, N.; Feroze, A.; de Ramirez, S.S.; Huang, C-M.; Razzak, J.A.; Hyder, A.A. Disseminating Childhood Home Injury Risk Reduction Information in Pakistan: Results from a Community-Based Pilot Study. Int. J. Environ. Res. Public Health 2013, 10, 1113-1124. 
Reprinted from Int. J. Environ. Res. Public Health. Cite as: Peltzer, K.; Pengpid, S. Injury and Social Correlates among in-School Adolescents in Four Southeast Asian Countries. Int. J. Environ. Res. Public Health 2012, 9, 2851-2862.

Article

\title{
Injury and Social Correlates among in-School Adolescents in Four Southeast Asian Countries
}

\author{
Karl Peltzer $^{1,2, *}$ and Supa Pengpid ${ }^{3}$
}

1 HIV/STI and TB (HAST) Research Programme, Human Sciences Research Council, 134 Pretorius Street, 0002 Pretoria, South Africa

2 Department of Psychology, University of Limpopo, Turfloof Campus, Sovenga, 0727 Limpopo, South Africa

3 Department of Health System Management and Policy, University of Limpopo, Ga-Rankuwa Campus, Medunsa, 0204 Pretoria, South Africa; E-Mail: supaprom@yahoo.com

* Author to whom correspondence should be addressed; E-Mail: kpeltzer@hsrc.ac.za.

Received: 16 July 2012; in revised form: 2 August 2012 / Accepted: 6 August 2012 /

Published: 13 August 2012

\begin{abstract}
The aim of this study was to determine estimates of the prevalence and social correlates of injury among adolescents in four Southeast Asian countries. Crosssectional national data from the Global School-based Health Survey (GSHS) included 9,333 students at the ages from 13 to 15 years inclusive from Indonesia, Myanmar, Sri Lanka and Thailand is chosen by a two-stage cluster sample design to represent all students in grades $6,7,8,9$, and 10 in each country. The percentage of adolescents reporting one or more serious injuries within the past 12 months was $42.2 \%$ for all countries, ranging from $27.0 \%$ in Myanmar to $46.8 \%$ in Thailand. By major activity, "fall" (14.6\%) was the leading external cause of injury, followed by playing or training for a sport $(9.9 \%)$ and vehicle accident $(6.1 \%)$. In multivariate regression analysis Thailand and Indonesia, being male, substance use (smoking and drinking alcohol) and psychological distress were associated with annual injury prevalence. Risk factors of substance use and psychological distress should be considered in an integrated approach to injury etiology in planning injury prevention and safety promotion activities among school children.
\end{abstract}

Keywords: injury; social correlates; school children; Indonesia; Myanmar; Sri Lanka; Thailand 


\section{Introduction}

Globally, 98\% of all childhood unintentional injuries occur in low and middle income countries [1]. Unintentional injuries are a major cause of death and disability among children [2]. An analysis of the 1990 Global Burden of Disease study found that the childhood injury rate was the highest in Africa and South Asia [3]. The annual prevalence of serious injuries was $68.2 \%$ among 13 to 15 year-olds in six African countries [4] and among 11-, 13- and 15-year old youth in 11 industrialised countries was $41.3 \%$ [5]. In a study among school children in Kamphaeng Phet Province in Thailand 66\% reported at least one injury in the previous year and the leading categories of non-fatal injuries were: animal bite, puncture wound, burn, near-drowning, fall from a height [6]. Among young people (10-24 years) injury is the most common (43\%) cause of death in the World Health Organization (WHO) Southeast Asia (SEA) region [7]. These include traffic accidents, violence, fire-related incidents, and drowning [8]. Community-based studies have shown the extent of the problem of unintentional injuries in children and young adolescents, with rates of non-fatal injuries of 14 per 1,000 in Thailand (1-17 years) and 220 in Sri Lanka (0-19 years) [9]. In a pilot study of childhood injuries in Yangon General Hospital, 2003, in Myanmar, 30.8\% of total injured patients reported were children under 15 years of age. Various types of "falls" $(66 \%)$ were identified as the major cause of child injury followed by road traffic accidents (22\%) [10]. A study among children (less than 13 years old) seeking hospital treatment in Sri Lanka found that unintentional injuries within the home and on the road comprised $56 \%$ and $8 \%$, respectively of all causes of injury [10]. In a community-based study in the Galle district, Southern Sri Lanka, 1.4\% and 1.1\% non-fatal injuries in the last 30 days were found among 10 to 14 year-olds and 15 to 19 year-olds, respectively [11]. The national injury surveillance system in Thailand found that transport accidents ranked first $(39.2 \%)$, followed by accidental falls $(27.6 \%)$ and exposure to inanimate forces (16.4\%) for severe injury in children less than 15 years in 2005 [10].

"The etiology of youth injury involves a complex interplay between human and environmental factors" [12]. Various studies have identified multiple risk behaviour including substance use, bullying and psychological distress [13-17], obesity [18], low socioeconomic status [12,19], male gender $[8,15]$, home and school environment [16] to be associated with injury risk.

There is lack of national data regarding injury and its social correlates among in-school adolescents in Southeast Asia. Therefore, the aim of this study was to determine estimates of the prevalence and social correlates of injury among adolescents in four Southeast Asian countries.

\section{Methodology}

\subsection{Description of Survey and Study Population}

This study involved secondary analysis of existing data from the Global School-Based Health Survey (GSHS) from four Southeast Asian countries (Indonesia, Myanmar, Sri Lanka and Thailand). Details and data of the GSHS can be accessed at http://www.who.int/chp/gshs/ methodology/en/index.html. The aim of the GSHS is to collect data from students of age 13 to 15 years inclusive. The GSHS is a school-based survey of students in grades 6, 7, 8, 9, and 10. These classes were selected because they contained the majority of 13 years to 15 years old school adolescents. A 
two-stage cluster sample design was used to collect data to represent all students in grades $6,7,8$, 9 , and 10 in the country. At the first stage of sampling, schools were selected with probability proportional to their reported enrollment size. In the second stage, classes in the selected schools were randomly selected and all students in selected classes were eligible to participate irrespective of their actual ages. Students completed the self-administered questionnaire during one classroom period under the supervision of trained survey administrators and recorded their responses to each question on an answer sheet suitable for computerized scanning.

\subsection{Measures}

The GSHS 10 core questionnaire modules address the leading causes of morbidity and mortality among children and adults world wide: tobacco, alcohol and other drug use; dietary behaviours; hygiene; mental health; physical activity; sexual behaviours that contribute to HIV infection, other sexually-transmitted infections, and unintended pregnancy; unintentional injuries and violence; hygiene; protective factors and respondent demographics [20]. One study assessed the validity of the GSHS questionnaire and found adequate retest reliability of GSHS content adapted for ethnic Fijian girls for assessing several risk behaviours [21].

Outcome Measure Injury: For the main outcome, study participants were asked, "During the past 12 months, how many times were you seriously injured?" (serious injury was defined as when it makes you miss at least one full day of usual activities (such as school, sports, or a job) or requires treatment by a doctor or nurse). Eight options were provided, ranging from $1=0$ times to $8=12$ or more times. A response of " 0 " was described as not having sustained a serious injury, while a response of one or more times was classified as having experienced a serious injury. Additional items on injury included close-ended questions that addressed activity (During the past 12 months, what were you doing when the most serious injury happened?), external cause (During the past 12 months, what was the major cause of the most serious injury that happened to you?), how it happened (During the past 12 months, how did the most serious injury happen to you?), and type of injury (During the past 12 months, what was the most serious injury that happened to you?) (Response options see Table 1).

Hunger: A measure of hunger was derived from a question reporting the frequency that a young person went hungry because there was not enough food at home in the past 30 days (response options were from $1=$ never to $5=$ always) (coded $1=$ most of the time or always and $0=$ never, rarely or sometimes).

Substance use variables: Smoking cigarettes: During the past 30 days, on how many days did you smoke cigarettes? (Response options were from $1=0$ days to $7=$ all 30 days) (Coded $1=1$ or 2 to all 30 days, and $0=0$ days). Alcohol use: during the past 30 days, on how many days did you have at least one drink containing alcohol. Response options were from $1=0$ days to $7=$ all 30 days; Coded $1=1$ or 2 to all 30 days, and $0=0$ days. Drugs: During your life, how many times have you used drugs, such as glue, benzene, marijuana, cocaine, or mandrax? Response options were from $1=0$ times to $4=10$ or more times; Coded $1=1$ or 2 to 10 or more times, and $0=0$ times.

Psychological distress: Psychological distress was assessed with 5 items. Loneliness: "During the past 12 months, how often have you felt lonely?" (Response options were from $1=$ never to 5 = always) (Coded $1=$ most of the time or always and $0=$ never, rarely or sometimes). 
Suicide ideation: "During the past 12 months, did you ever seriously consider attempting suicide?" (Response option was $1=$ yes and $2=$ no, coded $1=1,2=0$ ). No close friends:"How many close friends do you have?" (Response options $1=0$ to $4=3$ or more, coded $1=1,2-4=0$.). Anxiety or worried: During the past 12 months, how often have you been so worried about something that you could not sleep at night? (Response options were from $1=$ never to $5=$ always) (Coded $1=$ most of the time or always and $0=$ never, rarely or sometimes). Sadness: During the past 12 months, did you ever feel so sad or hopeless almost every day for two weeks or more in a row that you stopped doing your usual activities? (Response option $1=$ yes and $2=$ no) $($ Coded $1=1,2=0)$. A psychological index was created by adding up all 5 items, and recoding the sum into low $=$ no psychological distress, medium $=1$ item of psychological distress and high $=2$ or more psychological distresses endorsed.

\subsection{Data Analysis}

In order to compare study samples across countries each country sample was restricted to the age group 13 to 15 years inclusive, younger and older participants were excluded from the analyses. Data analysis was performed using STATA software version 10.0 (Stata Corporation, College Station, TX, USA). This software has the advantage of directly including robust standard errors that account for the sampling design, i.e., cluster sampling owing to the sampling of school classes. In further analysis, the injury risk variable was recoded into two categories: not injured (0); injured at least once (1). Associations between potential risk factors and injuries among school children were evaluated calculating odds ratios (OR). Logistic regression was used for evaluation of the impact of explanatory variables on risk for injury (binary dependent variable). The dependent variable was the injury event, and the independent variables were factors which significantly increased injury risk in the univariate analysis. For the individual risk behaviour analyses, crude and adjusted odds ratios (ORs) and associated $95 \%$ confidence intervals were calculated for each level of exposure.

In the analysis, weighted percentages are reported. The reported sample size refers to the sample that was asked the target question. The two-sided $95 \%$ confidence intervals are reported. The $P$-value less or equal to $5 \%$ is used to indicate statistical significance. Both the reported $95 \%$ confidence intervals and the $P$-value are adjusted for the multi-stage stratified cluster sample design of the study.

Table 1. Sample response rate and age distribution of students surveyed; GSHS 2007-2008.

\begin{tabular}{|c|c|c|c|c|c|c|c|c|c|c|}
\hline \multirow[t]{2}{*}{ Country } & \multirow{2}{*}{$\begin{array}{c}\text { Survey } \\
\text { sample N }\end{array}$} & \multirow{2}{*}{$\begin{array}{c}\text { Survey } \\
\text { year }\end{array}$} & \multirow{2}{*}{$\begin{array}{c}\text { Overall response } \\
\text { rate } \% *\end{array}$} & \multicolumn{3}{|c|}{ Age groups in years $(\%)$} & \multirow{2}{*}{$\begin{array}{c}\text { Boys in final } \\
\text { sample\% }\end{array}$} & \multirow{2}{*}{$\begin{array}{l}\text { Mean age of } \\
\text { final sample }\end{array}$} & \multicolumn{2}{|c|}{$\begin{array}{c}\text { Net primary school } \\
\text { enrolment rate \% } \\
{[22,23]}\end{array}$} \\
\hline & & & & $\begin{array}{c}13 \\
\text { years }\end{array}$ & $\begin{array}{c}14 \\
\text { years }\end{array}$ & $\begin{array}{c}15 \\
\text { years }\end{array}$ & & & Male & Female \\
\hline 1. Indonesia & 2,867 & 2008 & 93 & $\begin{array}{l}1,072 \\
(33.2)\end{array}$ & $\begin{array}{l}1,253 \\
(45.2)\end{array}$ & $\begin{array}{c}542 \\
(21.6)\end{array}$ & 49.5 & 13.9 & 97 & 94 \\
\hline 2. Myanmar & 1,983 & 2007 & 95 & $\begin{array}{c}585 \\
(37.1)\end{array}$ & $\begin{array}{c}628 \\
(34.3)\end{array}$ & $\begin{array}{c}770 \\
(28.6)\end{array}$ & 50.0 & 13.9 & 90 & 91 \\
\hline 3. Sri Lanka & 2,260 & 2007 & 89 & $\begin{array}{c}894 \\
(38.9)\end{array}$ & $\begin{array}{c}844 \\
(37.3)\end{array}$ & $\begin{array}{c}522 \\
(23.8)\end{array}$ & 50.4 & 13.8 & 99 & 100 \\
\hline 4. Thailand & 2,223 & 2008 & 93 & $\begin{array}{c}841 \\
(37.1)\end{array}$ & $\begin{array}{c}871 \\
(36.2)\end{array}$ & $\begin{array}{c}511 \\
(26.7)\end{array}$ & 49.2 & 13.9 & 91 & 89 \\
\hline
\end{tabular}

* Overall response rate, the product of school and the student response rate, refers to the entire sample including those students outside the targeted age range of 13 to 15 years. 


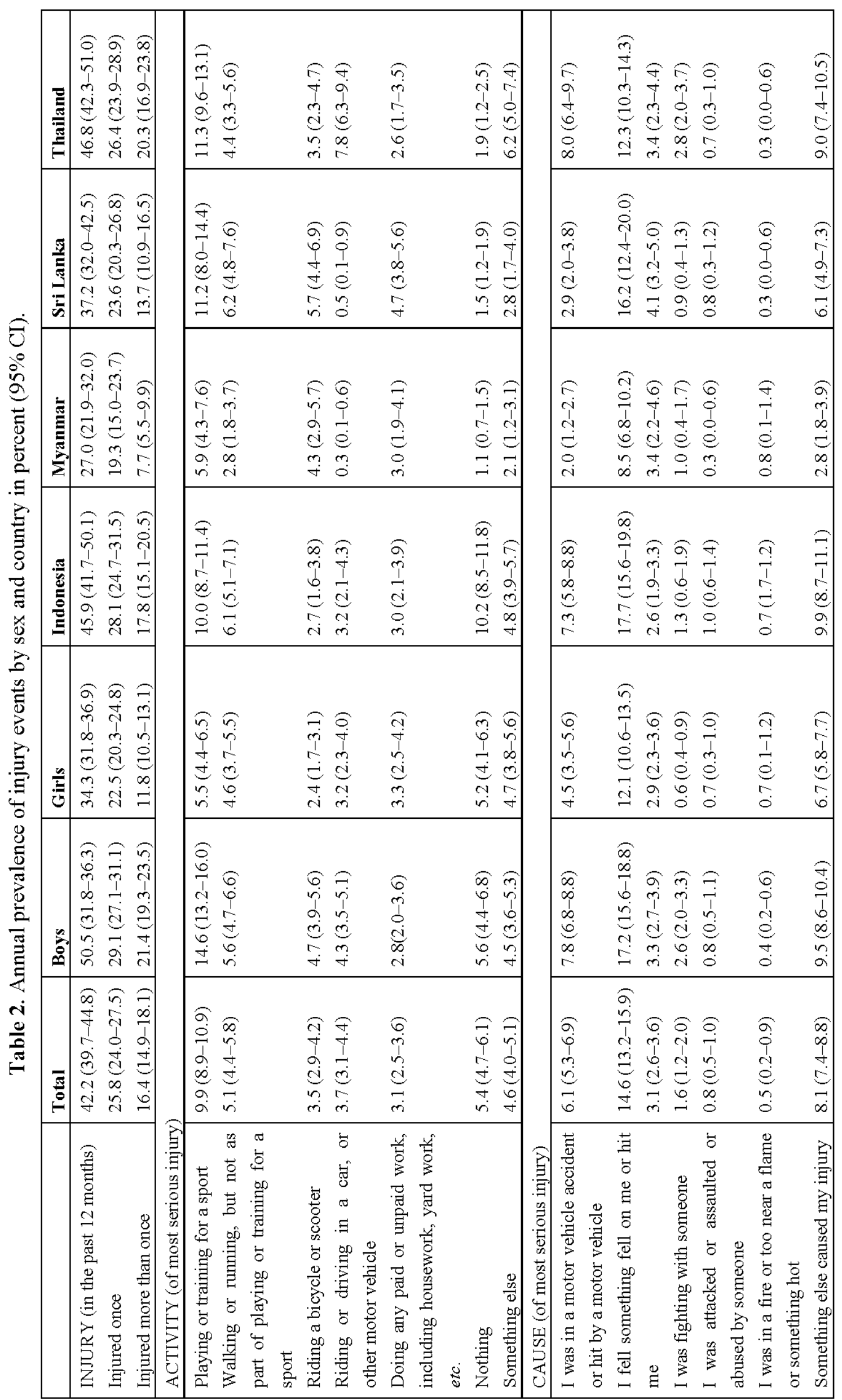




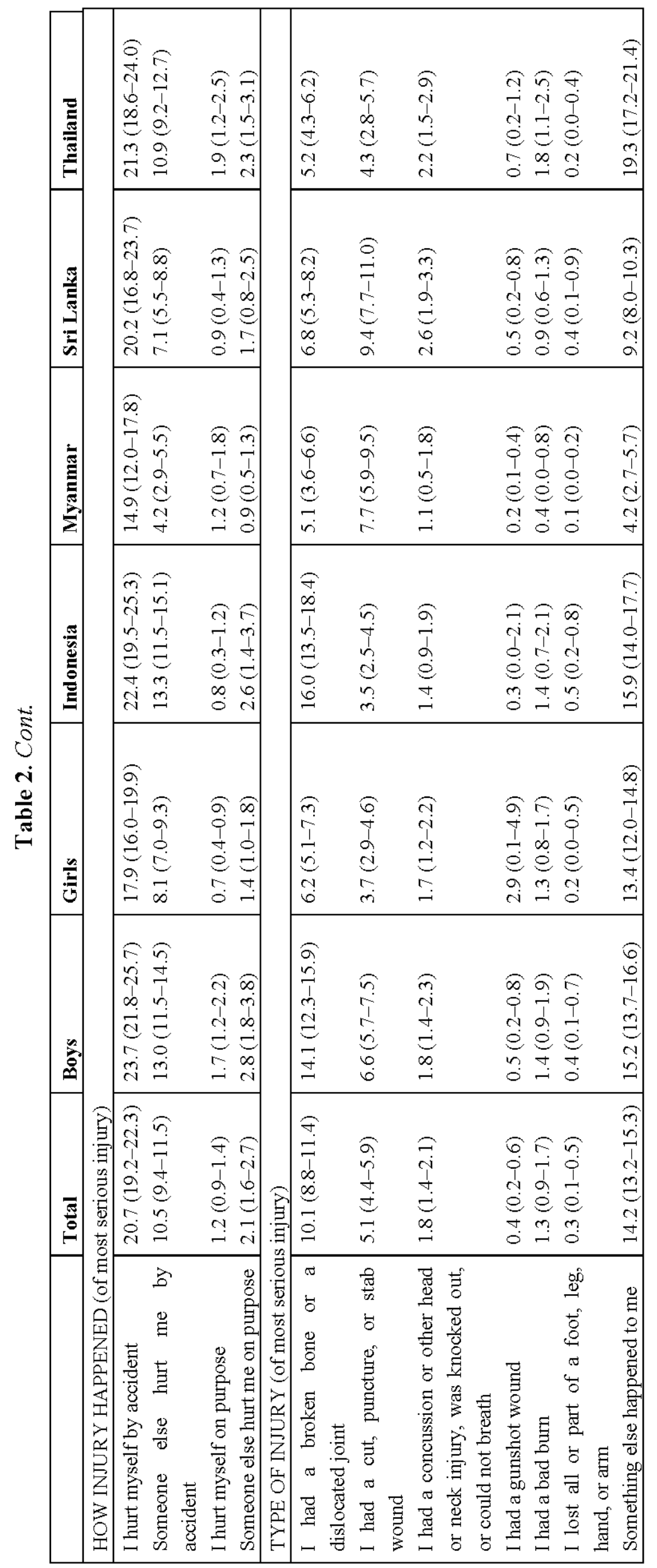




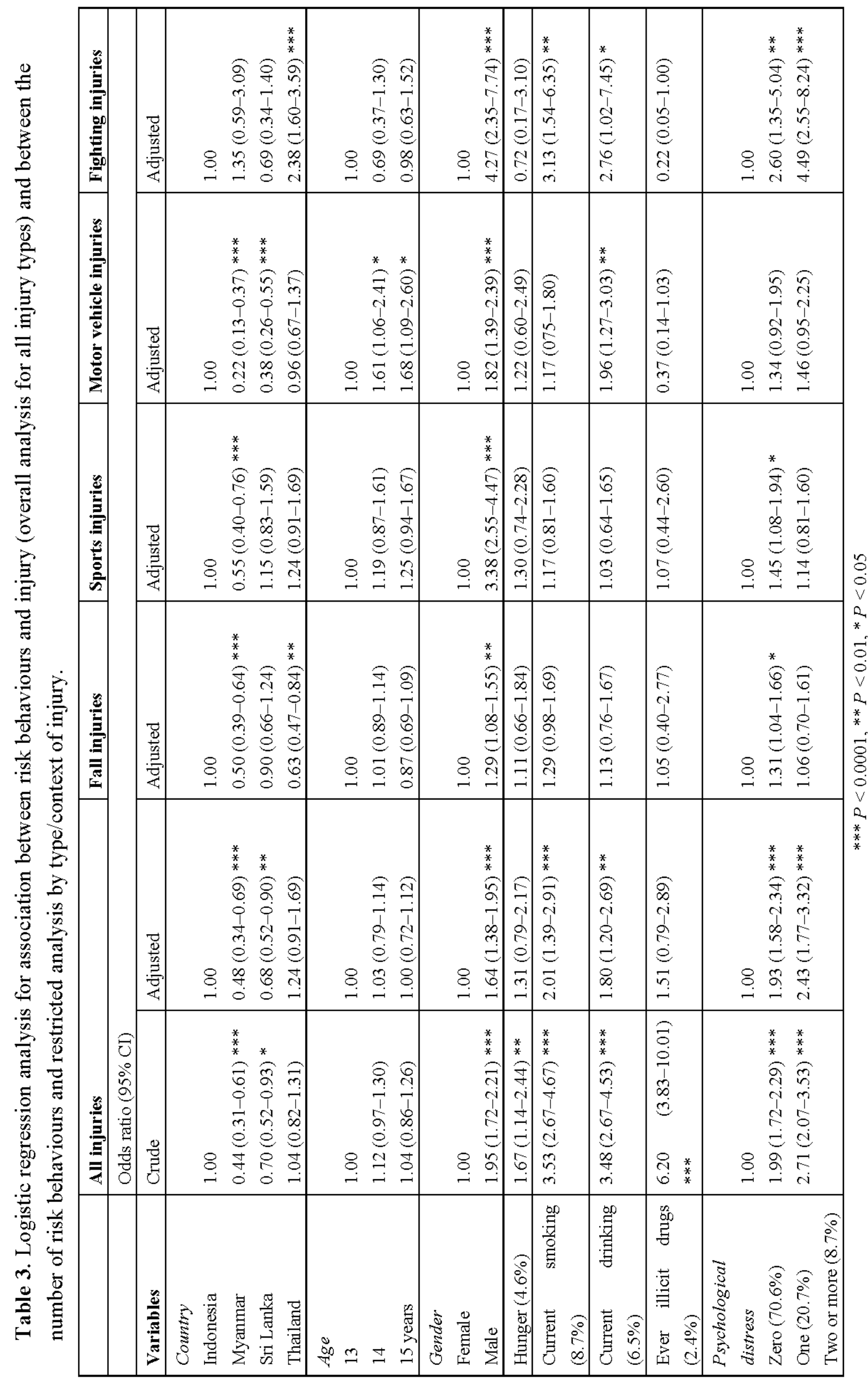




\section{Results and Discussion}

\subsection{Sample}

The sample included 9,333 students at the ages from 13 to 15 years from Southeast Asian countries; there were slightly more female $(50.4 \%)$ than male students $(49.6 \%)$ and the majority of the students $(76.2 \%)$ were attending school grades 8 or 9. Data from the different countries had been selected in 2007 or 2008 (see Table 1). The overall response rate, a product of school and student response rates, varied from $89 \%$ in Sri Lanka to $95 \%$ in Myanmar.

\subsection{Descriptive Results}

The percentage of adolescents reporting one or more serious injuries within the past 12 months was $42.2 \%$ for all countries, ranging from $27.0 \%$ in Myanmar to $46.8 \%$ in Thailand, and it has been slightly more often in boys (50.5\%) than girls (34.3\%) in all countries. Estimates of adolescents reporting a single injury were less variable, ranging from $19.3 \%$ in Myanmar to $28.1 \%$ in Indonesia, while similar differences in prevalence estimates by country were found in the number of adolescents reporting multiple injuries, ranging from $7.7 \%$ to $20.3 \%$ in Myanmar and Thailand, respectively. By major activity of all survey participants, "fall" (14.6\%) was the leading external cause of injury, followed by playing or training for a sport $(9.9 \%)$, vehicle accident $(6.1 \%)$, walking or running $(5.1 \%)$, riding a bicycle or scooter $(3.7 \%)$, fighting with someone $(1.6 \%)$, and attacked or assaulted or abused by someone $(0.8 \%)$. The majority of all surveyed adolescents $(20.7 \%)$ indicated that they had hurt themselves by accident. The injury sustained by most students of all surveyed involved broken bone/dislocated joint (10.1\%), followed by a cut, puncture, stab wound (5.1\%), concussion/head injury (1.8\%) and burn injury (1.3\%) (see Table 2).

\subsection{Associations with Annual Injury Prevalence}

Annual injury prevalence differed significantly by country, with Myanmar and Sri Lanka having significantly lower prevalence rates than Thailand and Indonesia. A similar country pattern was identified for specific injuries, for fall injuries Myanmar and Thailand were the lowest, for sports injuries Myanmar the lowest, for motor vehicle injuries Myanmar and Sri Lanka the lowest and for fighting injuries adolescents from Thailand were the highest. Boys had higher annual injury prevalence rates than girls which was true for the different types of injuries. Substance use (current smoking and drinking alcohol) and greater psychological distress were found to be associated with annual injury prevalence rates. The highest influence of psychological distress was found with fighting injuries. Hunger as an indicator for low economic status and overweight were not found to be associated with annual injury prevalence nor with any specific injury (see Table 3).

\section{Discussion and Study Limitations}

In this study of in-school adolescents in four Southeast Asian countries using the Global School Health Survey of 2007/2008, a high percentage of adolescents (44.2\%) reporting one or more serious injuries within the past 12 months was found, ranging from $27.0 \%$ in Myanmar to $46.8 \%$ in Thailand, and it has been significantly more often in boys $(50.5 \%)$ than girls $(34.3 \%)$ in all 
countries. This annual prevalence of severe injury was similar to that found in some other studies, South African Grade 8 students (52\% among boys and 33\% among girls) [24], Lithuanian school children (59\% among boys and 40\% among girls) [14], among 11-, 13- and 15-year old youth in 11 countries $41.3 \%$ [5], and among 35 countries between $33 \%$ and $62 \%$ across countries among males (19\% to $39 \%$ among females) [12], and Scottish school children 41.9\% [25] of all children were injured and needed medical treatment in the past 12 months. However, it was lower than found in a previous local study among school children in Thailand (66\%) [6] and among school children in six African countries (68.2\%) [4]. The annual injury prevalence rates found in this Southeast Asian sample may still be an underestimate considering a decline of estimates over a 12 month recall period. Mock et al. [26] found in a Ghanaian setting that longer recall periods significantly underestimate the injury rate compared to shorter recall periods. A possible explanation for the differences between injury rates in the different study countries may be due to differences in exposure to injury risk, e.g., traffic load on the roads, access to vehicles, access to sport opportunities, etc. More research is needed to understand the differences in injury risk between countries. Regarding the type of injury, the highest annual prevalence rate in this study was found for falls (14.6\%), sport (9.9\%) and vehicle accident-related injuries (6.1\%); also other studies report that these three were the most common activities associated with injury [10,27,28]. This analysis represents one of the first Southeast Asian cross national examinations of adolescent injury patterns. This study found large cross national variations in severe injury prevalence. It is not clear whether these variations are attributable to underlying differences in risk. The Myanmar sample had the lowest annual injury prevalence and Thailand the highest. Depending on the country the GSHS was administered at different times of the year. Risks for adolescent injury vary by season, and injuries are more reliably reported within three than 12 months [29]. Variations in the timing of the survey across countries may have impacted injury rates and hence the cross national comparisons [6]. In a multivariable regression analysis substance use (smoking and drinking) and mental distress were associated with injuries. Similar associations between risk behaviours and the occurrence of injury were found in other studies, e.g., substance use (smoking, drinking) and psychological distress [13-17]. Variations in the strength and direction of associations were observed for different combinations of social risk factors and types of injury. The highest influence of psychological distress was found with fighting injuries. Contrary to other studies, hunger as an indicator for low economic status and overweight were not found to be associated with annual injury prevalence nor with any specific injury $[12,18,19]$. This study found that the observed risk for all injuries increased with the increasing number of psychological distresses and other risk behaviours (substance use). Gradients in risk for adolescent injury also found in other studies [4] indicates support for the targeting of multiple forms of risk behaviour simultaneously in health interventions [7]. There is also a need to consider an integrated approach to injury etiology in planning injury prevention and safety promotion activities among school children, paying particular attention to lifestyle factors, which have the potential to influence risk for injuries. Efforts have to be intensified to include the prevention of violence and injury, along with sexual and reproductive health, healthy lifestyles, mental health and mental well-being, in adolescent health programmes [8]. 
This study had several limitations. Firstly, the GSHS only enrolls adolescents who are in school. School-going adolescents may not be representative of all adolescents in a country as the occurrence of injury and injury related risk behaviour may differ between the two groups. As the questionnaire was self-completed, it is possible that some study participants may have mis-reported either intentionally or inadvertently on any of the questions asked. Intentional miss-reporting was probably minimised by the fact that study participants completed the questionnaires anonymously. Furthermore, this study was based on data collected in a cross sectional survey. We cannot, therefore, ascribe causality to any of the associated factors in the study. Finally, the analysis was limited to the risk factors included in the GSHS. There are some other potentially important risk and protective factors (e.g., over-activity, failure to use seatbelts and bicycle helmets, being the perpetrator of an aggressive/bullying behaviour, ongoing conflict with parents, urban/rural situation, family, school or material supports, supervised or unsupervised school areas) $[16,27,30]$ that could be associated with the occurrence of injury that were not measured. Finally, the injury survey tool collects only information on the 'most serious injury' and therefore risks not reflecting the true burden of injuries in these communities if a large number of other injuries collectively cause a greater burden/distress/absence or have different aetiologies, consequences or associations.

\section{Conclusions}

In this study, a high annual injury prevalence was found among adolescents in four Southeast Asian countries. Risk behaviour including substance use (smoking and drinking) and mental distress were found to be associated with injuries. There is also a need to consider an integrated approach to injury etiology in planning injury prevention and safety promotion activities among school children, paying particular attention to lifestyle factors, which have the potential to influence risk for injuries. Efforts have to be intensified to include the prevention of violence and injury, along with sexual and reproductive health, healthy lifestyles, mental health and mental wellbeing, in adolescent health programmes [8].

\section{Acknowledgments}

We are grateful to the World Health Organization (Geneva) and the Centers for Disease Control and Prevention (Atlanta) for making the data available for analysis, and the country coordinators from Indonesia (Rachmalina S. Prasodjo), Myanmar (Aung Tun), Sri Lanka (Senaka Talagala), and Thailand (Ekachai and Sasiwimol), for their assistance in collecting the Global School-based Student Health Survey data. We also thank the Ministries of Education and Health and the study participants for making the Global School Health Survey in the four Southeast Asian countries possible. The governments of the respective study countries and the World Health Organization did not influence the analysis nor did they have an influence on the decision to publish these findings.

\section{Conflicts of Interest}

The authors declare that they have no competing interests. 


\section{References}

1. Hyder, A.A.; Puvanachandra, P.; Tran, N.H. Child and adolescent injuries: A new agenda for child health. Inj. Prev. 2008, 14, 67.

2. WHO/UNICEF. Child and Adolescent Injury Prevention: A Global Call to Action; WHO: Geneva, Switzerland, 2005.

3. Hyder, A.A.; Labinjo, M.; Muzaffar, S.S.F. A new challenge to child and adolescent survival in urban Africa: An increasing burden of road traffic injuries. Traffic Inj. Prev. 2006, 7, 381-388.

4. Peltzer, K. Injury and social determinants among in-school adolescents in six African countries. Inj. Prev. 2008, 14, 381-388.

5. Molcho, M.; Harel, Y.; Pickett, W. The epidemiology of non-fatal injuries among 11-, 13- and 15-year old youth in 11 countries: Findings from the 1998 WHO-HBSC cross-national survey. Int. J. Inj. Contr. Saf. Promot. 2006, 13, 205-211.

6. Kozik, C.A.; Suntayakorn, S.; Vaughn, D.W.; Suntayakorn, C.; Snitbhan, R.; Innis, B.L. Causes of death and unintentional injury among schoolchildren in Thailand. Southeast Asian J. Trop. Med. Publ. Health 1999, 30, 129-135.

7. Patton, G.C.; Coffey, C.; Sawyer, S.M.; Viner, R.M.; Haller, D.M.; Bose, K.; Vos, T.; Ferguson, J.; Mathers, C.D. Global patterns of mortality in young people: A systematic analysis of population health data. Lancet 2009, 374, 881-892.

8. Plianbangchang, S. Promoting adolescent health and development in South-East Asia. Indian J.Community Med. 2011, 36, 245-246.

9. Pant, P.R.; Towner, E. Systematic review of community-based studies of unintentional injuries in children in south east Asian countries. Inj. Prev. 2010, 16, doi:10.1136/ip.2010.029215.441.

10. WHO. Profile of Child Injuries: Selected Member States in the Asia-Pacific Region; Regional Office for South-East Asia, World Health Organization: New Dehli, India, 2010.

11. Navaratne, K.V.; Fonseka, P.; Rajapakshe, L.; Somatunga, L.; Ameratunga, S.; Ivers, R.; Dandona, R. Population-based estimates of injuries in Sri Lanka. Inj. Prev.2009, 15, 170-175.

12. Pickett, W.; Molcho, M.; Simpson, K.; Janssen, I.; Kuntsche, E.; Mazur, J.; Harel, Y.; Boyce, W.F. Cross national study of injury and social determinants in adolescents. Inj. Prev. 2005, 11, 213-218.

13. Pickett, W.; Schmid, H.; Boyce, W.F.; Simpson, K.; Scheidt, P.C.; Mazur, J.; Molcho, M.; King, M.A.; Godeau, E.; Overpeck, M.; Aszmann, A.; Szabo, M.; Harel, Y. Multiple risk behavior and injury: An international study of youth in 12 countries. Arch. Pediatr. Adolesc. Med. 2002, 156, 786-793.

14. Starkuniviene, S.; Zaborski, A. Links between accidents and lifestyle factors among Lithuanian school children. Medicina (Kaunas) 2005, 41, 73-80.

15. Pickett, W.; Garner, M.J.; Boyce, W.F.; King, M.A. Gradients in risk for youth injury associated with multiple-risk behaviours: A study of 11,329 Canadian adolescents. Soc. Sci.Med. 2002, 55, 1055-1068.

16. Mytton, J.; Towner, E.; Brussoni, M.; Gray, S. Unintentional injuries in school-aged children and adolescents: Lessons from a systematic review of cohort studies. Inj. Prev. 2009, 15, 111-124. 
17. Muula, A.S.; Siziya, S.; Rudatsikira, E. Prevalence and socio-demographic correlates for serious injury among adolescents participating in the Djibouti 2007 Global School-based Health Survey. BMC Res. Notes 2011, 4, doi:10.1186/1756-0500-4-372.

18. Bazelmans, C.; Coppieters, Y.; Godin, I.; Parent, F.; Berghmans, L.; Dramaix, M.; Levêque, A. Is obesity associated with injuries among young people? Eur. J. Epidemiol. 2004, 19, 1037-1042.

19. Simpson, K.; Janssen, I.; Craig, W.M.; Pickett, W. Multilevel analysis of associations between socioeconomic status and injury among Canadian adolescents. J. Epidemiol. Community Health 2005, 59, 1072-1077.

20. CDC. The Global School and Health Survey Background. Available online: http://www. cdc.gov/gshs/background/index.htm (accessed on 15 April 2010).

21. Becker, A.E.; Roberts, A.L.; Perloe, A.; Bainivualiku, A.; Richards, L.K.; Gilman, S.E.; Striegel-Moore, R.H. Youth health-risk behavior assessment in Fiji: The reliability of Global School-based Student Health Survey content adapted for ethnic Fijian girls. Ethn. Health 2010, 15, 181-197.

22. World Health Organization (WHO). World Health Statistics; WHO: Geneva, Switzerland, 2011.

23. UNICEF. Myanmar: Statistics. Available online: http://www.unicef.org/infobycountry/ myanmar_statistics.html\#90 (accessed on 10 July 2012).

24. Peltzer, K. Injury and lifestyle factors among school-aged Black and White South African children in the Limpopo Province. Afri. Saf. Promot. 2006, 4, 15-25.

25. Currie, C.E.; Williams, J.M.; Wright, P.; Beattie, T.; Harel, Y. Incidence and distribution of injury among schoolchildren aged 11-15. Inj. Prev. 1996, 2, 21-25.

26. Mock, C.N.; Acheampong, F.; Adjei, S.; Koepsell, T. The effect of recall on estimation of incidence rates for injury in Ghana. Int. J. Epidemiol. 1999, 28, 750-755.

27. Pickett, W.; Dostaler, S.; Craig, W.; Janssen, I.; Simpson, K.; Shelley, S.D.; Boyce, W.F. Associations between risk behavior and injury and the protective roles of social environments: An analysis of 7,235 Canadian school children. Inj. Prev. 2006, 12, 87-92.

28. Williams, J.M.; Wright, P.; Currie, C.E.; Beattie, T.F. Sports related injuries in Scottish adolescents aged 11-15. Br. J. Sports Med. 1998, 32, 291-296.

29. Harel, Y.; Overpeck, M.D.; Jones, D.H.; Scheidt, P.C.; Bijur, P.E.; Trumble, A.C.; Anderson, $\mathrm{J}$. The effect of recall on estimating annual nonfatal injury rates for children and adolescents. Am. J. Public Health 1994, 84, 599-605.

30. Jiang, X.; Li, D.; Boyce, W.; Pickett, W. Alcohol consumption and injury among Canadian adolescents: Variations by urban-rural geographic status. J. Rural Health 2008, 24, 143-147. 
Reprinted from Int. J. Environ. Res. Public Health. Cite as: Davis, A.L.; Schwebel, D.C.; Morrongiello, B.A.; Stewart, J.; Bell, M. Dog Bite Risk: An Assessment of Child Temperament and Child-Dog Interactions. Int. J. Environ. Res. Public Health 2012, 9, 3002-3013.

Article

\title{
Dog Bite Risk: An Assessment of Child Temperament and Child-Dog Interactions
}

\author{
Aaron L. Davis ${ }^{1}{ }^{*}$, David C. Schwebel ${ }^{1}$, Barbara A. Morrongiello ${ }^{2}$, Julia Stewart ${ }^{2}$ and \\ Melissa Bell $^{2}$
}

1 Department of Psychology, University of Alabama at Birmingham, 1300 University Blvd, CH 415, Birmingham, AL 35294, USA; E-Mail: schwebel@uab.edu

2 Department of Psychology, University of Guelph, 50 Stone Road East, Guelph, ON N1G 2W1, Canada; E-Mails: bmorrong@uoguelph.ca (B.A.M.); jstewa02@uoguelph.ca (J.S.); mbel101@uoguelph.ca (M.B.)

* Author to whom correspondence should be addressed; E-Mail: aldavis1821@gmail.com; Tel.: +1-205-934-4068; Fax: +1-205-975-6110.

Received: 18 June 2012; in revised form: 16 July 2012 / Accepted: 15 August 2012 /

Published: 20 August 2012

\begin{abstract}
Annually approximately 400,000 American children receive treatment for dog bites. Young children are at greatest risk and are frequently bitten following behavior that provokes familiar dogs. This study investigated the effects of child temperament on children's interaction with dogs. Eighty-eight children aged 3.5-6 years interacted with a live dog. Dog and child behaviors were assessed through observational coding. Four child temperament constructs-impulsivity, inhibitory control, approach and shyness-were assessed via the parent-report Children's Behavioral Questionnaire. Less shy children took greater risks with the dog, even after controlling for child and dog characteristics. No other temperament traits were associated with risk-taking with the dog. Based on these results, children's behavior with unfamiliar dogs may parallel behavior with other novel or uncertain situations. Implications for dog bite intervention programs include targeting at-risk children and merging child- and parent-oriented interventions with existing programs geared toward the physical environment and the dog.
\end{abstract}

Keywords: temperament; injury; dog bites; children; shyness 


\section{Introduction}

Approximately 377,000 American children receive medical attention for dog bites every year [1], and about sixteen die [2]. Although fatalities from dog bites are rare, there is a significant risk of injury. Most vulnerable are young children, partly because of their unintentionally provocative behavior with dogs [3] and partly because their short stature results in bites to the face and neck rather than to extremities [4]. Most bites to children are from familiar dogs; in fact, $78 \%$ of $\operatorname{dog}$ bites to young children occur in the home [5].

One reason children under the age of 5 are bitten by familiar dogs is because the children unknowingly provoke the animals $[3,6]$. Developmental psychologists have long recognized that young children have a poor understanding of the perspectives of other people [7] and therefore are unlikely to recognize the emotions or behavioral signals of dogs provoked by unwanted child behaviors [8]. For example, in one study of the interactions of children aged 2-5 years with the family dog, children frequently initiated risky interactions with the pets by pulling dogs' tails, hair or paws. On nearly one-third of such occasions, the dogs bit or attempted to bite the children [9]. Also placing young children at heightened risk of dog bites are children's natural tendencies to be active, loud and excitable, and to be protective of property. Running and screaming can scare and anger dogs. Child-dog conflicts over toys and other property can lead to biting incidents [3]. Further, although dogs have some ability to identify familiar faces [10], dogs obviously do not have cognitive skills of humans and are unable to recognize that children may be more provocative or animated than adults.

Although some researchers have suggested environmental circumstances that might lead dogs to bite young children [11,12], relatively little research has examined individual difference characteristics of children that might increase the risk for dog bites. There is some epidemiological evidence that boys are bitten slightly more often than girls [12-14], although one study found no significant difference in dog bites between boys and girls in The Netherlands [4]. Research has also shown that preschool-aged and school-aged children have somewhat elevated risk compared to infants, toddlers, and teenagers [13-15]. One factor that has not been studied carefully as a risk factor for dog bites is child temperament, or individual differences in reactivity and self-regulation [16]. A large body of research indicates children who are more impulsive, active and undercontrolled are likely to be at increased risk for injuries of all types [17], presumably due to behavior patterns of risk-taking, failing to inhibit impulses and engaging in the environment more actively.

The current study considered four temperament traits-impulsivity, inhibitory control, approach, and shyness - as possible correlates to children's risky behavior with dogs. These traits were assessed using the parent-report Children's Behavioral Questionnaire (detailed below). Eight-eight children aged 3.5 to 6 years interacted with an unfamiliar live dog for 15 minutes in a mixed (partly unstructured, partly semi-structured) laboratory protocol. Child and dog behaviors were videotaped, coded and then related to parental reports of children's temperament using a standardized questionnaire. We hypothesized that children who had high impulsivity, low inhibitory control, low shyness, and high approach would be more likely to approach a dog more quickly and to take more risks when interacting with an unfamiliar dog. 


\section{Method}

\subsection{Participants}

Participants in this two-site study were 88 children ages $3.5-6$ (mean age $=4.85$ years, $S D=0.90$ ). Participants were recruited from community sources, including laboratory databases of families interested in participating in research and via local schools. Because dog bite risk is much higher among children who frequently encounter dogs, the sample was restricted to children whose families owned between one and three pet dogs. Participants were recruited from two locations. Sixty-three children were recruited from the Birmingham, Alabama, USA area and 25 from Guelph, Ontario, Canada. Identical procedures were used at both study sites.

The sample was $46 \%$ male and $76 \%$ Caucasian. Household incomes were characterized as follows: $63 \%$ greater than $\$ 80,000,14 \%$ between $\$ 40,000$ and $\$ 79,000$, and $23 \%$ less than $\$ 39,000$ (US and Canadian currencies were priced very similarly at the time of the study). All parents provided signed informed consent indicating that the child would be engaging with a live certified therapy dog and all children age-appropriate verbal assent acknowledging they would be interacting with a dog. The study protocol was approved by the ethics review boards at both University of Alabama at Birmingham and University of Guelph.

\subsection{Live Dog Interaction Protocol}

As detailed below, children engaged with a certified therapy dog in a protocol that included both semi-structured and unstructured segments. All dogs and handlers had received certification in either the Delta Society Pet Partners or Canine Good Citizens programs. Dog breeds (and shapes/sizes) varied widely and included Cavalier King Charles Spaniels, Giant Poodles, Labrador Retrievers, and Greyhounds. Dogs and children were always unfamiliar to each other (that is, the dogs were not the children's pet dogs), and children were not informed of the interaction with the dog until the informed assent process on the day of the interaction, just before the interaction occurred. The interaction was videotaped for later coding of dog and child behaviors; details of the coding system appear below.

The full dog-child interaction lasted 15 minutes and consisted of four segments. The first 3-minute segment was unstructured. The child entered the experimental room with the researcher, the live dog, and the dog's handler, but without his or her parent. Figure 1 provides a diagram of the room layout. It was arranged with a small number of rather mundane child toys in one corner, a small number of dog toys in a second corner, and a dog bed along one wall. Each set of toys was neatly organized in a pile. The researcher said, "This is [dog's name]. He's [She's] visiting our lab today. [Handler's name] and I have to do a little work for a few minutes, so you can just do what you like while we work. There are some toys here for children. Those over there are the dog's toys." The handler stayed quiet and remained in the corner of the room, verbally or physically intervening only if he/she felt the dog or child might be at risk of injury (interventions were extremely rare, occurring only for two children, one who pulled the dog's fur and one who tried to lift a large dog up in the air). 
Figure 1. Diagram of Dog Interaction Room.

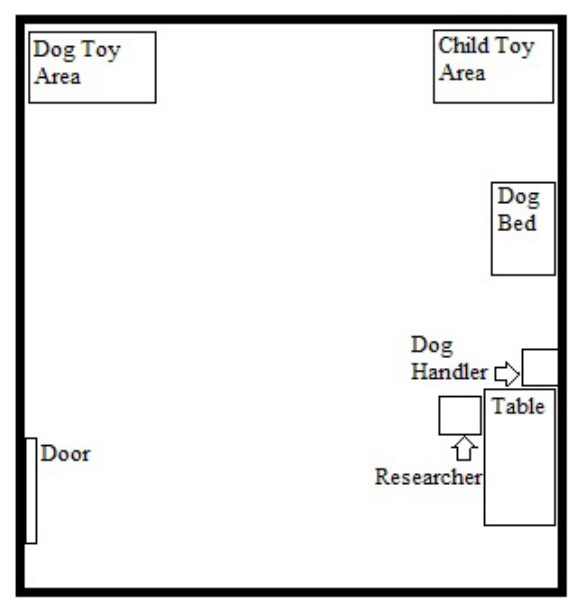

The second segment was semi-structured and lasted 1-2 minutes. The researcher said,

"OK, our work is done now. [Dog's name] is ready to play. You can play with the dog using one of these things. This is a ball and that is a brush and that is a bowl with three dog treats. If you choose the ball, you can stand over there and throw it to the dog. He[she] likes to retrieve balls. If you choose the brush, you can stand here, right next to the dog, and brush his[her] hair. He[she] likes that too. If you choose the treats, you should hold them in your palm like this [researcher demonstrates open palm] and let the dog lick them off your hand."

The child chose one of the three options and engaged in the activity under researcher supervision.

The third segment lasted 3 minutes and was unstructured. The child was told "Oh, look what time it is. The dog likes to rest at this time. You can do whatever you want for a few minutes while the dog rests and I finish my work with [handler's name]." During the fourth segment, which was also unstructured, the child's parent entered the room. The child, dog and parent spent 5 minutes engaged in activities. Because parents tended to control children's activities and behaviors during this segment and our focus was on the individual child's temperament without parent influence, activities during this segment were not included in our coding.

\subsection{Measures}

Demographics. Parents completed a brief demographics survey assessing basic child and family demographics.

Child Risk-Taking during Dog Interaction. Videotapes of children's behaviors during the interaction with the live dog were coded by a research assistant to assess a single construct of children's risk-taking with the dog via multiple behavioral measures. The research assistant was trained by the principal investigator of this study, and interrater reliability was obtained through independent post-training coding of videotapes by both the principal investigator and the research assistant. Interrater reliability on coding behaviors was high $(r>0.95$ on all continuous measures and kappa $>0.80$ on all categorical measures). Differences were resolved by using data from the primary coder, who rated all participants. 
Risk-taking was conceptualized as a behavior pattern of approaching, touching and interacting with the dog when the outcome of that behavior was uncertain [18]. We considered behaviors that were bold, brave, or assertive, but not necessarily behaviors that would typically lead to provocation of the dog or to dog bites. Table 1 shows the behaviors that were coded to derive the measure. Categorical variables were assigned ordinal numbers to represent increasing risk-taking. In order to create the single aggregated risk-taking measure for each child's interaction with the dog, the variables were each converted to z-scores and then averaged. Internal reliability for the scale was good (average intercorrelation $=0.44$; Cronbach's alpha $=0.73$ ).

Table 1. Children's Coded Behaviors during Live Dog Interaction.

1. What does child touch first after entering room? (Segment 1)

1. Child Toys; 2. Dog Toys; 3. Dog

2. Which activity does child choose? (Segment 2)

1. Ball; 2. Brush; 3. Treat

3. Does child pick up a dog toy? (Segments 1,3 )

1. No; 2. Yes

4. How long until child engages the dog? (in seconds) (full protocol)

5. How does child engage dog for the first time? (Segments 1, 3)

1. Throws toy to dog; 2. Calls dog to him/her; 3. Approaches dog;

4. Touches dog after dog approaches child

6. How long until child approaches dog 1st time? (in seconds) (full protocol)

7. How does child first approach dog? (full protocol)

1. Hesitantly/Cautiously; 2. Approaches and then backs away;

3. Quickly/Unhesitatingly approaches

8. How long until child touches the dog for the 1st time? (in seconds) (full protocol)

9. How does child first touch dog? (full protocol)

1. Hesitantly/Cautiously; 2. Touches then withdraws; 3. Quickly/Unhesitatingly

10. Number of times child touches the dog with hand. (full protocol)

11. Number of times child put their face to the dog's face. (full protocol)

12. Child's approach during "nap." (Segment 3)

1. Looks at dog; 2. Gets within arm's reach of dog; 3. Touches dog

13. Child's reaction to dog's approach during free play. (Segment 1)

1. Runs From Dog; 2. Freezing/Cautious; 3. Tells dog to go away;

4. Smiling/Laughing; 5. Pushes Dog away

14. Child's reaction to dog's approach during activity. (Segment 2)

1. Runs From Dog; 2. Freezing/Cautious; 3. Tells dog to go away;

4. Smiling/Laughing; 5. Petting/Touching Dog; 6. Pushes Dog away

15. Child's reaction to dog's approach during nap time. (Segment 3)

1. Runs From Dog; 2. Freezing/Cautious; 3. Tells dog to go away;

4. Smiling/Laughing; 5. Petting/Touching Dog; 6. Pushes Dog away; 7. NA

Dog Behavior. Because different children engaged with different dogs, we coded dog behavior and size from the videotapes as covariate measures. The same two coders independently rated $20 \%$ of the sample using objective coding criteria and achieved strong interrater reliability (kappa $>0.80$ ) 
on all measures. The primary coder subsequently coded the full sample and data from the primary coder were used.

Dog size was coded on a 4-point scale as small (less than 25 pounds), medium (25-50 pounds), large (51-75 pounds), or very large (75+ pounds). The dogs' behavior was coded in two domains, activity level and level of approach. In each case, the constructs were assessed on 5-point Likert scales ranging from low to high during each of the three relevant segments of the interaction (See Table 2). Scores from the three segments were averaged to obtain one overall measure of dog activity level and one of dog approach for each child's interaction with the dog. Then, to create a single variable for the dog's behavior during the interaction, the average of the dog's activity level and approach were each converted to z-scores and then averaged, creating a single score for the dog's behavior. Activity level and approach correlated well, $r=0.67$.

Table 2. Dog's Coded Activity Level and Approach during Each Segment of the Interaction.

Dog's activity level

1. Very inactive (Moves around room very rarely)

2. Somewhat inactive (Moves some, but spends majority of time not moving)

3. Not inactive or active (Spends about equal amounts of time moving and not moving)

4. Somewhat active (Does not move some, but spends majority of time moving around room)

5. Very active (Moving around room all or almost all the time)

Level of approach for dog (approach defined as: DOG moves or positions itself within child's arm's length of the child)

1. Low approach (Never approaches child)

2. Somewhat low approach (Only approaches child once)

3. Neither low nor high approach (Approaches child 2-3 times)

4. Somewhat high approach (Approaches child 4-6 times)

5. High approach (Approaches child 7 or more times)

Child Temperament. Parents completed four subscales - impulsivity, inhibitory control, shyness, and approach-from the Children's Behavior Questionnaire (CBQ) [19], a standard parent-report measure of child temperament designed for use with children ages 3 to 7. Each subscale is comprised of 13 items, and all items are answered by parents on a 7-point Likert scale ranging from extremely untrue to extremely true. Impulsivity is defined as the speed of response initiation; a sample item assessing impulsivity is, "My child usually rushes into an activity without thinking about it." Inhibitory control is defined as the capacity to plan and to suppress inappropriate responses under instructions in novel or uncertain situations. A sample item assessing inhibitory control is, "My child can lower his/her voice when asked to do so." Shyness is defined as slow or inhibited approach in situations involving novelty or uncertainty, and is exemplified by this sample item, "My child sometimes prefers to watch rather than join other children playing." Approach is defined as the amount of excitement and positive anticipation for expected pleasurable activities. A sample item assessing approach is, "My child gets so worked up before an exciting event that s/he has trouble sitting still" [20]. Internal reliability of all four scales is good, Cronbach's alphas ranging from 0.74-0.94 [19]. 


\subsection{Data Analysis Plan}

Data analyses were completed in three steps: (a) descriptive statistics; (b) Pearson correlations between risk-taking and the four temperament traits (impulsivity, inhibitory control, shyness, approach); and (c) linear regression models to predict risk-taking by temperament after controlling for relevant dog-specific and child-specific covariates.

\section{Results}

Descriptive data are presented in Table 3. We considered bivariate correlations between the four temperament traits of interest, impulsivity, inhibitory control, approach and shyness, and risktaking with the live dog. As shown in Table 4, the four temperament traits tended to intercorrelate with each other, although shyness was not closely related to inhibitory control or approach. Our focus for this study was how the four temperament traits correlated to risk-taking with the dog. No significant correlations were found between risk-taking and impulsivity $(r=0.16)$, inhibitory control $(r=-0.12)$, or approach $(r=0.10)$. A significant correlation did emerge between risk-taking and shyness $(r=-0.23, p<0.05)$, with higher levels of shyness associated with less risk-taking with the dog.

Table 3. Descriptive Statistics for Variables.

\begin{tabular}{cc}
\hline Variable & M (SD) or \% \\
\hline Age (in years) & $4.85(0.90)$ \\
Gender & $46 \%$ male \\
Impulsivity (on 7-point scale) & $4.44(0.83)$ \\
Approach (on 7-point scale) & $5.25(0.67)$ \\
Shyness (on 7-point scale) & $3.64(1.16)$ \\
Inhibitory Control (on 7-point scale) & $4.82(0.73)$ \\
Standardized Risk-Taking with Live Dog & $-0.03(0.60)$ \\
Aggregate (z-score) & \\
Dog Size & $61 \%$ Small [1] \\
& $4 \%$ Medium [2] \\
& $35 \%$ Large [3] \\
Dog Activity Level & 13\% Very Large [4] Inactive [1] \\
& $33 \%$ Somewhat Inactive [2] \\
& $47 \%$ Not Inactive or Active [3] \\
& $8 \%$ Somewhat Active [4] \\
& $0 \%$ Very Active [5] \\
Dog Approach & 13\% Low Approach [1] \\
& Somewhat Low Approach [2] \\
& $48 \%$ Neither High or Low [3] \\
& 5\%omewhat High Approach [4] \\
& $0 \%$ High Approach [5]
\end{tabular}


Table 4. Pearson Correlations of Risk-taking and Impulsivity, Inhibitory Control, Approach and Shyness $(\mathrm{N}=88)$.

\begin{tabular}{lcccccccc}
\hline & $\mathbf{2}$ & $\mathbf{3}$ & $\mathbf{4}$ & $\mathbf{5}$ & $\mathbf{6}$ & $\mathbf{7}$ & $\mathbf{8}$ & $\mathbf{9}$ \\
\hline 1. Risk-Taking & 0.16 & -0.01 & 0.10 & $-0.23^{*}$ & -0.01 & 0.09 & 0.16 & 0.12 \\
2. Impulsivity & - & $-0.53 *$ & $0.54 * *$ & $-0.63 * *$ & $-0.24 *$ & -0.10 & -0.04 & -0.03 \\
3. Inhibitory Control & & - & $0.44 * *$ & 0.09 & 0.16 & 0.13 & -0.10 & 0.02 \\
4. Approach & & & - & -0.20 & -0.19 & -0.07 & -0.01 & -0.07 \\
5. Shyness & & & & - & 0.19 & 0.06 & 0.14 & -0.08 \\
6. Gender & & & & & - & 0.10 & 0.09 & 0.04 \\
7. Age & & & & & & - & 0.03 & -0.15 \\
8. Dog Behavior & & & & & & & - & $0.31 *$ \\
9. Dog Size & & & & & & & - \\
\hline
\end{tabular}

$$
* p<0.05 ; * * p<0.01 \text {. }
$$

Given bivariate results, we constructed a hierarchical linear regression model to test the relation between shyness and risk-taking after controlling for potential covariates (See Table 5). Four covariates were included in the first step of the model: child age, child gender, dog size, and dog behavior $\left(R^{2}=0.07, F(4,87)=1.56\right.$, ns). With shyness included in the second step, all predictors accounted for $13 \%$ of the variance in risk-taking, and the overall model was significant $\left(R^{2}=0.13\right.$, $F(5,87)=2.49, p<0.05)$. The association between shyness and risk-taking remained statistically significant after controlling for all covariates $(\beta=-0.26, t(82)=-2.42, p<0.05)$. The only other significant predictor in the final model was the dog's behavior during the interaction $(\beta=0.25$, $t(82)=2.27, p<0.05$ ), which indicated that the more active/approaching the dog was, the more risk-taking the child showed.

Table 5. Summary of Hierarchical Linear Regression Analysis for Variables Predicting Risk-Taking $(\mathrm{N}=88)$.

\begin{tabular}{lccc}
\hline \multicolumn{1}{c}{ Variable } & $\boldsymbol{B}$ & $\boldsymbol{S E} \boldsymbol{B}$ & $\mathbf{B}$ \\
\hline Step 1 & & & \\
Gender & -0.06 & 0.13 & -0.05 \\
Age & 0.08 & 0.07 & 0.12 \\
Dog Size & 0.13 & 0.07 & 0.21 \\
Dog Behavior & 0.15 & 0.05 & $0.22 *$ \\
\hline Step 2 & & \\
Gender & -0.01 & 0.13 & -0.01 \\
Age & 0.08 & 0.07 & 0.12 \\
Dog Size & 0.12 & 0.07 & 0.19 \\
Dog Behavior & 0.17 & 0.07 & $0.25 *$ \\
Shyness & -0.13 & 0.06 & $-0.26 *$ \\
\hline & \multirow{2}{*}{$* p<0.05}$. &
\end{tabular}

\section{Discussion}

Temperamental shyness, but not approach, impulsivity, or inhibitory control, was related to children's risk-taking behavior with a previously unfamiliar live dog. This association was 
maintained after controlling for various covariates, including children's age and gender and the dog's behavior (approach and activity level) and size. In this study, shyness was conceptualized as "slow or inhibited approach in situations involving novelty or uncertainty" [20]. Our findings indicate, therefore, that children may have interpreted the interaction with the live dog as a novel and uncertain encounter. Those children who were rated by their parents as more shy - those rated as more cautious and fearful in novel or uncertain social situations - tended to be somewhat more cautious and fearful in interacting with the dog. Those parents who rated their children to be less shy-whose children were rated as bolder and less fearful in social situations-were somewhat more likely to take risks in interacting with the dog.

The fact that greater shyness was associated with lower risk-taking with the dog is sensible. It reflects the possibility that risk-taking by young children with dogs, including behaviors that may sometimes provoke the dog into biting the child, may be driven partially by temperamental traits. In particular, such risk-taking may be more likely in children who are not shy, who are bold and outgoing in social situations, and who respond to novel, unfamiliar, or uncertain situations with some degree of disinhibition or approach tendency. Children who are more cautious, inhibited, or shy in such situations may be protected somewhat from dog-bite injury risk, partly because they avoid potentially injurious situations and therefore have reduced exposure to potentially injurious situations. The finding also supports results from Vollrath and colleagues [21], who found that low scores on a measure of shyness were related to children's exposure to injuries in traffic and recreational environments.

One surprising aspect of our results was the fact that approach, impulsivity, and inhibitory control were all unrelated to risk-taking with the dog. Previous work has linked both impulsivity and inhibitory control to general unintentional injury risk in this age group [17], and all three traits include behavioral tendencies we expected may have related to risk-taking with the dog.

Our results suggest children's behavior with dogs is driven more by shyness than by tendencies to approach pleasure (approach) [20] or engage quickly in response to stimuli (impulsivity) [20]. The null finding with approach is surprising. Dogs are likely to invoke pleasure in many children, but perhaps less than other stimuli children encounter. Alternatively, children may not have interpreted an unexpected encounter with an unfamiliar dog as pleasurable; it may instead have aroused emotions of caution, fear, or-as our results suggest-shyness. The null result with impulsivity was also surprising. One possible explanation is that impulsivity may play a greater role in environments where potentially injurious decisions are made quickly (e.g., pedestrian settings) than in less time-urgent situations such as an interaction with an unfamiliar dog.

The fact that inhibitory control was not related to children's behavior with the dog implies children's behaviors with the dog were not driven by their capacity to suppress responses. Inhibitory control is expressed via behavioral suppression in at least two circumstances. First, it is expressed when danger is recognized. It is possible that young children did not recognize the danger in interacting with unfamiliar dogs, and therefore had no need to suppress approach responses with them (although therapy dogs were used, children were not explicitly told this fact). Second, inhibitory control is expressed when children face a situation they know is prohibited. It may be that most young children with pet dogs do not have prohibitions (e.g., from parents) against playing 
with unfamiliar dogs when adults are present, and therefore inhibitory control was not associated with their risk-taking in the experiment. Future research might evaluate these and other possibilities.

\section{Strengths, Limitations, Implications and Conclusions}

There are several strengths in this study. While past research has relied on medical records or parent report of dog bite history to assess the risks for dog bites, this study used a laboratory-based observational design to assess children's actual behavior with a live dog and then code that behavior via videotape, a methodological strategy that may have improved the validity of assessing children's behavior with a dog. Several limitations should be noted. First, we relied only on parent report to assess child temperament and did not have a behavioral measure. Second, the sample size was rather modest, although statistical power was sufficient $(>0.75)$ to detect medium effect sizes in the regression model. Third, the live dogs used in the protocol were unfamiliar to the children and were certified therapy dogs. Results may not translate to familiar or pet dogs. Further, although children were not explicitly told the dogs were certified therapy dogs (parents were told during consenting), the dog's calm nature may have been apparent to them. Fourth, we focused our analysis primarily on temperament and demographic factors. Our regression model accounted for only $13 \%$ of the variance in children's behavior, suggesting other factors of interest were not evaluated in this study. Last, our coding scheme was developed specifically for this study and, though based in theory and previous child temperament research, may not have construct validity to detect variance in the constructs of interest.

The study has implications for both future research and for development of dog-bite intervention programs. From a research perspective, future work might consider laboratory-based experimental designs as one means to continue to explore which children have increased risk of dog bites and under which circumstances. We were able to successfully study children's interactions with live therapy dogs in a controlled setting, offering a unique first-hand perspective of children's risk-taking behavior with unfamiliar but certified-to-be-calm dogs. From the perspective of intervention development, our findings suggest children's individual differences may play a role in risk for dog bite injuries. Current dog bite prevention programs tend to focus primarily on changing dogs and their owners via policy and regulations concerning matters such as use of leashes, controls on high-risk breeds, and obedience training. Educational programs for children have also been found to be somewhat successful in children's behavior around dogs [22]. Our results suggest interventions targeting children might offer a different avenue toward preventing dog bites. Our results do not indicate that only a certain group of children (non-shy ones) are at risk of dog bites, so broad interventions targeting children would be optimal. With limited resources however, our results do suggest that children who are not shy and live in homes with dogs may have somewhat increased risk of bites and therefore might form a logical choice for more intensive adult supervision while playing with the family pet or for more intensive training in dog safety lessons. In the end, combining broad child-oriented interventions with programs and policy targeting dogs and their owners may be the best strategy to reduce dog bite incidence worldwide. 


\section{Acknowledgments}

Work on this project was supported by the Blue Dog Trust. The content is solely the responsibility of the authors and does not necessarily represent the official views of the Blue Dog Trust. Thanks to Ed Cook, Bart Hodgens, Grazyna Kochanska, and Josh Klapow for their input on interpreting the results. Also thanks to Elizabeth O'Neal and many other research assistants who contributed to the data collection, entry and coding. Finally, we thank the dogs and dog owners, particularly Judy Sheeska at UG, for their enthusiastic participation.

\section{Conflicts of Interest}

The authors declare no conflict of interest.

\section{References}

1. Sacks, J.J.; Kresnow, M.; Houston, B. Dog bites: How big a problem? Inj. Prev. 1996, 2, $52-54$.

2. Centers for Disease Control and Prevention. Dog Bite Prevention; 2008. Available online: http://www.cdc.gov/HomeandRecreationalSafety/Dog-Bites/dogbit-factsheet.html (accessed on 16 June 2011).

3. Bernardo, L.M.; Gardner, M.J.; O’Connor, J.; Amon, N. Dog bites in children treated in a pediatric emergency department. J. Soc. Pediatr. Nurs. 2000, 5, 87-95.

4. Lang, M.E.; Kalssen, T. Dog bites in Canadian children: A five-year review of severity and emergency department management. CJEM 2005, 7, 309-314.

5. Ashby, K.; Routley, V.; Stathakis, V. Enforcing legislative and regulatory injury prevention strategies. Hazard 1998, 34, 1-5.

6. Cornelissen, J.M.R.; Hopster, H. Dog bites in The Netherlands: A study of victims, injuries, circumstances and aggressors to support evaluation of breed specific legislation. Vet. J. 2010, 186, 292-298.

7. Piaget, J. The stages of the intellectual development of the child. Bull. Menninger Clin. 1962, 26, 120-128.

8. Sodian, B.; Taylore, C.; Harris, P.L.; Perner, J. Early deception and the child's theory of mind: False trails and genuine markers. Child Dev. 1991, 62, 468-483.

9. Millot, J.L.; Filiatre, J.C.; Gagnon, A.C.; Eckerlin, A.; Montagner, H. Children and their pet dogs: How they communicate. Behav. Process. 1988, 17, 1-15.

10. Racca, A.; Amadei, E.; Ligout, S.; Guo, K.; Meints, K.; Mills, D. Discrimination of human and dog faces and inversion responses in domestic dogs (Canis familiaris). Anim. Cogn. 2012, 13, $525-533$.

11. Ashby, K. Dog bites. Hazard 1996, 30, 7-13.

12. Mathews, J.R.; Lattel, K.A. A behavioral analysis of dog bites to children. J. Dev. Behav. Pediatr. 1994, 15, 44-52.

13. Reisner, I.R.; Nance, M.L.; Zeller, J.S.; Housekneckt, E.M.; Sassam-Adams, N.; Wiebe, D.J. Behavioural characteristics associated with dog bites to children presenting to an urban trauma centre. Inj. Prev. 2010, 10, 1136-1140. 
14. Weiss, H.B.; Friedman, D.I.; Coben, J.H. Incidence of dog bite injuries treated in emergency departments. JAMA 1998, 279, 51-53.

15. Kaye, A.E.; Belz, J.M.; Kirschner, R.E. Pediatric dog bite injuries: A 5 year review of the experience at the Children's Hospital of Philadelphia. Plast. Reconstr. Surg. 2009, 124, 551-558.

16. Rothbart, M.K.; Bates, J.E. Temperament. In History of Temperament: Research on Childhood; Damon, W., Ed.; Wiley: Hoboken, NJ, USA, 2006; pp. 99-166.

17. Schwebel, D.C.; Barton, B.K. Temperament and Children's Unintentional Injuries. In Handbook of Personality and Health; Vollrath, M., Ed.; Wiley: New York, NY, USA, 2006; pp. 51-71.

18. Little, H. Children's risk-taking behaviour: implications for early childhood policy and practice. Int. J. Early Years Educ. 2006, 14, 141-154.

19. Rothbart, M.K.; Ahadi, S.A.; Hershey, K.L.; Fisher, P. Investigations of temperament at 3-7 years: The Children's Behavior Questionnaire. Child Dev. 2001, 72, 1394-1408.

20. Rothbart, M.K. Temperament, development, and personality. Curr. Dir. Psychol. Sci. 2007, $16,207-212$.

21. Vollrath, M.; Landolt, M.A.; Ribi, K. Personality of children with accident-related injuries. Eur. J. Pers. 2003, 17, 299-307.

22. Chapman, S.; Cornwall, J.; Righetti, J.; Sung, L. Preventing dog bites in children: randomised controlled trial of an educational intervention. BMJ 2000, 320, 1512-1513. 
Reprinted from Int. J. Environ. Res. Public Health. Cite as: Brussoni, M.; Olsen, L.L.; Pike, I.; Sleet, D.A. Risky Play and Children's Safety: Balancing Priorities for Optimal Child Development. Int. J. Environ. Res. Public Health 2012, 9, 3134-3148.

Review

\title{
Risky Play and Children's Safety: Balancing Priorities for Optimal Child Development
}

Mariana Brussoni $^{1, *}$, Lise L. Olsen ${ }^{2}$, Ian Pike ${ }^{3}$ and David A. Sleet ${ }^{4}$

1 Department of Pediatrics, School of Population and Public Health, British Columbia Injury Research and Prevention Unit, Child and Family Research Institute, University of British Columbia, British Columbia Children's Hospital, L408-4480 Oak Street, Vancouver, V6H 3V4 BC, Canada

2 British Columbia Injury Research and Prevention Unit, Child and Family Research Institute, L408-4480 Oak Street, Vancouver, V6H 3V4 BC, Canada; E-Mail: lolsen@cw.bc.ca

3 Department of Pediatrics, British Columbia Injury Research and Prevention Unit, Child and Family Research Institute University of British Columbia, British Columbia Children's Hospital, L408-4480 Oak Street, Vancouver, V6H 3V4 BC, Canada; E-Mail: ipike@cw.bc.ca

4 Centers for Disease Control and Prevention, National Center for Injury Prevention and Control, 4770 Buford Highway NE F-62, Atlanta, GA 30341, USA; E-Mail: dds6@cdc.gov

* Author to whom correspondence should be addressed; E-Mail: mbrussoni@cw.bc.ca; Tel.: +1-604-875-3712; Fax: +1-604-875-3569.

Received: 18 July 2012; in revised form: 3 August 2012 / Accepted: 22 August 2012 /

Published: 30 August 2012

\begin{abstract}
Injury prevention plays a key role in keeping children safe, but emerging research suggests that imposing too many restrictions on children's outdoor risky play hinders their development. We explore the relationship between child development, play, and conceptions of risk taking with the aim of informing child injury prevention. Generational trends indicate children's diminishing engagement in outdoor play is influenced by parental and societal concerns. We outline the importance of play as a necessary ingredient for healthy child development and review the evidence for arguments supporting the need for outdoor risky play, including: (1) children have a natural propensity towards risky play; and, (2) keeping children safe involves letting them take and manage risks. Literature from many disciplines supports the notion that safety efforts should be balanced with opportunities for child development through outdoor risky play. New avenues for investigation and action are emerging seeking optimal strategies for keeping children "as safe as necessary," not "as safe as possible."
\end{abstract}


This paradigm shift represents a potential for epistemological growth as well as crossdisciplinary collaboration to foster optimal child development while preserving children's safety.

Keywords: injury prevention; outdoor play; risky play; active play; child development; playground safety

\section{Introduction}

Unintentional injuries are a leading cause of death and hospitalization for children worldwide, taking the lives of nearly a million children each year [1]. As deaths from communicable diseases are decreasing, injuries remain a leading cause of childhood mortality and morbidity and represent an increasingly significant public health burden [2]. The grim statistics that on average 720 Canadian [3], over 12,000 American children [4] and 42,000 European children [5] ages 0-19 die every year from injuries make the need for injury prevention abundantly clear.

Injury prevention plays a key role in promoting children's safety, which is considered to involve keeping children free from the occurrence or risk of injury. However, emerging research suggests that imposing too many restrictions on children's outdoor risky play may be hampering their development. Like safety, play is deemed so critical to child development and their physical and mental health that it is included in Article 31 of the United Nations Convention on the Rights of the Child. Thus, limitations on children's play opportunities may be fundamentally hindering their health and well-being. Eager and Little [6] describe a risk deprived child as more prone to problems such as obesity, mental health concerns, lack of independence, and a decrease in learning, perception and judgment skills, created when risk is removed from play and restrictions are too high. Findings from disciplines such as psychology, sociology, landscape architecture and leisure studies, challenge the notion that child safety is paramount and that efforts to optimize child safety in all circumstances is the best approach for child development [7-10]. Furthermore, parents, popular culture, the media, and researchers in other disciplines have expressed views that child safety efforts promote overprotection of children [9,11]. For example, numerous media stories have suggested that excessive health and safety regulations and overprotective parenting practices serve to diminish children's outdoor risky play opportunities [12-14]. Likewise, numerous parenting books disparagingly describe parents perceived to be excessively curtailing their children's independence and voluntary physical risk taking opportunities [15-18]. These have the potential to trigger a backlash against proven safety promotion strategies, such as child safety seats or necessary supervision [19], possibly reversing the significant gains that have been made in reducing child injuries [20,21]. In short, it is timely and important to reflect on our approach towards safety with respect to children's outdoor risky play opportunities and to consider the impact on healthy child development.

In this paper, we explore from an interdisciplinary, public health oriented perspective, the relationship between child development, play, and conceptions of risk taking relating to outdoor risky play. Our aim is to contribute to the discussion on whether the goal of unintentional physical 
injury prevention should be to keep children as safe as possible or as safe as necessary. We conclude with recommendations for child play safety efforts based on key empirical and theoretical findings.

\section{What is Free Play?}

No matter how you define play, it is a dominant activity of children's daily life in all cultures [22]. The study of play has been truly interdisciplinary, yielding research literature from nearly every field affecting human health and well being. By definition, free play is intrinsically motivated and not provoked by instrumental goal-directed behaviour [23]. It is a goal in itself and lacks external rules and structure [23]. Thus, activities such as organized sports would not be considered free play.

Three main types of free play have been well described in the literature: physical activity play (e.g., exercise play, rough-and-tumble play); object play (e.g., manipulating objects, toys); and pretend play (e.g., socio-dramatic) [24]. Risky play is subsumed within physical activity play and has been defined as thrilling and exciting and where there is a risk of physical injury [25]. Sandseter [26] further categorizes risky play into play involving: heights, speed, dangerous tools, or near dangerous elements (e.g., fall into something), and where children can get lost. The focus of this paper is on free play with specific attention to risky play occurring in the outdoors.

\section{Why is Free Play Important?}

Children's free play has been recognized as a major agent in young children's development and learning [27]. Through play, children learn societal roles, norms, and values and develop physical and cognitive competencies, creativity, self-worth and efficacy [24,28]. Play has been described as the work of children which helps them develop intrinsic interests, learn how to make decisions, problem-solve, exert self-control, follow rules, regulate emotions, and develop and maintain peer relationships [23]. Risk taking in play helps children test their physical limits, develop their perceptual-motor capacity, and learn to avoid and adjust to dangerous environments and activities [29]. Play is biologically based and provides an evolutionary contribution to human development and changes [22]. Furthermore, children also report being happiest when at play [30].

A U.S. longitudinal study provides compelling evidence of the importance of free play on healthy development [31]. Sixty-eight disadvantaged children were randomly assigned to participate in one of three preschool curricula at ages 3 to 4 years. Two of the classes included at least $21 \%$ free play and child-initiated activity component. The third class focused on direct instruction of academic skills and allowed for only $2 \%$ of free play activities. When tested at age 15 , children in the latter class were significantly more likely than the other classes to experience misconduct, and less likely to participate in active sports or contribute to their family or community. Furthermore, at age 23, problems worsened with significantly higher levels of work suspensions and arrests [31]. These findings underline that free play is fundamental to healthy child development, and that restriction of free play in the preschool years might potentially have lifelong repercussions.

Animal research provides further evidence of the impact of early free play on healthy development. Rats isolated during the two weeks of development when they most frequently play (weeks 4 and 5) displayed subsequent social disturbances [32]. Additional research with rats indicated that plentiful free play opportunities facilitated maturation of the frontal lobe and thus 
executive functioning $[33,34]$. In children, these brain areas house regulatory skills, which help control impulsive urges and promote self-reflection, creativity and empathy.

Outdoor free play, especially in versatile natural environments, is important for developing motor fitness and abilities, environmental awareness and navigation competencies, as well as promoting creativity $[24,35]$. A Scandinavian study comparing an experimental group of 46 children aged 5 to 7 years in a kindergarten with ready access to a natural play environment with 29 children from two kindergartens with access to traditional outdoor playgrounds found that children in the experimental group used the environment to play in more versatile ways and, nine months later, showed significantly greater improvement in various measures of motor ability [36]. The studies described above and many others [37] strongly support abundant opportunities for outdoor free play as a basic and essential need for healthy child development.

\section{Declining Opportunities for Outdoor Free Play}

There is considerable evidence that children's opportunities to engage in outdoor free play and their geographic freedom have steadily declined across the past several generations [38-41]. A recent U.S. study reported almost half of preschool children were not being taken outside to play by a parent on a daily basis [42]; and while $70 \%$ of U.S. mothers reported daily outdoor free play when they were children, only $31 \%$ reported that their own children did the same [43]. One study of U.S. childhood experiences from 1915 to 1976 showed substantial decreases in children's free play and access to their neighbourhoods beginning in the 1940s and declining steadily over time [44].

Children's ready access to computers and televisions has contributed to an increased proportion of their leisure time being spent indoors, both historically and as children age; and outdoor free play activities are being substituted with organized sporting or other activities such as music lessons [10]. U.S. reports showed a $37 \%$ decline in participation in outdoor activities for children aged 6 to 12 years from 1997 to 2003 [39]. Furthermore, in one study 59\% of children aged 5 to 12 years preferred indoor play to any other location [45]. In Canada, a study of 878 children aged 6 to 11 years wearing accelerometers indicated 7.6 hours of sedentary time per day [46]. Their parent reported an average of 2.5 hours/day of this was screen time. In a survey of 51,922 Canadian children and youth in Grades 6 to 12 (aged approximately 11-18 years), they self-reported an average of 7.8 hours of screen time daily [47]. These studies suggest that children and adolescents increase their sedentary behaviour and screen time as they age. By all accounts, children's leisure lives appear to be moving indoors.

The changes in children's play habits and subsequent effects on their physical and mental health are concerning. Childhood obesity rates have steadily increased, which have been linked to a decrease in physical activity. In 1978-1979, 15\% of Canadian children were considered overweight or obese [48]. The figure rose to $26 \%$ in 2004 and continues to climb. In the U.S., childhood obesity rates have tripled in 30 years [49]. In 2008, 30\% of children were considered overweight or obese [50]. Research in Europe also indicates increasing paediatric obesity [51], with current estimates for 6 to 9 year olds at 24\% [52]. Research has indicated the importance of encouraging free play as an antidote to rising obesity and as a means to increase daily physical activity [53].

A recent review documents the decline of outdoor play and the rise of psychopathology in children and adolescents suggesting a causal link [54]. Gray [54] argues that play deprivation can contribute to a reduced sense of personal control, reduced ability to control emotions, increased 
social isolation, and reduced happiness; all of which are associated with anxiety and/or depression. Indeed, anxiety and depression scores on standardised measurement tools have increased sharply since the 1950's, with current generations of young people having five to eight times more clinically significant scores $[55,56]$.

\section{Why Outdoor Free Play is Declining}

Societal influences on parents have been cited as important drivers of changes in children's outdoor play opportunities. Increased societal concerns about child safety have heightened parental concerns, especially with regard to traffic dangers and child abduction by strangers $[10,43,45,57]$. For example, in a U.K. study of 1,011 parents, $43 \%$ believed that children under the age of 14 years should not be allowed outside unsupervised, and half of those parents felt they should not be allowed outside unsupervised until they were 16 years of age [58]. Parents' perceptions about danger can be disproportionate to actual dangers. While traffic concerns are borne out by statistics, child abductions by strangers are exceedingly rare. Ironically, "stranger-danger" concerns have resulted in increasing volumes of traffic, with corresponding increases in traffic-related dangers [57].

Furthermore, current Western middle class social pressures to maximize children's opportunities and adhere to practices of "intensive parenting" support the notion that parents should have children attend the "best" schools, participate in a multitude of organized activities, and provide as much protection as possible — potentially more than they personally perceive as necessary [10,57,59-61]. The result has been creation of a "backseat generation" with little unstructured play time and reliance on automobile-based commuting from one activity to the next [38].

In an Australian study asking 50 children aged 4 to 8 years old to photograph their daily activities, half of the children included photographs of being driven [59]. Additionally in a U.K. study, girls from middle class backgrounds displayed less knowledge about their neighbourhoods than girls from less affluent backgrounds, because more of their leisure time was spent indoors or in supervised activities, which could affect their ability to negotiate public space safely [10]. These changes in exposure to opportunities to interact with the environment can deprive children of the opportunity to learn important survival skills that only experience with risk can provide. The goal should not be to eliminate all risks, but to control risk, and teach children and adolescents how best to manage risks [62].

Recent decades have seen changes in societal perceptions of children's competencies and resilience [61]. From once considering children as actively responsible and capable, we have more recently moved to viewing them as inadequate by comparison to adults, leading to a perception that children need to be protected from their own inadequacies [10,63]. These trends have contributed to placing limits on children's exploration and access to outdoor free play opportunities $[10,64]$. For example, stemming from their study of children's use of playspaces in 16 childcare centres, Herrington and Nicholls [9] argued that the Canadian Standards Association's own standards for children's playspaces and equipment did not reflect children's developmental and play needs, but rather the goals of risk reduction.

In a similar study examining the play preferences and playground equipment usage of Australian boys and girls ages 48 to 64 months, the authors noted children's preference for equipment and activities that allowed them to experience the sensations of height and speed such as 
slides, swings, monkey bars and climbing ropes [8]. They also noted that the equipment at the five parks studied provided few opportunities for building on or mastery of existing skills, or for learning new skills. They concluded that the equipment provided reflected the priorities of local government (with perhaps a strong focus on safety) rather than those of the children and their preferences for risky play [8]. Jambor [65] noted the concern that insufficient challenge can easily lead to boredom, potentially promoting inappropriate equipment use and excessive risk taking behaviour that is often associated with unintentional injury.

The result of parental and societal fears and influences has been a decline in play spaces offering children opportunities to test out their competencies and imagination. This is despite indications that fears are at odds with trends showing steady decreases in injury rates [20,21] and the relative rarity of playground-related deaths. For example, Ball [7] estimated the odds of playground-related death in the U.K. as less than 1 in 30 million children per annum for children aged 0 to 16 years. While we do not advocate dangerous play environments, we believe it is appropriate to consider how to optimize play opportunities to support children's developmental needs while considering safety.

\section{Support for Outdoor Risky Play}

Research indicates that children have a need for outdoor risky play opportunities. Two main bodies of evidence are reviewed below.

\subsection{Children Have a Natural Propensity towards Outdoor Risky Play}

Undoubtedly, some children have greater appetite for risks than others [66,67]. However, children's propensity for some degree of risky play appears to be universal [25,37]. Naturalistic observations of preschool children engaging in outdoor free play indicate deliberate exposures to risk, such as playing at heights and high speeds [68]. The author notes that children appeared to understand their personal competencies and the level of risk they were comfortable with and moderated their risky play to these internal boundaries. They also understood and accepted that peers would have different levels of comfort and ability.

A study of Australian children ages 48 to 64 months that collected observational and interview data on 38 children indicated that when provided with a choice $74 \%$ of participants preferred to play on the more challenging playground equipment. Furthermore, while only $21 \%$ to $34 \%$ of children had experience using the higher risk equipment (e.g., flying fox, space net, tubular slide), $70 \%$ to $90 \%$ expressed the desire to play on this type of equipment [8]. While there may be the need to use caution in interpreting these results, as children's stated desires may not equate to behaviours, Morrongiello [69] has found a correlation between children's willingness to engage in risk taking behaviours and actual risk taking behaviours.

Animal research demonstrates the propensity for risk taking during play across species. For example, primates at play deliberately expose themselves to moderately frightening situations where they repeatedly lose and regain control of bodily movements [70]. During play fighting, rats prefer the riskier, more physically and emotionally challenging subordinate position [71].

Research suggests that if children perceive they are not obtaining challenging and interesting risky play opportunities in public play areas, they may seek these opportunities elsewhere. A 
survey of 1,973 children aged 11 to 14 years in a deprived area of England indicated that over $40 \%$ regularly visited and played in wastelands, building sites, underpasses, rivers, abandoned buildings and quarries [72]. These children were also more likely to have sustained an injury in the previous month. The surveyed children overwhelmingly reported wanting their local area to be made safer and have more interesting things to do, suggesting that they recognized the danger and risk of injury of their chosen play spaces but had little choice of available and desirable play spaces.

There is evidence to support concerns that absence of opportunities for outdoor risky play will result in children disengaging from physical activity. One Canadian study documenting preschool children's use of play equipment in 16 childcare centres found that play equipment was used only $13 \%$ of the time and was used as intended only $3 \%$ of the time [73]. U.S. childcare providers in one study expressed concerns that overly strict standards had rendered outdoor play areas unchallenging and uninteresting to children, thus hampering their physical activity [74]. Furthermore, participants noted that some children used equipment in unsafe ways to maintain challenge.

\subsection{Keeping Children Safe Involves Letting Them Take and Manage Risks}

Parental concerns regarding children's safety have been shown to be the most significant influence on children's access to independent play [40,45]. Research has found that parents recognize that their early restrictions on children's play has the potential for putting their children at increased risk once they gain more independence [10,11]. Numerous studies indicate that children want to be trusted with decisions with respect to managing risks and safety $[10,75,76]$. In one U.K. study, focus groups were conducted with 93 children aged 7 to 11 years and living in urban and rural areas. Results showed that the children felt strongly about being afforded opportunities for assessing risk for themselves [75]. They created identities reflecting maturity and competence and which included being able to display their ability to manage risks. Taking risks allowed them to display courage and physical skills to themselves and their peers. Interestingly, while they viewed minor injuries as a way to show that risks had been taken, there was an understanding that too many injuries indicated carelessness or clumsiness, which was perceived in derogatory ways [75]. Thus, they appeared to have their own regulatory system for maintaining risks and injuries at a manageable level.

Children in other U.K. research [10] perceived themselves as competent at negotiating their own safety. Furthermore, they felt that they, and not their parents, were primarily responsible for their own safety. In many cases the children had more detailed knowledge of the local area than their parents and used it to negotiate spaces safely.

There is evidence that children learn risk management strategies for themselves and their peers as a result of risky play experiences. Observational studies of children at play found they exposed themselves to risk but displayed clear strategies for mitigating harm $[68,76]$. Australian children, for the most part, engaged in behaviours that were well within their current capabilities [8]. Children appeared aware of potential dangers and adjusted activities accordingly. Notably, children drew on their risk experiences not only to develop understanding of their own constitutions and skills, but also of playmates. These understandings facilitated support for each other's risk engagement and safety [76]. 
Sandseter and Kennair [25] theorized that children's engagement in risky play has an adaptive function in reducing fear of stimuli (e.g., heights) through repeatedly naturally and progressively exposing themselves to the stimuli. They argued that if children were not provided with sufficient risky play opportunities, they will not experience their ability to cope with fear-inducing situations. Furthermore, they will maintain their fear, which may translate into anxiety disorders. Support for these argument also comes from animal research, which has shown that young rhesus monkeys and rats deprived of play during critical development points later show excessive fear, inappropriate aggression and exaggerated emotional reactions in stressful situations [71,77]. Importantly, anxiety disorders are the most prevalent mental disorder in children and adolescents and parental overprotection has been associated with increased rates [78].

\section{Alternative Free Play Environments that Manage Risks}

"Adventure playgrounds" may be a potential solution to providing safe play environments that afford opportunities for risk taking [79]. First established in 1943 by Danish landscape architect Sørensen after observing children's play in construction sites and junkyards, he sought to provide children with dedicated space to foster otherwise prohibited play [80,81]. Adventure playgrounds were subsequently championed in England during the postwar era in reaction to the lack of interest children showed to conventional playgrounds and in seeking to provide creative spaces appealing to boys and girls of all ages [80]. They emerged as staffed and unstaffed play spaces where play workers could provide supervision and assistance, while still giving children the freedom to pursue their own interests. Adventure playgrounds provide child-centered and child-directed play spaces where children create and modify their own environments [80]. Children have access to raw materials such as building supplies and tools, as well as sand, dirt and water. In some cases, adventure playgrounds include trained play workers and volunteers for supervision and "professional scaffolding" that facilitates children's play and removes play barriers [81]. Different opportunities exist for children of varying developmental levels and interests to try new things, such as climbing that is graded for developmental requirements, allowing children to select risk they are comfortable with. Some adventure playgrounds in proximity to farms or community gardens provide children with the opportunity to interact with and care for animals, and grow and cook their own food [81]. While there are estimates of approximately 1,000 adventure playgrounds in Europe, they have not been widespread in North America, which is believed to be the result of culture-specific safety concerns [81].

Research on adventure playgrounds, safety and child development is in its infancy and few academic peer-reviewed articles are available. There are accounts in the grey literature indicating lower injury rates than conventional playgrounds [81], reductions in aggressive behaviour and gains in social responsibility and social problem solving [82]. Organizations such as Play England [79] are exploring methods for promoting playground settings and adventure playgrounds that do not have the same cost implications of staffed adventure playgrounds, yet manage injury risk. Their guide describes how to undertake a risk-benefit assessment to determine the benefits and risks of a play area and activity focusing on "hazards with the potential to cause real harm" and incorporating considerations with respect to local circumstances and needs [79]. Clearly further investigation is required to understand the developmental and safety implications of adventure playgrounds. 
However, early data are promising and encourage serious consideration of this model in promoting child risky play.

\section{Conclusions}

Children's need for play has been globally recognized as a basic childhood right. Numerous developmental and health advantages have also been linked to children's need for outdoor risky play as a means to learn through experience. Societal trends limiting children's access to outdoor risky play opportunities combined with a culturally dominant excessive focus on safety can pose a threat to healthy child development. Eager and Little [6] have coined the term "Risk Deficit Disorder" to describe a set of problems that children can experience resulting from attempts to remove risk from their lives. Our examination of the evidence would suggest that such a label is premature. However, we share their concerns with respect to the trends evident in aspects of child safety efforts relating to outdoor play.

We would encourage the injury prevention field to foster opportunities to engage in outdoor risky play that align with safety efforts. An approach can be encouraged that focuses on eliminating hazards, which Wallach [83] (as cited in [65]) defines as a source of harm that is not obvious to the child, such that the potential for injury is hidden, such as a broken railing; but does not eliminate all risks, which involve a situation that allows the child to recognize and evaluate the challenge and decide on a course of action that is not dangerous, but may still involve an element of risk. This approach has been advocated elsewhere [84] and is a central component of the Adventure Playground movement. Notably, European and Australian organizations and researchers appear to be attempting to operationalise this idea in practice, with North American efforts lagging. For example, the National Institute for Health and Clinical Excellence in the U.K. released injury prevention guidelines that called for policies that counter "excessive risk aversion" and promote children's need "to develop skills to assess and manage risks, according to their age and ability" [85]. Both injury and play organizations, such as the U.K.'s Royal Society for the Prevention of Accidents [62] and Play Safety Forum [84] promote the idea of keeping children as safe as necessary, not as safe as possible. International collaboration would benefit from translating this into practice in a manner that is sensitive to concerns for child safety and children's developmental needs for risky play.

Research is emerging which considers optimal strategies for providing children with outdoor risky play opportunities that minimize hazards, such as adventure playgrounds $[6,79,86]$ or provision of unstructured play materials that can be freely manipulated in conventional playgrounds $[73,87]$. These novel areas of investigation have the potential to open up many exciting avenues for injury prevention and represent an opportunity for epistemological growth, cross-disciplinary and international collaboration to foster optimal child development.

\section{Acknowledgments}

Career support for Mariana Brussoni is provided by a Michael Smith Foundation for Health Research (MSFHR) scholar award and a British Columbia Child and Family Research Institute salary award. Career support for Ian Pike is provided by a British Columbia Child and Family 
Research Institute (CFRI) salary award. Lise Olsen is supported by a CFRI post doctoral award. Special thanks to Genevieve Creighton and Lori Wagar for their assistance in the preparation of this article. The opinions expressed are those of the authors and do not necessarily represent the official views of the Centers for Disease Control and Prevention.

\section{Conflicts of Interest}

The authors declare no conflict of interest.

\section{References}

1. Peden, M.; Oyegbite, K.; Ozanne-Smith, J.; Hyder, A.A.; Branche, C.; Rahman, A.D.M.F.; Rivara, F.; Bartolomeos, K. Reference. In World Report on Child Injury Prevention; World Health Organization Press: Geneva, Switzerland, 2008.

2. Meddings, D. Child injury prevention and child survival. Inj. Prev. 2011, 17, 145-146.

3. Public Health Agency of Canada. Reference. In Child and Youth Injury in Review, 2009 Edition-Spotlight on Consumer Product Safety; Public Health Agency of Canada: Ottawa, ON, Canada, 2009.

4. Centers for Disease Control and Prevention, CDC Childhood Injury Report: Patterns of Unintentional Injuries among 0-19 Year Olds in the United States, 2000-2006. In Centers for Disease Control and Prevention; National Center for Injury Prevention and Control: Atlanta, GA, USA, 2008.

5. Sethi, D.; Towner, E.; Vincenten, J.; Segui-Gomez, M.; Racioppi, F. Reference. In European Report on Child Injury Prevention; World Health Organization: Rome, Italy, 2008.

6. Eager, D.; Little, H. Risk Deficit Disorder. In Proceeding of IPWEA International Public Works Conference, Canberra, Australia, 21-24 August 2011.

7. Ball, D.J. Policy issues and risk-benefit trade-offs of "safer surfacing" for children's playgrounds. Accid. Anal. Prev. 2004, 36, 661-670.

8. Little, H.; Eager, D. Risk, challenge and safety: Implications for play quality and playground design. Eur. Early Child Educ. Res. J. 2010, 18, 497-513.

9. Herrington, S.; Nicholls, J. Outdoor play spaces in Canada: The safety dance of standards as policy. Crit. Soc. Policy 2007, 27, 128-138.

10. Valentine, G. "Oh yes I can" "Oh no you can't": Children and parents' understandings of kids' competence to negotiate public space safely. Antipode 1997, 29, 65-89.

11. Brussoni, M.; Olsen, L. The perils of overprotective parenting: Fathers' perspectives explored. Child. Care Health Dev. 2012, doi:10.1111/j.1365-2214.2011.01361.x.

12. Batty, D. Health and Safety Review to Curb the 'Nanny State'. Available online: http://www. guardian.co.uk/society/2010/oct/02/health-safety-review-nanny-state (accessed 24 August 2012).

13. Marano, H.E. A Nation of Wimps. Available online: http://www.psychologytoday.com/ articles/200411/nation-wimps (accessed on 24 August 2012)

14. Baluja, T.; McGinn, D. Parental Fear Contributing to Sedentary Lifestyle of Canadian Children: Report. Available online: http:/www.theglobeandmail.com/news/national/parental-fear- 
contributing-to-sedentary-lifestyle-of-canadian-children-report/article4217180/ (accessed on 29 May 2012).

15. Ungar, M. Reference. In Too Safe for Their Own Good; McClelland \& Stewart: Toronto, ON, Canada, 2007.

16. Skenazy, L. Reference. In Free Range Kids: Giving Our Children the Freedom We Had without Going Nuts with Worry; Jossey-Bass: San Francisco, CA, USA, 2009.

17. Honoré, C. Reference. In Under Pressure: Rescuing Our Children from the Culture of Hyper-Parenting; Knopf: Toronto, ON, Canada, 2008.

18. Marano, H.E. Reference. In A Nation of Wimps: The High Cost of Invasive Parenting; Broadway Books: New York, NY, UK, 2008.

19. Vincenten, J.; Mackay, M.; Brussoni, M.; Towner, E.; Fuselli, P. Reference. In Child Safety Good Practice Guide: Good Investments in Unintentional Child Injury Prevention and Safety Promotion-Canadian Edition; Safe Kids Canada: Toronto, ON, Canada, 2011.

20. Birken, C.S.; Parkin, P.C.; To, T.; Macarthur, C. Trends in rates of death from unintentional injury among Canadian children in urban areas: Influence of socioeconomic status. Can. Med. Assoc. J. 2006, 175, 867-868.

21. Centers for Disease Control and Prevention. Vital signs: Unintentional injury deaths among persons aged 0-19 years-United States, 2000-2009. MMWR 2012, 61, 270-276.

22. Hyun, E. Culture and Development in Children's Play. In Making Sense of Developmentally and Culturally Appropriate Practice (DCAP) in Early Childhood Education; Peter Lang Publishing: New York, NY, UK, 1998; pp. 15-30.

23. Pellegrini, A.D. Play: What is It? In The role of Play in Human Development; Oxford University Press: Oxford, UK, 2009; pp. 6-20.

24. Smith, P.K. Play: Types and Functions in Human Development. In Origins of the Social Mind: Evolutionary Psychology and Child Development; Ellis, B.J., Bjorklund, D.F., Eds.; Guilford Press: New York, NY, USA, 2005.

25. Sandseter, E.B.H.; Kennair, L.E.O. Children's risky play from an evolutionary perspective: The anti-phobic effects of thrilling experiences. Evol. Psychol. 2011, 9, 257-284.

26. Sandseter, E.B.H. Categorising risky play—How can we identify risk-taking in children's play? Eur. Early Child Educ. Res. J. 2007, 15, 237-252.

27. Fromberg, D.P.; Bergen, D. Reference. In Play from Birth to Twelve: Contexts, Perspectives and Meanings; 2nd ed.; Routledge: New York, NY, USA, 2006.

28. Milteer, R.M.; Ginsburg, K.R. The importance of play in promoting healthy child development and maintaining strong parent-child bond: Focus on children in poverty. Pediatrics 2012, 129, e204-e213.

29. Jambor, T. Challenge and Risk-Taking in Play. In Play from Birth to Twelve and Beyond: Contexts, Perspectives, and Meanings; Fromberg, D.P., Bergen, D., Eds.; Routledge: New York, NY, USA, 1998.

30. Csikszentmihalyi, M.; Hunter, J. Happiness in everyday life: The uses of experience sampling. J. Happiness Stud. 2003, 4, 185-199.

31. Weikart, D.P. Changing early childhood development through educational intervention. Prev. Med. 1998, 27, 233-237. 
32. Hol, T.; van den Berg, C.L.; Van Ree, J.M.; Spruijt, B.M. Isolation during the play period in infancy decreases adult social interactions in rats. Behav. Brain Res. 1999, 100, 91-97.

33. Panksepp, J.; Burgdorf, J.; Turner, C.; Gordon, N. Modeling ADHD-type arousal with unilateral frontal cortex damage in rats and beneficial effects of play therapy. Brain Cogn. 2003, 52, 97-105.

34. Panksepp, J. Can play diminish ADHD and facilitate the construction of the social brain? J. Can. Acad. Child Adolesc. Psychiatry 2007, 16, 57-66.

35. Taylor, A.F.; Kuo, F.E. Is Contact with Nature Important for Healthy Child Development? State of the Evidence. In Children and Their Environments; Spencer, C., Blades, M., Eds.; Cambridge University Press: Cambridge, UK, 2006; pp. 124-140.

36. Fjørtoft, I. The natural environment as a playground for children: The impact of outdoor play activities in pre-primary school children. Early Child. Educ. J. 2001, 29, 111-117.

37. Bruner, J.S.; Jolly, A.; Sylva, K. Reference. In Play-It's Role in Development and Evolution; Basic Books, Inc.: New York, NY, USA, 1976.

38. Karsten, L. It all used to be better? Different generations on continuity and change in urban children's daily use of space. Child. Geogr. 2005, 3, 275-290.

39. Hofferth, S.L. Changes in American children's time-1997 to 2003. Electron. Int. J. Time Use Res. 2009, 6, 26-47.

40. Valentine, G.; McKendrick, J. Children's outdoor play: Exploring parental concerns about children's safety and the changing nature of childhood. Geoforum 1997, 28, 219-235.

41. Hofferth, S.L.; Sandberg, J.F. How American children spend their time. J. Marriage Fam. 2001, 63, 295-308.

42. Tandon, P.S.; Zhou, C.; Christakis, D.A. Frequency of parent-supervised outdoor play of US preschool-aged children. Arch. Pediatr. Adolesc. Med. 2012, doi:10.1001/archpediatrics. 2011.1835.

43. Clements, R. An investigation of the status of outdoor play. Contemp. Issues Early Child. 2004, 5, 68-80.

44. Gaster, S. Urban children's access to their neighborhood: Changes over three generations. Environ. Behav. 1991, 23, 70-85.

45. Tandy, C.A. Children's diminishing play spaces: A study of inter-generational change in children's use of their neighbourhoods. Aust. Geogr. Stud. 1999, 37, 154-164.

46. Colley, R.C.; Wong, S.L.; Garriaguet, D.; Janssen, I.; Connor, S.G.; Tremblay, M.S. Physical activity, sedentary behaviour and sleep in Canadian children: Parent-reported versus direct measures and relative associations with health risk. Health Rep. 2012, 23, 1-8.

47. Leatherdale, S.T.; Ahmed, R. Screen-based sedentary behaviours among a nationally representative sample of youth: Are Canadian children couch potatoes? CDIC 2011, 31, 141-146.

48. Colman, R.; Hayward, K. Reference. In Childhood Overweight and Obesity: Summary of Evidence from the 'Cost of Obesity in Alberta' Report; Alberta Health Services: Calgary, AB, Canada, 2010.

49. Centers for Disease Control and Prevention. Adolescent and Social Health. Available online: http://www.cdc.gov/healthyyouth/obesity/facts.htm (accessed on 2 May 2012). 
50. Ogden, C.L.; Carroll, M.D.; Curtin, L.R.; Lamb, M.M.; Flegal, K.M. Prevalence of high body mass index in US children and adolescents, 2007-2008. JAMA 2010, 303, 242-249.

51. Livingstone, M.B.E. Childhood obesity in Europe: A growing concern. Public Health Nutr. 2001, 4, 109-116.

52. World Health Organization. European Childhood Obesity Surveillance Initiative (COSI). Available online: http:/www.euro.who.int/en/what-we-do/health-topics/disease-prevention/ nutrition/policy/member-states-action-networks/childhood-obesity-surveillance/europeanchildhood-obesity-surveillance-initiative-cosi (accessed on 13 July 2012).

53. Burdett, H.L.; Whitaker, R.C. Resurrecting free play in young children: Looking beyond fitness and fatness to attention, affiliation, and affect. Arch. Pediatr. Adolesc. Med. 2005, 159, $46-50$.

54. Gray, P. The decline of play and the rise of psychopathology in children and adolescents. Am. J. Play 2011, 3, 443-463.

55. Twenge, J.M. The age of anxiety? Birth cohort change in anxiety and neuroticism, 1952-1993. J. Pers. Soc. Psychol. 2000, 79, 1007-1021.

56. Twenge, J.M.; Gentile, B.; Dewall, C.N.; Ma, D.; Lacefield, K.; Shurtz, D.R. Birth cohort increases in psychopathology among young Americans, 1938-2007: A cross-temporal meta-analysis of the MMPI. Clin. Psychol. Rev. 2010, 30, 145-154.

57. Carver, A.; Timperio, A.; Crawford, D. Playing it safe: The influence of neighbourhood safety on Children's physical activity_A review. Health Place 2008, 14, 217-227.

58. Living Streets. No Ball Games Here. Available online: http:/noballgames.eu/uploads/documents/ no-ball-games\%20report\%20by\%20living\%20streets.pdf (accessed on 24 August 2012).

59. Malone, K. The bubble-wrap generation: Children growing up in walled gardens. Environ. Educ. Res. 2007, 13, 513-527.

60. Shirani, F.; Henwood, K.; Coltart, C. Meeting the challenges of intensive parenting culture: Gender, risk management and the moral parent. Sociology 2012, 46, 25-40.

61. Hoffman, D.M. Risky investments: Parenting and the production of the 'resilient child'. Health Risk Soc. 2010, 12, 385-394.

62. Leisure Safety: Safety and Risk Education. Available online: http://www.rospa.com/leisuresafety/ adviceandinformation/safetyandriskeducation/default.aspx (accessed on 2 May 2012).

63. Cunningham, H. Reference. In Children and Childhood in Western Society since 1500; Pearson Education Ltd: Harlow, UK, 2005.

64. Valentine, G. Exploring children and young people's narratives of identity. Geoforum 2000, 31, 257-267.

65. Jambor, T. Coordinating the Elusive Playground Triad: Managing Children's Risk-Taking Behavior while Facilitating Optimal Challenge Opportunities within a Safe Environment. In Proceeding of International Conference on Playground Safety, University Park, PA, USA, 10 October 1995.

66. Morrongiello, B.A.; Lasenby-Lessard, J. Psychological determinants of risk taking by children: An integrative model and implications for interventions. Inj. Prev. 2007, 13, 20-25.

67. Mytton, J.; Towner, E.; Brussoni, M.; Gray, S. Unintentional injuries in school-aged children and adolescents: Lessons from a systematic review of cohort studies. Inj. Prev. 2009, 15, 111-124. 
68. Sandseter, E.B.H. Risky play and risk management in Norwegian preschools - A qualitative observational study. Safety Sci. Monitor 2009, 13, 1-12.

69. Morrongiello, B.A. Do children's intentions to risk take relate to actual risk taking? Inj. Prev. 2004, 10, 62-64.

70. Spinka, M.; Newberry, R.C.; Bekoff, M. Mammalian play: Training for the unexpected. Q. Rev. Biol. 2001, 76, 141-168.

71. Pellis, S.M.; Pellis, V.C.; Bell, H.C. The function of play in the development of the social brain. Am. J. Play 2010, 2, 278-296.

72. Grundy, S.; Towner, E.; Sparks, G.; Hughes, K. Reference. In Social Characteristics of Leisure Injuries and Risk Taking among 11-14 Year Olds; Child Accident Prevention Trust: London, UK, 2002.

73. Herrington, S.; Lesmeister, C.; Nicholls, J.; Stefiuk, K. Seven Cs: An informational Guide to Young Children's Outdoor Play Spaces. Available online: http://www.wstcoast.org/playspaces/ outsidecriteria/7Cs.pdf (accessed on 24 August 2012).

74. Copeland, K.A.; Sherman, S.N.; Kendeigh, C.A.; Kalkwarf, H.J. Societal values and policies may curtail preschool children's physical activity in child care centres. Pediatrics 2012, 129, 265-274.

75. Green, J. Risk and the construction of social identity: Children's talk about accidents. Sociol. Health Illn. 1997, 19, 457-479.

76. Christensen, P.; Mikkelsen, M.R. Jumping off and being careful: Children's strategies of risk management in everyday life. Sociol. Health Illn. 2008, 30, 112-130.

77. LaFreniere, P. Evolutionary functions of social play: Life histories, sex differences, and emotion regulation. Am. J. Play 2011, 3, 464-488.

78. Beesdo, K.; Knappe, S.; Pine, D.S. Anxiety and anxiety disorders in children and adolescents: Developmental issues and implicatons for DSM-V. Psychiatr. Clin. North Am. 2009, 32, 483-524.

79. Ball, D.; Gill, T.; Spiegal, B. Managing Risk in Play Provision: Implementation Guide; Play England: London, UK, 2008.

80. Kozlovsky, R. Adventure Playgrounds and Postwar Reconstruction. In Designing Modern Childhoods: History, Space and the Material Culture of Children: An International Reader; Gutman, M., Coninck-Smith, N.D., Eds.; Rutgers University Press: New Brunswick, NJ, Canada, 2008.

81. Staempfli, M.B. Reintroducing adventure into children's outdoor play environments. Environ. Behav. 2009, 41, 268-280.

82. Sutton, L. Adventure Playgrounds: A Children's World in the City. Available online: http://adventureplaygrounds.hampshire.edu/adventureplay.pdf (accessed on 25 June 2012).

83. Wallach, F. Playground safety: What did we do wrong? Park. Recreat. 1992, 27, 52-57.

84. Play Safety Forum. Managing Risk in Play Provision: A Position Statement. Available online: http://www.playengland.org.uk/media/120462/managing-risk-play-safety-forum.pdf (accessed on 24 August 2012). 
85. National Institute for Health and Clinical Excellence. NICE Public Health Guidance 29. Strategies to Prevent Unintentional Injuries among Children and Young People Aged under 15s. Available online: http://publications.nice.org.uk/strategies-to-prevent-unintentionalinjuries-among-the-under-15s-ph29 (accessed on 24 August 2012).

86. Gill, T. Reference. In No Fear: Growing up in a Risk Averse Society; Calouste Gulbenkian Foundation: London, UK, 2007.

87. Bundy, A.C.; Naughton, G.; Tranter, P.; Wyver, S.; Baur, L.; Schiller, W.; Bauman, A.; Engelen, L.; Ragen, J.; Luckett, T.; et al. The Sydney Playground Project: Popping the bubblewrap-Unleashing the power of play: A cluster randomized controlled trial of a primary school playground-based intervention aiming to increase children's physical activity and social skills. BMC Public Health 2011, doi:10.1186/1471-2458-11-680. 
Reprinted from Int. J. Environ. Res. Public Health. Cite as: Snidero, S.; Soriani, N.; Baldi, I.; Zobec, F.; Berchialla, P.; Gregori, D. Scale-Up Approach in CATI Surveys for Estimating the Number of Foreign Body Injuries in the Aero-Digestive Tract in Children. Int. J. Environ. Res. Public Health 2012, 9, 4056-4067.

Article

\title{
Scale-Up Approach in CATI Surveys for Estimating the Number of Foreign Body Injuries in the Aero-digestive Tract in Children
}

\author{
Silvia Snidero ${ }^{1}$, Nicola Soriani ${ }^{2}$, Ileana Baldi ${ }^{2}$, Federica Zobec ${ }^{3}$, Paola Berchialla ${ }^{4}$ and \\ Dario Gregori ${ }^{2, *}$
}

1 Department of Public Health and Microbiology, University of Torino, Torino, 10126, Italy; E-Mails: silvia.snidero@gmail.com (S.S.); paola.berchialla@unito.it (P.B.)

2 Unit of Biostatistics, Epidemiology and Public Health, Department of Cardiac, Thoracic and Vascular Sciences, University of Padova, Padova, 35121, Italy; E-Mails: nicola.soriani@unipd.it (N.S.); ileana.baldi@unipd.it (I.B.)

3 ZETA Research Incorporation, Trieste, 34129, Italy; E-Mail: federica.zobec@zetaresearch.com

4 Department of Clinical and Biological Sciences, University of Torino, Orbassano, Torino, 10043, Italy; E-Mail: paola.berchialla@unito.it

* Author to whom correspondence should be addressed; E-Mail: dario.gregori@unipd.it; Tel.: +39-049-827-5384; Fax: +39-02-700-445-089.

Received: 3 July 2012; in revised form: 22 October 2012 / Accepted: 8 November 2012 / Published: 12 November 2012

\begin{abstract}
Foreign body injuries are a well-known threat to children due to the high risk of ingestion of small objects and choking. In order to depict the epidemiological framework of such injuries, data are mostly available for hospitalizations and partially for emergency room visits. The hidden part of the phenomenon consisting of minor self-resolved injuries is still unknown. The purpose of this paper is to provide an estimate of the overall burden of such injuries in children in Italy. Our paper proposes the use of the scale up technique to overcome most of the pitfalls of classical techniques in the estimation of the number of children aged 0-14 that suffered a foreign body injury in 2004. Our results, based on a CATI survey on 1,081 women, show that the estimated number of children under 15 years that incurred in a foreign body injury was 15,829 (95\% CI: 14,376-17,282), of these 12,844 were treated in hospital or in emergency department (95\% CI: 11,535-14,153). The scale-up method in conjunction
\end{abstract}


with a CATI survey provides a reliable estimate of the size of hard-to-count populations as those of injured children at lower costs with respect to classical sampling schemes.

Keywords: population size estimation; foreign body injuries; social network; scale up methods; self-resolved injuries

\section{Introduction}

Foreign body injuries in the upper aero-digestive tract are due to the aspiration/ingestion/insertion of objects and they are one of the leading causes of injury and death in children [1,2]. Difficulties in estimating the impact of this phenomenon arise because of the large sample size required by classical statistical methods and the consequent possible high costs in planning and processing the surveys $[3,4]$. To overcome the limitations of classical sampling schemes, several non-probabilistic sampling methods like the capture-recapture method, the snowball and the adaptive sampling have been proposed. Nevertheless, such methods are difficult to implement in the area of foreign body injuries, since: (i) injury rates are highly variable from region to region and are not clustered according to some specific socio-demographic groups. If it were possible to recognize homogenous groups of people that present a bigger incidence of foreign body injuries, then it would be more likely to find people who know a number of other subjects with the same characteristics (and then techniques like snowball sampling could be used); (ii) the lack of completeness of injury registries and the poor reliability and coverage of health administrative data sources which makes the capture-recapture techniques very hard to apply, and (iii) the sensitivity of the questions related to injuries about children, in particular when these are directly asked to parents; indeed, quite a relevant reluctance of parents has been observed, in providing information about injuries occurred to their children [5].

In addition, we should notice that incidence estimates of such injuries usually result from the hospital discharge records and from the death certificates. However, since a large number of foreign bodies injury cases are self-resolved (e.g., parents help children to discharge the object) without accessing the health care services, underestimation of the actual incidence rates is likely to result.

To overcome these drawbacks, our approach proposes the usage of the scale-up methodology [6,7]. Scale-up method is a probabilistic sampling technique that arose in the field of social networks [8-10]. A social network is defined as the set of people that each person knows. The basic idea underlying the scale-up methodology consists in estimating the social network sizes for any given individual surveyed [11].

The estimated network size information is combined with the responses to the questions about how many people the respondents know in the population of children who experienced a foreign body injury. In order to estimate the social network size, individual responses are taken into account for a set of subpopulations with known size and then they are scaled up using the sizes of these groups to the general population.

Contrarily to the other survey techniques, scale-up methodology does not require asking people directly about problems. This presents two main advantages: first, people are more willing to 
answer to questions that do not touch directly their person, especially when the topic under investigation is a sensitive issue. Secondly, researchers are able to collect information about all respondents' social network. This is relevant in particular for studying events with low prevalence, since it allows the use of samples of smaller size as compared to other survey techniques.

This work is aimed at applying the scale-up method to the estimate of the magnitude of the foreign body injury phenomenon, including in this both the known part of it (i.e., the referral to the health care system) and the unknown part (i.e., the self-resolved injuries). Our specific goals were: (i) to estimate the number of foreign body injuries in Italy and (ii) to empirically evaluate the correctness and the efficiency of the scale up estimator in a telephone survey setting.

\section{The Scale-Up and the Social Network Size Estimators}

The scale-up method was developed by Bernard and his colleagues in the 1990s [12,13]. We proposed a maximum likelihood estimator [7] that relies on the assumption that the number $m_{i o}$ of children who suffered a foreign body injury known by the $i$-th respondent follows a Binomial distribution:

$$
\begin{gathered}
\operatorname{Prob}\left(m_{i 0}\right)=\left(\begin{array}{c}
c_{i} \\
m_{i 0}
\end{array}\right) p^{m_{i 0}}(1-p)^{c_{i-} m_{i 0}} \\
p=\frac{e_{0}}{t}
\end{gathered}
$$

where $c_{i}$ is the social network size of the respondent.

The maximum likelihood scale-up estimator for the size $e_{0}$ of the subpopulation $E_{0}[12,13]$ is given by:

$$
\hat{e}_{0}=t \frac{\sum_{i} m_{i 0}}{\sum_{i} c_{i}}
$$

where the size of the general population $T$ is multiplied by the ratio between the total number of children who suffered a foreign body injury known by the respondents and the sum of the respondents' social network sizes. It has been proven that Equation (3) is an unbiased estimator [13].

The estimator (3) requires just computing the sum of the social network's size $c_{i}$ over all respondents. These latter parameters also need to be estimated. Several estimators have been proposed in this regard [8,12-20]. In this work, we decided to use the proportional estimator [7,12], which has the same basic underlying idea as the scale-up method, that is, to estimate the social network size of each respondent. People are asked about how many people they know in several subpopulations of known size. Therefore, the proportional estimator for the social network size of the $i$-th respondent is given by the following formula:

$$
\hat{c}_{i}=t \frac{\sum_{j=1}^{L} m_{i j}}{\sum_{j=1}^{L} e_{j}}
$$

where $m_{i j}$ is the number of people known by the $i$-th respondent in the $j$-th subpopulation of known size $e_{j}$. As in the scale-up estimator the quantities $c_{j}$ are assumed known, in this case they are estimated from subpopulations of known size (i.e., the $e_{j}$ terms are fixed). 


\section{The Selection of Known Size Subpopulations}

A sensitive task in the estimation of the social network size is the choice of the subpopulations of known size [19,21]. The basic idea of the scale-up method is that the mean number of people known in a subpopulation is linearly proportional to the size of the same subpopulation [22]. On the other hand, the scale-up estimator relies on the following assumptions: (i) each subject in $T$ should have the same probability to know a subject in the subpopulations; (ii) everyone in $T$ should know all about his/her acquaintances and (iii) the difficulty to recall in short time all the people known in a certain subpopulation should be assumed to be negligible. It is well known that all these assumptions challenge the linear proportionality relationship [6,22].

\section{Results}

Two-thousand-four-hundred-fifty women have been contacted for the interview, and 1,081 accepted, with a response rate of 44\%. Out of a total of 35,673 items, 2,039 answers were not given $(5.7 \%)$ of which 1,038 referred to the political questions $(2.9 \%)$. These missing values were replaced imputing the median value of each question. The 1,081 interviewed women recalled a total of 437 children that suffered a foreign body injury, out of which 351 were treated in hospital. The regression model with all the 33 subpopulations (Table 1) accounted just for the $21 \%$ of the variability (see Figure 1).

Table 1. Subpopulation of known size used to estimate the respondents' social network sizes.

\begin{tabular}{|c|c|c|c|}
\hline Subpopulations of known size & $\begin{array}{c}\text { Size in } \\
\text { thousands }\end{array}$ & Subpopulations of known size & $\begin{array}{c}\text { Size in } \\
\text { thousands }\end{array}$ \\
\hline $\begin{array}{l}\text { People voted for Casa delle Libertà } \\
\text { in } 2001 \text { elections }\end{array}$ & 18,300 & Widows younger than 60 years & 506 \\
\hline Families with 2 children & 4,436 & $\begin{array}{l}\text { People sentenced for driving under the } \\
\text { influence of alcohol in } 2004\end{array}$ & 426 \\
\hline $\begin{array}{l}\text { People volunteer in non-profit } \\
\text { associations }\end{array}$ & 3,481 & People went in business during 2004 & 426 \\
\hline People bought a new car & 2,249 & Bought a motorcycle & 409 \\
\hline $\begin{array}{l}\text { Families with only one parent } \\
\text { living alone with children }\end{array}$ & 2,101 & $\begin{array}{c}\text { Competitive basket players members } \\
\text { of FIP }\end{array}$ & 169 \\
\hline $\begin{array}{l}\text { People voted for Rifondazione } \\
\text { Comunista in } 2004 \text { elections }\end{array}$ & 1,972 & $\begin{array}{c}\text { Competitive athletes members of } \\
\text { FIDAL }\end{array}$ & 127 \\
\hline $\begin{array}{l}\text { Families with } 5 \text { or more } \\
\text { components }\end{array}$ & 1,635 & People doing a temporary job & 119 \\
\hline $\begin{array}{l}\text { People owing a car with gas or } \\
\text { methane }\end{array}$ & 1,356 & People currently detained in prison & 57 \\
\hline People reported a robbery & 1,303 & Children adopted in 2004 & 6 \\
\hline Families with 3 or more children & 1,276 & People 100 or more years old & 6 \\
\hline Own a Mercedes car & 956 & People committed suicide in 2004 & 3 \\
\hline
\end{tabular}


Table 1. Cont.

\begin{tabular}{cccc}
\hline $\begin{array}{c}\text { Subpopulations of known size } \\
\text { thousands }\end{array}$ & $\begin{array}{c}\text { Size in } \\
\text { Subpopulations of known size }\end{array}$ & $\begin{array}{c}\text { Size in } \\
\text { thousands }\end{array}$ \\
\hline $\begin{array}{c}\text { People working in hotels and } \\
\text { restaurants }\end{array}$ & 859 & People reported a rape in 2004 & 2 \\
Teachers & 707 & People had a kidney transplantation in & 1.7 \\
$\begin{array}{c}\text { People with a specialization or a } \\
\text { PhD }\end{array}$ & 644 & People killed in 2004 & 0.7 \\
People owing a BMW car & 630 & People had a heart transplantation in & 0.3 \\
Women had a child in 2004 & 528 & 2004 & \\
\hline
\end{tabular}

Figure 1. Regression model with all the 33 subpopulations of known size. The circles highlight the subpopulations that were eliminated with the analysis of residuals.

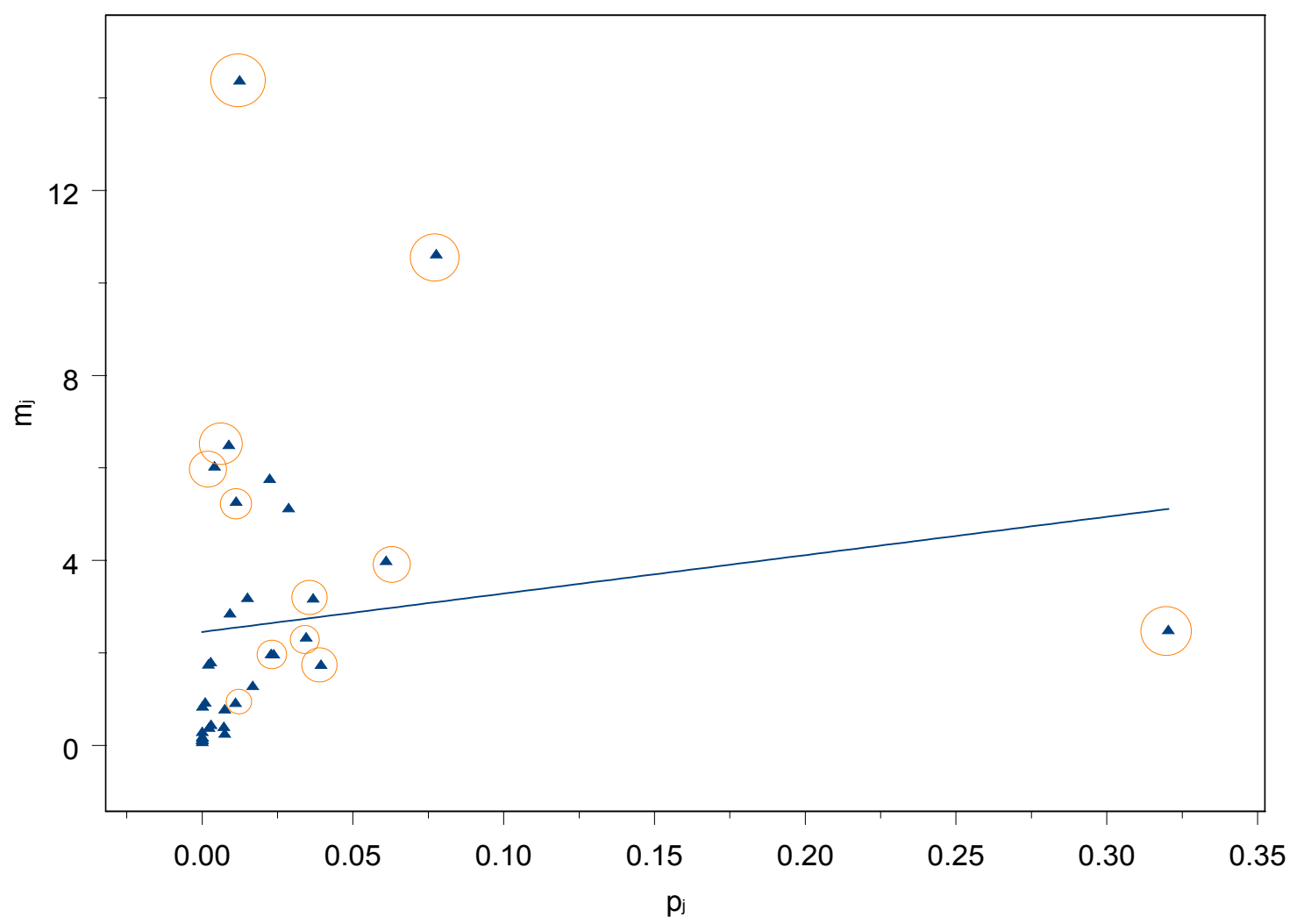

Therefore, we decided to choose the final subgroups to be used in the estimation by assessing the linear relation between the subpopulation sizes and the mean number of people recalled by respondents for each subgroup. Following Snidero et al. [7], we performed a visual inspection of the residuals, eliminating those less fitting the linear relationship between subpopulation sizes and mean number recalled by respondents. This lead us to exclude some subpopulations, eliminating at the very end 13 subpopulations and thus obtaining a regression model that accounted for the $79 \%$ of the variability (see Figure 2). 
Figure 2. Regression model with the 20 selected subpopulations of known size chosen for the final estimates.

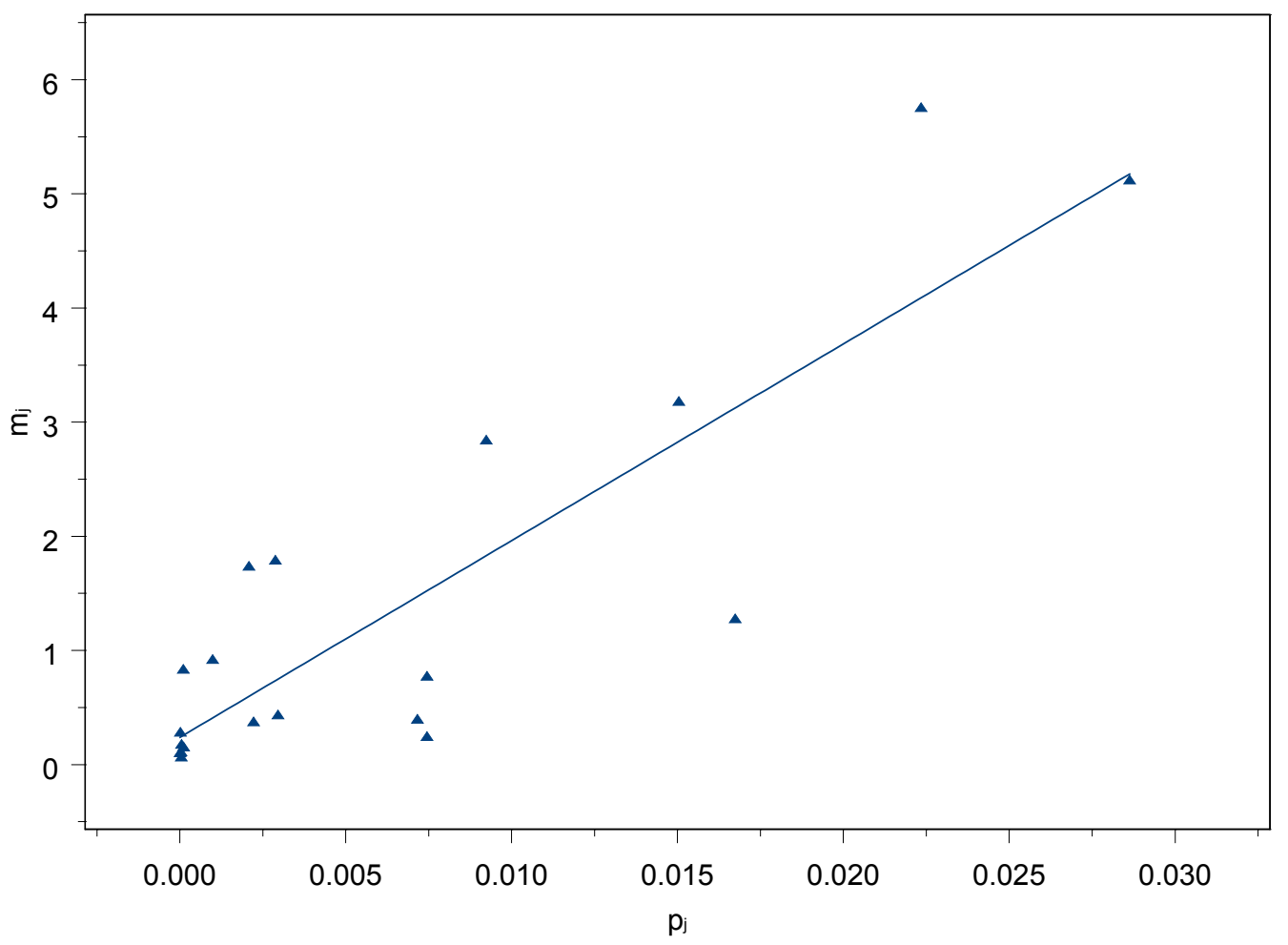

As shown in Table 2, this algorithm excluded those subpopulations that are less known by women (e.g., people owing a car with gas or methane) or of bigger size. In the latter case, it is expected that people asked about subpopulations where they know a high number of people, find it difficult to remember the correct number of people that belongs to them (e.g., Teachers, Families with two children, etc.).

Table 2. Subpopulations excluded from the analysis using the algorithm based on the regression model.

\begin{tabular}{c}
\hline Excluded subpopulations \\
People bought a new car \\
People owing a BMW car \\
People owing a car with gas or methane \\
Teachers \\
Teachers of primary school \\
People volunteer in non-profit associations \\
People with a specialization or a Ph.D \\
Widows younger than 60 years \\
Families with 2 children \\
People voted for Casa delle Libertà in 2001 elections \\
People voted for Rifondazione Comunista in 2004 elections \\
People reported a robbery
\end{tabular}

Using the remaining 20 subpopulations, the estimated mean social network $\left(\hat{c}_{i}\right)$ was of 218.3 people and with probability $95 \%$, the interval (142.5-294.2) includes the true value for $c_{i}$. This 
result is not statistically different from a previous estimate of the social network size of an American study that amounted at 286 persons [13].

The estimated number of children under 15 years that incurred in a foreign body injury $\left(\widehat{e}_{01}\right)$ was 15,829 with a $95 \%$ CI equal to $(14,376-17,282)$. Out of them, 12,844 cases $\left(\widehat{e}_{02}\right)$ were treated in hospital or in emergency department (95\% CI: 11,535-14,153).

Table 3. Results of the sensitivity analysis for each subpopulation excluded from the analysis.

\begin{tabular}{cccc}
\hline Excl. subpopulation & $\hat{\mathbf{c}}$ & Injury & Hospitalized \\
\hline Bought a motorcycle & $229.0(40.9)$ & $15,087.6(706.5)$ & $12,242.1(636.4)$ \\
Own a Mercedes car & $232.5(41.8)$ & $14,862.8(696.0)$ & $12,059.7(627.0)$ \\
Competitive athletes members of FIDAL & $219.2(39.2)$ & $15,759.2(738.0)$ & $12,787.0(664.8)$ \\
Competitive basket players members of FIP & $220.1(39.3)$ & $15,699.1(735.2)$ & $12,738.3(662.2)$ \\
Families with 5 or more components & $229.8(45.3)$ & $15,032.8(704.0)$ & $12,197.6(634.1)$ \\
People went in business during 2004 & $225.8(40.6)$ & $15,302.8(716.6)$ & $12,416.7(645.5)$ \\
Families with 3 or more children & $208.7(41.4)$ & $16,558.0(775.4)$ & $13,435.2(698.5)$ \\
People 100 or more years old & $217.3(38.6)$ & $15,902.9(744.7)$ & $12,903.7(670.8)$ \\
People doing a temporary job & $207.3(38.0)$ & $16,664.0(780.4)$ & $13,521.2(702.9)$ \\
People working in hotels and restaurants & $219.0(41.3)$ & $15,782.6(739.1)$ & $12,806.0(665.8)$ \\
People sentenced for driving under the influence of & $230.5(41.1)$ & $14,990.1(702.0)$ & $12,163.0(632.3)$ \\
alcohol in 2004 & & & \\
Children adopted in 2004 & $211.5(38.1)$ & $16,333.0(764.9)$ & $13,252.7(689.0)$ \\
People had a heart transplantation in 2004 & $217.5(38.6)$ & $15,886.9(744.0)$ & $12,890.7(670.2)$ \\
People had a kidney transplantation in 2004 & $217.5(38.6)$ & $15,887.2(744.0)$ & $12,890.9(670.2)$ \\
Women had a child in 2004 & $211.8(39.4)$ & $16,315.3(764.0)$ & $13,238.3(688.2)$ \\
People killed in 2004 & $216.0(38.6)$ & $15,996.6(749.1)$ & $12,979.7(674.8)$ \\
People reported a rape in 2004 & $217.9(38.7)$ & $15,858.8(742.7)$ & $12,867.9(669.0)$ \\
People committed suicide in 2004 & $217.0(38.6)$ & $15,924.6(745.7)$ & $12,921.3(671.7)$ \\
People dead for a cancer in 2004 & $208.3(38.1)$ & $16,587.7(776.8)$ & $13,459.3(699.7)$ \\
People currently detained in prison & $212.3(38.7)$ & $16,270.3(762.0)$ & $13,201.8(686.3)$ \\
\hline
\end{tabular}

Notes: $\hat{\mathrm{c}}$ is the network size, Injury is the social network size estimate of the number of injuries, for $\hat{c}$; Hospitalized is the estimated number of hospitalized injuries; $d$ is standard errors in brackets.

In Table 3 the mean estimates of the social network sizes $(c)$ and the target subpopulation size $\left(e_{0}\right)$ obtained omitting one at time of the subpopulations $\left(e_{j}\right)$ are shown. The estimated social network sizes are quite similar for each excluded subpopulation (range: 207.3-232.5) and also the estimates for the number of children that suffered a foreign body injury are in a quite close range $(14,863-16,664)$. This means that the maximum likelihood scale-up estimator and the social network estimator are quite robust to the choice of the subpopulations themselves, in particular when subgroups are first evaluated with a selection procedure to discard those poorly fitting the linearity assumptions of the model. 


\section{Discussion}

Our study estimated that 15,829 children suffered a foreign body injury in Italy in 2004, of which 12,844 were hospitalized or visited at the emergency department. Therefore, the estimated incidence of foreign body injuries in children in Italy is about $0.2 \%$.

Taking into account that the official number of hospitalized children for such injury was 1,814 in 2003 [23], one child out of nine who incurred in a foreign body injury was hospitalized and one children out of eight who was visited in an emergency department was thereafter hospitalized. These figures are consistent with findings in the injury literature, where a ratio ranging from 1:10 to $1: 17$ is often observed between hospitalizations and emergency visits [24-26].

The main limitation is that no extrapolations to any subset of the population are allowed by the method, therefore specific incidence rate such as for any foreign body type cannot be derived by this work.

With the scale-up method we obtained the target information about a number of people virtually equal to the interviewed sample size multiplied by the social network size of each respondent (about 235,000 people). The standard error was quite small (741 persons), corresponding, in relative terms, to $0.9 \times 10^{-4}$ if we divide it by the total number of children aged $0-14$ in Italy. In order to getting the same standard error magnitude using the classical probabilistic schemes, we should have planned a sample of exactly 236,254 people. Clearly, the scale up has a multiplying effect on the sample size, due to the indirect contact of a number of people. This is of course particularly appealing in view of rapidity of the CATI survey and of the lower costs associated with it. Indeed, the number of missed items was negligible, and this was obtained while the survey was conducted by interviewers not particularly experienced in the usage of the scale-up technique.

\section{Methods}

\subsection{Study Design}

The study was designed to estimate the number of children aged 0-14 that incurred in a foreign body injury in Italy. The sample was formed randomly selecting 1,081 women aged 18-50 who answered to a CATI survey. The respondents were asked to answer to a questionnaire about:

- The number of people they know in 33 questions about populations of known size;

- The number of children they know that suffered a foreign body injury and some more details related to the injuries (target questions).

The target questions, which were referred to the 2004 year, were:

- "How many children do you know that had an injury due to the swallowing/ingestion of a foreign body?", aimed at identifying the first target subpopulation of size $e_{01}$;

- "Of those, how many children went to the emergency service or were hospitalized?" aimed at identifying the second target subpopulation of size $e_{02}$.

Table 1 shows the 33 subpopulations of known size selected from the census and other official sources [27]. Among many definitions of social network given in literature, we adopted that one of 
"active network", i.e., "Mutually recognize each other by sight or name, can be contacted, and have had a contact within the last two years, either in person, by phone or mail" $[12,13,16]$.

\subsection{Statistical Analysis}

We applied a regression model with the mean number known in each subpopulation as dependent variable and the relative size of the subpopulation as independent variable to select the subpopulations of known size that meet the request of linear proportionality. Therefore, we proceeded to exclude some of the 33 subpopulations with a graphical analysis of residuals.

According to the formulas given in Equations (1) and (2) we estimated the mean social network size and the target subpopulation size along with $95 \%$ confidence interval (95\% CI).

In order to understand how estimates depend on the specific choice of the subpopulations used in the analysis we carried out a sensitivity analysis. A leave-one-out strategy was adopted: one population among the selected subpopulations was picked up and excluded from the sample. This was repeated such that each population was left out once. The analysis was carried out with S-plus ver. 6.2 [28].

\section{Conclusions}

The scale-up technique has been shown to have a potential for application in the injury field. A comparison with known figures on foreign bodies injuries has shown a strong consistency with them: of course, since no data exists at the time being on the number of non-hospitalized foreign bodies injuries, the above conclusion is based on common sense and expert opinions. Further data are needed to better understand the hidden epidemiology of such injuries.

From the methodological point of view, the procedure of selecting sub-populations is still based on the empirical evaluation of the residuals. Less subjective approaches should be investigated. In this sense also the issue of missing data on recalled subpopulation sizes needs further developments; the approach based on the median which has been used in this analysis tends to underestimate standard errors, as shown in some simulation-based investigations in the field of public health research [29], but no data are available for the scale up approach so far.

Injury research constitutes a terrain where most of the classical techniques can easily fail, due in particular to the high sensitiveness of some questions. In particular, a sensitive problem is how to estimate the number of children who have suffered from injuries or violence at a certain point in their life. This is important public health issue because many children who suffered from injuries often do not go to a hospital or clinic for treatment, in particular in case of facts of lower impact. In addition, children who suffered from violence in their family also find difficulty in reporting the facts. The adaptation of scale up methods to such populations could be a first step toward its use for other public health issues where some cases may be treated outside of the medical system: knowing the size of such populations is important for planning and reducing inequalities in the access of public health care systems. These considerations are emphasized when injuries are related to children and thus when the interviewed parents have to face their sense of inadequacy and guilt. In addition, such technique can successfully be used when official data are not fully recorded or when the 
data extraction can be costly and time inefficient. In this setting, the possibility to have a reasonable, quick and cost-effective estimation of the magnitude of the phenomenon is surely appealing.

\section{Acknowledgments}

The project has been partially financed under the project PGR00064, by the Direzione Generale per la Promozione e la Cooperazione Culturale of the Italian Ministry of Foreign Affairs (MAE) and the Secretaría de Ciencia, Tecnología e Innovación Productiva (MINCYT), Argentina and by an unrestricted grant of Prochild ONLUS.

\section{Conflicts of Interest}

The authors declare no conflict of interest.

\section{References}

1. Gregori, D.; Scarinzi, C.; Morra, B.; Salerni, L.; Berchialla, P.; Snidero, S.; Corradetti, R.; Passali, D.; ESFBI Study Group. Ingested foreign bodies causing complications and requiring hospitalization in European children: Results from the ESFBI study. Pediatr. Int. 2010, 52, 26-32.

2. Petrinco, M.; Di Cuonzo, D.; Berchialla, P.; Gilardetti, M.; Foltran, F.; Scarinzi, C.; Costa, G.; Gregori, D. Economic burden of injuries in children: Cohort study based on administrative data in a northwestern Italian region. Pediatr. Int. 2011, 53, 846-850.

3. Frerichs, R.R.; Shaheen, M.A. Small community-based surveys. Annu. Rev. Public Health 2001, 22, 231-247.

4. Frerichs, R.R.; Tar Tar, K. Computer-assisted rapid surveys in developing countries. Public Health Rep. 1989, 104, 14-23.

5. Cummings, P.; Rivara, F.P.; Thompson, R.S.; Reid, R.J. Ability of parents to recall the injuries of their young children. Inj. Prev. 2005, 11, 43-47.

6. Snidero, S.; Corradetti, R.; Gregori, D. The network scale-up method: A simulation study in case of overlapping sub-populations. Metodoloski Zvezki 2004, 1, 395-405 (in English).

7. Snidero, S.; Morra, B.; Corradetti, R.; Gregori, D. Use of the scale-up methods in injury prevention research: An empirical assessment to the case of choking in children. Soc. Networks 2007, 29, 527-538.

8. Bernard, H.R.; Johnsen, E.C.; Killworth, P.D.; Robinson, S. Estimating the size of an average personal network and of an event subpopulation: Some empirical results. Soc. Sci. Res. 1991, 20, 109-121.

9. Bernard, H.R.; Killworth, P.D.; Johnsen, E.C.; Shelley, G.A.; McCarty, C. Estimating the ripple effect of a disaster. Connections 2001, 24, 18-22.

10. Johnsen, E.C.; Bernard, H.R.; Killworth, P.D.; Shelley, G.A.; McCarty, C. A social network approach to corroborating the number of AIDS/HIV victims in the US. Soc. Networks 1995, 17, 167-187. 
11. Bernard, H.R.; Hallet, T.; Iovita, A.; Johnsen, E.C; Lyerla, R.; McCarty, C.; Mahy, M.; Salganik, M.J.; Saliuk, T.; Scutelniciuc, O.; et al. Counting hard-to-count populations: The network scale-up method for public health. Sex. Transm. Infect. 2010, 86, 111-115.

12. Killworth, P.D.; Johnsen, E.C.; McCarty, C.; Shelley, G.A.; Bernard, H.R. A social network approach to estimating seroprevalence in the United States. Soc. Networks 1998, 20, 23-50.

13. Killworth, P.D.; McCarty, C.; Bernard, H.R.; Shelley, G.A.; Johnsen, E.C. Estimation of seroprevalence, rape and homelessness in the U.S. using a social network approach. Evaluation Rev. 1998, 22, 289-308.

14. Bernard, H.R.; Johnsen, E.C.; Killworth, P.D.; Robinson, S. Estimating the Size of an Average Personal Network and of an Event Population. In The Small World; Ablex Publishing: Norwood, NJ, USA, 1989; pp. 159-179.

15. Bernard, H.R.; Johnsen, E.C.; Killworth, P.D.; McCarty, C.; Shelley, G.A.; Robinson, S. Comparing four different methods for measuring personal social networks. Soc. Networks 1990, 12, 179-215.

16. Killworth, P.D.; Johnsen, E.C.; Bernard, H.R.; Shelley, G.A.; McCarty, C. Estimating the size of personal networks. Soc. Networks 1990, 12, 289-312.

17. Killworth, P.D.; Bernard, H.R.; McCarty, C. Measuring patterns of acquaintenceship. Curr. Anthropol. 1984, 23, 381-397.

18. McCarty, C.; Bernard, H.R.; Killworth, P.D.; Shelley, G.A.; Johnsen, E.C. Eliciting representative samples of personal networks. Soc. Networks 1997, 19, 303-23.

19. McCarty, C.; Killworth, P.D.; Bernard, H.R.; Johnsen, E.C.; Shelley, G.A. Comparing two methods for estimating network sizes. Hum. Organ. 2000, 60, 28-39.

20. Freeman, L.C.; Thompson, C.R. Estimating Acquaintanceship Volume. In The Small World; Ablex Publishing: Norwood, NJ, USA, 1989; pp. 147-158.

21. Salganik, M.J.; Fazito, D.; Bertoni, N.; Abdo, A.H.; Mello, M.; Bastos, F.I. Assessing network scale-up estimates for groups most at risk of HIV/AIDS: Evidence from a multiple-method study of heavy drug users in Curitiba, Brazil. Am. J. Epidemiol. 2011, 174, 1190-1196.

22. Killworth, P.D.; McCarty, C.; Bernard, H.R.; Johnsen, E.C.; Domini, J.; Shelley, G.A. Two interpretations of reports of knowledge of subpopulation sizes. Soc. Networks 2002, 25, 141-160.

23. Ministero della Salute. Rapporto Annuale Sull'attività di Ricovero Ospedaliero-Anno 2006. Available online: www.salute.gov.it/ricoveriOspedalieri/paginaInternaRicoveriOspedalieri. jsp?menu=rapporti\&id=1356\&lingua=italiano (accessed on 20 June 2010).

24. Hoff, G.L.; Cai, J.; Kendrick, R.; Archer, R. Emergency department visits and hospitalizations resulting from dog bites, Kansas City, MO, 1998-2002. Mo Med. 2005, 102, 565-568.

25. Mintegui Raso, S.; Benito Fernandez, J.; Vázquez Ronco, M.A.; Ortiz Andrés, A.; Capapé Zache, S.; Fernández Landaluce, A. Children's unscheduled return visits to an emergency department. An. Esp. Pediatr. 2000, 52, 542-547 (in Spanish).

26. Trifiro, G.; Calogero, G.; Ippolito, F.M.; Cosentino, M.; Giuliani, R.; Conforti, A.; Venegoni, M.; Mazzaglia, G.; Caputi, A.P. Adverse drug events in emergency department population: A prospective Italian study. Pharmacoepidemiol. Drug Saf. 2005, 14, 333-340.

27. ISTAT. $14^{\circ}$ Censimento Generale Della Popolazione e Delle Abitazioni: 21 Ottobre 2001. Available online: dawinci.istat.it/MD/dawinciMD.jsp (accessed on 23 June 2010). 
28. Insightful Corporation. S-PLUS® 6.2 for Windows; Insightful Corporation: Seattle, WA, USA, 2003.

29. Zhou, X.H.; Eckert, G.J.; Tierney, W.M. Multiple imputation in public health research. Stat. Med. 2001, 20, 1541-1549. 
Reprinted from Int. J. Environ. Res. Public Health. Cite as: Wilson, M.L.; Dunlavy, A.C.; Viswanathan, B.; Bovet, P. Suicidal Expression among School-Attending Adolescents in a Middle-Income Sub-Saharan Country. Int. J. Environ. Res. Public Health 2012, 9, 4122-4134.

Article

\title{
Suicidal Expression among School-Attending Adolescents in a Middle-Income Sub-Saharan Country
}

\author{
Michael L. Wilson ${ }^{1, *}$, Andrea C. Dunlavy ${ }^{1}$, Bharathi Viswanathan ${ }^{2}$ and Pascal Bovet ${ }^{2,3}$ \\ 1 Centre for Injury Prevention and Community Safety (CIPCS), PeerCorps Trust Fund, \\ P.O. Box 22499 Dar es Salaam, Tanzania; E-Mail: andrea.dunlavy@peercorpstrust.org \\ 2 Ministry of Health, Victoria, Republic of Seychelles; \\ E-Mails: barathi.viswanathan@health.gov.sc (B.V.); pascal.bovet@chuv.ch (P.B.) \\ 3 Institute of Social and Preventive Medicine (IUMSP), Lausanne University Hospital (CHUV) \\ Lausanne 1010, Switzerland
}

* Author to whom correspondence should be addressed; E-Mail: michael.wilson@peercorpstrust.org; Tel.: +255-715-636-963.

Received: 21 August 2012; in revised form: 30 October 2012 / Accepted: 1 November 2012 / Published: 13 November 2012

\begin{abstract}
We investigated correlates for suicidal expression among adolescents in the Seychelles. Data on 1,432 students (52\% females) were derived from the Global School-based Health Survey. Participants were divided into three groups: those with no suicidal behavior $(\mathrm{N}=1,199)$; those with suicide ideation/SI $(\mathrm{N}=89)$; and those reporting SI with a plan to carry out a suicide attempt/SISP $(\mathrm{N}=139)$, each within a 12-month recall period. Using multinomial logistic regression, we examined the strength of associations with social, behavioral and economic indicators while adjusting for covariates. Sixteen percent of school-attending adolescents reported a suicidal expression (10\% with a plan $/ 6.2 \%$ without). Those reporting SI were younger (relative risk ratio $\mathrm{RRR}=0.81 ; \mathrm{CI}=0.68-0.96)$, indicated signs of depression $(\mathrm{RRR}=1.69$; $\mathrm{CI}=1.05-2.72)$ and loneliness $(\mathrm{RRR}=3.36 ; \mathrm{CI}=1.93-5.84)$. Tobacco use $(\mathrm{RRR}=2.34$; $\mathrm{CI}=1.32-4.12)$ and not having close friends $(\mathrm{RRR}=3.32 ; \mathrm{CI}=1.54-7.15)$ were significantly associated with SI. Those with SISP were more likely to be female $(\mathrm{RRR}=0.47 ; 0.30-0.74)$, anxious $(\mathrm{RRR}=3.04 ; \mathrm{CI}=1.89-4.88)$ and lonely $(\mathrm{RRR}=1.74$; $\mathrm{CI}=1.07-2.84)$. Having no close friends $(\mathrm{RRR}=2.98 ; 1.56-5.69)$ and using tobacco $(\mathrm{RRR}=2.41 ; 1.48-3.91)$ were also strongly associated. Having parents who were understanding was protective $(\mathrm{RRR}=0.50 ; \mathrm{CI}=0.31-0.82)$. Our results suggest that school health promotion programs may benefit from targeting multiple factors associated with suicidal expression. More research, particularly multilevel designs are needed to
\end{abstract}


identify peer and family influences which may modify associations with suicidality.

Keywords: suicidal expression; adolescent; school health; sub-Saharan Africa

\section{Introduction}

Suicide ranks as the third leading cause of mortality among adolescents worldwide [1], and according to recent research, suicidal expression may be on the rise [2]. While few cross-nationally representative studies of suicide exist, one study among 34 nations documented that suicide was responsible for the deaths of more than 15,000 adolescents during a one-year period [3].

Suicidal expression has long been associated with several psychosocial indicators, many of which are intensified during adolescence [4]. Some of these include poor mental health, poverty, being bullied, substance use and having poor relationships with parents [5-8]. While most suicide attempters are female, males are overrepresented in suicide completions [9]. These indicators however, are largely representative of adolescents in high-income country (HIC) settings where surveillance data have generally greater accuracy. Among low- and middle income country (LMIC) settings however, the picture remains less clear, particularly in countries of the African region [10]. For example some countries report data which are not disaggregated by age, making estimations of suicide among adolescents difficult. In young people, death by suicide is often obscured by other mortality diagnoses or documented as being accidental. Cultural and religious barriers also make it difficult to classify a death as a suicide. Even the ascertainment of suicide by health care professionals is not uniform in all settings [9,11].

Adolescents who attempt a suicide and fail may injure themselves seriously enough to require medical attention. The trauma which follows an unsuccessful attempt may be physically disfiguring, or result in long term disability. The mental health consequences of attempts are equally significant, and there are fewer rehabilitative resources available in LMIC settings. Subsequent to an attempt, the associated stigma or physical scarring may affect school attendance. Those who fail to return and complete school are less likely to find employment as adults. Parents, often faced with few treatment options, may be forced to reduce meaningful economic activity to reintegrate their adolescent into the family and community [11]. Among poor households, this means being driven deeper into poverty [12]. Despite this, research on correlates for suicidal expression among adolescents in LMICs remains a neglected public health priority. The aim of this study was to examine the social and demographic factors associated with two forms of self-reported suicidal expression among adolescents in a middle-income sub-Saharan country. 


\section{Methods}

\subsection{Setting}

This study is based on data collected in the Republic of Seychelles. The Seychelles constitutes a group of islands located approximately $1,800 \mathrm{~km}$ east of Kenya. With a gross domestic product of USD $\$ 8,000$ in 2007, the Seychelles is considered an upper middle-income country [13].

\subsection{Sample}

The data for this study were drawn from the Seychelles contribution to the Global School-based Student Health Survey (GSHS). The GSHS was developed by the World Health Organization in collaboration with the US Centers for Disease Control. It collects relevant information for the discernment of behavioral and health risks among adolescents of school age in 43 countries. In the Seychelles, 1,432 secondary school students (52\% females) aged 11-17 years participated in the survey which had a response rate of $82 \%$. We excluded five participants that did not have complete information resulting in a final sample of 1,427 participants. Detailed information on data collection methods, the questionnaire and procedures are published elsewhere [14]. At the time of data collection, the research committee of the Ministry of Health and the Ministry of Education approved the study including the questionnaire. Informed consent by parents was not necessary.

\subsection{Measurements}

Participants were divided into three groups: those not reporting suicidal expression $(\mathrm{N}=1,199)$; those reporting suicide ideation but not suicide planning (SI group; $\mathrm{N}=89$ ), and those reporting both SI and planning (SISP group; $\mathrm{N}=139$ ) each with a 12-month period of recall. We derived our dependent variables from the responses to two questions in the GSHS: "During the past 12 months, did you ever seriously consider attempting suicide?" and "During the past 12 months, did you make a plan about how you would attempt suicide?" The response options were "yes/no". Those who responded "yes" to SI and "no" to planning were considered part of the ideation only group. Those who responded "yes" to planning regardless of whether they had prior SI were considered part of the SISP group.

Our analyses targeted contextually relevant demographic, psychosocial and family factors which have been found to be associated with suicidal expression in the peer-reviewed literature. These factors included: food deprivation, anxiety, loneliness, signs of depression, social support (friendships), truancy, bullying, parent involvement, tobacco use, substance use and alcohol misuse $[5,6,8,15,16]$. Based on these, the following survey questions served as the basis for the selection of independent variables.

To examine associations with food deprivation, anxiety and loneliness we used: "During the past 30 days, how often did you go hungry because there was not enough food in your home?", "During the past 12 months, how often have you been so worried about something that you could not sleep at night?" and "During the past 12 months, how often have you felt lonely?". The response options to each of these questions were "never", "rarely", "sometimes", "most of the time", or "always". These were dichotomized into "yes" corresponding to "most of the 
time/always" and "no" corresponding to "never/rarely/sometimes". To examine associations with signs of depression we used "During the past 12 months, did you ever feel so sad or hopeless almost every day for two weeks or more in a row that you stopped doing your usual activities?". The responses were "yes/no". For social support we used "How many close friends do you have?" Response options were "0", "1", "2", and "3 or more friends".

We examined associations with truancy by using: "During the past 30 days, on how many days did you miss classes or school without permission?". Response items were " 0 ", "1-2", "3-5", "6-9" and "10 or more days". Students were considered truant if they missed more than 3 days of school within the reference period using a prior threshold by Wilson et al. [17]. To examine associations with experiences of being bullied, the following was used: "During the past 30 days, on how many days were you bullied?" Response items were "0", "1-2", "3-5", "6-9", "10-19", "20-29" and "all 30 days". One category for bullying in the last 30 days was created using three or more days. For parental involvement in school, parent-child relationship quality and whether parents were knowledgeable about their child's leisure time activities we used: "During the past 30 days how often did your parents or guardians check to see if your homework was done?", "During the past 30 days, how often did your parents or guardians understand your problems and worries?" and "During the past 30 days, how often did your parents or guardians really know what you were doing with your free time?". The response options to each of these were "never", "rarely", "sometimes", "most of the time", and "always". These were dichotomized into "most of the time/always", which was re-coded as a "yes" response, for comparison with "never/rarely/sometimes", or a "no" response.

Associations with tobacco use were examined using: "During the last 30 days, on how many days did you smoke cigarettes?". The responses options were: "0", “1-2", "3-5", "6-9", "10-19", and "all 30 days". One category for any cigarette use within the past 30 days was created using one or more days. Associations with substance use were examined using: "During your life, how many times have you used drugs such as marijuana, cannabis or hashish, steam, stuff, joint, lapay or tyalas ("lapay" and "tyalas" are Creole names for marijuana)?" The response items were " 0 ", " $1-2$ ", "3-9" and "10 or more times". One category for any lifetime substance use was created using one or more days. Finally, we examined associations with lifetime alcohol misuse by using: "During your life, how many times have you ever had a hang-over, felt sick, got into trouble with your family or friends, missed school, or got into fights, as a result of drinking alcohol?". Responses were "0”, “1-2”, “3-9" and "10 or more times". One category for lifetime alcohol misuse was created using one or more days.

\subsection{Statistical Analysis}

We first examined the distribution of selected variables within each of the three suicide expression categories. Significant differences between each category and independent variables were explored using Pearson's chi-square for categorical variables and ANOVA for continuous variables (age). We then used two multinomial logistic regression (MLR) models to examine independent variable associations with those without suicidal expression, those with SI and those reporting SISP while adjusting for covariates. Compared with binary logistic regression, MLR is an extension which allows for the prediction of the probabilities of more than two outcomes of a 
categorically distributed dependent variable. Given that our dependent variable had three categories, MLR was more suitable than a standard binary logistic regression. In the first MLR model, we included all variables which were statistically significant in the bivariate analyses at $p<0.05$. In the second model we adjusted for age and sex. The measures of association were reported as relative risk ratios (RRR) along with their with 95\% confidence intervals (CI). All analyses were conducted using Stata for Linux, version 12 (StataCorp, College Station, TX, USA, 2011).

\section{Results}

Within the recall period, $16 \%$ of adolescents reported suicidal expression, $10 \%$ of whom reported a plan and $6.2 \%$ of whom reported ideation alone. Sixty-eight percent of those who reported having made a plan to carry out a suicide attempt were female. The mean age of the sample was 14.0 (SD 1.5). Thirty-percent of respondents reported signs of depression, with 14\% indicating loneliness and $12 \%$ percent anxiety. Thirty-six percent of respondents reported alcohol misuse, $19 \%$ reported substance use at least once during their lifetimes and $23 \%$ had used tobacco. Slightly more than $18 \%$ reported being deprived of food within the 30 days prior to the survey.

Table 1 shows the crude distribution of selected factors according to suicide expression category. We found significant differences across all categories of psychological health and the broad category of substance use. Each were associated with higher levels of SI and SISP. Males were overrepresented among those with suicidal ideation $(p<0.001)$ as were those who reported being bullied three or more days during the recall period $(p<0.001)$. Adolescents who had parents who were understanding of their worries or concerns, were significantly less likely to report SI or SISP $(p<0.001)$. We found what appeared to be a linear association between the number of close friends reported and the rate of suicidal ideation and planning $(p<0.001)$. No significant differences were found with respect to age, truancy or whether parents had spent time assisting their adolescents with homework tasks.

Table 1. Distribution of selected factors according to categories of suicide expression among school-attending adolescents in the Seychelles.

\begin{tabular}{ccccc}
\hline Variable & $\begin{array}{c}\text { No suicide expression } \\
(\mathbf{n = 1 , 1 9 9 )}\end{array}$ & $\begin{array}{c}\text { Suicide ideation } \\
(\mathbf{n = 8 9})\end{array}$ & $\begin{array}{c}\text { Suicide planning } \\
(\mathbf{n}=\mathbf{1 3 9})\end{array}$ & $\boldsymbol{P}$-value \\
\hline Age (SD) & $14.0(1.5)$ & $13.6(1.5)$ & $14.1(1.4)$ & $\mathrm{ns}$ \\
Sex (male) & 48.5 & 57.3 & 32.4 & $<0.001$ \\
Food deprivation & 17.0 & 25.8 & 23.7 & 0.024 \\
Anxiety & 9.3 & 18.0 & 34.5 & $<0.001$ \\
Signs of depression & 25.9 & 43.8 & 59.0 & $<0.001$ \\
Loneliness & 10.2 & 32.6 & 30.2 & $<0.001$ \\
Bullied & 34.5 & 53.9 & 50.4 & $<0.001$ \\
Truancy & 18.7 & 24.7 & 22.3 & $\mathrm{~ns}$ \\
Parent helps with & 44.7 & 47.2 & 35.3 & $\mathrm{~ns}$ \\
homework & & & & \\
Parent knowledgeable & 45.1 & 47.2 & 33.1 & 0.021 \\
about free time & 43.0 & 37.1 & 23.7 & $<0.001$ \\
\hline
\end{tabular}


Table 1. Cont.

\begin{tabular}{ccccc}
\hline Variable & $\begin{array}{c}\text { No suicide expression } \\
(\mathbf{n = 1 , 1 9 9 )}\end{array}$ & $\begin{array}{c}\text { Suicide ideation } \\
(\mathbf{n = 8 9 )}\end{array}$ & $\begin{array}{c}\text { Suicide planning } \\
(\mathbf{n = 1 3 9 )}\end{array}$ & $\boldsymbol{P}$-value \\
\hline Tobacco use & 20.0 & 37.1 & 36.0 & $<0.001$ \\
Substance use & 18.0 & 25.8 & 23.7 & 0.040 \\
Alcohol misuse & 21.7 & 34.8 & 33.1 & $<0.001$ \\
Close friends & & & & \\
0 friend & 4.1 & 12.6 & 14.5 & $<0.001$ \\
1 friend & 14.7 & 16.1 & 15.9 & - \\
2 friends & 17.1 & 18.4 & 20.3 & - \\
$\geq 3$ friends & 64.1 & 52.9 & 49.3 & - \\
\hline
\end{tabular}

All variables are expressed as proportions (in \%) except for age (mean and standard deviation).

After adjusting for all associated covariates (Table 2), and compared to those without suicide expression, those reporting SI were younger $(\mathrm{RRR}=0.81 ; \mathrm{CI}=0.68-0.96)$, more likely to report signs of depression $(\mathrm{RRR}=1.69 ; \mathrm{CI}=1.05-2.72)$ and feel lonely $(\mathrm{RRR}=3.36$; $\mathrm{CI}=1.93-5.84)$. We also found significant associations with tobacco use $(\mathrm{RRR}=2.34 ; \mathrm{CI}=1.32-4.12)$ and not having close friends $(\mathrm{RRR}=3.32 ; \mathrm{CI}=1.54-7.15)$. Those with SISP were more likely to be female $(\mathrm{RRR}=0.47 ; \mathrm{CI}=0.30-0.74)$, anxious $(\mathrm{RRR}=3.04 ; \mathrm{CI}=1.89-4.88)$ and lonely $(\mathrm{RRR}=1.74$; $\mathrm{CI}=1.07-2.84)$. Having no friends $(\mathrm{RRR}=2.98 ; 1.56-5.69)$ and using tobacco $(\mathrm{RRR}=2.41$; 1.48-3.91) were also strongly associated with SISP. Having parents who were understanding was protective $(\mathrm{RRR}=0.50 ; \mathrm{CI}=0.31-0.82)$. Initial associations with food deprivation, bullying, substance use and alcohol misuse disappeared once other covariates were included in the model.

In Table 3, we show the results for the analysis adjusted for age and sex. Those who reported SI only were more anxious $(\mathrm{RRR}=1.98 ; \mathrm{CI}=1.11-3.54)$, depressed $(\mathrm{RRR}=2.26 ; \mathrm{CI}=1.46-3.53)$ and lonely $(\mathrm{RRR}=4.33 ; \mathrm{CI}=7.04)$. Being bullied $(\mathrm{RRR}=2.00 ; \mathrm{CI}=1.29-3.11)$ was significantly associated as well as tobacco $(\mathrm{RRR}=2.30 ; \mathrm{CI}=1.44-3.67)$ and alcohol misuse $(\mathrm{RRR}=1.85$; $\mathrm{CI}=1.16-2.94)$. Not having friends $(\mathrm{RRR}=3.88 ; \mathrm{CI}=1.88-8.02)$ was also significantly associated with SI. For those reporting SISP, only having one $(\mathrm{RRR}=1.33 ; \mathrm{CI}=0.80-2.22)$ or two $(\mathrm{RRR}=1.44 ; \mathrm{CI}=0.90-2.30)$ friends were non-significant.

Table 2. Multivariate analysis of suicide ideation and planning among school-attending adolescents in the Seychelles.

\begin{tabular}{ccccc}
\hline Variable & $\begin{array}{c}\text { Suicidal ideation } \\
\text { RRR }(\mathbf{C I})\end{array}$ & $\boldsymbol{P}$-value & $\begin{array}{c}\text { Suicidal planning } \\
\text { RRR }(\mathbf{C I})\end{array}$ & $\boldsymbol{P}$-value \\
\hline Age & $0.81(0.68-0.96)$ & 0.014 & $1.05(0.92-1.21)$ & $\mathrm{ns}$ \\
Sex (male) & $1.43(0.87-2.34)$ & $\mathrm{ns}$ & $0.47(0.30-0.74)$ & 0.001 \\
Food deprivation & $1.21(0.70-2.08)$ & $\mathrm{ns}$ & $1.12(0.70-1.80)$ & $\mathrm{ns}$ \\
Anxiety & $1.05(0.54-2.02)$ & $\mathrm{ns}$ & $3.04(1.89-4.88)$ & $<0.001$ \\
Signs of depression & $1.69(1.05-2.72)$ & 0.032 & $2.68(1.80-4.00)$ & $<0.001$ \\
Loneliness & $3.36(1.93-5.84)$ & $<0.001$ & $1.74(1.07-2.84)$ & 0.026 \\
Bullied & $1.33(0.82-2.14)$ & $\mathrm{ns}$ & $1.41(0.94-2.14)$ & $\mathrm{ns}$ \\
Parent knowledgeable about free time & $1.33(0.80-2.20)$ & $\mathrm{ns}$ & $0.92(0.59-1.44)$ & $\mathrm{ns}$ \\
\hline
\end{tabular}


Table 2. Cont.

\begin{tabular}{ccccc}
\hline Variable & $\begin{array}{c}\text { Suicidal ideation } \\
\text { RRR }(\mathbf{C I})\end{array}$ & $\begin{array}{c}\boldsymbol{P} \text {-value } \\
\text { Parents were understanding }\end{array}$ & $\begin{array}{c}\text { Suicidal planning } \\
\text { RRR (CI) }\end{array}$ & $\boldsymbol{P}$-value \\
Tobacco use & $0.71(0.41-1.21)$ & $\mathrm{ns}$ & $0.50(0.31-0.82)$ & 0.006 \\
Substance use & $2.34(1.32-4.12)$ & 0.003 & $2.41(1.48-3.91)$ & $<0.001$ \\
Alcohol misuse & $0.83(0.42-1.62)$ & $\mathrm{ns}$ & $0.97(0.55-1.69)$ & $\mathrm{ns}$ \\
Close friends & $1.23(0.74-2.22)$ & $\mathrm{ns}$ & $1.28(0.81-2.03)$ & $\mathrm{ns}$ \\
0 friend & & & & \\
1 friend & $3.32(1.54-7.15)$ & 0.002 & $2.98(1.56-5.69)$ & 0.001 \\
2 friends & $1.21(0.63-2.33)$ & $\mathrm{ns}$ & $1.09(0.63-1.91)$ & $\mathrm{ns}$ \\
$\geq 3$ friends (reference) & $1.26(0.67-2.34)$ & $\mathrm{ns}$ & $1.09(0.65-1.83)$ & $\mathrm{ns}$ \\
\hline
\end{tabular}

RRR $=$ Relative Risk Ratio; CI $=95 \%$ Confidence Interval; All estimates are adjusted for all variables listed in the table.

Table 3. Multivariate analysis of suicide ideation and planning among school-attending adolescents in the Seychelles.

\begin{tabular}{ccccc}
\hline Variable & $\begin{array}{c}\text { Suicidal ideation } \\
\text { RRR (CI) }\end{array}$ & $\boldsymbol{P}$-value & $\begin{array}{c}\text { Suicidal planning } \\
\text { RRR (CI) }\end{array}$ & P-value \\
\hline Food deprivation & $1.60(0.97-2.64)$ & $\mathrm{ns}$ & $1.55(1.01-2.36)$ & 0.043 \\
Anxiety & $1.98(1.11-3.54)$ & 0.020 & $5.23(3.48-7.85)$ & $<0.001$ \\
Signs of depression & $2.26(1.46-3.53)$ & $<0.001$ & $3.95(2.75-5.69)$ & $<0.001$ \\
Loneliness & $4.33(2.66-7.04)$ & $<0.00$ & $3.65(2.42-5.50)$ & $<0.001$ \\
Bullied & $2.00(1.29-3.11)$ & $<0.002$ & $2.21(1.53-3.17)$ & $<0.001$ \\
Parent knowledgeable about free time & $0.75(0.48-1.18)$ & $\mathrm{ns}$ & $0.43(0.29-0.65)$ & $<0.001$ \\
Parents were understanding & $0.75(0.48-1.18)$ & $\mathrm{ns}$ & $0.43(0.29-0.64)$ & $<0.001$ \\
Tobacco use & $2.30(1.44-3.67)$ & $<0.001$ & $2.76(1.87-4.08)$ & $<0.001$ \\
Substance use & $1.51(0.90-2.52)$ & $\mathrm{ns}$ & $1.85(1.19-2.86)$ & 0.006 \\
Alcohol misuse & $1.85(1.16-2.94)$ & 0.010 & $2.03(1.38-3.00)$ & $<0.001$ \\
Close friends & & & & \\
0 friend & $3.88(1.88-8.02)$ & $<0.001$ & $4.67(2.60-8.37)$ & $<0.001$ \\
1 friend & $1.35(0.72-2.52)$ & $\mathrm{ns}$ & $1.33(0.80-2.22)$ & $\mathrm{ns}$ \\
2 friends & $1.38(0.76-2.51)$ & $\mathrm{ns}$ & $1.44(0.90-2.30)$ & $\mathrm{ns}$ \\
$\geq 3$ friends (reference) & - & - & - & - \\
\hline
\end{tabular}

$\mathrm{RRR}=$ Relative Risk Ratio; $\mathrm{CI}=95 \%$ Confidence Interval; All estimates are adjusted for age and sex.

\section{Discussion}

We found that suicide expression here (16\%) was lower than reported rates elsewhere in the SSA region (20-36\%) using a comparable period of recall [10,18-20], but similar to those in HIC settings [21]. Higher average living standards and greater stability in the Seychelles, as compared with countries in the region, may partially explain these differences [22]. A favorable social context may potentially mitigate suicidal expression among adolescents, including social cohesion linked to the Creole culture, comprehensive education and health care services which are available free of cost, high community involvement due to the small size of the country, and low unemployment. 
Suicidality is reported in the literature as being a non-specific marker for a broad range of psychosocial distresses such as political unrest and poor life quality [23]. These have been previously shown to negatively impact mental health at the individual level, potentially to the extent of self-harm [24,25]. While SI in the present sample was less prevalent among older adolescents, no significant association between age and SISP was found when other covariates were added to the model. This is in contrast to previous research which suggests that suicidality among those at risk increases after age 14 years. This may be due to increasing social pressures and expectations about pending adulthood [26]. In the Seychelles however, several government sponsored efforts exist to allow, for example, to pursue post secondary education and to find employment for school leavers, which can ease the transition between adolescence and adulthood.

Females were more likely to have reported planning a suicide attempt. This was consistent with findings elsewhere in the region [18,19] and internationally [27,28]. Other gender sensitive research on suicide suggests that while females may be more likely to think about suicide, males were more likely to successfully complete a suicide attempt [29]. Signs of depression and loneliness were both associated with SI and SISP, a finding which was congruent with other research highlighting mental ill-health as one important factor in suicidality [30].

Unlike prior research which informed that food deprivation was associated with higher rates of SI [5], we were not able to replicate this finding in the present sample. One hypothesis might be that although some participants reported not having enough food in the home, they may have had access to food while in school. Additionally, in the tropical climate of the Seychelles, fruits and vegetables are widely accessible throughout the year. It is also plausible that other factors such as family or sibling support offer protective mechanisms which confound associations between suicidality and food deprivation [31].

Consistent with prior research, tobacco use was elevated among adolescents with suicidal ideation [32,33]. We found that tobacco was use significantly associated with higher rates of self-reported SI and SISP. This may be related to evidence which supports tobacco use being used as a coping mechanism for negative life events, anger and stress [34], or other stressful situations such as physical transformation, sexuality, independence and social pressures [4].

Our finding that not having close friends was associated with an increase in suicidal expression, was congruent with the literature [30,35]. Adolescence is a period during which the formation of peer groups and friendships is an important aspect of their psychosocial development. Not having friends or being excluded from desirable peer groups, can have negative consequences for individual well-being and mental health [36]. Parent influence on the social behavior of children decreases during adolescence, with increased influence from peers [37]. However, our results demonstrate that parents may too play an important supportive role in the socialization process. Having understanding parents in our sample was associated with lower rates of SISP. This potentially suggests that adolescents who have open communication with their parents may be more likely to address their concerns.

After adjusting for covariates, we found no association between suicidal expression and parent knowledge about their child's free time activities. Other research presented mixed results upon examining the link between parent supervision and adolescent suicidal expression. For example, among 2,598 pre/early adolescents in the United States, it was found that parent supervision played 
a significant role in reducing suicidal expression, but mainly among girls [38]. Other research has suggested that low parental monitoring, was independently associated with increased suicide expression [39]. Another longitudinal study provided even more inconclusive information-that parental vigilance was associated with increased rates of suicidality [40].

We found that reported rates of suicidal expression did not increase among those who reported being bullied, a finding not consistent with the literature [41]. Prior research from the Seychelles using similar measures and a similar period of recall, found that mental well-being declined in the presence of bullying [17]. However, this decline in mental health, may not have been sufficiently severe as to demonstrate higher levels of suicidal expression. It is also plausible that bullying rates among those who were victimized were underreported, thus obscuring the association with suicidal expression.

Despite research highlighting increased substance and alcohol use among those with suicidal expression $[42,43]$, we were unable to replicate previous research findings using the current sample. One hypothesis concerning alcohol, may be the fact that other research considers alcohol use and not alcohol misuse as a correlate as was done in the present study. Thus there still exists the discrete possibility that alcohol use may be correlated with suicidal expression in the current sample, but misuse was not. The lack of an association with substance use may be explained by limitations in the data. Roughly $14 \%$ of all respondents reported some form of substance use during their lifetimes. It is likely that most of the substance use was due to experimentation, rather than as a coping mechanism in the presence of mental ill health. Furthermore, it is difficult to assess alcohol intake by use of a questionnaire, and imprecision in assessment of alcohol intake tends to drive an association to the null [44].

\section{Limitations}

This study provides valuable insight into a rarely explored public health phenomenon among adolescents in LMICs, and specifically in a sub-Saharan middle-income setting. To our knowledge this is the only study to have examined suicidal expression among adolescents in the Seychelles. Despite this, the results must be viewed in light of several limitations. First, the study remains silent on suicidal expression among adolescents who were absent on the day of the survey or who do not attend school. A previous survey in among school-attending adolescents in the Seychelles showed markedly higher unhealthy behaviors among students absent from school [45]. Secondly, although this survey was designed to be administered cross-culturally, there may have existed ambiguity in how questions were interpreted by respondents. For example, questions concerning mental health such as signs of depression, anxiety, or loneliness may manifest themselves differently cross culturally [46], and as such the reported symptoms may not be accurately captured when using Western measurement scales. Suicidal expression by peers and family has been documented as an important correlate for suicidal expression among adolescents. Thus the inclusion of information on family and peers in the survey would have strengthened the study [40]. Further research with culturally competent, standardized, multiple item measurements for signs of depression, anxiety, loneliness, as well as parent-child relationship quality are recommended.

Finally, cultural taboos against suicidal expression may also have skewed our findings in the form of an underreporting bias. The 12-month recall period for suicidal expression may be subject to recall or social desirability biases. The cross-sectional design of the study did not allow for the 
determination of causal relationships between suicidal expression and associated factors. Finally, all items in the questionnaire were self-reported. Because the body of research on suicide expression in sub-Saharan settings is limited at present, the results should be limited to self-reported SI and SISP in the school-based adolescent population.

\section{Conclusions}

Our results suggest that school health programs in the Seychelles may benefit from simultaneously targeting multiple factors associated with suicidal expression. Efforts should take into account the range of psychosocial characteristics of school-attending adolescents who report suicidal expression such as mental well-being, interaction with peers and substance use behaviors. Further research would benefit by making use of culturally appropriate and validated questionnaires to allow for enhanced reliability in examining factors such as parent-child relationship and mental health. Multilevel research designs are also suggested to identify peer and family influences which may modify associations with suicidality. The findings presented here may also be used to augment programs which emphasize the importance of healthy peer relationships, and help in the creation of environments in which healthy peer relationships can form.

\section{Acknowledgments}

The authors thank the Ministry of Health and the Ministry of Education, Republic of Seychelles, for their support for epidemiological and social research; the Centers for Disease Control and Prevention (Atlanta, GA, USA); and the World Health Organization (Geneva, Switzerland). We would also like to thank all the survey officers and students who took part in the study.

\section{References}

1. Eisenberg, M.E. Associations of weight-based teasing and emotional well-being among adolescents. Arch. Pediatr. Adolesc. Med. 2003, 157, doi:10.1001/archpedi.157.8.733.

2. Blum, R.; Sudhinaraset, M.; Emerson, M.R. Youth at risk: Suicidal thoughts and attempts in Vietnam, China, and Taiwan. J. Adolesc. Health 2012, 50, S37-S44.

3. Johnson, G.R.; Krug, E.G.; Potter, L.B. Suicide among adolescents and young adults: A cross-national comparison of 34 countries. Suicide Life-Threaten. Behav. 2000, 30, 74-82.

4. Burrows, S.; Laflamme, L. Suicide among urban South African adolescents. Int. J. Adolesc. Med. Health 2008, 20, 519-528.

5. Alaimo, K.; Olson, C.M.; Frongillo, E.A. Family food insufficiency, but not low family income, is positively associated with dysthymia and suicide symptoms in adolescents. $J$. Nutr. 2002, 132, 719-725.

6. Whitley, E.; Gunnell, D.; Dorling, D.; Smith, G.D. Ecological study of social fragmentation, poverty, and suicide. BMJ 1999, 319, 1034-1037.

7. Garrison, C.Z.; McKeown, R.E.; Valois, R.F.; Vincent, M.L. Aggression, substance use, and suicidal behaviors in high school students. Amer. J. Public Health 1993, 83, 179-184.

8. Stivers, C. Parent-adolescent communication and its relationship to adolescent depression and suicide proneness. Adolescence 1988, 23, 291-295. 
9. Wasserman, D.; Cheng, Q.; Jiang, G.-X. Global suicide rates among young people aged 15-19. World Psychiat. 2005, 4, 114-120.

10. Muula, A.S.; Kazembe, L.N.; Rudatsikira, E.; Siziya, S. Suicidal ideation and associated factors among in-school adolescents in Zambia. Tanzan. Health Res. Bull. 2007, 9, 202-206.

11. Krug, E.G.; Mercy, J.A.; Dahlberg, L.L.; Zwi, A.B. The world report on violence and health. Lancet 2002, 360, 1083-1088.

12. Mock, C.N.; Gloyd, S.; Adjei, S.; Acheampong, F.; Gish, O. Economic consequences of injury and resulting family coping strategies in Ghana. Accid. Anal. Prev. 2003, 35, 81-90.

13. Alwan, H.; Viswanathan, B.; Paccaud, F.; Bovet, P. Is accurate perception of body image associated with appropriate weight-control behavior among adolescents of the Seychelles. J. Obes. 2011, 2011, 817242, doi:10.1155/2011/817242.

14. WHO. Global school-based student health survey (GSHS). Available online: http://www.who.int/chp/gshs/en/ (accessed on 26 February 2012).

15. Alwan, H.; Viswanathan, B.; Rousson, V.; Paccaud, F.; Bovet, P. Association between substance use and psychosocial characteristics among adolescents of the Seychelles. BMC Pediat. 2011, 11, doi:10.1186/1471-2431-11-85.

16. Lyon, M.E.; Benoit, M.; O’Donnell, R.M.; Getson, P.R.; Silber, T.; Walsh, T. Assessing African American adolescents' risk for suicide attempts: attachment theory. Adolescence 2000, 35, 121-134.

17. Wilson, M.L.; Bovet, P.; Viswanathan, B.; Suris, J.-C. Bullying among adolescents in a sub-Saharan middle-income setting. J. Adolesc. Health 2012, 51, 96-98.

18. Page, R.M.; West, J.H. Suicide ideation and psychosocial distress in sub-Saharan African youth. Am. J. Health Behav. 2011, 35, 129-141.

19. Rudatsikira, E.; Siziya, S.; Kazembe, L.N.; Muula, A.S. Prevalence and associated factors of physical fighting among school-going adolescents in Namibia. Ann. Gen. Psychiat. 2007, 6, doi:10.1186/1744-859X-6-18.

20. Omigbodun, O.; Dogra, N.; Esan, O.; Adedokun, B. Prevalence and correlates of suicidal behaviour among adolescents in southwest Nigeria. Int. J. Soc. Psychiatry 2008, 54, 34-46.

21. Riesch, S.K.; Jacobson, G.; Sawdey, L.; Anderson, J.; Henriques, J. Suicide ideation among later elementary school-aged youth. J. Psychiat. Ment. Health Nurs. 2008, 15, 263-277.

22. Perdrix, J.; Bovet, P.; Larue, D.; Yersin, B.; Burnand, B.; Paccaud, F. Patterns of alcohol consumption in the Seychelles Islands (Indian Ocean). Alcohol Alcoholism. 1999, 34, 773-785.

23. Franic, T.; Kardum, G.; Marin Prizmic, I.; Pavletic, N.; Marcinko, D. Parental involvement in the war in Croatia 1991-1995 and suicidality in Croatian male adolescents. Croat. Med. J. 2012, 53, 244-253.

24. Scholte, W.F.; Olff, M.; Ventevogel, P.; de Vries, G.-J.; Jansveld, E.; Cardozo, B.L.; Crawford, C.A.G. Mental health symptoms following war and repression in eastern Afghanistan. JAMA 2004, 292, 585-593.

25. Araya, M.; Chotai, J.; Komproe, I.H.; de Jong, J.T. Effect of trauma on quality of life as mediated by mental distress and moderated by coping and social support among postconflict displaced Ethiopians. Qual. Life Res. 2007, 16, 915-927. 
26. Sharma, R.; Grover, V.L.; Chaturvedi, S. Suicidal behavior amongst adolescent students in south Delhi. Indian J. Psychiat. 2008, 50, 30-33.

27. Eaton, D.; Kann, L.; Kinchen, S.; Shanklin, S.; Ross, J.; Hawkins, J.; Harris, H.; Lowry, R.; McManus, T.; Chyen, D.; Lim, C.; Brener, N.; Wechsler, H.; Centers for Disease Control and Prevention (CDC). Youth Risk Behavior Surveillance-United States, 2007. Available online: http://ukpmc.ac.uk/abstract/MED/18528314/reload=0 (accessed on 3 July 2012).

28. Liu, X.; Tein, J.-Y.; Zhao, Z.; Sandler, I.N. Suicidality and correlates among rural adolescents of China. J. Adolesc. Health 2005, 37, 443-451.

29. Horesh, N.; Gothelf, D.; Ofek, H.; Weizman, T.; Apter, A. Impulsivity as a correlate of suicidal behavior in adolescent psychiatric inpatients. Crisis 1999, 20, 8-14.

30. Jones, A.C.; Schinka, K.C.; van Dulmen, M.H.M.; Bossarte, R.M.; Swahn, M.H. Changes in loneliness during middle childhood predict risk for adolescent suicidality indirectly through mental health problems. J. Clin. Child. Adolesc. Psychol. 2011, 40, 818-824.

31. Tingvold, L.; Hauff, E.; Allen, J.; Middelthon, A.-L. Seeking balance between the past and the present: Vietnamese refugee parenting practices and adolescent well-being. IJIR 2012, 36, 563-574.

32. Viswanathan, B.; Warren, C.W.; Jones, N.R.; Asma, S.; Bovet, P. Linking Global Youth Tobacco Survey (GYTS) data to the WHO Framework Convention on Tobacco Control (FCTC): The case for the Seychelles. Prev. Med. 2008, 47 Suppl. 1, S33-S37.

33. McGee, R.; Williams, S.; Nada-Raja, S. Is cigarette smoking associated with suicidal ideation among young people? Am. J. Psychiat. 2005, 162, 619-620.

34. Siqueira, L.; Diab, M.; Bodian, C.; Rolnitzky, L. Adolescents becoming smokers: The roles of stress and coping methods. J. Adolesc. Health 2000, 27, 399-408.

35. Stravynski, A.; Boyer, R. Loneliness in relation to suicide ideation and parasuicide: A population-wide study. Suicide Life-Threaten. Behav. 2001, 31, 32-40.

36. Sumter, S.R.; Bokhorst, C.L.; Steinberg, L.; Westenberg, P.M. The developmental pattern of resistance to peer influence in adolescence: Will the teenager ever be able to resist? J. Adolescence 2009, 32, 1009-1021.

37. Masten, C.L.; Juvonen, J.; Spatzier, A. Relative importance of parents and peers differences in academic and social behaviors at three grade levels spanning late childhood and early adolescence. J. Early Adolesc. 2009, 29, 773-799.

38. Logan, J.E.; Crosby, A.E.; Hamburger, M.E. Suicidal ideation, friendships with delinquents, social and parental connectedness, and differential associations by sex: Findings among high-risk pre/early adolescent population. Crisis 2011, 32, 299-309.

39. King, R.A.; Schwab-Stone, M.; Flisher, A.J.; Greenwald, S.; Kramer, R.A.; Goodman, S.H.; Lahey, B.B.; Shaffer, D.; Gould, M.S. Psychosocial and risk behavior correlates of youth suicide attempts and suicidal ideation. J. Am. Acad. Child. Adolesc. Psychiatry 2001, 40, 837-846.

40. Wichstrøm, L. Predictors of adolescent suicide attempts: A nationally representative longitudinal study of Norwegian adolescents. J. Am. Acad. Child. Adolesc. Psychiatry 2000, $39,603-610$.

41. Hepburn, L.; Azrael, D.; Molnar, B.; Miller, M. Bullying and suicidal behaviors among urban high school youth. J. Adolesc. Health 2012, 51, 93-95. 
42. Swahn, M.H.; Bossarte, R.M. Gender, early alcohol use, and suicide ideation and attempts: Findings from the 2005 youth risk behavior survey. J. Adolesc. Health 2007, 41, 175-181.

43. Vega, W.A.; Gil, A.; Warheit, G.; Apospori, E.; Zimmerman, R. The relationship of drug use to suicide ideation and attempts among african american, hispanic, and white non-hispanic male adolescents. Suicide Life-Threaten. Behav. 1993, 23, 110-119.

44 Williams, A.; Clark, D. Alcohol consumption in university students: The role of reasons for drinking, coping strategies, expectancies, and personality traits. Addict. Behav. 1998, 23, 371-378.

45. Bovet, P.; Viswanathan, B.; Faeh, D.; Warren, W. Comparison of smoking, drinking, and marijuana use between students present or absent on the day of a school-based survey. J. Sch. Health 2006, 76, 133-137.

46. Segal, U.A.; Mayadas, N.S. Assessment of issues facing immigrant and refugee families. Child. Welfare 2005, 84, 563-583. 
Reprinted from Int. J. Environ. Res. Public Health. Cite as: Xia, X.; Xiang, J.; Shao, J.; Smith, G.A.; Yu, C.; Zhu, H.; Xiang, H. Characteristics and Trends of Hospitalized Pediatric Abuse Head Trauma in Wuhan, China: 2002-2011. Int. J. Environ. Res. Public Health 2012, 9, 4187-4196.

Article

\title{
Characteristics and Trends of Hospitalized Pediatric Abuse Head Trauma in Wuhan, China: 2002-2011
}

\author{
Xin Xia ${ }^{1}$, Joe Xiang ${ }^{2}$, Jianbo Shao ${ }^{3}$, Gary A. Smith ${ }^{4,5}$, Chuanhua Yu ${ }^{1}$, Huiping Zhu ${ }^{6, *}$ and \\ Huiyun Xiang ${ }^{4,5}, *$
}

1 School of Public Health, Wuhan University, 115 Donghu Road, Wuhan, 430071, China;

E-Mails: xiaxin84@163.com (X.X.); yuchua@163.com (C.Y.)

2 Case Western Reserve University, Cleveland, OH 44120, USA; E-Mail: yxx125@case.edu

3 Wuhan Children's Hospital, 100 Hongkong Road, Wuhan, 430016, China;

E-Mail: shaojb2002@sina.com

4 Center for Injury Research and Policy, The Research Institute at Nationwide Children's Hospital, 700 Children's Drive, Columbus, OH 43205, USA; E-Mail: Gary.Smith@nationwidechildrens.org

5 The Ohio State University College of Medicine, 370 West 9th Avenue, Columbus, OH 43210, USA

6 School of Public Health and Family Medicine, Capital Medical University, 10 Xitoutiao, Youanmen, Beijing, 100069, China

* Authors to whom correspondence should be addressed; E-Mails: zhuhuiping@ccmu.edu.cn (H.Z.); Huiyun.Xiang@nationwidechildrens.org (H.X.); Tel.: +86-10-8391-1777 (H.Z.); +1-614-355-5893 (H.X.); Fax: +86-10-8391-1777 (H.Z.); +1-614-355-5897 (H.X.).

Received: 20 October 2012; in revised form: 12 November 2012 / Accepted: 12 November 2012 / Published: 15 November 2012

\begin{abstract}
This study investigated characteristics and trends of hospitalized abuse-related traumatic brain injuries (TBI) treated at a large pediatric medical center in Wuhan, China during the past 10 years. De-identified hospital discharge data for patients 0-4 years old hospitalized at the Wuhan Medical Care Center for Women and Children were analyzed, and ICD-10 codes were used to identify cases of TBI. Medical notes provided by doctors in the medical record were used to identify TBI cases in which suspected child abuse was the cause. From 2002 to 2011, 3,061 pediatric TBI patients were hospitalized and 4.6\% (140) of these cases were suspected child abuse-related. The majority of suspected child abuse cases involved children younger than 1 year of age $(68.6 \%)$ and usually affected males $(63.6 \%)$. Children with non-Abusive Head Trauma (AHT) were more likely to have full recovery outcome (68.4\%, 95\% CI: $66.6 \%-70.0 \%)$ than children with suspected AHT (44.3\%, 95\% CI: 36.1\%-52.5\%).
\end{abstract}


The proportion of all childhood TBI attributable to abuse did not appear to have increased in the 10-year period at this medical center. This is the first comprehensive study highlighting the important role of suspected child abuse in causing TBIs among Chinese children. Child abuse as a major cause of TBIs among infants in China should be studied further, and there should be greater awareness of this important social and medical problem in China.

Keywords: abusive head trauma; child abuse; children; China

\section{Introduction}

Child abuse, a common and serious problem around the World, refers to all forms of neglect, physical, emotional or sexual abuse that results in harm to a child's health, development or dignity [1-3]. Every year, 155,000 deaths occur in children globally as a result of abuse or neglect [4], yet the number of abused children has been and continues to be largely underestimated [5]. The incidence of child abuse in the USA is estimated at 23.1 per 1,000 children [5], and an estimated 100,000-160,000 children are victims of child abuse annually in The Netherlands [6]. Children who suffered child abuse can develop physical, emotional, and cognitive conditions, which can significantly impact neurological development [7]. As such, prevention of child abuse and the reduction of abusive injuries and their negative impacts should be a global health priority.

The leading cause of child abuse fatalities is abusive traumatic brain injury (TBI), which includes shaken baby syndrome (SBS) and other abuse-related head trauma [8-10]. Abusive head trauma (AHT) may lead to significant morbidity among survivors, and is remarkably over-represented for children in the first year of life [11]. The incidence of AHT ranges from 20 to 30 cases per 100,000 children under 1 year of age, with the peak incidence at 3 months of age [12-16]. Previous studies indicate that children with AHT appear to have more severe consequences than children with similar severity, non-abusive injuries [17,18]. Approximately $7 \%-30 \%$ of infants with AHT die, $30 \%-50 \%$ experience significant neurological and cognitive deficits, and up to $30 \%$ have long-term adverse effects $[19,20]$.

In China, social and cultural traditions as well as a lack of public awareness regarding appropriate child discipline has caused child abuse to remain as an undetected issue. Most Chinese people still follow a deep-rooted traditional belief in "spare the rod, spoil the child." As a result, a large proportion of Chinese people have experienced some types of physical abuse during their childhood [21]. Researchers found that although Chinese children are diagnosed with fractures, disability, and even death because they are struck by their parents, there are still a certain percentage of parents who do not realize that their behaviors constitute child abuse, and instead believe that their type of discipline is the normal way of educating their children [22]. Furthermore, child abuse remains undetected in China because the healthcare system lacks a standardized procedure in reporting child abuse cases. Not only is there no official standard in defining child abuse, but physicians are also not mandated by Chinese law to report child abuse or suspected child abuse. It should also be noted that most physicians in Chinese hospitals lack training and expertise 
in identifying child abuse cases. As such, it is of utmost importance to raise awareness about abusive head trauma among pediatricians and policymakers, as well as among the general public in China.

Research about epidemiological characteristics and outcomes of TBI were mostly conducted in adult Chinese population. An epidemiologic study investigating 246,812 participants living in rural and urban areas from 21 provinces of China found that assaults were the third leading causes of TBI in both areas [23]. However, evidence suggests that data about abusive TBI among children are unavailable in China, neither from official registries nor in scientific literatures. Taking into consideration the large information gap about pediatric AHT in China, as well as the significant adverse effects of AHT, this study was designed to investigate epidemiological characteristics of hospitalized children with suspected AHT from 2002 to 2011 at a large urban pediatric medical center in China. Overall, this study hypothesized that: (1) the majority of hospitalizations for AHT would occur in children less than 2 years of age, and (2) girls were more likely to be abused than boys among AHT cases. This study also investigated the trend of proportion (\%) of suspected pediatric abusive head trauma (AHT) in all inpatient children 0-4 years of age with traumatic brain injuries from 2002 to 2011, a period that saw rapid economic developments and dramatic social changes in China.

\section{Methods}

\subsection{Setting}

Wuhan Medical Care Center for Women and Children (WMCCWC) is the largest regional hospital providing clinical services and health promotion and prevention for women and children in central China. WMCCWC has four outpatient departments, two inpatient buildings and 1,112 beds serving Hubei and the surrounding provinces. Each year, approximately 30,000 inpatients and a total of 900,000 children are treated at outpatient and emergency departments (ED) of WMCCWC. Data from the Wuhan Bureau of Health indicated that about 55\% 60\% of total pediatric outpatients and ED patients in Wuhan city were treated at the WMCCWC. De-identified hospital discharge data from the WMCCWC were analyzed for this study. This study was approved by the institutional review board of Tongji Medical College School of Public Health in Wuhan, China.

\subsection{Subjects}

The study population consisted of children less than 5 years of age admitted to WMCCWC with a discharge diagnosis of traumatic brain injury from January 1, 2002 to December 31, 2011. Data were retrospectively collected via reviewing the medical records database of the WMCCWC. Subjects were classified as "suspicious for abuse" and "non-abuse" according to the notes in the medical record written by physicians who treated the patient. In WMCCWC, for the diagnosis of suspected AHT, physicians mainly rely on the combination of radiographic and physical examination information, and history of the injury provided by the caretaker. Every child attending to the WMCCWC needs to be evaluated by a doctor. When the doctor finds some physical symptoms of inflicted injuries (e.g., whip scars, occult multiple fractures, bruises, subcutaneous bleeding or hematoma) in combination with a head injury, he/she may ask the adult caregiver about 
the detailed injury history. If there was a witnessed inflicted head injury or confession of intentional injury by a caregiver, then the doctor make notes in the medical record. In China, making such notes is still a voluntary behavior of doctors. In this study, each medical record was reviewed by one of the authors (Xin Xia at the Wuhan University School of Public Health) who categorized patients into two groups mentioned above. Subjects were excluded from the study if there was not enough information in the medical record to determine if the injury was "suspicious for abuse" and "non-abuse". Unlike the USA and other countries, physicians in China are not required to confirm child abuse cases or refer them to a child protection agency. As such, this study could only use "suspected child abuse" herein to report these cases, since a systematic legal procedure for confirming suspected child abuse cases does not exist in China.

\subsection{Measures}

Data were extracted from the WMCCWC medical records database for all eligible subjects. Diagnosis codes of all inpatients treated at the WMCCWC were assigned using ICD-10 codes. Information collected from the medical record included: patient identification number, date of birth, gender, date of admission, admission diagnosis, severity of condition at admission, head CT scanning results, discharge date, discharge ICD-10 codes, type of conditions (injury and poisoning or other), description of injury events and stated cause of injury, outcomes at discharge, and length of stay. The stated cause of injury was defined as the injury mechanism reported by the caretakers when the child was admitted to the hospital. Causes of injury were classified as suspected child abuse or non-abuse (traffic crashes, falls, strike by/against objects, sports, and other causes) in this study.

\subsection{TBI Case Definition}

TBI cases in the WMCCWC medical record were identified using the USA definition of TBI based on the International Classification of Diseases, Tenth Revision (ICD-10) diagnosis codes. These codes included S01.1-S01.9, S02.0-S02.3, S02.7-S02.9, S04.0, S06.0-S06.9, S09.7-S09.9, T90.1, T90.2, T90.4, T90.5, T90.8, and T90.9. A total of 3,061 hospitalized TBI cases among children aged 0-4 years were identified. All suspected child abuse cases were required to have detailed and complete documentation of the injury circumstances either from an eyewitness, a caregiver, or any other person involved who admitted an abusive behavior that caused the TBI. This information was provided by the physician who treated the child and wrote notes about suspected abuse in the patient medical record.

\subsection{Data Analysis}

Suspected AHT and non-AHT were compared with respect to gender, age, outcome, and length of hospital stay using Chi-squared test and student $t$ test. Frequency and percentage distribution of suspected AHT and non-AHT hospitalizations by age were calculated along with the proportion of suspected AHT among all TBI cases. Age distribution (in months) of suspected AHT and non-AHT in children $<2$ years old was also provided. Proportions $(\%)$ and $95 \%$ confidence intervals $(95 \%$ CI) of suspected AHT in all inpatient children with TBI for each year from 2002-2011 were 
calculated. All statistical analyses were performed using the SAS statistical software. Any $p$-value less than or equal to 0.05 was considered statistically significant.

\section{Results}

Among 3,061 inpatient children with traumatic brain injuries, 140 were identified as suspected AHT cases, and $63.6 \%$ of AHT cases were boys (Table 1). There was no significant gender difference between children with suspected AHT and non-AHT; however two groups differed significantly with regard to age distribution. The age groups of children who had the highest proportion of AHT were $<1$ year old $(96,68.6 \%), 1$ year old $(14,10.0 \%)$, and 2 year olds $(16,11.4 \%)$. Among all inpatients with suspected AHT, $68.6 \%$ occurred among children $<1$ year of age compared with $23.2 \%$ of non-AHT inpatients. The proportion of TBI caused by suspected child abuse in all pediatric TBI decreased from $12.4 \%$ in children $<1$ year to $1.2 \%$ in children 4 years of age (data not shown). The mean length of hospital stay was 7.8 days for children with suspected AHT and 7.0 days for children with non-AHT ( $p=0.060, t$ test). When discharged from the hospital, children with non-AHT were more likely to have full recovery outcome $(68.4 \%, 95 \% \mathrm{CI}$ : $66.6 \%-70.0 \%)$ than children with suspected AHT (44.3\%, 95\% CI: 36.1\%-52.5\%).

Table 1. Characteristics of hospitalized children with suspected AHT $(\mathrm{n}=140)$ and non-AHT $(\mathrm{n}=2,921)$.

\begin{tabular}{|c|c|c|c|c|c|}
\hline & \multicolumn{2}{|c|}{ Suspected AHT } & \multicolumn{2}{|c|}{ Non-AHT } & \multirow{2}{*}{$p$ Value } \\
\hline & Sample N & $\%(95 \%$ CI $)$ & Sample N & $\%(95 \%$ CI $)$ & \\
\hline Gender & & & & & 0.868 \\
\hline Male & 89 & $63.6(55.6-71.5)$ & 1,877 & $64.3(62.5-66.0)$ & \\
\hline Female & 51 & $36.4(28.5-44.4)$ & 1,044 & $35.7(34.0-37.5)$ & \\
\hline Age (Years) & & & & & $<0.001$ \\
\hline$<1$ & 96 & $68.6(60.9-76.3)$ & 680 & $23.2(21.8-24.8)$ & \\
\hline 1 & 14 & $10.0(5.0-15.0)$ & 530 & $18.1(16.8-19.5)$ & \\
\hline 2 & 16 & $11.4(6.16-16.7)$ & 781 & $26.7(25.1-28.3)$ & \\
\hline 3 & 9 & $6.4(2.4-10.5)$ & 528 & $18.1(16.7-19.5)$ & \\
\hline 4 & 5 & $3.6(0.5-6.7)$ & 402 & $13.8(12.5-15.0)$ & \\
\hline Outcomes & & & & & $<0.001$ \\
\hline Full recovery & 62 & $44.3(36.1-52.5)$ & 1,994 & $68.4(66.6-70.0)$ & \\
\hline Partial recovery & 77 & $55.0(46.7-63.2)$ & 842 & $28.5(27.2-30.5)$ & \\
\hline Death & 0 & 0 & 8 & $0.3(0.1-0.5)$ & \\
\hline Unknown & 1 & $0.7(0.0-2.1)$ & 77 & $2.8(2.1-3.2)$ & \\
\hline \multicolumn{6}{|c|}{ Length of stay (days) } \\
\hline Mean (S.D.) & 140 & $7.8(4.5)$ & 2,921 & $7.0(5.9)$ & 0.060 \\
\hline Min-Max & & $1.1-23.6$ & & $0.3-166.9$ & \\
\hline
\end{tabular}

Figure 1 shows the number of hospitalized head injury cases by months of age in children 2 years old or younger, for both suspected AHT and non-AHT patients. The peak of age in AHT group was 4 months. In contrast, the non-AHT group illustrated a peak at 13 months of age.

Figure 2 reports the year trend of proportion (\%) of suspected AHT in all inpatient children 0-4 years of age with traumatic brain injuries from 2002 to 2011 . The proportion of TBI caused by 
suspected child abuse was at the lowest level of $1.9 \%(95 \% \mathrm{CI}=0.3 \%-3.5 \%)$ in 2006 . After 2006 , proportion of TBI caused by suspected child abuse increased and peaked in 2009 (7.8\%, 95\% $\mathrm{CI}=5.0 \%-10.6 \%$ ). The proportion of all childhood TBI attributable to abuse did not appear to have increased in the 10 -year period.

Figure 1. Number of hospitalized children $<2$ years with suspected AHT and non-AHT by month of age.

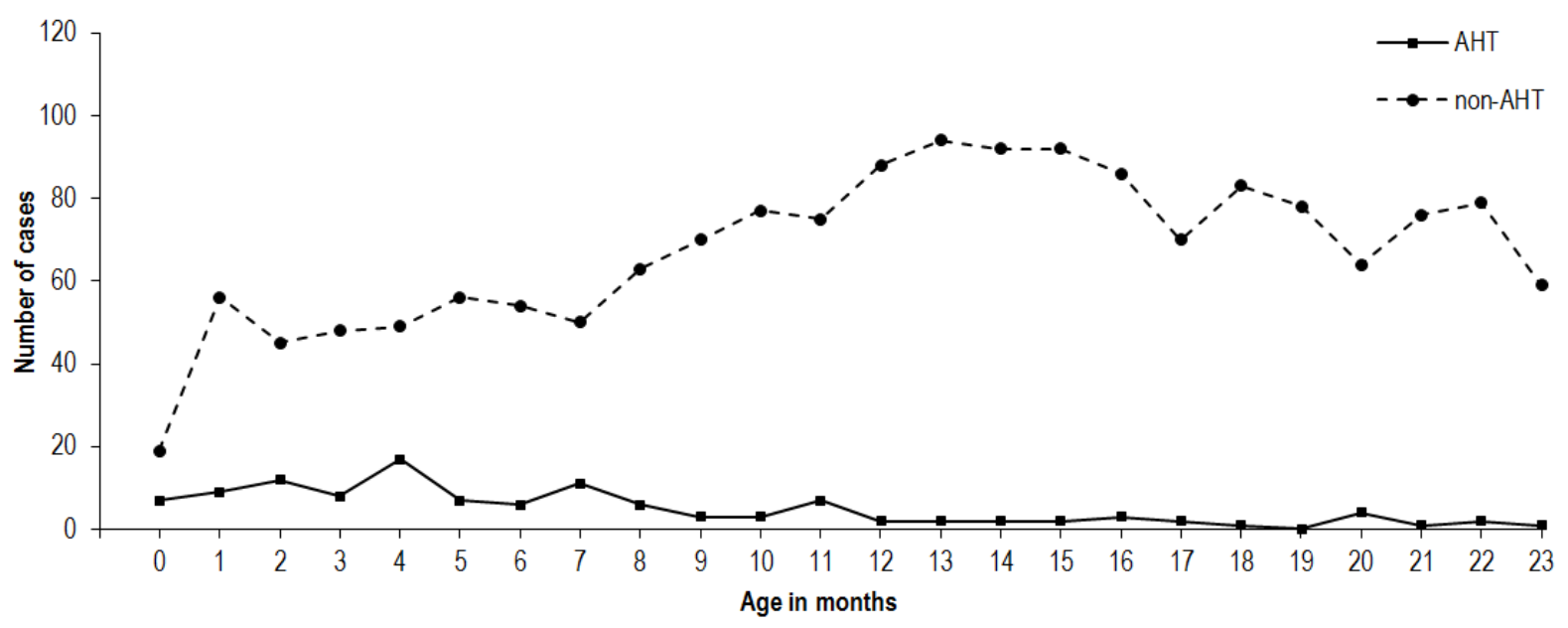

Figure 2. Year trend of proportion of suspected AHT in all inpatient children 0-4 years of age with traumatic brain injuries.

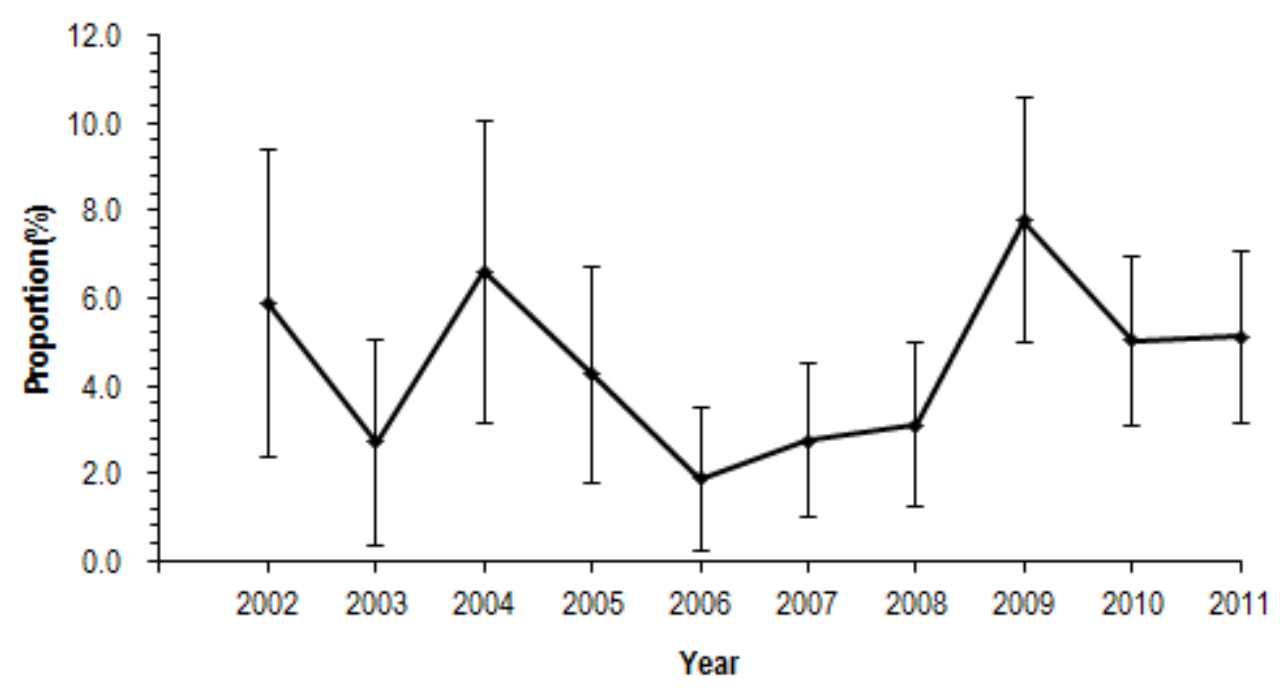

\section{Discussion and Study Limitations}

Previous studies about abusive head trauma in children were mostly from high income countries [24-27]. Our study is possibly the first study that reports the characteristics of abuse-related TBIs among children in China. We found that $63.6 \%$ of AHT patients were boys. A similar finding was reported in previous studies: $60.0 \%$ of boys in a study of AHT using the Healthcare Cost and Utilization Project (HCUP)-Nationwide Inpatient Sample (NIS) database; $67.2 \%$ of boys in a study of North Carolina traumatic brain injury registry data; and $57.2 \%$ of boys in a North Carolina review of hospital medical records [28-30]. 
Interestingly, we did not find a statistically significant difference between boys $(4.5 \%, 89 / 1,966)$ and girls $(4.7 \%, 51 / 1,095)$ in the proportion of suspected AHT in all pediatric head trauma patients $(p=0.868)$. This finding did not support our initial hypothesis that girls were more likely to experience abuse than boys among all children with TBI. Traditionally, the idea that men are superior to women exists in China, so parents may treat boys more favorably and are less likely to abuse boys than girls. Our result based on pediatric patients treated at this large urban medical center did not support the hypothesis that girls were more likely than boys to sustain abuse head trauma. A study of suspected AHT in pediatric head trauma patients in rural areas is warranted to further test our study hypothesis because many traditional Chinese views are still deep rooted in rural areas of China.

Our study is consistent with other existing literatures that reported that most hospitalizations for AHT occur in children $<2$ years of age [28,31]. Our study also found that the peak of age in children with AHT was at 4 months, which was within the range reported in several other studies (the peak hospitalization rates for AHT occurred at the first 2-4 months of life) [26,31-33]. Previous studies indicated that significant social stigma might have biased people's answers and people are more likely to lie or not admitting their behaviors, especially those behaviors that are less socially acceptable [34]. This may partly interpret the relatively small number of AHT cases identified over a 10-year period in our study. In China, although child abuse is not included in China's criminal law at present, there are still other laws and regulations like Law of the People's Republic of China on the Protection of Minors that stipulate that the minors should not be maltreated or forsaken. However, unlike the child abuse reporting procedures in medical practice that required by laws in the USA, there is no law or regulation in China that mandates reporting of child abuse by physicians to law enforcement agencies. Therefore, underreporting of child abuse might have biased our findings in this study.

In this study, we found that children with non-AHT were more likely to have full recovery outcome at discharge than children with suspected AHT. This result was consistent with the findings from previous studies that reported worse outcomes in AHT children compared with children with non-abusive traumatic brain injury [14,35]. There are two possible explanations for this phenomenon. First, in our sample of head trauma patients, the majority of children with suspected abusive TBI were less than 1 year of age. A previous study found that younger children are much more vulnerable to sustain a head trauma than older children, and often have more severe traumatic brain injury [36]. Second, children with abusive TBI are often not brought to hospital until they have severe serious symptoms due to stigma and the caregiver's fear of possible legal trouble [26]. Therefore, pediatric patients with AHT are significantly less likely than non-AHT children to have a good outcome at hospital discharge.

There are several limitations in our study. First, our results may not reflect the true number of AHT cases in the community, as our study subjects were selected from the medical record database in only one large regional children's medical center in China. However, results regarding demographical characteristics, statistical comparisons, proportion, and year trend were still valid and provided preliminary findings about a significant social and medical issue in China. Second, patients in this study were retrospectively identified from the inpatient medical record database. Emergency department patients were not included because hospitals in China do not keep medical 
records for patients who are treated and discharged from the emergency department. Third, this study relied heavily on documentation of trauma history of the hospital patients and voluntary reporting of physicians in the medical records to identify suspicious AHT. Thus, our results might be subject to reporting bias as AHT cases were determined by a suspected child abuse note written by the physician in the medical record. In Chinese culture, some types of discipline by parents, which may be considered child abuse in Western cultures, are often believed by the Chinese society as an acceptable form of authoritative punishment. Also, physicians in China have inadequate knowledge and training to recognize abuse injury; therefore, TBI caused by child abuse might have been underreported in our study. Furthermore, there are no standard criteria for diagnosis of AHT, and previous studies in the USA used different operational definitions of AHT. Some investigators defined pediatric AHT based on the findings by a social service agency or a hospital child protective expert panel, while others used clinical criteria [37-39]. Finally, we could not calculate rates nor could age standardized rates be calculated to assess the year trend of suspected AHT due to lack of an appropriate denominator.

Unfortunately, there are neither special social service agencies nor a specialized evaluation team in hospitals for identifying and reporting child abuse in China. Therefore, establishing a clear case definition that allows for a more accurate assessment of the burden of abuse-related head trauma in children and evaluation of the effect of future prevention and education programs is a top priority in TBI research and prevention in China.

\section{Conclusions}

Our study confirmed the important role of suspected child abuse in causing TBIs in young children in China. This study is significant because previous publications from China have not studied children with suspected AHT. Our study provided some important preliminary findings about this social and medical problem in China.

\section{Acknowledgments}

The authors would like to thank Chunxiang Yan at Wuhan Children's Hospital for her data preparation assistance.

\section{Competing interests}

The authors declare no conflict of interest.

\section{References}

1. World Health Organization. World Report on Violence and Health; WHO: Geneva, Switzerland, 2002.

2. Newton, A.W.; Vandeven, A.M. Unexplained infant and child death: A review of sudden infant death syndrome, sudden unexplained infant death, and child maltreatment fatalities including shaken baby syndrome. Curr. Opin. Pediatr. 2006, 18, 196-200.

3. Tenney-Soeiro, R.; Wilson, C. An update on child abuse and neglect. Curr. Opin. Pediatr. 2004, 16, 233-237. 
4. Gilbert, R.; Widom, C.S.; Browne, K.; Fergusson, D.; Webb, E.; Janson, S. Burden and consequences of child maltreatment in high-income countries. Lancet 2009, 373, 68-81.

5. Louwers, E.C.; Affourtit, M.J.; Moll, H.A.; de Koning, H.J.; Korfage, I.J. Screening for child abuse at emergency departments: A systematic review. Arch. Dis. Child 2010, 95, 214-218.

6. Louwers, E.C.; Korfage, I.J.; Affourtit, M.J.; Scheewe, D.J.; van de Merwe, M.H.; Vooijs-Moulaert, F.A.; Woltering, C.M.; Jongejan, M.H.; Ruige, M.; Moll, H.A.; de Koning, H.J. Detection of child abuse in emergency departments: A multi-center study. Arch. Dis. Child 2011, 96, 422-425.

7. Al-Saadoon, M.; Elnour, I.B.; Ganesh, A. Shaken baby syndrome as a form of abusive head trauma. Sultan. Qaboos. Univ. Med. J. 2011, 11, 322-327.

8. Runyan, D.K.; Berger, R.P.; Barr, R.G. Defining an ideal system to establish the incidence of inflicted traumatic brain injury. Am. J. Prev. Med. 2008, 4, Suppl., S163-S168.

9. Ryan, M.A.; Lloyd, D.W.; Conlin, A.M.; Gumbs, G.R.; Keenan, H.T. Evaluating the epidemiology of inflicted traumatic brain injury in infants of U.S. military families. Am. J. Prev. Med. 2008, 4, Suppl., S143-S147.

10. Matschke, J.; Herrmann, B.; Sperhake, J.; Körber, F.; Bajanowski, T.; Glatzel, M. Shaken baby syndrome: A common variant of non-accidental head injury in infants. Dtsch .Arztebl. Int. 2009, 106, 211-217.

11. Minns, R.A.; Brown, J.K.; Bell, J. Shaking and Other Non-Accidental Head Injuries in Children: Neuropathology of Non-accidental Head Injury; Mac Keith Press: London, UK, 2006; pp. 1-106.

12. Barlow, K.M.; Thomson, E.; Johnson, D.; Minns, R.A. Late neurologic and cognitive sequelae of inflicted traumatic brain injury in infancy. Pediatrics 2005, 116, e174-e185.

13. Ellingson, K.D.; Leventhal, J.M.; Weiss, H.B. Using hospital discharge data to track inflicted traumatic brain injury. Am. J. Prev. Med. 2008, 4, Suppl., S157-S162.

14. Eisele, J.A.; Kegler, S.R.; Trent, R.B.; Coronado, V.G. Nonfatal traumatic brain injury-related hospitalization in very young children-15 states, 1999. J. Head Trauma Rehabil. 2006, 21, 537-543.

15. Pounder, D.J. Shaken adult syndrome. Am. J. Forensic Med. Pathol. 1997, 18, 321-324.

16. Ludwig, S.; Warman, M. Shaken baby syndrome: A review of 20 cases. Ann. Emerg. Med. 1984, 13, 104-107.

17. Loh, J.K.; Lin, C.L.; Kwan, A.L.; Howng, S.L. Acute subdural hematoma in infancy. Surg. Neurol. 2002, 58, 218-524.

18. Reece, R.M.; Sege, R. Childhood head injury. Arch. Pediatr. Adolesc. Med. 2002, 154, 11-15.

19. Altimier, L. Shaken baby syndrome. J. Perinat. Neonatal Nurs. 2008, 22, 68-78.

20. Díaz-Olavarrieta, C.; García-Piña, C.A.; Loredo-Abdala, A.; Paz, F.; Garcia, S.G.; Schilmann, A. Abusive head trauma at a tertiary care children's hospital in Mexico City: A preliminary study. Child Abuse Negl. 2011, 35, 915-923.

21. Zhang, T.; Chow, A.; Wang, L.; Dai, Y.; Xiao, Z. Role of childhood traumatic experience in personality disorders in China. Compr. Psychiatry 2011, 53, 829-836.

22. Meng, Q.Y.; Liu, X.Z.; Zhang, H. The definition of child abuse by the general public: A sampling survey. Chin. J. Soc. Med. 1994, 50, 10-14. 
23. Zhao, Y.D.; Wang, W. Neurosurgical trauma in People's Republic of China. World J. Surg. 2001, 25, 1202-1204.

24. Keenan, H.T.; Runyan, D.K.; Marshall, S.W.; Nocera, M.A.; Merten, D.F.; Sinal, S.H. A population-based study of inflicted traumatic brain injury in young children. JAMA-J. Am. Med. Assoc. 2003, 290, 621-626.

25. Minns, R.A.; Jones, P.A.; Mok, J.Y. Incidence and demography of non-accidental head injury in southeast Scotland from a national database. Am. J. Prev. Med. 2008, 4, Suppl., S126-S133.

26. Fujiwara, T.; Okuyama, M.; Miyasaka, M. Characteristics that distinguish abusive from non-abusive head trauma among young children who underwent head computed tomography in Japan. Pediatrics 2008, 122, e841-e847.

27. Woodman, J.; Pitt, M.; Wentz, R.; Taylor, B.; Hodes, D.; Gilbert, R.E. Performance of screening tests for child physical abuse in accident and emergency departments. Health Technol. Assess. 2008, 12, 1-95.

28. Parks, S.; Sugerman, D.; Xu, L.; Coronado, V. Characteristics of non-fatal abusive head trauma among children in the USA, 2003-2008: Application of the CDC operational case definition to national hospital inpatient data. Inj. Prev. 2012, doi:10.1136/injuryprev-2011-040234.

29. Keenan, H.T.; Runyan, D.K.; Marshall, S.W.; Nocera, M.A.; Merten, D.F. A population-based comparison of clinical and outcome characteristics of young children with serious inflicted and non-inflicted traumatic brain injury. Pediatrics 2004, 114, 633-639.

30. Keenan, H.T. Practical aspects of conducting a prospective statewide incidence study: The incidence of serious inflicted traumatic brain injury in North Carolina. Am. J. Prev. Med. 2008, 4, Suppl., S120-S125.

31. Barlow, K.M.; Minns, R.A. Annual incidence of shaken impact syndrome in young children. Lancet 2000, 356, 1571-1572.

32. Barr, R.; Trent, R.B.; Cross, J. Age-related incidence curve of hospitalized shaken baby syndrome cases: convergent evidence for crying as a trigger to shaking. Child Abuse Negl. 2006, 30, 7-16.

33. Lee, C.; Barr, R.G.; Catherine, N.; Wicks, A. Age-related incidence of publicly reported shaken baby syndrome cases: Is crying a trigger for shaking? J. Dev. Behav. Pediatr. 2007, 28, 288-293.

34. Appel, A.E.; Holden, G.W. The co-occurrence of spouse and physical child abuse: A review and appraisal. J. Fam. Psychol. 1998, 12, 578-599.

35. Ewing-Cobbs, L.; Kramer, L.; Prasad, M.; Canales, D.N.; Louis, P.T.; Fletcher, J.M.; Vollero, H.; Landry, S.H.; Cheung, K. Neuroimaging, physical, and developmental findings after inflicted and non-inflicted traumatic brain injury in young children. Pediatrics 1998, 102, 300-307.

36. Kellogg, N.D. American Academy of Pediatrics Committee on Child Abuse and Neglect. Evaluation of suspected child physical abuse. Pediatrics 2007, 119, 1232-1241.

37. Dias, M.S.; Smith, K.; DeGuehery, K.; Mazur, P.; Li, V.; Shaffer, M.L. Preventing abusive head trauma among infants and young children: A hospital-based, parent education program. Pediatrics 2005, 115, 470-477.

38. Hymel, K.P.; Abshire, T.C.; Luckey, D.W.; Jenny, C. Coagulopathy in pediatric abusive head trauma. Pediatrics 1997, 99, 371-375. 
39. Duhaime, A.C.; Alario, A.J.; Lewander, W.J.; Schut, L.; Sutton, L.N.; Seidl, T.S.; Nudelman, S.; Budenz, D.; Hertle, R.; Tsiaras, W.; et al. Head injury in very young children: Mechanisms, injury types, and ophthalmologic findings in 100 hospitalized patients younger than 2 years of age. Pediatrics 1992, 90, 179-185. 
Reprinted from Int. J. Environ. Res. Public Health. Cite as: van Beelen, M.E.J.; van Beeck, E.F.; den Hertog, P.; Beirens, T.M.J.; Raat, H. Correlates of Unsupervised Bathing of Infants: A Cross-Sectional Study. Int. J. Environ. Res. Public Health 2013, 10, 856-866.

Article

\title{
Correlates of Unsupervised Bathing of Infants: A Cross-Sectional Study
}

\author{
Mirjam E. J. van Beelen ${ }^{1}$, Eduard F. van Beeck ${ }^{1}$, Paul den Hertog ${ }^{2}$, Tinneke M. J. Beirens ${ }^{1,3}$ \\ and Hein Raat ${ }^{1, *}$
}

1 Department of Public Health, Erasmus MC-University Medical Center, P.O. Box 2040, Rotterdam 3000 CA, The Netherlands; E-Mails: m.vanbeelen@erasmusmc.nl (M.E.J.B.); e.vanbeeck@erasmusmc.nl (E.F.B.); t.beirens@erasmusmc.nl (T.M.J.B.)

2 Consumer Safety Institute, P.O. Box 75169, Amsterdam 1070 AD, The Netherlands;

E-Mail: p.denhertog@veiligheid.nl

3 Dutch Association for Youth Health Care Physicians, Churchillaan 11, Utrecht 3527 GV, The Netherlands

* Author to whom correspondence should be addressed; E-Mail: h.raat@erasmusmc.nl; Tel.: +31-10-703-8580; Fax: +31-10-703-8475.

Received: 10 January 2013; in revised form: 25 February 2013 / Accepted: 25 February 2013 / Published: 4 March 2013

\begin{abstract}
Drowning represents the third leading cause of fatal unintentional injury in infants ( $0-1$ years). The aim of this study is to investigate correlates of unsupervised bathing. This cross-sectional study included 1,410 parents with an infant. Parents completed a questionnaire regarding supervision during bathing, socio-demographic factors, and Protection Motivation Theory-constructs. To determine correlates of parents who leave their infant unsupervised, logistic regression analyses were performed. Of the parents, $6.2 \%$ left their child unsupervised in the bathtub. Parents with older children (OR 1.24; 95\% CI 1.00-1.54) were more likely to leave their child unsupervised in the bathtub. First-time parents (OR 0.59; 95\% CI 0.36-0.97) and non-Western migrant fathers (OR 0.18 ; 95\% CI 0.05-0.63) were less likely to leave their child unsupervised in the bathtub. Furthermore, parents who perceived higher self-efficacy (OR 0.57; 95\% CI 0.47-0.69), higher response efficacy (OR 0.34; 95\% CI $0.24-0.48$ ), and higher severity (OR $0.74 ; 95 \%$ CI $0.58-0.93$ ) were less likely to leave their child unsupervised. Since young children are at great risk of drowning if supervision is absent, effective strategies for drowning prevention should be developed and evaluated. In the meantime, health care professionals should inform parents with regard to the importance of supervision during bathing.
\end{abstract}


Keywords: children; supervision; bathing; drowning; safety

Clinical Trials Registration: This study was registered in the Netherlands National Trial Register (NTR), Trial Registration Number NTR1836.

\section{Introduction}

Drowning is a major health problem among children around the globe [1]. Drowning refers to an event in which a child's airway is immersed in a liquid medium, leading to difficulty in breathing [2]. This event may result in death or (permanent) disability. In the United States, drowning represents the third leading cause of fatal unintentional injury in infants less than one year of age, and over half of these fatal drownings occur in bathtubs [3,4]. Up to the age of twelve months infants may be able to sit up unsupported, although some are still unable to right themselves if they fall over in the bathtub $[5,6]$. At young age, infants fully rely on their parents to prevent potential harm.

Adequate child supervision is likely to be the most effective defense against many childhood unintentional injuries [7]. However, still many injuries to young children, for example drowning, poisoning, or falls, occur in their homes when caregivers are responsible for a safe environment and adequate supervision [8]. It has been shown that parents' opinions about the necessity of adult supervision are associated with parent behavior and family and household characteristics [7]. In acute poisoning, an increased number of children in the home is associated with less parental supervision related to the presence of older children [9]. So far, little is known about the correlates of unsupervised bathing, although in over three quarters of bathtub drownings, lack of adequate adult supervision is involved $[10,11]$. Two previous studies found that some parents believe they can leave their infant unsupervised in the bathtub for a short moment $[3,12]$. One single study showed that many parents fail to realize the severity of drowning [13].

To develop strategies for infant drowning prevention, more insight is needed into the correlates of unsafe behaviour. In addition to the role of socio-demographic characteristics, insight with regard to psychosocial constructs of unsupervised bathing is needed, using a theoretical model. Protection Motivation Theory (PMT) is a framework particularly suited for interventions of protective, precautionary behaviours [14]. PMT is suggested to be applied to assess the influence of psychosocial factors on parental safety behaviour. According to PMT, the probability of health protective behaviour or an "adaptive response"-in this case supervision during bathing-is increased by four factors: (1) the threat is perceived as severe (severity); (2) the threat is perceived as high of personal relevance (vulnerability); (3) the adaptive response is perceived as affective for warding off the threat (response efficacy); and (4) the personal abilities and self-confidence to engage in the adaptive response is perceived as high (self-efficacy). The aim of this study is thus to investigate correlates of unsupervised bathing. 


\section{Experimental Section}

\subsection{Participants and Setting}

The present cross-sectional study used data obtained at enrolment in the "BeSAFE" study, a randomized controlled trial which aims to assess the effects of internet-based, tailored safety information combined with personal counselling on parents' child safety behaviours, as described in detail elsewhere [15]. The "BeSAFE" study addressed several topics with regard to the safety in and around the home, such as the prevention of falling, poisoning, drowning and burning. The Medical Ethics Committee of the Erasmus Medical Center gave a "declaration of no objection" for this study (MEC-2008-370).

Parents of infants (4-12 months), attending a regular well-child visit were invited by their child health care professional to participate in a home safety survey on multiple home safety topics. An opportunity sample of five child health care organizations, located in both urban and rural areas of the Netherlands, invited a total of 3,147 parents between 2009 and 2010. A total of 1,440 parents (45.8\%) provided informed consent for the baseline questionnaire and completed the baseline questionnaire (in Dutch). Parents who did not wish to participate in the follow-up of the "BeSAFE" study were invited to anonymously complete the baseline questionnaire. Sixty parents completed the baseline questionnaire anonymously and 1,380 parents provided informed consent for participation in the complete "BeSAFE" study. A total of 30 records were removed, because parents did not bathe their child. A study population of 1,410 parents and children was complete for data analysis.

\subsection{Design}

Parents received written information about the study, were asked to provide informed consent and complete the baseline questionnaire on home safety. The baseline questionnaire included questions on socio-demographic factors, safety behaviour and PMT constructs.

\subsection{Parental Supervision}

Parental supervision of their infant during bathing was assessed by the item asking parents "How often do you leave your child alone when he/she is in the bathtub, even just for a short time?"; answering very often/often/sometimes/rarely/never.

\subsection{Potential Correlates}

We used socio-demographic variables and PMT constructs to investigate potential correlates of supervision during bathing. The socio-demographic variables, age, gender, number of parents and siblings, and parental employment, education and ethnicity, included in this study were chosen based on earlier studies reporting the influence of these variables on safety behaviours [16-18].

Ethnicity of the parents (Dutch or Western migrant; non-Western migrant) was determined on the basis of grandmothers' and grandfathers' country of birth according to the definitions of Statistics Netherlands [19]. The parent was of non-Western ethnic origin if at least one of their 
parents was born in a non-Western country. If both their parents were born in a non-Western country, ethnicity was determined according to the mother's country of birth.

Crawling was defined as the child being able to: "crawl on hands and knees and/or crawl on their tummy and/or shuffle on their bottom" (yes/no).

Additionally, psychosocial constructs were measured within the domain of PMT. All items related to PMT were measured on bipolar five-point scales. Self-efficacy was measured by the item asking parents how difficult or easy they perceive taking the safety measures to be (from-2 = very difficult to $+2=$ very easy). Response efficacy was measured by the item assessing how helpful parents perceived the specific behaviour to be for preventing an injury (from-2 = not very helpful to $+2=$ very helpful). Vulnerability was measured by the item asking parents their perception of their child's risk of an unintentional injury on each specific subject (from $-2=$ low risk to $+2=$ high risk). Severity was measured by the item assessing how seriously parents perceived the consequences of an injury occurring in the bathtub (from $-2=$ not serious at all to $+2=$ very serious).

\subsection{Statistical Analyses}

Statistical analyses were performed using SPSS 17.0 (SPSS Inc., Chicago, IL, USA). Level of supervision was dichotomized into leaving the child unsupervised (very often/often/sometimes/rarely) and never leaving the child unsupervised. Frequency tables were used to explore the socio-demographic characteristics of the total study population, and those categorized as left unsupervised and never left unsupervised. Mean and frequency differences between children who were left unsupervised and children who were never left unsupervised were evaluated through independent sample $t$-tests and Chi-square statistics, respectively.

Correlations were calculated to assess multicollinearity. All correlations were under 0.60 , indicating that multicollinearity would not be an issue for multiple logistic regression analyses.

To determine significant correlates of parents who leave their infant unsupervised, three steps of logistic regression analyses were performed with supervision during bathing (left unsupervised/never left unsupervised) as the dependent variable and potential correlates (socio-demographic and PMT constructs) as independent variables. In Model 1 the potential correlates were entered univariate. Secondly, a multiple model was constructed using a manual-enter selection method in which all independent socio-demographic variables were included. Subsequently all variables with the highest $p$ value were deleted from the model, until all variables had a $p$ value of 0.05 or less. In Model 3 a multiple model with socio-demographic variables and PMT constructs were included, using the same stepwise backward analyses as performed in Model 2.

\section{Results and Discussion}

\subsection{Participants}

The mean age of the children was 7.2 months (SD 1.1; range 4-12 months); 48.3\% were girls; $34.4 \%$ could crawl. Of the participating families $93.3 \%$ of the mothers completed the questionnaire and $48.4 \%$ had one child (Table 1 ). 
Table 1. Child and family characteristics and PMT constructs of supervision of infants in bathtubs $(\mathrm{n}=1,410)$.

\begin{tabular}{|c|c|c|c|c|}
\hline & Total group & $\begin{array}{l}\text { Children left } \\
\text { unsupervised }\end{array}$ & $\begin{array}{c}\text { Children never left } \\
\text { unsupervised }\end{array}$ & $p$ value \\
\hline Infant is bathed in bathtub & $\mathrm{n}=1,410$ & $\mathrm{n}=87$ & $\mathrm{n}=1,319$ & \\
\hline Child characteristics & n (\%) & n $(\%)$ & n (\%) & \\
\hline Mean age in months (SD) & $7.2(1.1)$ & $7.5(1.2)$ & $7.2(1.1)$ & $0.01 * *$ \\
\hline Range in months & $4-12$ & $4-12$ & $4-12$ & \\
\hline \multicolumn{5}{|l|}{ Gender } \\
\hline Girl & $681(48.3)$ & $47(54.0)$ & $633(48.0)$ & $0.28 *$ \\
\hline \multicolumn{5}{|l|}{ Child can crawl } \\
\hline Yes & $484(34.4)$ & $34(39.1)$ & $450(34.2)$ & $0.35 *$ \\
\hline Family characteristics & n (\%) & n (\%) & n (\%) & \\
\hline Mother is respondent & $1,315(93.3)$ & $83(95.4)$ & $1,229(93.2)$ & $0.71 *$ \\
\hline \multicolumn{5}{|l|}{ Family situation } \\
\hline One-parent family & $39(2.8)$ & $3(3.5)$ & $36(2.7)$ & $0.67 *$ \\
\hline \multicolumn{5}{|l|}{ Number of children in family } \\
\hline One child & $682(48.4)$ & $34(39.1)$ & $645(48.9)$ & $0.08 *$ \\
\hline Two or more children & $728(51.6)$ & $53(60.9)$ & $674(51.1)$ & \\
\hline \multicolumn{5}{|l|}{ Mother } \\
\hline \multicolumn{5}{|l|}{ Employment } \\
\hline Paid job fulltime & $90(6.6)$ & $7(8.5)$ & $83(6.5)$ & $0.63 *$ \\
\hline Paid job part time & $1,024(75.1)$ & $63(76.8)$ & $959(75.1)$ & \\
\hline No paid job & $249(18.3)$ & $12(14.6)$ & $235(18.4)$ & \\
\hline \multicolumn{5}{|l|}{ Educational level } \\
\hline Low & $234(16.6)$ & $11(12.6)$ & $222(16.9)$ & $0.51 *$ \\
\hline Intermediate & $623(44.2)$ & $38(43.7)$ & $583(44.3)$ & \\
\hline High & $551(39.1)$ & $38(43.7)$ & $512(38.9)$ & \\
\hline \multicolumn{5}{|l|}{ Ethnicity } \\
\hline Western & $1,292(91.6)$ & $79(90.8)$ & 1,211 (91.8) & $0.55 *$ \\
\hline Non Western & $118(8.4)$ & $8(9.2)$ & $108(8.2)$ & \\
\hline \multicolumn{5}{|l|}{ Father } \\
\hline \multicolumn{5}{|l|}{ Employment } \\
\hline Paid job fulltime & $1,149(85.7)$ & $70(87.5)$ & $1,076(85.6)$ & $0.81^{*}$ \\
\hline Paid job part time & $138(10.3)$ & $6(7.5)$ & $131(10.4)$ & \\
\hline No paid job & $54(4.0)$ & $4(5.0)$ & $50(4.0)$ & \\
\hline \multicolumn{5}{|l|}{ Educational level } \\
\hline Low & $319(22.9)$ & $23(27.1)$ & $295(22.6)$ & $0.62 *$ \\
\hline Intermediate & $569(40.8)$ & $32(37.6)$ & $536(41.1)$ & \\
\hline High & $506(36.3)$ & $30(35.3)$ & $474(36.3)$ & \\
\hline \multicolumn{5}{|l|}{ Ethnicity } \\
\hline Western & $1,284(91.8)$ & $81(95.3)$ & $1,200(91.6)$ & $0.30 *$ \\
\hline Non-Western & $115(8.2)$ & $4(4.7)$ & $110(8.4)$ & \\
\hline PMT constructs & Mean (SD) & Mean (SD) & Mean (SD) & \\
\hline Self-efficacy $(-2,+2)$ & $1.49(1.0)$ & $0.57(1.0)$ & $1.56(0.9)$ & $<0.0001 * *$ \\
\hline Response efficacy $(-2,+2)$ & $1.74(0.5)$ & $1.16(0.7)$ & $1.77(0.5)$ & $<0.0001 * *$ \\
\hline Vulnerability $(-2,+2)$ & $-1.42(0.9)$ & $-1.21(0.8)$ & $-1.43(0.9)$ & $0.02 * *$ \\
\hline Severity $(-2,+2)$ & $1.39(0.9)$ & $0.92(1.0)$ & $1.42(0.9)$ & $<0.0001 * *$ \\
\hline
\end{tabular}

* Chi-square-test. ** Independent sample $t$-test. Missing values were 4 for infant is bathed; 1 for child's gender; 3 for respondent's gender, 4 for number of children; 47 for mother's employment; 4 for mother's educational level; 4 for mother's ethnicity; 69 for father's employment; 16 for father's educational level; and 11 for father's ethnicity. 
Of the parents, $6.2 \%$ left their child unsupervised in the bathtub (4.8\% rarely, $1.2 \%$ sometimes, and $0.2 \%$ (very) often).

The percentage of children who were left unsupervised in the bathtub rose with increasing age; $5.1 \%$ of children aged $4-6$ months were left unsupervised; $5.7 \%$ of children aged $6-8$ months were left unsupervised; $8.1 \%$ of children aged 8-1 0 months were left unsupervised and $13.3 \%$ of children aged 10-12 months were left unsupervised (Figure 1).

Figure 1. Percentage of children left unsupervised by age group.

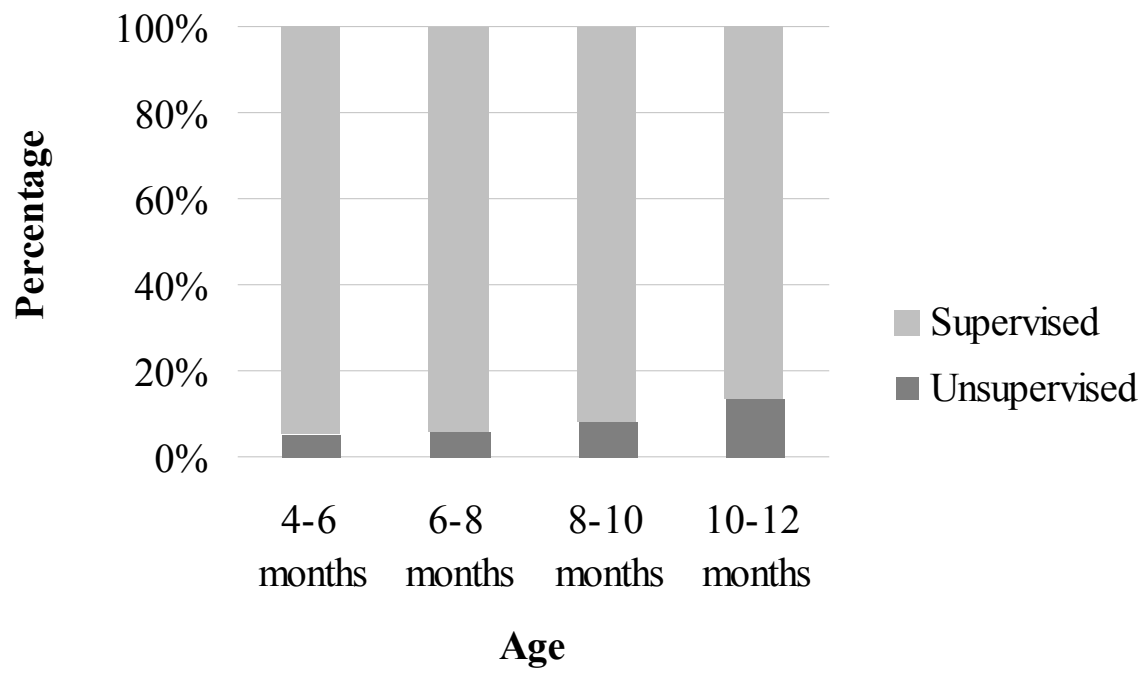

Parents with only one child left their infant less often alone in the bathtub compared to parents with two or more children $(p=0.08)$. Compared to parents who never left their child unsupervised in the bathtub, parents who left their child unsupervised had lower self-efficacy; mean 0.57 (SD 1.0) vs. 1.56 (SD 0.9), reported higher vulnerability; mean-1.21 (SD 0.8) vs. -1.43 (SD 0.9), perceived lower severity; mean 0.92 (SD 1.0) vs. 1.42 (SD 0.9), and reported lower response-efficacy; mean 1.16 (SD 0.7) vs. 1.77 (SD 0.5) (all $p<0.05$; Table 1).

\subsection{Correlates of Leaving the Infant Unsupervised in the Bathtub}

Table 2 presents results of the univariate and multiple logistic regression analyses.

In the first model, age, self-efficacy, response efficacy, vulnerability, and severity were significant correlates of supervision of their infant $(p<0.05)$.

In the second model only age was significantly associated with leaving the infant unsupervised in the bathtub (OR 1.29; 95\% CI 1.06-1.57).

In the subsequent step, when PMT constructs were added to Model 2 (Model 3), a model with six correlates was significant $(p<0.05)$. With rising age of the child, the more likely parents were to leave their child unsupervised in the bathtub (OR 1.24; 95\% CI 1.00-1.54). Parents with one child were less likely to leave their child unsupervised in the bathtub (OR 0.59; 95\% CI 0.36-0.97). Fathers of non-Western ethnicity were less likely to leave their infant unsupervised than fathers of Western ethnicity (OR 0.18; 95\% CI 0.05-0.63). Parents who leave their infant unsupervised in the bathtub reported significantly less self-efficacy (OR 0.57; 95\% CI 0.47-0.69), response efficacy (OR 0.34; 95\% CI 0.24-0.48) and perceived severity (OR 0.74; 95\% CI $0.58-0.93$ ). 
Table 2. Odds ratios (OR) and 95\% confidence intervals from univariate (Model 1) and multiple logistic regression analyses with leaving the infant unsupervised in the bathtub as dependent variable and demographic variables (Model 2) and Protection Motivation Theory (PMT) variables (Model 3$)$ as independent factors $(n=1,410)$.

\begin{tabular}{|c|c|c|c|c|c|c|}
\hline & \multicolumn{6}{|c|}{ Infant left unsupervised in the bathtub } \\
\hline & $\begin{array}{c}\text { Model } 1 \\
\text { OR (95\% CI) }\end{array}$ & $p$ value & $\begin{array}{c}\text { Model } 2 \\
\text { OR (95\% CI) }\end{array}$ & $p$ value & $\begin{array}{c}\text { Model 3 } \\
\text { OR (95\% CI) }\end{array}$ & $p$ value \\
\hline \multicolumn{7}{|l|}{ Demographic variables } \\
\hline \multicolumn{7}{|l|}{ Infants } \\
\hline Age in months & $1.29(1.06-1.57)$ & 0.01 & $1.29(1.06-1.57)$ & 0.01 & $1.24(1.00-1.54)$ & 0.05 \\
\hline Girl & $1.27(0.82-1.97)$ & 0.28 & - & - & - & - \\
\hline Infant can crawl & $0.81(0.52-1.26)$ & 0.35 & - & - & - & - \\
\hline \multicolumn{7}{|l|}{ Family } \\
\hline One-parent family & $1.30(0.39-4.30)$ & 0.67 & - & - & - & - \\
\hline First-time parent & $0.67(0.43-1.05)$ & 0.08 & - & - & $0.59(0.36-0.97)$ & 0.04 \\
\hline \multicolumn{7}{|l|}{ Mother } \\
\hline \multicolumn{7}{|l|}{ Employment } \\
\hline Paid job fulltime & 1.00 & - & - & - & - & - \\
\hline Paid job part time & $0.78(0.35-1.76)$ & 0.55 & - & - & - & - \\
\hline No paid job & $0.61(0.23-1.59)$ & 0.31 & - & - & - & - \\
\hline \multicolumn{7}{|l|}{ Educational level } \\
\hline Low & 1.00 & - & - & - & - & - \\
\hline Intermediate & $1.32(0.66-2.62)$ & 0.44 & - & - & - & - \\
\hline High & $1.50(0.75-2.98)$ & 0.25 & - & - & - & - \\
\hline Non-Western migrant & $1.14(0.54-2.41)$ & 0.74 & - & - & - & - \\
\hline \multicolumn{7}{|l|}{ Father } \\
\hline \multicolumn{7}{|l|}{ Employment } \\
\hline Paid job fulltime & 1.00 & - & - & - & - & - \\
\hline Paid job part time & $0.70(0.30-1.65)$ & 0.42 & - & - & - & - \\
\hline No paid job & $1.23(0.43-3.50)$ & 0.70 & - & - & - & - \\
\hline \multicolumn{7}{|l|}{ Educational level } \\
\hline Low & 1.00 & - & - & - & - & - \\
\hline Intermediate & $0.77(0.44-1.33)$ & 0.35 & - & - & - & - \\
\hline High & $0.81(0.46-1.42)$ & 0.47 & - & - & - & - \\
\hline Non-Western migrant & $0.54(0.19-1.50)$ & 0.24 & - & - & $0.18(0.05-0.63)$ & 0.01 \\
\hline \multicolumn{7}{|l|}{ PMT constructs ${ }^{\text {a }}$} \\
\hline Self-efficacy $(-2,+2)$ & $0.53(0.45-0.62)$ & $<0.001$ & - & - & $0.57(0.47-0.69)$ & $<0.001$ \\
\hline Response efficacy $(-2,+2)$ & $0.26(0.19-0.35)$ & $<0.001$ & - & - & $0.34(0.24-0.48)$ & $<0.001$ \\
\hline Vulnerability $(-2,+2)$ & $1.30(1.05-1.61)$ & 0.02 & - & - & - & - \\
\hline Severity $(-2,+2)$ & $0.63(0.52-0.76)$ & $<\mathbf{0 . 0 0 1}$ & - & - & $0.74(0.58-0.93)$ & 0.01 \\
\hline
\end{tabular}

${ }^{\mathrm{a}}$ The OR represents a one-unit change in the scale score.

\subsection{Discussion}

Parents reported leaving their infants unsupervised in the bathtub. These parents expose their infant to the avoidable risk of becoming immersed in water, which could lead to fatal drowning. 
Since some young children are unable to right themselves if they fall over in the bathtub, they are at great risk of drowning if supervision is absent during bathing. Therefore, effective strategies for drowning prevention, aimed at improved parental supervision during bathing, should be developed.

Our analyses indicate the need for tailoring these strategies to parents with older infants (8-12 months) and parents with low Protection Motivation Theory constructs.

When infants grow older, parents in our study reported they were more likely to leave their infant unsupervised in the bathtub. However, such young children below the age of 12 months may still not be able to prevent themselves from drowning and therefore should never - not even for a moment-be left alone [20].

When parents have two or more children, they are even more likely to leave their infant alone in the bathtub. Reasons for this could be that they are busy with their other child or children, having to leave their infant alone, maybe just for a few moments, not realizing the risk for the infant. It is also possible that parents do not think of the risk of drowning, because nothing has happened before with their infant or older children, so these parents may have considerations like "why would there be a risk now?". Parents' may also belief that their child does not need to be supervised all time.

Parents who leave their infant unsupervised in the bathtub reported less self-efficacy, response efficacy and severity. It could be possible that parents do not believe they are able to always supervise their child, do not think supervision could help prevent their child from drowning, and are not aware of the consequences of an injury occurring in the bathtub. Enhancing parents' knowledge and abilities for never leaving their child unsupervised and explaining why supervision helps to prevent infants from drowning, could increase parental understanding of the importance to supervise their infants in the bathtub. Furthermore, parents need to be better informed about the potential severity of getting injured in the bathtub. Improving these insights could lead to more safe behaviour. Therefore, interventions should aim at enlarging the knowledge about these items.

Various studies have reported inadequate supervision as an important risk factor for drowning in children [3,12,13,21]. A study by Lee et al. reported unsupervised bathing by $5 \%$ of parents [3]. Our study reports unsupervised bathing of very young children (4-12 months). Furthermore, correlates of unsupervised bathing were determined with this study, which can be used to identify specific target groups of parents in campaigns which promote safe behaviour.

Some limitations of this study need to be addressed. Because our study relied on self-report of supervision during bathing, misclassification could have occurred: for example, parents might have given socially desirable answers. This might result in underestimating the percentage of parents leaving their infant unsupervised in the bathtub.

Participation rate in this study, $46 \%$, was low. There is no data available on the characteristics of parents who did not wish to participate in this study. It is difficult to ascertain whether the associations found would be different in non-responders. Also, it is not clear whether parents who did not wish to participate showed less or more unsafe behaviour with regard to supervision of their infant.

In $93 \%$ of participants, it was the mother who responded to the invitation to participate in the survey and completed the questionnaire. In the written information we provided to parents we asked if the parent spending most time with the child could complete the questionnaire. This could explain why most participants were mothers. 
We dichotomized the level of supervision, instead of using five different categories, in order to get large enough subgroups for analysis. Although there is a difference in leaving a child unsupervised in the bathtub very often and rarely, the recommendation of the American Academy of Pediatrics is to never leave the child unsupervised [20].

To change the undesirable parental beliefs and, more importantly, parental behaviours, physicians and nurses are crucial in educating parents about the risks and consequences of infants drowning in bathtubs when left unsupervised [20]. Parents need to be informed about the risks and we recommend discussing possible solutions for this issue during the well-child visits.

We used one single question to address the level of supervision during bathing. Further research could be extended with the length of time parents estimated that they left their child alone in the bathtub. This could also be important in order to gain insight in what parents think about the time they can leave a child alone in the bathtub and the reasons for parents to leave their child unsupervised in the bathtub. Furthermore the depth of water the child was left unsupervised in could be addressed. A small child can drown in a few centimetres of water at the bottom of the bathtub [1]. Data can be collected on use of devices in the bathtub, like infant bath seats. Such devices could give a false sense of security and a parent or caregiver might be more likely to leave the child alone in the bathtub $[6,13,22]$. Therefore, they should not be recommended by health care professionals to use as safety devices. In addition shared bathing can be addressed, where infants are not supervised by adults, but are bathed in the company of an older sibling. This may also be a risk factor with regard to drowning in the bathtub [21].

Furthermore, we recommend theory and evidence-based development of strategies to promote drowning prevention, effect-evaluation of such strategies and wide scale implementation. Future studies could also be extended with home safety observations in order to eliminate possible misclassification. Furthermore, analyses of fatal or nonfatal drowning could give more insight in the validity of parent responses regarding their supervision skills and behaviour.

\section{Conclusions}

Young children are in need of supervision to prevent them from drowning. Strategies for infant drowning prevention in bathtubs should target the following parents: those of older infants, who have more than one child, where the father is a non-Western migrant, who have low self-efficacy, response efficacy and perceived severity in relation to infant bath drowning, since these are important correlates of leaving a child unsupervised in the bathtub.

\section{Acknowledgments}

This study was funded by ZonMw (project No. 50-50205-98-25028000).

\section{Conflicts of Interest}

The authors declare no conflict of interest. 


\section{References}

1. Peden, M.; Oyegbite, K.; Ozanne-Smith, J.; Hyder, A.A.; Branche, C.; Fazlur Rahman, A.K.M.; Rivara, F.; Bartolomeos, K. World Report on Child Injury Prevention; WHO: Geneva, Switzerland, 2008.

2. van Beeck, E.F.; Branche, C.M.; Szpilman, D.; Modell, J.H.; Bierens, J.J. A new definition of drowning: Towards documentation and prevention of a global public health problem. Bull. World Health Organ. 2005, 83, 853-856.

3. Lee, L.K.; Thompson, K.M. Parental survey of beliefs and practices about bathing and water safety and their children: Guidance for drowning prevention. Accid Anal. Prev. 2007, 39, 58-62.

4. Quan, L.; Cummings, P. Characteristics of drowning by different age groups. Inj. Prev. 2003, 9, 163-168.

5. Byard, R.W.; Lipsett, J. Drowning deaths in toddlers and preambulatory children in South Australia. Am. J. Forensic. Med. Pathol. 1999, 20, 328-332.

6. Sibert, J.; John, N.; Jenkins, D.; Mann, M.; Sumner, V.; Kemp, A.; Cornall, P. Drowning of babies in bath seats: Do they provide false reassurance? Child Care Health Dev. 2005, 31, 255-259.

7. Porter, T.R.; Crane, L.A.; Dickinson, L.M.; Gannon, J.; Drisko, J.; DiGuiseppi, C. Parent opinions about the appropriate ages at which adult supervision is unnecessary for bathing, street crossing, and bicycling. Arch. Pediatr. Adolesc. Med. 2007, 161, 656-662.

8. Shannon, A.; Brashaw, B.; Lewis, J.; Feldman, W. Nonfatal childhood injuries: A survey at the Children's Hospital of Eastern Ontario. Can. Med. Assn. J. 1992, 146, 361-365.

9. Sinclair, K.A.; Morrongiello, B.A.; Dowd, M.D. Parenting behaviors and attitudes about supervision among parents of acutely poisoned children. Ambul. Pediatr. 2008, 8, 135-138.

10. Somers, G.R.; Chiasson, D.A.; Smith, C.R. Pediatric drowning: A 20-year review of autopsied cases: III. Bathtub drownings. Am. J. Forensic. Med. Pathol. 2006, 27, 113-116.

11. Petrass, L.A.; Blitvich, J.D.; Finch, C.F. Lack of caregiver supervision: A contributing factor in Australian unintentional child drowning deaths, 2000-2009. Med. J. Aust. 2011, 194, 228-231.

12. Simon, H.K.; Tamura, T.; Colton, K. Reported level of supervision of young children while in the bathtub. Ambul. Pediatr. 2003, 3, 106-108.

13. Turner, J. Prevention of drowning in infants and children. Dimens. Crit. Care Nurs. 2004, 23, 191-193.

14. Rogers, R. Protection Motivation Theorie; Plenum Press: New York, NY, USA, 1997.

15. Van Beelen, M.E.; Beirens, T.M.; Struijk, M.K.; den Hertog, P.; Oenema, A.; van Beeck, E.F.; Raat, H. "BeSAFE", effect-evaluation of internet-based, tailored safety information combined with personal counselling on parents' child safety behaviours: Study design of a randomized controlled trial. BMC Public Health 2010, 10, 466, doi: 10.1186/1471-2458-10-466.

16. Beirens, T.M.J.; Brug, J.; van Beeck, E.F.; Dekker, R.; den Hertog, P.; Raat, H. Assessing psychosocial correlates of parental safety behaviour using Protection Motivation Theory: Stair gate presence and use among parents of toddlers. Health Educ. Res. 2008, 23, 723-731. 
17. Beirens, T.M.J.; Brug, J.; van Beeck, E.F.; Dekker, R.; Juttmann, R.E.; Raat, H. Presence and use of stair gates in homes with toddlers (11-18 months old). Accid. Anal. Prevent. 2007, 39, 964-968.

18. Beirens, T.M.J.; van Beeck, E.F.; Dekker, R.; Brug, J.; Raat, H. Unsafe storage of poisons in homes with toddlers. Accid. Anal. Prevent. 2006, 38, 772-776.

19. Statistics Netherlands. Available online: http://statline.cbs.nl/StatWeb/publication/?VW=T\&DM= SLNL\&PA=71102ned \&D1=a\&D2=0\&D3=(1-11)-1\&HD=080901-1401 (accessed on 16 May 2012).

20. Committee on Injury, Violence, and Poison Prevention. Prevention of drowning. Pediatrics 2010, 126, e253-e262.

21. Byard, R.; de Koning, C.; Blackbourne, B.; Nadeau, J.; Krous, H.F. Shared bathing and drowning in infants and young children. J. Paediatr. Child Health 2001, 37, 542-544.

22. Byard, R.W.; Donald, T. Infant bath seats, drowning and near-drowning. J. Paediatr. Child Health 2004, 40, 305-307. 
Reprinted from Int. J. Environ. Res. Public Health. Cite as: Shen, J.; Li, S.; Xiang, H.; Pang, S.; Xu, G.; Schwebel, D.C. A Multi-Site Study on Knowledge, Attitudes, Beliefs and Practice of Child-Dog Interactions in Rural China. Int. J. Environ. Res. Public Health 2013, 10, 950-962.

Article

\title{
A Multi-Site Study on Knowledge, Attitudes, Beliefs and Practice of Child-Dog Interactions in Rural China
}

\author{
Jiabin Shen ${ }^{1}{ }^{*}$, Shaohua $\mathrm{Li}^{2}$, Huiyun Xiang ${ }^{3}$, Shulan Pang ${ }^{4}$, Guozhang Xu ${ }^{5}$ and \\ David C. Schwebel ${ }^{1, *}$
}

1 Department of Psychology, University of Alabama at Birmingham, 1300 University Blvd., CH 415, Birmingham, AL 35294, USA

2 School of Public Health Management, Anhui Medical University, 81 Meishan Road, Hefei, Anhui 230032, China; E-Mail: lishaohua168@hotmail.com

3 Center for Injury Research and Policy, The Research Institute at Nationwide Children's Hospital, 700 Children's Drive, Columbus, OH 43205, USA;

E-Mail: Huiyun.Xiang@nationwidechildrens.org

4 School of Public Health, Hebei United University, 46 West Xinhua Road, Tangshan, Hebei 063009, China; E-Mail: pangshu_lan@263.net

5 Ningbo Municipal Center for Disease Control and Prevention, 237 Yongfeng Road, Ningbo, Zhejiang 315010, China; E-Mail: xugz@nbcdc.org.cn

* Authors to whom correspondence should be addressed; E-Mails: jiabin@uab.edu (J.S.); schwebel@uab.edu (D.C.S.); Tel.: +1-205-934-8745; Fax: +1-205-975-6110.

Received: 16 January 2013; in revised form: 25 February 2013 / Accepted: 27 February 2013 / Published: 7 March 2013

\begin{abstract}
This study examines demographic, cognitive and behavioral factors that predict pediatric dog-bite injury risk in rural China. A total of 1,537 children (grades 4-6) in rural regions of Anhui, Hebei and Zhejiang Provinces, China completed self-report questionnaires assessing beliefs about and behaviors with dogs. The results showed that almost $30 \%$ of children reported a history of dog bites. Children answered $56 \%$ of dog-safety knowledge items correctly. Regressions revealed both demographic and cognitive/behavioral factors predicted children's risky interactions with dogs and dog-bite history. Boys behaved more riskily with dogs and were more frequently bitten. Older children reported greater risks with dogs and more bites. With demographics controlled, attitudes/beliefs of invulnerability, exposure frequency, and dog ownership predicted children's self-reported risky practice with dogs. Attitudes/beliefs of invulnerability, dog exposure, and dog ownership predicted dog bites. In conclusion, both demographic
\end{abstract}


and cognitive/behavioral factors influenced rural Chinese children's dog-bite injury risk. Theory-based, empirically-supported intervention programs might reduce dog-bite injuries in rural China.

Keywords: dog bites; injury; safety; China; rural health

\section{Introduction}

Dog-bite injury is one of the most common unintentional injuries to children worldwide, both in developed [1-3] and developing countries [4-6]. Age, gender, and environmental exposure (e.g., dog ownership in the family) are among the most-cited risk factors for dog-bite injuries across cultures [7-9], with male children under the age of 14 years with dogs in the home the most common victims of dog-bite injuries globally [6,7,10,11]. In most cultures, rural children are at greater risk of animal-related injuries (including dog-bite injuries) than urban children due to the higher rates of dog ownership and exposure in rural areas $[12,13]$.

Accurate data quantifying dog-bite injuries in China are lacking. Pilot epidemiology suggests animal bites are the third-leading cause of agricultural injuries among rural Chinese, with particularly high rates for rural children $[13,14]$, but no published data focus specifically on dog-bite risk in China. Epidemiologists in Taiwan have found young children were among the most vulnerable populations for dog bites [8]. Researchers in Hong Kong reported similar results, with an average age of dog-bite victims of 11.82 years old [15]. Furthermore, when children experience dog bites, they are more likely to be seriously injured than adults, as indicated by findings in Hong Kong and elsewhere that dogs tend to attack the childrens' head and neck while adults are injured more frequently on their arms and legs [11,12,15-17].

As in much of the world, the risk and significance of pediatric dog-bite injuries is likely greater in rural China than in urban cities for several reasons. First, as a country heavily dependent on agriculture, China has a rural population of over 800 million people, including about 150 million children under age 14 living in rural areas. Children in rural China suffer from the same developmental disadvantages that increase dog-bite vulnerability to children around the world. Compared with adults, children are physically and psychologically underdeveloped [18]. When they encounter dogs, children's short stature, poor information processing capacity, poor judgment of risk, and immature executive functions endanger them [19]. This threat is substantiated by findings that children are more likely to be bitten by dogs than adults both in developed nations such as the US and in lower income countries like South Africa and Trinidad [4,7,9,20,21]. Second, there are large numbers of dogs in rural China, and thus high exposure opportunity. Unlike urban areas in China where dogs are primarily kept as pets and leashed out of the home [22], dogs are raised in rural China for protection and left to wander the streets unleashed. Protection is deemed important because many adults (especially men) leave rural villages to seek work in larger cities. Dogs are raised to protect the women, elderly and children who remain at home in the rural areas [23]. These dogs escape fences and wander rural areas, posing threat [24,25]. Third, many dogs in rural China have rabies [26-28], a factor which substantially increases bite risks to human health and 
also makes animals more likely to bite. From 1996 to 2006, China experienced a rabies incidence increase of about $2,000 \%$, and the rate has remained stable since [26,27]. Almost all rabies cases in China are transmitted via dog bites [26].

The most commonly practiced measure to prevent dog bites globally is educational campaigns which impart knowledge concerning safe behavior with dogs via live or electronic programs. Empirical research on such campaigns reported mixed success in early evaluations, many of them finding improved knowledge but not safer behaviors [29]. An alternative approach is one that addresses not only an increase in safety knowledge but also considers two other relevant dimensions of cognition, attitudes and beliefs [30]. The Knowledge-Attitudes-Beliefs-Practices (KABP) strategy is recommended by public health specialists to reveal a more complete picture of risk factors underlying health behaviors [31-33], and provides valuable information for intervention designed to not only improve knowledge but also translate the knowledge to safer practice of the health behavior.

This study used a culturally-sensitive KABP questionnaire to evaluate knowledge, attitudes, beliefs, and practices of dog safety among children in rural China. Beyond examining descriptive data concerning knowledge, attitudes, beliefs, practices, and self-reported bite history of the sample, we asked five questions: (1) Do children act more riskily with dogs as they grow older? (2) Do boys act more riskily with dogs than girls? (3) Do children who have more frequent contact with dogs, including current or previous ownership of dogs, act more riskily with dogs? (4) Do children with less knowledge about dog safety act more riskily with dogs? and (5) Do children with beliefs/attitudes of invulnerability from dog bites act more riskily with dogs?

\section{Methods}

\subsection{Participants}

A total of 1,537 children $(\mathrm{M}=11.26$ years old, $\mathrm{SD}=1.29)$ were recruited from the largest primary school in three rural towns: Baishan Town in Hefei City (Anhui Province, $N=441$ ), Luanzhou Town in Tangshan City (Hebei Province, $N=569$ ) and Hongtang Town in Ningbo City (Zhejiang Province, $N=527$ ). All children in grades 4 (age range: 9-11 years old), 5 (age range: 10-12 years old), and 6 (age range: 11-13 years old) in those schools were invited to participate. Each school had three classes in each grade, with class sizes ranging from 50 to 60 students per class. About $95 \%$ of children in each classroom participated. The sample was $55 \%$ male and $45 \%$ female. $96 \%$ of the sample self-reported Han ethnicity, with the remaining $4 \%$ identifying with one of several minority ethnic groups present in China.

The study protocol was approved by IRB panels at both University of Alabama at Birmingham (USA) and Anhui Medical University (China). The protocol number from the IRB panel at University of Alabama at Birmingham is X120109007; Anhui Medical University does not provide protocol numbers, but the approval is dated 24 December 2011. Written informed consent was obtained from participating children and their parents/legal guardians, as well as from principals of participating schools. 


\subsection{Measures}

A Knowledge-Attitudes-Beliefs-Practice (KABP) Questionnaire on child-dog interactions was developed by the authors using the following six steps: (a) thorough review of scientific literature and internet (using structured search strategies) for appropriate content areas on child-dog interaction safety, (b) preparation of items in English by principal investigator (Shen), (c) expert review, face validity review, and editing of items by two senior members of research team, one of them native Chinese (Xiang) and the other familiar with Chinese culture (Schwebel), (d) translation and back-translation from English to Chinese by social scientists fluent in both languages (small differences in translation were resolved through discussion), (e) expert review, face validity review, and editing of items by senior researcher based in China and immersed in culture (Li), and (f) final review and approval by primary investigators (Shen, Schwebel, Xiang).

The questionnaire included four scaled scores: knowledge, attitudes/beliefs, practice, and exposure risk, plus a single item concerning dog bite history. The knowledge scale consisted of 23 questions concerning safe ways to engage with dogs. It was scored as percentile correct, ranging from 0 to 100, with higher scores indicating better mastery of safety knowledge. An example item is as follows: The Lees are going shopping in the grocery close to their home. They have a child the same age as you are. Their family also keeps a dog that is very friendly. Which of the following choices do you think the Lees should not make? (a) The Lees should leave their child at home and let the dog guard the child and the house; (b) The Lees should take their child with them and let the dog guard the house; (c) The Lees should take both the child and dog with them and lock the house; or (d) The Lees should let one parent stay at home with the child and dog, and let the other parent go shopping.

The attitudes/beliefs scale consisted of 12 items answered on 5-point scales. The items addressed children's attitudes and beliefs of invulnerability toward child-dog interactions. An average of responses to the 12 items was used for analysis (range $=1-5$ ), with higher scores indicating riskier attitudes and beliefs and therefore greater levels of perceived invulnerability toward child-dog interactions. Example items are "I think a small scratch from dog bite does not need going to hospital." and "I think the dog in my own family is less likely to bite people than the average dog."

The practice scale consisted of 8 items answered on 5-point scales (range $=1-5$ ), with higher scores indicating higher frequency of self-reported risky behavior with dogs. Example items are "Pet a sleeping dog" and "Play with puppy dogs when their mother is present".

The exposure scale consisted of a single item, "How often do you usually interact with dogs?" Children chose the response that is closest to their situation on a 6-point scale ranging from "Never-I've never interacted with a dog" to "At least once a day". Higher scores indicate more frequent contact with dogs. The dog bite history item assessed self-reported frequency of actual dog bites, which was dichotomized into lifetime history of no bites versus one or more bites.

Psychometrics of relevant scales were strong. Cronbach's alphas for the attitudes/beliefs and practice sections were 0.77 and 0.76 , respectively. We did not compute Cronbach's alpha for the knowledge section because different domains of safety knowledge on dogs may be theoretically 
expected to be unrelated to each other. In addition to the other items, children completed brief items concerning their age, gender, and ethnicity.

\section{Results}

Table 1 shows descriptive statistics and intercorrelations between primary variables. $29.7 \%$ of children $(n=459)$ reported a history of being bit by a dog. The mean score for exposure frequency to dogs was 4.59 ( $\mathrm{SD}=1.59$ ), indicating that children on average interacted with dogs several times a month. $64 \%$ of the sample indicated daily or weekly interactions with dogs. The mean score on dog safety knowledge was $55.5 \%(\mathrm{SD}=14.2 \%)$, indicating the children knew just over half the facts presented to them about how to behave safely with dogs. The mean score of attitudes/beliefs of invulnerability was 1.91 ( $\mathrm{SD}=0.58)$, suggesting on average the youth had moderately safe attitudes and beliefs about engagement with dogs (2.00 reflected "somewhat disagreeing" with conducting dangerous activities with dogs). The mean score for practice was 1.63 ( $\mathrm{SD}=0.57$ ), indicating the children behaved relatively safely with dogs in their daily life (1 represented "never" and 2 "occasionally" for conducting dangerous activities with dogs). Assumptions for the inferential statistical analyses were examined and no serious violations were found.

Table 1. Descriptive statistics and correlation matrix of age, gender, exposure frequency of exposure, knowledge, attitudes/beliefs, practice and bite history.

\begin{tabular}{|c|c|c|c|c|c|c|c|c|c|}
\hline Variable & Mean & SD & 1 & 2 & 3 & 4 & 5 & 6 & 7 \\
\hline $\begin{array}{l}\text { 1. Age } \\
\text { (Years) }\end{array}$ & 11.26 & 1.29 & 1.00 & & & & & & \\
\hline $\begin{array}{l}\text { 2. Gender } \\
(0=\text { Female, } 1=\text { Male })\end{array}$ & 0.55 & 0.50 & 0.05 & 1.00 & & & & & \\
\hline $\begin{array}{l}\text { 3. Safety knowledge } \\
(\% \text { correct, } 0-100 \text { scale })\end{array}$ & 55.53 & 14.17 & -0.03 & $-0.07 * *$ & 1.00 & & & & \\
\hline $\begin{array}{l}\text { 4. Attitudes/beliefs } \\
\text { (5-point scale, } 1-5 \text { ) }\end{array}$ & 1.91 & 0.58 & $0.18 * *$ & 0.06 * & $-0.43 * *$ & 1.00 & & & \\
\hline $\begin{array}{l}\text { 5. Risky practice } \\
(5 \text {-point scale, } 1-5)\end{array}$ & 1.63 & 0.57 & $0.18 * *$ & $0.14 * *$ & $-0.23 * *$ & $0.47 * *$ & 1.00 & & \\
\hline $\begin{array}{l}\text { 6. Exposure frequency } \\
\text { (6-point scale, } 1-6)\end{array}$ & 4.59 & 1.59 & $0.12 * *$ & $0.09 * *$ & $-0.06 *$ & $0.21 * *$ & $0.35 * *$ & 1.00 & \\
\hline $\begin{array}{l}\text { 7. Bite history } \\
(0=\text { No, } 1=\text { Yes })\end{array}$ & 0.30 & 0.46 & $0.07 * *$ & $0.10 * *$ & -0.03 & $0.09 * *$ & $0.12 * *$ & $0.11 * *$ & 1.00 \\
\hline
\end{tabular}

$$
{ }^{*} p<0.05 ; * * p<0.01 \text {. }
$$

Gender comparisons revealed that boys $(\mathrm{M}=4.72, \mathrm{SD}=1.51)$ had more frequent exposure to dogs than girls $(\mathrm{M}=4.43, \mathrm{SD}=1.68), t(1,390)=3.50, p<0.001$. Boys $(\mathrm{M}=54.64, \mathrm{SD}=14.47)$ also scored slightly lower on the knowledge scale than girls $(\mathrm{M}=56.59, \mathrm{SD}=13.74), t(1,504)=-2.70$, $p<0.001$. On attitudes/beliefs of invulnerability, boys $(\mathrm{M}=1.94, \mathrm{SD}=0.60)$ scored higher (thus riskier) than girls $(\mathrm{M}=1.87, \mathrm{SD}=0.55), t(1,507)=2.26, p<0.05$. Finally, boys $(\mathrm{M}=1.70$, $\mathrm{SD}=0.59)$ reported higher (thus riskier) behavioral practices with dogs than girls $(\mathrm{M}=1.54$, 
$\mathrm{SD}=0.53), t(1,508)=5.49, p<0.001$. The gender differences were reflected also in self-reported bite history, with $34.0 \%$ of boys reporting having been bitten by dogs while only $24.8 \%$ of girls reported having bite history, $\chi^{2}(1)=15.33, p<0.001$. Children's age was significantly correlated with greater exposure to $\operatorname{dogs}(r=0.12, p<0.001)$, riskier attitudes/beliefs of invulnerability $(r=0.18, p<0.001)$, riskier behaviors with dogs $(r=0.18, p<0.001)$, and history of dog-bites $(r=0.07, p<0.01)$, but not with safety knowledge.

Relations between knowledge, attitudes/beliefs, practice, and bite history were considered next (see Table 1). Children with more safety knowledge tended to hold fewer attitudes/beliefs of invulnerability toward child-dog interactions $(r=-0.43, p<0.001)$, and also reported safer behavior in their daily interaction with $\operatorname{dogs}(r=-0.23, p<0.001)$. As expected, the attitudes/beliefs score was positively correlated with the risky practice score $(r=0.47, p<0.001)$. Bite history was significantly correlated with attitudes/beliefs of invulnerability $(r=0.09, p<0.001)$ and risky practice $(r=0.12, p<0.001)$ but not safety knowledge $(r=-0.03)$.

Among the 1528 children ( $99.4 \%$ of sample) who responded validly concerning dog ownership, $578(37.8 \%)$ reported they currently owned a dog at home, 657 children (43.0\%) reported that they once owned a dog but did not have one now, and 293 children (19.2\%) reported no history of owning a dog at home. There were no gender or age differences.

One-way analysis of variance (ANOVA) compared the three dog-ownership groups on exposure frequency to dogs, safety knowledge, attitudes/beliefs of invulnerability, risky practice with dogs, and dog bite history (see Table 2). There were no significant differences among the three groups in safety knowledge. On attitudes/beliefs of invulnerability, children who had never owned a dog at home $(M=1.80, S D=0.51)$ perceived less vulnerability than both children who owned a $\operatorname{dog}$ before but not now $(M=1.94, S D=0.56)$ and children who owned a dog currently $(M=1.92$, $S D=0.63), F(2,1,498)=6.19, p<0.01$. No significant differences were found between the latter two groups in post-hoc tests. Similar results were found concerning children's self-reported risky practice with dogs, with children who had no history of owning a dog at home reporting safer behavior with dogs $(M=1.39, S D=0.42)$ than children who previously owned a dog but not now $(M=1.67, S D=0.54)$ and children who currently owned a dog at home $(M=1.70, S D=0.61)$, $F(2,1,498)=34.23, p<0.01$. On exposure frequency, children who currently owned a dog at home had the highest exposure frequency $(M=5.15, S D=1.34)$, followed by children who previously owned a dog at home but not now $(M=4.57, S D=1.49)$ and children who had never owned a $\operatorname{dog}(M=3.52, S D=1.73), F(2,1,506)=114.75, p<0.001$.

The final step of analysis was construction of two-step multivariate regression models to evaluate whether exposure frequency, dog-ownership, knowledge and attitudes/beliefs predicted risky practice and/or history of bites, after controlling for demographic factors. Dog ownership was dummy-coded with no history of dog ownership as the referent.

In the models predicting self-reported risky practice with dogs (see Table 3), gender and age were entered first as independent variables and accounted for 5\% of the variance in children's self-reported risky behavior practice with dogs, $R^{2}=0.05, F(2,1,467)=40.18, p<0.001$. As children grew older, they behaved more riskily with dogs. Boys also behaved more riskily with dogs than girls. The second regression model predicting risky practice with dogs evaluated whether exposure frequency, dog-ownership, safety knowledge, and attitudes/beliefs of invulnerability 
predicted risky behavior after controlling for demographic factors. Exposure frequency $(t=9.75$, $p<0.001)$, owning a dog now $(t=3.33, p<0.001)$, owning a dog before but not now $(t=3.69$, $p<0.001)$, and attitudes/beliefs $(t=15.19, p<0.001)$ but not knowledge $(t=-1.28)$, accounting for a significant proportion of the variance, $R^{2}$ change $=0.26, F(5,1,462)=111.27, p<0.001$. Thus, children acted more riskily with dogs if they had more frequent exposure to dogs, if they had owned a dog before or currently, and if they held riskier attitudes/beliefs of invulnerability toward dogs. They did not act more riskily with dogs if they had less knowledge about dog safety.

Table 2. Comparison of exposure frequency, bite history and KABP among different dog-ownership groups.

\begin{tabular}{|c|c|c|c|c|c|}
\hline & $\begin{array}{l}\text { Never own a dog } \\
(\mathrm{n}=\mathbf{2 9 3}, \mathbf{1 9 . 2 \% )})\end{array}$ & $\begin{array}{c}\text { Previously own a } \\
\operatorname{dog}(n=657,43.0 \%)\end{array}$ & $\begin{array}{c}\text { Currently own a dog } \\
(\mathrm{n}=\mathbf{5 7 8 , 3 7 . 8 \% )}\end{array}$ & $F$ & $\eta^{2}$ \\
\hline $\begin{array}{l}\text { Safety knowledge } \\
(\% \text { correct, } 0-100 \text { scale })\end{array}$ & 56.94 (13.53) & $55.38(14.05)$ & $54.98(14.62)$ & 1.92 & 0.00 \\
\hline $\begin{array}{l}\text { Attitudes/beliefs } \\
\text { (5-point scale, 1-5) }\end{array}$ & $1.80(0.51)^{\mathrm{a}, \mathrm{b}}$ & $1.94(0.56)^{\mathrm{a}}$ & $1.92(0.63)^{b}$ & $6.19 * *$ & 0.01 \\
\hline $\begin{array}{c}\text { Risky practice } \\
\text { (5-point scale, } 1-5)\end{array}$ & $1.39(0.42)^{\mathrm{c}, \mathrm{d}}$ & $1.67(0.54)^{\mathrm{c}}$ & $1.70(0.61)^{\mathrm{d}}$ & $34.23 * *$ & 0.04 \\
\hline $\begin{array}{l}\text { Exposure frequency } \\
\text { (6-point scale, } 1-6)\end{array}$ & $3.52(1.73)^{\mathrm{e}}$ & $4.57(1.49)^{\mathrm{e}}$ & $5.15(1.34)^{\mathrm{e}}$ & $114.75 * *$ & 0.13 \\
\hline $\begin{array}{l}\text { Bite history }{ }^{1} \\
(0=\text { No, } 1=\text { Yes })\end{array}$ & $4.30 \%{ }^{\mathrm{f}, \mathrm{g}}$ & $13.90 \%{ }^{\mathrm{f}}$ & $11.60 \%^{\mathrm{g}}$ & $10.47 * *$ & 0.08 \\
\hline
\end{tabular}

Table 3. Hierarchical linear regression analysis predicting children's risky practice with dogs.

\begin{tabular}{|c|c|c|c|c|c|c|}
\hline \multirow{2}{*}{ Variable } & \multicolumn{3}{|c|}{ Model 1} & \multicolumn{3}{|c|}{ Model 2} \\
\hline & $\boldsymbol{B}$ & $S E B$ & $\beta$ & $B$ & $S E B$ & $\boldsymbol{\beta}$ \\
\hline Age (Years) & 0.08 & 0.01 & $0.18 * *$ & 0.04 & 0.01 & $0.08 * *$ \\
\hline Gender $(0=$ Female, $1=$ Male $)$ & -0.15 & 0.03 & $0.13 * *$ & -0.10 & 0.03 & $0.09 * *$ \\
\hline \multicolumn{7}{|l|}{$\begin{array}{l}\text { Dog ownership } \\
\text { (No dog ownership history: referent) }\end{array}$} \\
\hline Owning a dog now & - & - & - & 0.12 & 0.04 & $0.11 * *$ \\
\hline Owning a dog before but not now & - & - & - & 0.13 & 0.04 & $0.11 * *$ \\
\hline Safety knowledge (\% correct, $0-100$ scale) & - & - & - & -0.00 & 0.00 & -0.03 \\
\hline Attitudes/beliefs (5-point scale, $1-5$ ) & - & - & - & 0.37 & 0.02 & $0.38 * *$ \\
\hline Exposure frequency (6-point scale, 1-6) & - & - & - & 0.08 & 0.01 & $0.27 * *$ \\
\hline$R^{2}$ change & \multicolumn{3}{|c|}{0.05} & \multicolumn{3}{|c|}{0.26} \\
\hline$d f 1 / d f 2$ for $R^{2}$ change & \multicolumn{3}{|c|}{$2 / 1,467$} & \multicolumn{3}{|c|}{$5 / 1,462$} \\
\hline$F$ for $R^{2}$ change & \multicolumn{3}{|c|}{$40.18 * *$} & \multicolumn{3}{|c|}{$111.27 * *$} \\
\hline
\end{tabular}

In models predicting dog bite history (see Table 4), the same predictors were entered into a logistic regression. Gender and age were entered in the first model as demographic predictors and 
were found to contribute significantly to the prediction of children's dog-bite history, $\chi^{2}(2)=21.51$, $p<0.001$. Boys were 1.56 times more likely to be bitten by dogs than girls $(O R=1.56$, $95 \% \mathrm{CI}=1.24-1.96)$. A one-year increase in age was associated with 1.12 times more likely risk for bites $(O R=1.12,95 \% \mathrm{CI}=1.02-1.22)$. Knowledge, attitudes/beliefs, exposure frequency and dog-ownership were entered along with age and gender in the second logistic regression model predicting dog-bite history. The full model significantly reduced the -2 Log Likelihood of the first model by $22.10, \chi^{2}(5)=22.10, p<0.001$. With all predictors included, gender $(O R=1.50$, $95 \% \mathrm{CI}=1.19-1.89)$ was still a significant predictor but age was not. Also significant predictors were higher attitudes/beliefs of invulnerability $(O R=1.26,95 \% \mathrm{CI}=1.01-1.57)$, more frequent exposure to $\operatorname{dogs}(O R=1.11,95 \% \mathrm{CI}=1.02-1.20)$, and previously owning a $\operatorname{dog}(O R=1.45$, $95 \% \mathrm{CI}=1.03-2.05)$. Thus, male gender, attitudes/beliefs of invulnerability, more frequent exposure to dogs, and previous but not current ownership of a dog were associated with history of a dog bite. Knowledge about dog safety and current dog ownership was not.

Table 4. Hierarchical logistic regression analysis predicting children's dog-bite history.

\begin{tabular}{lcccc}
\hline \multirow{2}{*}{ Variable } & \multicolumn{2}{c}{ Model 1 } & \multicolumn{2}{c}{ Model 2 } \\
\cline { 2 - 5 } & OR & 95\%CI & OR & 95\% CI \\
\hline Age (Years) & $1.12 *$ & $1.02-1.22$ & 1.08 & $0.98-1.89$ \\
\hline Gender (0 = Female, 1 = Male) & $1.56 * *$ & $1.24-1.96$ & $1.50 * *$ & $1.19-1.89$ \\
\hline Dog ownership & & & & \\
\hline (No dog ownership history: referent) & & & & \\
Owning a dog now & - & - & 1.28 & $0.89-1.84$ \\
Owning a dog before but not now & - & - & $1.45 *$ & $1.03-2.05$ \\
\hline Safety knowledge (\% correct, 0-100 scale) & - & - & 1.00 & $0.99-1.01$ \\
\hline Attitudes/beliefs (5-point scale, $1-5)$ & - & - & $1.26 *$ & $1.01-1.57$ \\
\hline Exposure frequency (6-point scale, $1-6)$ & - & - & $1.11 *$ & $1.02-1.20$ \\
\hline & $* p<0.05, * * p<0.01$. & & &
\end{tabular}

\section{Discussion}

\subsection{Risk Factors for Pediatric Dog-Bite Injuries in Rural China}

Consistent with findings from other countries [7,8,11,12,34], gender and age were significant risk factors for pediatric dog-bite injuries in rural China. Boys reported taking greater risks in interacting with dogs and higher rates of bite injury than girls. As children grew older and approached adolescence, they tended to report riskier attitudes, beliefs about invulnerability to risk with dogs, and self-reported riskier behaviors with dogs, despite the fact that they had similar levels of safety knowledge as the younger counterparts. These children also reported more bites in their history. These findings are particularly concerning since older children may have greater independence in deciding how to act when unsupervised around dogs.

Cognitive/behavioral factors influenced children's self-reported risky behaviors with dogs. After controlling for age and gender, greater exposure to dogs and perceptions of greater invulnerability to bites were associated with riskier child-dog interactions. We cannot infer causality from this cross-sectional dataset, but one possible explanation is that children with a higher familiarity with 
dogs perceive dogs as less dangerous and less likely to bite them, and therefore take greater risks with dogs. This hypothesis is supported by findings from college students in the United States [35].

Cognitive/behavioral factors also influenced children's self-reported history of dog bites. After controlling for age and gender, holding more attitudes/beliefs of invulnerability, having previous experience owning a dog and having more frequent exposure to dogs contributed to children's self-reported dog bite history. Therefore, it appears that children who held more attitudes/beliefs of invulnerability, and who had experience raising a dog and higher exposure frequency to dogs not only engaged in dangerous interactions with dogs but also were more likely to have experienced dog bites. The significant correlation between dog bite history and risky practice $(r=0.12, p<0.01)$ also supported this conclusion. Current ownership of dogs was not associated with history of dog bites even though previous dog ownership was. It may be that some families whose dogs bite children kill or remove the dog from the home.

\subsection{Implications for Intervention Development}

Several programs aiming to prevent dog-bite injuries among children have been developed and tested globally. Some focus on individual (e.g., child or parent) change and others focus on environmental change. At the individual level, the most promising programs incorporate behavioral strategies to improve children's knowledge and behavior, either in classroom environments or via computer software [36-41]. In general, these programs are effective at helping children learn more about dog safety but show limited evidence of creating behavior change [36,40].

Other programs focus on environmental changes. With collaborative effort from entire communities, these is some evidence that dog bite incidence can be reduced [42]. Both behavioral and community-based environment change strategies may be effective to reduce risk in rural China.

Of course, any interventions in rural China will need to be sensitive to local cultural and contextual issues. On average, children in this study answered only 56\% of safety knowledge questions correctly, suggesting pre-teens in rural China have poor knowledge about how to interact safely with dogs, even though stray dogs routinely wander the streets in their communities. Improving children's knowledge could be one important intervention strategy that ultimately leads to safer behavior and a reduction of pediatric dog bites in rural China. The correlations between knowledge and both attitudes/beliefs and practice support the reasoning that improved knowledge might result in healthier attitudes and beliefs and ultimately in safer practice.

The fact that rural Chinese children with perceived invulnerability to risk reported riskier behavior with dogs and higher rates of bite injuries could also lead to other intervention strategies, including behavioral strategies to increase perceived vulnerability and to change peer norms. Taken together, public health interventions targeting knowledge, attitudes, beliefs, and behavioral change might all be instituted with awareness of the local culture. The Chinese education system supports classroom-based education on both knowledge and attitudes/behavioral skills [43], and intervention programs should be consistent with cultural practices concerning health education. 


\subsection{Limitations and Future Directions}

One limitation of this study is that the data were self-reported. Although anonymous, it is possible that children, and perhaps especially older boys, felt proud to showcase their "brave" but risky interactions with dogs, especially given the fact that data were collected in a classroom setting with peers and teachers nearby. Self-reporting was also unable to detect the difference between children's perceived "dog bite" and a clinically diagnosed dog bite. It also is possible that children's recall of bite injuries and actual practice with dogs was biased or incorrect. Another limitation is the relatively narrow age range of our sample, with all children recruited from grades 4 to 6. It is possible that the age range was insufficient to detect developmental trends in knowledge, attitudes and/or behaviors with dogs in rural China that occur in younger or older children. Finally, we did not assess for history of exposure to rabies. It may be that children exposed to rabies react differently to dog bites versus those exposed to bites from dogs known to be non-rabid.

Future research might take several directions. Behavioral measures (e.g., naturalistic observation of children's daily interactions with dogs) would be valuable, as would review of medical records to obtain more accurate bite injury history data to compare with children's self-reported dog bites. Replication of this study with children across a larger age range, or in other regions (both rural and urban) of China, and with children from other low- and middle-income nations would also be valuable.

\section{Conclusions}

This study investigated dog-bite risk among children in grades 4-6 in rural China. Our results suggest that male gender, older age, frequent exposure to dogs, previous ownership of dogs, and attitudes/beliefs of invulnerability are factors that place children at increased risk of dog-bite injuries in rural China. More specifically, boys were more frequently exposed to dogs than girls. They also possessed less safety knowledge but riskier attitudes, beliefs of invulnerability, and more dangerous self-reported practices with dogs than girls. As children grew older, they reported greater exposure to dogs, but they also held riskier attitudes/beliefs and reported more risky behavior practices with dogs. Furthermore, children with riskier attitudes, beliefs of invulnerability, and those who were more frequently exposed to dogs and who previously owned a dog tended to report taking more risks with dogs and to be bitten by dogs more often.

\section{Acknowledgments}

Thanks to the Department of Education in the Towns of Baishan, Luanzhou and Hongtang for their assistance in participant recruitment. Thanks also to Yikun Schwebel for assistance with translation and Anna Helova for assistance with financial matters. This work was supported by the Lizette Peterson-Homer Injury Prevention Grant (American Psychological Association, Division 54); Society of Public Health and Education; University of Alabama at Birmingham Department of Psychology; and internal funding of the Research Institute at Nationwide Children's Hospital.

\section{Conflicts of Interest}

The authors declare no conflict of interest. 


\section{References}

1. Jalongo, M.R. Beyond a pets theme: Teaching young children to interact safely with dogs. Early Childhood Educ. J. 2008, 36, 39-45.

2. Schalamon, J.; Ainoedhofer, H.; Singer, G.; Petnehazy, T.; Mayr, J.; Kiss, K.; Höllwarth, M.E. Analysis of dog bites in children who are younger than 17 years. Pediatrics 2006, 117, e374-e379.

3. Cornelissen, J.M.R.; Hopster, H. Dog bites in The Netherlands: A study of victims, injuries, circumstances and aggressors to support evaluation of breed specific legislation. Vet. J. 2010, 186, 292-298.

4. Dwyer, J.; Douglas, T.; Van As, A. Dog bite injuries in children-a review of data from a South African trauma unit. S. Afr. Med. J. 2007, 97, 597-600.

5. Windiyaningsih, C.; Wilde, H.; Meslin, F.; Suroso, T.; Widarso, H. The rabies epidemic on Flores Island, Indonesia (1998-2003). J. Med. Assn. Thailand (Chotmaihet thangphaet) 2004, 87, 1389-1393.

6. Bhanganada, K.; Wilde, H.; Sakolsataydorn, P.; Oonsombat, P. Dog-bite injuries at a Bangkok teaching hospital. Acta Tropica 1993, 55, 249-255.

7. Overall, K.L.; Love, M. Dog bites to humans-Demography, epidemiology, injury, and risk. J. Amer. Vet. Med. Assn. 2001, 218, 1923-1934.

8. Yeh, C.C.; Liao, C.C.; Muo, C.H.; Chang, S.N.; Hsieh, C.H.; Chen, F.N.; Lane, H.Y.; Sung, F.C. Mental disorder as a risk factor for dog bites and post-bite cellulitis. Injury 2011, 43, 1903-1907.

9. Georges, K.; Adesiyun, A. An investigation into the prevalence of dog bites to primary school children in Trinidad. BMC Public Health 2008, 8, 85-91.

10. Moore, D.A.; Sischo, W.M.; Hunter, A.; Miles, T. Animal bite epidemiology and surveillance for rabies postexposure prophylaxis. J. Amer. Vet. Med. Assn. 2000, 217, 190-194.

11. Mcheik, J.N.; Vergnes, P.; Bondonny, J.M. Treatment of facial dog bite injuries in children: A retrospective study. J. Pediat. Surg. 2000, 35, 580-583.

12. Ozanne-Smith, J.; Ashby, K.; Stathakis, V. Dog bite and injury prevention-Analysis, critical review, and research agenda. Injury Prev. 2001, 7, 321-326.

13. Yin, X.L.; Xie, Z.P.; Dong, Y.M.; Qian, X.Y.; Ge, J.; Wang, L.M. Farm-related injuries among rural residents of Daur ethnic minority group in Qiqihar, Heilongjiang Province, China. Chin. J. Public Health 2010, 26, 628-629.

14. Shen, M.; Yang, S.; Han, J.; Shi, J.; Yang, R.; Du, Y.; Stallones, L. Non-fatal injury rates among the "left-behind children" of rural China. Injury Prev. 2009, 15, 244-247.

15. Hon, K.E.; Fu, C.A.; Chor, C.; Tang, P.H.; Leung, T.; Man, C.Y.; Ng, P. Issues associated with dog bite injuries in children and adolescents assessed at the emergency department. Pediatr. Emerg. Care 2007, 23, 445-449.

16. Gandhi, R.R.; Liebman, M.A.; Stafford, B.L.; Stafford, P.W. Dog bite injuries in children: A preliminary survey. Amer. Surg. 1999, 65, 863-864.

17. Bernardo, L.; Gardener, M.J.; Rosenfield, R.L.; Cohen, B.; Pitetti, R. A comparison of dog bite injuries in younger and older children treated in a pediatric emergency department. Pediatr. Emerg. Care 2002, 18, 247-249. 
18. Schwebel, D.C.; Pickett, W. The role of child and adolescent development in the occurrence of agricultural injuries: An illustration using tractor-related injuries. J. Agromed. 2012, 17, 214-224.

19. Avner, J.R.; Baker, M.D. Dog bites in urban children. Pediatrics 1991, 88, 55-57.

20. Sacks, J.J.; Sattin, R.W.; Bonzo, S.E. Dog bite-related fatalities from 1979 through 1988. J. Amer. Med. Assn. 1989, 262, 1489-1492.

21. Brogan, T.V.; Bratton, S.L.; Dowd, M.D.; Hegenbarth, M.A. Severe dog bites in children. Pediatrics 1995, 96, 947-950.

22. Headey, B.; Na, F.; Zheng, R. Pet dogs benefit owners' health: A "natural experiment" in China. Soc. Indic. Res. 2008, 87, 481-493.

23. Duan, B.S. Do not neglect the danger of dogs in rural areas (in Chinese). Henan Sci. Technol. 2008, 4, 44.

24. Guo, F.Y.; Zhu, Y.C.; Wu, Y.H.; Hai, M. An analysis of animal-bite injury among 12891 cases (in Chinese). Pract. Prev. Med. 2007, 1, 120-121.

25. Deng, K.J.; Tan, J.G.; Zhang, X. An epidemiological analysis of animal-bite cases in Futian District, Shenzhen City between 2000 and 2002 (in Chinese). Chin. J. Public Health Manag. 2004, 1, 52-53.

26. Si, H.; Guo, Z.M.; Hao, Y.T.; Liu, Y.G.; Zhang, D.M.; Rao, S.Q.; Lu, J.H. Rabies trend in China (1990-2007) and post-exposure prophylaxis in the Guangdong province. BMC Infect. Dis. 2008, 8, 113-122.

27. Song, M.; Tang, Q.; Wang, D.-M.; Mo, Z.-J.; Guo, S.-H.; Li, H.; Tao, X.-Y.; Rupprecht, C.E.; Feng, Z.-J.; Liang, G.-D. Epidemiological investigations of human rabies in China. BMC Infect. Dis. 2009, 9, 210, doi:10.1186/1471-2334-9-210.

28. Kureishi, A.; Xu, L.; Wu, H.; Stiver, H. Rabies in China: Recommendations for control. B. World Health Organ. 1992, 70, 443-450.

29. Duperrex, O.; Bunn, F.; Roberts, I. Safety education of pedestrians for injury prevention: A systematic review of randomised controlled trials. Brit. Med. J. 2002, 324, 1129-1131.

30. Bettinghaus, E.P. Health promotion and the knowledge-attitude-behavior continuum. Prev. Med. 1986, 15, 475-491.

31. Zhang, X.; Luo, B.; Zhang, K. A KABP (knowledge, attitude, belief and practice) study about AIDS among taxi drivers and hotel attendants in Beijing. Chin J. Epidemiol. 1994, 15, 323-327.

32. Radhakrishnan, K.; Pandian, J.; Santhoshkumar, T.; Thomas, S.; Deetha, T.; Sarma, P.; Jayachandran, D.; Mohamed, E. Prevalence, knowledge, attitude, and practice of epilepsy in Kerala, South India. Epilepsia 2000, 41, 1027-1035.

33. Matuja, W.; Rwiza, H. Knowledge, attitude and practice (KAP) towards epilepsy in secondary school students in Tanzania. Cent.Afr. J. Med. 1994, 40, 13-18.

34. Horisberger, U.; Stärk, K.D.C.; Rüfenacht, J.; Pillonel, C.; Steiger, A. The epidemiology of dog bite injuries in Switzerland - Characteristics of victims, biting dogs and circumstances. Anthrozoös 2004, 17, 320-339.

35. Moss, S.P.; Wright, J.C. The effects of dog ownership on judgments of dog bite likelihood. Anthrozoös 1987, 1, 95-99. 
36. Meints, K.; de Keuster, T. Don't kiss a sleeping dog: The first assessment of "The Blue Dog" bite prevention program. J. Pediat. Psychol. 2009, 34, 1084-1090.

37. Chapman, S.; Cornwall, J.; Righetti, J.; Sung, L. Preventing dog bites in children: Randomised controlled trial of an educational intervention. Brit. Med. J. 2000, 320, 1512, doi: $10.1136 /$ bmj.320.7248.1512.

38. Spiegel, I.B. A pilot study to evaluate an elementary school-based dog bite prevention program. Anthrozoos 2000, 13, 164-173.

39. Wilson, F.; Dwyer, F.; Bennett, P.C. Prevention of dog bites: Evaluation of a brief educational intervention program for preschool children. J. Community Psychol. 2003, 31, 75-86.

40. Schwebel, D.C.; Morrongiello, B.A.; Davis, A.L.; Stewart, J.; Bell, M. The Blue Dog: Evaluation of an interactive software program to teach young children how to interact safely With dogs. J. Pediat. Psychol. 2012, 37, 272-281.

41. Morrongiello, B.A.; Schwebel, D.C.; Stewart, J.; Bell, M.; Davis, A.L.; Corbett, M.R. Examining parents' behaviors and supervision of their children in the presence of an unfamiliar dog: Does The Blue Dog intervention improve parent practices? Accid. Anal. Prevent. 2013, in press.

42. Beaver, B.V. A community approach to dog bite prevention. J. Am. Vet. Med. Assn. 2001, 218, 1732-1749.

43. He, M.; Ye, L. Status of school reform in China (in Chinese). J. East China Norm. Univ. (Educ. Sci.) 2002, 3, 26-44. 
Reprinted from Int. J. Environ. Res. Public Health. Cite as: Chandran, A.; Khan, U.R.; Zia, N.; Feroze, A.; de Ramirez, S.S.; Huang, C.-M.; Razzak, J.A.; Hyder, A.A. Disseminating Childhood Home Injury Risk Reduction Information in Pakistan: Results from a Community-Based Pilot Study. Int. J. Environ. Res. Public Health 2013, 10, 1113-1124.

Article

\title{
Disseminating Childhood Home Injury Risk Reduction Information in Pakistan: Results from a Community-Based Pilot Study
}

\author{
Aruna Chandran ${ }^{1, *}$, Uzma Rahim Khan ${ }^{2}$, Nukhba Zia ${ }^{1}$, Asher Feroze ${ }^{2}$, \\ Sarah Stewart de Ramirez ${ }^{1}$, Cheng-Ming Huang ${ }^{1}$, Junaid A. Razzak ${ }^{2}$ and Adnan A. Hyder \\ 1
}

1 International Injury Research Unit (IIRU), Department of International Health, Johns Hopkins University Bloomberg School of Public Health, Baltimore, MD 21205, USA;

E-Mails: nzia@jhsph.edu (N.Z.); sderamirez@jhmi.edu (S.S.R.); chuang@jhsph.edu (C.-M.H.); ahyder@jhsph.edu (A.A.H.)

2 Department of Emergency Medicine, Aga Khan University, Karachi 74800, Pakistan; E-Mails: uzma.khan@aku.edu (U.R.K.); asher.feroze@aku.edu (A.F.); junaid.razzak@aku.edu (J.A.R.)

* Author to whom correspondence should be addressed; E-Mail: archandr@jhsph.edu; Tel. +1-410-361-9580; Fax: +1-410-396-1617.

Received: 25 January 2013; in revised form: 7 March 2013 / Accepted: 7 March 2013 /

Published: 15 March 2013

\begin{abstract}
Background: Most childhood unintentional injuries occur in the home; however, very little home injury prevention information is tailored to developing countries. Utilizing our previously developed information dissemination tools and a hazard assessment checklist tailored to a low-income neighborhood in Pakistan, we pilot tested and compared the effectiveness of two dissemination tools. Methods: Two low-income neighborhoods were mapped, identifying families with a child aged between 12 and 59 months. In June and July 2010, all enrolled households underwent a home hazard assessment at the same time hazard reduction education was being given using an in-home tutorial or a pamphlet. A follow up assessment was conducted 4-5 months later. Results: 503 households were enrolled; 256 received a tutorial and 247 a pamphlet. The two groups differed significantly $(p<0.01)$ in level of maternal education and relationship of the child to the primary caregiver. However, when controlling for these variables, those receiving an in-home tutorial had a higher odds of
\end{abstract}


hazard reduction than the pamphlet group for uncovered vats of water (OR 2.14, 95\% CI: $1.28,3.58$ ), an open fire within reach of the child (OR 3.55, 95\% CI: 1.80, 7.00), and inappropriately labeled cooking fuel containers (OR 1.86, 95\% CI: 1.07, 3.25). Conclusions: This pilot project demonstrates the potential utility of using home-visit tutorials to decrease home hazards in a low-income neighborhood in Pakistan. A longer-term randomized study is needed to assess actual effectiveness of the use of allied health workers for home-based injury education and whether this results in decreased home injuries.

Keywords: unintentional injuries; home injuries; children; accidents; trauma; home visits; Pakistan

\section{Background}

Unintentional injuries are major causes of mortality and morbidity among children, resulting in over 875,000 deaths annually in children $<18$ years of age annually around the World [1]. For young children between 1 and 5 years of age, not only are unintentional injuries the leading cause of death, but they are also responsible for millions of non-fatal injuries, often leaving children with lifelong disabilities [2]. Because of the long periods of time that children spend in the home, in combination with the variety of potential hazards that are present in the household environment, a substantial proportion of childhood unintentional injuries occur in this setting [3-5]. As has been shown in several studies mostly focused in high-income countries (HIC), a substantial number of childhood unintentional injuries can be prevented through modifications to the home environment [6-8].

A variety of methods for promoting home injury prevention to caretakers of young children have been proven effective in HICs. For example, a number of recent studies offer strong evidence that home visits by community health workers or similar allied health professionals can reduce childhood injuries in HICs [9-15]. In addition, healthcare practitioners in most HICs have an abundance of pre-designed pamphlets and information sheets regarding methods for "safety-proofing" a home for young children [16,17]. However, few such resources for improving home safety have been tailored to a low and middle income country (LMIC) setting, and there is limited information regarding the best methods and tools for dissemination of home safety information in LMICs. This lack of research regarding the most effective method for dissemination of home injury risk and potential prevention information in LMICs has resulted in limited ways for health professionals to share knowledge with parents [2].

Pakistan is a low-income country with a population of over 176 million [18]. Studies in Pakistan have shown that the unintentional injury burden is substantial in young children, and that the majority of those occur in the home [3,19-22]. A recent randomized trial in which injury reduction counseling was provided in a home visit following a child being discharged from an emergency department showed a significant reduction in the presence of both fall and choking hazards [23]. To our knowledge, no similar studies have been done in this setting focusing on unintentional injury hazards beyond choking and falls. 
This study was motivated by the need for additional evidence-based approaches for the dissemination of home injury prevention information in order to reduce childhood injury risk in LMIC. The study design and initial assessment of the prevalence of existing household risk for childhood injury in the chosen neighborhoods have been previously described [24]. This study describes the results of a pilot study comparing the difference in prevalence of home injury risks before and after the dissemination of two different hazard reduction tools: an educational pamphlet and an in-home tutorial.

\section{Methods}

\subsection{Tool Development}

Details of the development of the home hazard assessment checklist as well as two different tools containing information on identifying and correcting common home hazards that can result in unintentional injuries in young children (an educational pamphlet and an in-home tutorial) have been previously described [24]. Briefly, the home hazard assessment checklist included a detailed assessment of the presence of home injury hazards divided by room or living area as viewed by a trained data collector. Basic information highlighting common home injury hazards that were specific and relevant to this population, as well as low-cost easily implemented methods for reducing or eliminating those hazards was drafted; both the educational pamphlet and the in-home tutorial contained the same information. The educational pamphlet was designed such that the information was presented in a format not requiring the presence of a health practitioner for understanding or use. In contrast, the in-home tutorial was an interactive tool that allowed a trained data collector to provide home injury risk information and prevention ideas while walking through the house with the child's caregiver. All tools were translated into Urdu, the local language commonly spoken in Karachi.

\subsection{Study Design}

Two neighborhoods were identified within a low-income government housing community in Karachi, Pakistan. This community was selected on the basis of a lower middle-income status of residents, homes with permanent structures, relatively high literacy level of residents, and ease of access from the local research institution. The neighborhoods were approximately $1 / 4$ mile apart, separated by several large and busy streets; previous observations by AKU staff suggest very little mixing between the two populations. One neighborhood was arbitrarily chosen as the "educational pamphlet group" and the other as the "in-home tutorial group". The two neighborhoods were mapped, and then enrollment screening took place. The sample size for projected enrollment was calculated based on hazard prevalence shown by previous studies in Pakistan [19,23], an anticipated $10 \%$ difference in the in-home tutorial vs. educational pamphlet groups following the intervention, $90 \%$ power, $5 \%$ significance, $15 \%$ consent decline, and $10 \%$ loss to follow up.

Eligibility criteria for enrollment into the study included: presence of at least one child between the ages of 12 and 59 months, a caregiver who was able to read in Urdu, and a current plan to live in the same house for at least another three months. Eligibility was confirmed at the beginning of the interaction. Following confirmation of eligibility and obtaining of written informed consent, 
households were enrolled. If a household had more than one child between 12-59 months of age, the caregiver was asked to select one as the index child.

Three data collectors (DCs) were trained in the use of the home hazard assessment checklist as well as how to share the information contained in the educational pamphlet and in-home tutorial. For the educational pamphlet households, the DCs conducted the home hazard assessment, presented the pamphlet, and encouraged the caregiver to read it and share it with others involved in the care of the child. For the in-home tutorial households, the DCs conducted the home hazard assessment and then utilized the tutorial guide with the respondent by going room to room pointing out potential hazards and sharing ideas on how they might be corrected.

A follow up assessment using the identical tool as the initial hazard assessment was done 4-5 months following the intervention was done by the same DCs. At that time, the in-home tutorial households were also given an educational pamphlet to keep with them for future reference; the educational pamphlet households were not given an in-home tutorial at that time.

The interventions were conducted in June-July 2010, and the follow up assessments were done in November 2010. Approval for the study was obtained from the Ethical Review Committee of the Aga Khan University (Pakistan) and the Institutional Review Board of Johns Hopkins Bloomberg School of Public Health (USA).

\subsection{Statistical Analysis}

All data was entered into an EpiData database. Data analysis was done using Stata Version 10 (Statacorps LP, College Station, TX, USA). Demographic variables as well as the presence of hazards were compared between groups using the Student's $t$-Test for continuous variables and the Fisher's Exact Chi-Squared for dichotomous variables. Logistic regression analysis utilizing data from those households for which both pre and post information was available was used to assess the odds of change in hazard presence while controlling for several demographic variables including those that were statistically significantly different between the two groups.

\section{Results}

A total of 503 households were enrolled in the study; 256 were assigned to receive an in-home tutorial while 247 received an educational pamphlet (Figure 1). The demographic profiles of the two groups are shown in detail in Table 1. Overall, the mean age of the index children was 34.8 months (range 12 to 59 months), with a relatively equal number of males $(50.7 \%)$ and females $(49.3 \%)$. The respondents were nearly all female (98.8\%) and occupied as housewives (93.0\%). Roughly half of the respondents (53.3\%) were in the 20-29 year age group. Importantly and unexpectedly, the two groups differed significantly in two demographic characteristics; the educational pamphlet group had higher levels of maternal education $(p<0.01)$ and a higher proportion of index children having the mother as the primary caregiver $(p<0.01)$. The basic injury history and risk factor characteristics of this cohort have been reported elsewhere (submitted for publication by the authors).

Table 2 outlines a comparison of the types of injury hazards present both before and after the interventions for both groups. Notably, there were significant differences between the two groups in the prevalence of several pre-intervention hazards; this is likely influenced by the demographic 
differences between the two groups. In both the in-home tutorial group as well as the educational pamphlet group, there was a statistically significant $(p<0.01)$ decrease in the following injury hazards after the intervention: falls (walker present), drowning (open buckets and vats/pools of water), burns (water heater, matches and stove within reach of the child), poisonings (cleaning supplies and shampoos accessible to the child), and lacerations (knives and breakable objects within reach of the child). Additionally, the in-home tutorial group had a decrease in the prevalence of medicines within reach of the child $(p<0.01)$ and open fire within reach of the child $(p=0.03)$. For reasons that are not clear, a few hazards increased in prevalence in the educational pamphlet group after the intervention as compared with before; there were a higher proportion of irons within reach of the child $(p=0.04)$ and open fires within reach of the child $(p=0.04)$.

Figure 1. Flow chart of study household enrollment.

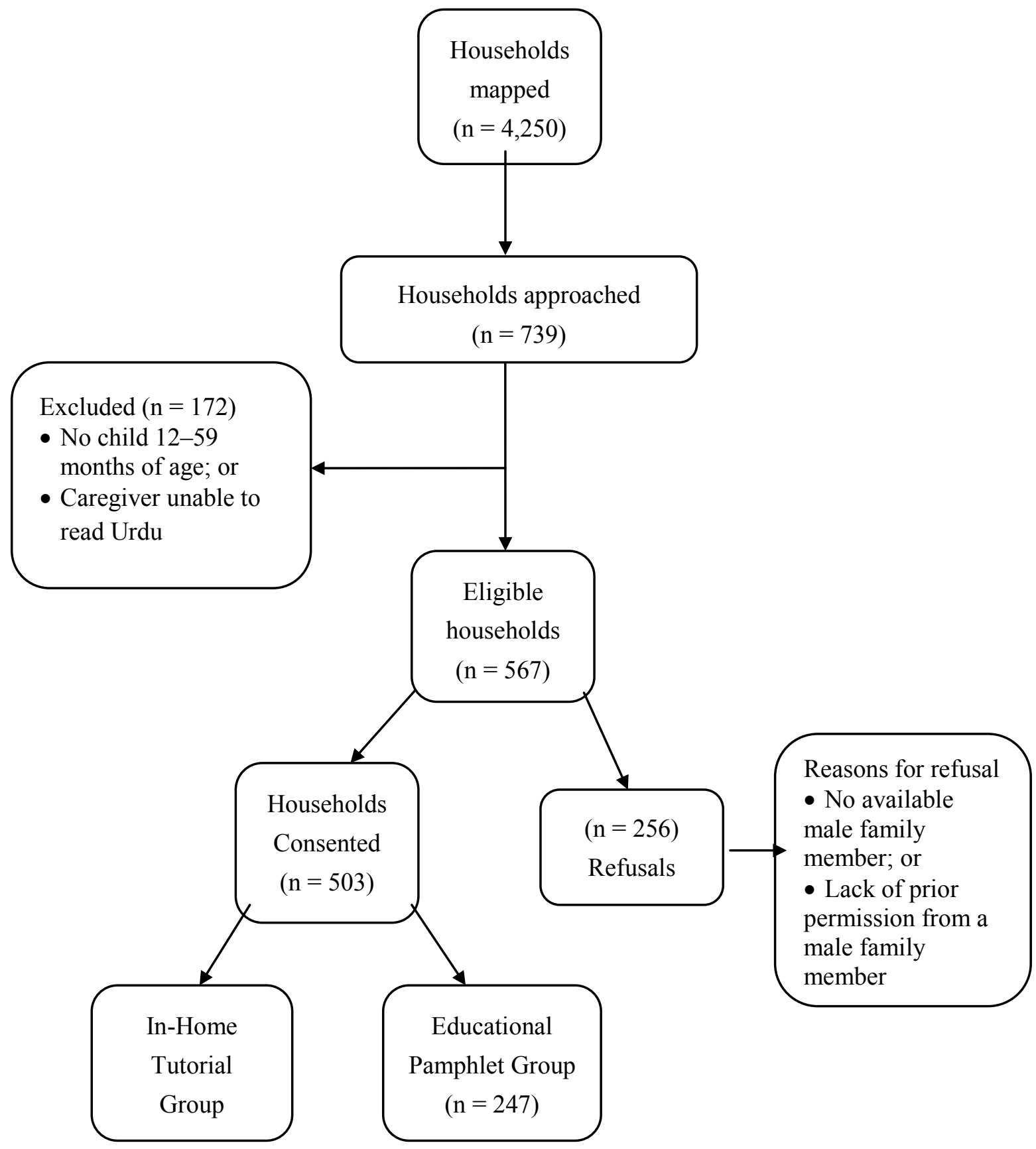

Table 1. Demographic characteristics of enrollees by group. 


\begin{tabular}{|c|c|c|c|}
\hline Characteristics & $\begin{array}{l}\text { In-Home Tutorial Group; } \\
\qquad \mathrm{N}=\mathbf{2 5 6}(\%) \\
\end{array}$ & $\begin{array}{l}\text { Educational Pamphlet Group; } \\
\qquad \mathbf{N}=\mathbf{2 4 7}(\%) \\
\end{array}$ & $\begin{array}{c}\text { Comparison } \\
(p \text { value })\end{array}$ \\
\hline \multicolumn{4}{|c|}{ Respondent Characteristics } \\
\hline \multicolumn{4}{|l|}{ Gender } \\
\hline Female & $254(99.2)$ & $243(98.4)$ & \multirow{2}{*}{$p=0.39$} \\
\hline Male & $2(0.8)$ & $4(1.6)$ & \\
\hline \multicolumn{4}{|l|}{ Age Group } \\
\hline$<20$ years & $6(2.3)$ & $8(3.2)$ & \multirow{5}{*}{$p=0.12$} \\
\hline 20-29 years & $124(48.4)$ & $144(58.3)$ & \\
\hline $30-39$ years & $95(37.1)$ & $78(31.6)$ & \\
\hline $40-49$ years & $19(7.4)$ & $11(4.5)$ & \\
\hline $50+$ years & $12(4.7)$ & $6(2.4)$ & \\
\hline \multicolumn{4}{|l|}{ Education Level } \\
\hline$<$ Grade 9 & $104(40.6)$ & $59(23.9)$ & \multirow{2}{*}{$p<0.01$} \\
\hline$\geq$ Grade 9 & $152(59.4)$ & $188(76.1)$ & \\
\hline \multicolumn{4}{|l|}{ Occupation of Mother } \\
\hline Housewife & $235(91.8)$ & $233(94.3)$ & \multirow{2}{*}{$p=0.53$} \\
\hline Other & $21(8.2)$ & $14(5.7)$ & \\
\hline \multicolumn{4}{|l|}{ Child Characteristics } \\
\hline Mean Age (months) & 34.3 & 35.2 & $p=0.42$ \\
\hline \multicolumn{4}{|l|}{ Gender } \\
\hline Male & $131(51.2)$ & $124(50.2)$ & \multirow{2}{*}{$p=0.83$} \\
\hline Female & $125(48.8)$ & $123(49.8)$ & \\
\hline \multicolumn{4}{|c|}{ Child's Primary Caregiver } \\
\hline Mother & $218(85.2)$ & $233(94.3)$ & \multirow{3}{*}{$p<0.01$} \\
\hline Father & $9(3.5)$ & $2(0.8)$ & \\
\hline Other & $29(11.3)$ & $12(4.9)$ & \\
\hline
\end{tabular}

When directly comparing the two interventions, the homes that received an educational pamphlet had a lower prevalence of several hazards than those homes that received an in-home tutorial, including the presence of open buckets of water $(p=0.02)$, a stove within reach of a child $(p<0.01)$, matches within reach of a child $(p<0.01)$, inappropriate labeled cooking fluid containers $(p<0.01)$, cleaning supplies within reach of a child $(p<0.01)$, and knives within reach of a child $(p<0.01)$ (Table 2). Conversely, the in-home tutorial group had a slightly lower prevalence of accessible rooftops without railings, iron within reach of the child, medicines within reach of a child, and breakable objects accessible to the child; however, these differences were not statistically significant. Of note, many of these differences were present between the two groups prior to the implementation of the intervention. 


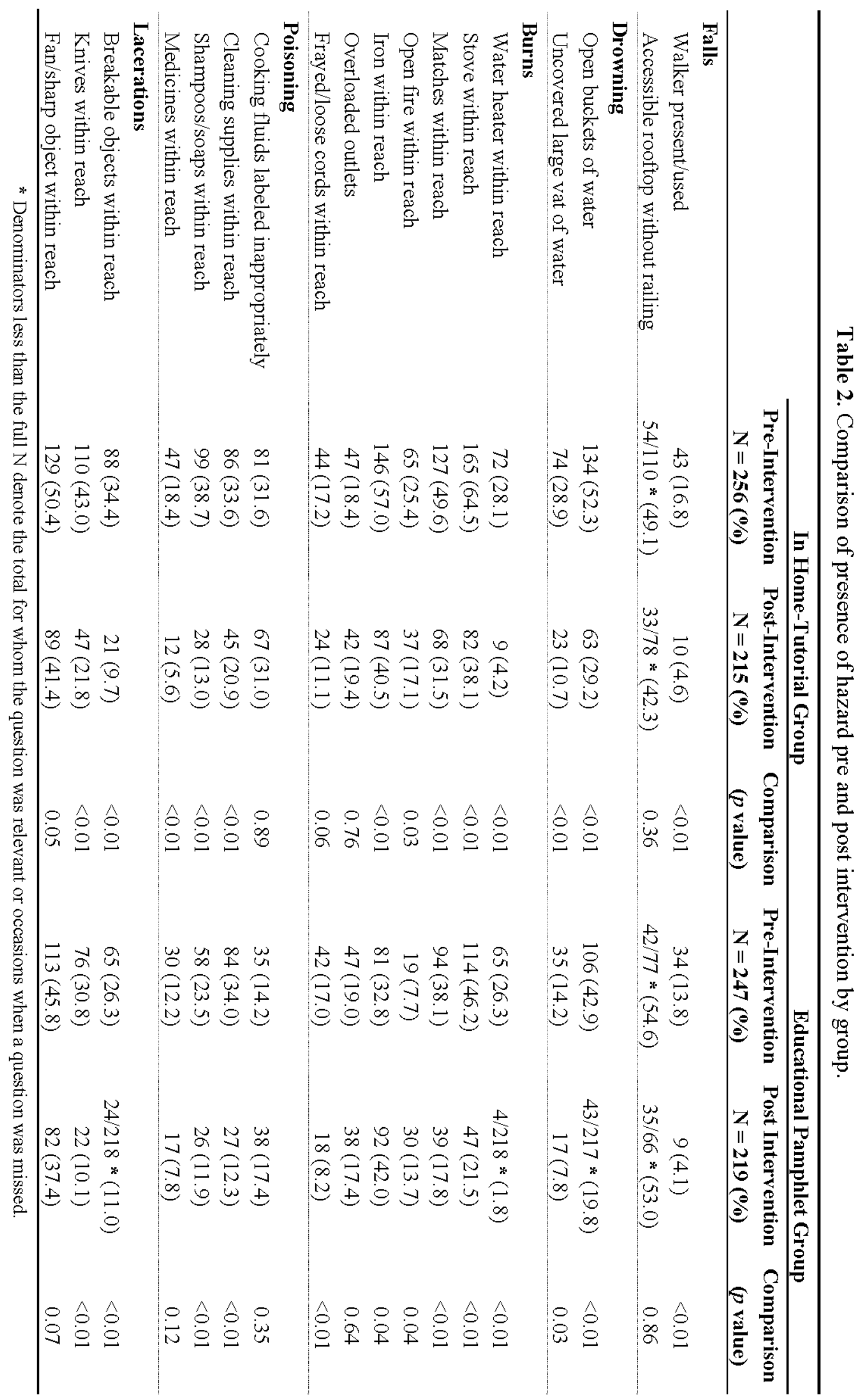


In order to address the intervention results in light of the significant demographic differences between the two groups, we calculated the odds of a household having changed from the presence of a hazard in the pre-intervention assessment to lack of that hazard in the post-intervention assessment, while controlling for various demographic variables including level of maternal education and relationship of primary caregiver. The educational pamphlet group served as the reference group (Table 3). Results demonstrated that the households in the in-home tutorial group had a higher odds of no longer having an open vat of water (OR 2.14, 95\% CI: 1.28, 3.58), an open fire within reach of a child (OR 3.55, 95\% CI: 1.80, 7.00), an iron within reach of a child (OR 1.95, 95\% CI: 1.21, 3.12), inappropriately labeled cooking fluid containers (OR 1.86, 95\% CI: 1.07, 3.25 ), and shampoos/soaps within reach of the child (OR 1.78, 95\% CI: 1.12, 2.82). Alternately, the educational pamphlet group had trend of improvement of having overloaded outlets (OR 0.75, 95\% CI: $0.43,1.30$ ), frayed/loose cords within reach of a child (OR 0.84, 95\% CI: 0.48, 1.47), and cleaning supplies within reach of a child (OR 0.86, 95\% CI: $0.54,1.37$ ); however none of these were statistically significant.

Table 3. Odds of change from presence to lack of specific hazards in the in-home tutorial group as opposed to the educational pamphlet group.

\begin{tabular}{|c|c|c|}
\hline Hazard Description & Odds Ratio (OR) * & $95 \% \mathrm{CI}$ \\
\hline \multicolumn{3}{|l|}{ Falls } \\
\hline Walker present/used & 1.48 & $0.84,2.62$ \\
\hline Accessible rooftop without railing & 1.04 & $0.61,1.79$ \\
\hline \multicolumn{3}{|l|}{ Drowning } \\
\hline Open bucket of water & 1.27 & $0.83,1.95$ \\
\hline Uncovered vat/pool of water & 2.14 & $1.28,3.58$ \\
\hline \multicolumn{3}{|l|}{ Burns } \\
\hline Water heater within reach & 1.20 & $0.76,1.88$ \\
\hline Stove within reach & 1.09 & $0.72,1.67$ \\
\hline Matches within reach & 1.07 & $0.69,1.66$ \\
\hline Open fire within reach & 3.55 & $1.80,7.00$ \\
\hline Iron within reach & 1.95 & $1.21,3.12$ \\
\hline Overloaded outlets & 0.75 & $0.43,1.30$ \\
\hline Frayed/loose cords within reach & 0.84 & $0.48,1.47$ \\
\hline \multicolumn{3}{|l|}{ Poisoning } \\
\hline Cooking fluids labeled inappropriately & 1.86 & $1.07,3.25$ \\
\hline Cleaning supplies within reach & 0.86 & $0.54,1.37$ \\
\hline Medicines within reach & 1.45 & $0.82,2.55$ \\
\hline Shampoos/soaps within reach & 1.78 & $1.12,2.82$ \\
\hline \multicolumn{3}{|l|}{ Cuts } \\
\hline Breakable objects within reach & 1.52 & $0.96,2.41$ \\
\hline Knives within reach & 1.11 & $0.71,1.72$ \\
\hline Fan/sharp objects within reach & 1.17 & $0.73,1.89$ \\
\hline
\end{tabular}

* Variables being controlled for in the Multivariate Logistical Regression model: level of maternal education, relationship of primary caregiver, child's gender, child's age, and respondent age. 


\section{Discussion}

Our study showed an overall significant decrease in 13 out of 18 potential hazards for all major types of unintentional injuries following the conduct of a home hazard assessment and provision of prevention information, either in the form of an educational pamphlet that the caregiver(s) could read on their own or an in-home tutorial done jointly with a caregiver and a study data collector. Whether the changes were due to new information gained by the caregivers or simply the pointing out of safety hazards during the conduct of the hazard assessment is unclear; either way, in the immediate 4-5 months following this intervention, there were fewer childhood hazards present in these low-income housing communities in Karachi, Pakistan. Our findings are similar to what other studies and meta-analyses have found following home visits in other settings $[10,12-15]$ in that home visits and information dissemination can result in behavior change regarding presence of injury hazards in the home.

The analysis of the odds of a positive change in hazard presence (that is, going from presence of a hazard in the initial assessment to lack of that hazard present in the follow up assessment) allowed a direct comparison of the two interventions while controlling for the various demographic variables including those that differed significantly between the two groups. This analysis showed that the odds of change were statistically significantly higher for many hazards in the in-home tutorial group versus the educational pamphlet group. In contrast, the hazards which had a higher odds of change in the educational pamphlet group did not reach statistical significance. Therefore, our study suggests that the use of an in-home tutorial may be a more effective method for the dissemination of childhood hazard prevention methods. This could be because of the added benefit of having someone point out hazards and talk through possible reduction strategies with caregivers as opposed to simply handing a caregiver a pamphlet. However, further comparison studies will be needed in order to establish the optimum strategies for injury prevention information dissemination in LMIC settings.

Although we employed general data collectors for the implementation of the intervention, health workers (HWs) already involved in delivering health information to communities could easily be trained to implement these interventions. Given the widespread use of health workers in several health-related areas (including infectious and chronic diseases) in many countries [25-28], this study suggests a tremendous potential for the impact of using trained HWs for the dissemination of injury prevention information in LMIC settings. Incorporating injury prevention into the topic areas covered by community health workers has been suggested in a few contexts previously [29,30].

Our study had several limitations. First, enrollees were not randomized to an intervention, which likely contributed to the significant differences between the two neighborhoods. Ideally, a follow up trial should be considerably larger in which several communities or neighborhoods could be cluster-randomized to receiving each of these interventions. Second, the two groups differed significantly in level of respondent education and the relationship of the primary caregiver to the child. Therefore, it might have been predicted that the educational pamphlet group had a lower prevalence of most home hazards prior to any intervention. However, it is important to note that hazard improvement after versus before the intervention occurred in both groups. Third, we assessed only changes in presence of hazards, but did not demonstrate a difference in incidence of 
unintentional injuries. We are in the process of conducting a longer-term follow up (15-18 months following the initial intervention) in which we will assess both ongoing presence of hazards as well as recent unintentional injury history in the index children. Fourth, we utilized the same individuals (DCs) to do the hazard assessments as well as implement the interventions. While this facilitated building up a necessary rapport with the families, it did introduce a potential bias in the hazard assessments if the DCs had pre-conceived notions about the benefits of one intervention strategy versus the other. Future studies should consider utilizing different people for hazard assessment conductors versus interventionalists. Finally, there was a 10-15\% loss to follow up between the initial and follow-up assessments. While this was accounted for in our sample size calculations, every effort should be made to minimize this gap in future studies.

\section{Conclusions}

Our study supports the findings from many studies from HICs and a few studies in LMICs that have demonstrated a significant change in knowledge and presence of injury hazards following dissemination of targeted childhood injury prevention information [10,12-15]. In this pilot study, it appeared that in-home tutorials are the most effective method for information dissemination, although the use of an educational pamphlet also showed positive impact. There are of course other considerations (resource needs, literacy requirements, etc.) that should be taken into account when choosing to use an in-home tutorial or an educational pamphlet in other areas within Pakistan or in other LMIC settings. Future studies in LMIC settings should focus on assessment of both of these types of tools, and also explore the use of educational pamphlets by healthcare providers as is commonly done in HICs. A larger randomized trial could be helpful in comparing these two information dissemination methods; future trials should address the limitations encountered in this study as well as conduct pre-trial assessments of the target populations to assess characteristics such as literacy level.

The development of effective home hazard reduction educational materials could have significant impact on the burden of home injuries in children particularly in lower-income countries such as Pakistan. These advances would heed the call by the World Health Organization for more targeted interventions to address the global burden of child injuries.

\section{Acknowledgment}

This work was supported by the World Health Organization's Division of Violence and Injury Prevention, and the Johns Hopkins Center for Global Health. AAH, URK, and JAR were also partially supported by the Fogarty International Center of the US National Institutes of Health, Grant Number D43-TW007-292. AC was also partially supported by the Fogarty International Center of the US National Institutes of Health, Grant Number D43-TW007-292Z.

\section{References}

1. Mock, C.; Peden, M.; Hyder, A.A.; Butchart, A.; Krug, E. Child injuries and violence: The new challenge for child health. Bull. WHO 2008, 86, 420, doi:10.2471/BLT.08.054767. 
2. Peden, M. World report on child injury prevention appeals to "keep kids safe". Inj. Prev. 2008, 14, 413-414.

3. Zia, N.; Khan, U.R.; Razzak, J.A.; Puvanachandra, P.; Hyder, A.A. Understanding unintentional childhood home injuries: Pilot surveillance data from Karachi, Pakistan. BMC Res. Notes 2012, 5, 37, doi: 10.1186/1756-0500-5-37.

4. Sengoelge, M.; Hasselberg, M.; Laflamme, L. Child home injury mortality in Europe: A 16-country analysis. Eur. J. Public Health 2011, 21, 166-170.

5. Mahalakshmy, T.; Dongre, A.R.; Kalaiselvan, G. Epidemiology of childhood injuries in rural Puducherry, South India. Indian J. Pediatr. 2011, 78, 821-825.

6. Irving, L. Preventing unintentional injuries in children and young people under 15. Community Pract. 2011, 84, 36-38.

7. Gururaj, G. Injury prevention and care: An important public health agenda for health, survival and safety of children. Indian J. Pediatr. 2012, doi: 10.1007/s12098-012-0783-z.

8. Phelan, K.J.; Khoury, J.; Xu, Y.; Liddy, S.; Hornung, R.; Lanphear, B.P. A randomized controlled trial of home injury hazard reduction: The home injury study. Arch. Pediatr. Adolesc. Med. 2011, 165, 339-345.

9. Kendrick, D.; Coupland, C.; Mulvaney, C.; Simpson, J.; Smith, S.J.; Sutton, A.; Watson, M.; Woods, A. Home safety education and provision of safety equipment for injury prevention. Cochrane Database Syst. Rev. 2007, CD005014, doi: 10.1002/14651858.CD005014.pub3.

10. Kendrick, D.; Elkan, R.; Hewitt, M.; Dewey, M.; Blair, M.; Robinson, J.; Williams, D.; Brummell, $\mathrm{K}$. Does home visiting improve parenting and the quality of the home environment? A systematic review and meta analysis. Arch. Dis. Child. 2000, 82, 443-451.

11. Elkan, R.; Kendrick, D.; Hewitt, M.; Robinson, J.J.; Tolley, K.; Blair, M.; Dewey, M.; Williams, D.; Brummell, K. The effectiveness of domiciliary health visiting: A systematic review of international studies and a selective review of the British literature. Health Technol. Assess. 2000, 4, 1-339.

12. Babul, S.; Olsen, L.; Janssen, P.; McIntee, P.; Raina, P. A randomized trial to assess the effectiveness of an infant home safety programme. Int. J. Inj. Contr. Saf. Promot. 2007, 14, 109-117.

13. Odendaal, W.; van Niekerk, A.; Jordaan, E.; Seedat, M. The impact of a home visitation programme on household hazards associated with unintentional childhood injuries: A randomised controlled trial. Accid. Anal. Prev. 2009, 41, 183-190.

14. Carlsson, A.; Bramhagen, A.C.; Jansson, A.; Dykes, A.K. Precautions taken by mothers to prevent burn and scald injuries to young children at home: An intervention study. Scand. J. Public Health 2011, 39, 471-478.

15. Swart, L.; van Niekerk, A.; Seedat, M.; Jordaan, E. Paraprofessional home visitation program to prevent childhood unintentional injuries in low-income communities: A cluster randomized controlled trial. Inj. Prev. 2008, 14, 164-169.

16. Nansel, T.R.; Weaver, N.L.; Jacobsen, H.A.; Glasheen, C.; Kreuter, M.W. Preventing unintentional pediatric injuries: A tailored intervention for parents and providers. Health Educ. Res. 2008, 23, 656-669. 
17. Sznajder, M.; Leduc, S.; Janvrin, M.P.; Bonnin, M.H.; Aegerter, P.; Baudier, F.; Chevallier, B. Home delivery of an injury prevention kit for children in four french cities: A controlled randomized trial. Inj. Prev. 2003, 9, 261-265.

18. Pakistan: Country at a Glance. Available online: www.worldbank.org/en/country/pakistan (accessed on 15 December 2012).

19. Lasi, S.; Rafique, G.; Peermohamed, H. Childhood injuries in Pakistan: Results from two communities. J. Health Popul. Nutr. 2010, 28, 392-398.

20. Fatmi, Z.; Kazi, A.; Hadden, W.C.; Bhutta, Z.A.; Razzak, J.A.; Pappas, G. Incidence and pattern of unintentional injuries and resulting disability among children under 5 years of age: Results of the national health survey of Pakistan. Paediatr. Perinat. Epidemiol. 2009, 23, 229-238.

21. Hyder, A.A.; Wali, S.; Fishman, S.; Schenk, E. The burden of unintentional injuries among the under-five population in South Asia. Acta Paediatr. 2008, 97, 267-275.

22. Hyder, A.A.; Sugerman, D.E.; Puvanachandra, P.; Razzak, J.; El-Sayed, H.; Isaza, A.; Rahman, F.; Peden, M. Global childhood unintentional injury surveillance in four cities in developing countries: A pilot study. Bull. WHO 2009, 87, 345-352.

23. Rehmani, R.; Leblanc, J.C. Home visits reduce the number of hazards for childhood home injuries in Karachi, Pakistan: A randomized controlled trial. Int. J. Emerg. Med. 2010, 3, 333-339.

24. Hyder, A.A.; Chandran, A.; Khan, U.R.; Zia, N.; Huang, C.M.; de Ramirez, S.S.; Razzak, J. Childhood unintentional injuries: Need for a community-based home injury risk assessments in Pakistan. Int. J. Pediatr. 2012, 2012, doi: 10.1155/2012/203204.

25. Wong, C.X.; Carson, K.V.; Smith, B.J. Home care by outreach nursing for chronic obstructive pulmonary disease. Cochrane Database Syst. Rev. 2012, 4, CD000994, doi:10.1002/ 14651858.CD000994.pub2.

26. Viswanathan, M.; Kraschnewski, J.; Nishikawa, B.; Morgan, L.C.; Thieda, P.; Honeycutt, A.; Lohr, K.N.; Jonas, D. Outcomes of Community Health Worker Interventions; Rockville (MD): Rockville, USA, 2009; pp. 1-144, Evidence Reports/Technology Assessments, No. 181.

27. Viswanathan, M.; Kraschnewski, J.L.; Nishikawa, B.; Morgan, L.C.; Honeycutt, A.A.; Thieda, P.; Lohr, K.N.; Jonas, D.E. Outcomes and costs of community health worker interventions: A systematic review. Med. Care 2010, 48, 792-808.

28. Lewin, S.; Munabi-Babigumira, S.; Glenton, C.; Daniels, K.; Bosch-Capblanch, X.; van Wyk, B.E.; Odgaard-Jensen, J.; Johansen, M.; Aja, G.N.; Zwarenstein, M.; et al. Lay health workers in primary and community health care for maternal and child health and the management of infectious diseases. Cochrane Database Syst. Rev. 2010, CD004015, doi:10.1002/ 14651858.CD004015.pub3.

29. Forst, L.; Lacey, S.; Chen, H.Y.; Jimenez, R.; Bauer, S.; Skinner, S.; Alvarado, R.; Nickels, L.; Zanoni, J.; Petrea, R.; et al. Effectiveness of community health workers for promoting use of safety eyewear by Latino farm workers. Am. J. Ind. Med. 2004, 46, 607-613.

30. Marsh, P.; Kendrick, D.; Williams, E.I. Health visitors' knowledge, attitudes and practices in childhood accident prevention. J. Public Health Med. 1995, 17, 193-199. 
Reprinted from Int. J. Environ. Res. Public Health. Cite as: Corso, P.S.; Ingels, J.B.; Roldos, M.I. A Comparison of Willingness to Pay to Prevent Child Maltreatment Deaths in Ecuador and the United States. Int. J. Environ. Res. Public Health 2013, 10, 1342-1355.

Article

\title{
A Comparison of Willingness to Pay to Prevent Child Maltreatment Deaths in Ecuador and the United States
}

\section{Phaedra S. Corso ${ }^{1, *}$, Justin B. Ingels ${ }^{1}$ and M. Isabel Roldos ${ }^{2}$}

1 College of Public Health, University of Georgia, 110 E. Clayton Street, Suite 300, Athens, GA 30602, USA; E-mail: jingels@uga.edu

2 School of Medicine, Universidad San Francisco de Quito, Quito EC170157, Ecuador;

E-Mail: mroldos@usfq.edu.ec

* Author to whom correspondence should be addressed; E-Mail: pcorso@uga.edu;

Tel.: +1-706-369-5958; Fax: +1-706-369-5997.

Received: 18 February 2013; in revised form: 21 March 2013 / Accepted: 21 March 2013 /

Published: 28 March 2013

\begin{abstract}
Estimating the benefits of preventing child maltreatment (CM) is essential for policy makers to determine whether there are significant returns on investment from interventions to prevent CM. The aim of this study was to estimate the benefits of preventing $\mathrm{CM}$ deaths in an Ecuadorian population, and to compare the results to a similar study in a US population. The study used the contingent valuation method to elicit respondents' willingness to pay (WTP) for a 1 in 100,000 reduction in the risk of CM mortality. After adjusting for differences in purchasing power, the WTP to prevent the CM mortality risk reduction in the Ecuador population was \$237 and the WTP for the same risk reduction in the US population was $\$ 175$. In the pooled analysis, WTP for a reduction in $\mathrm{CM}$ mortality was significantly impacted by country $(p=0.03)$, history of CM $(p=0.007)$, payment mechanism $(p<0.001)$, confidence in response $(p=0.014)$, and appropriateness of the payment mechanism $(p<0.001)$. These findings suggest that estimating benefits from one culture may not be transferable to another, and that lowand middle-income countries, such as Ecuador, may be better served by developing their own benefits estimates for use in future benefit-cost analyses of interventions designed to prevent $\mathrm{CM}$.
\end{abstract}

Keywords: child maltreatment (CM); economic evaluation; willingness-to-pay (WTP); benefit-cost analysis (BCA); contingent valuation $(\mathrm{CV})$ surveys 


\section{Introduction}

Economic evaluation methods, such as benefit-cost analysis (BCA), are increasingly being used to show returns on investment of violence prevention interventions. BCA includes a comparison of an intervention's costs to an intervention's benefits measured in monetary units. The challenge, however, in using BCA is trying to put a monetary value on the benefits of these interventions, such as preventing child maltreatment (CM) morbidity or mortality [1,2]. While the field has made considerable progress in estimating the value of preventing $\mathrm{CM}$ events from a human capital perspective (e.g., valuing medical costs and productivity losses averted) [2-6], these estimates are invariably an underestimate of the true benefit of preventing a case of CM because long-term effects are hard to quantify, impacts on quality of life are not included, and it fails to capture any intangible benefits that may be at least as important to taxpayers $[6,7]$.

Another methodology to value the benefits of preventing violent outcomes for use in a BCA is the contingent valuation (CV) method. The CV methodology relies on surveys to elicit the subjective value that individuals place on public goods that are not traded in the marketplace, such as clean air or clean water, or for a violence-free society in our example [8]. The logic of the CV method is that respondents are asked to think about the public good as if it could be purchased in the marketplace (that is, contingent upon an actual market), and then they are asked how much they would be willing to pay for it. As such, respondents' willingness-to-pay (WTP) amount is a reflection of the value they place on the public good, that can thus be used as the benefits measure in a BCA. For example, Ludwig and Cook $[9,10]$, in a CV study of respondents being asked to value the prevention of violence caused by firearms, found that respondents' total WTP to reduce gun violence by $30 \%$ equaled $\$ 1.2$ million per injury (in 1998 US\$). Coupled with the programmatic costs associated with preventing gun violence, this benefits measure could be very useful in a future BCA of a gun violence prevention intervention.

Other studies have also applied the CV methodology to estimate the benefits of preventing violent outcomes [11-13]. For example, Cohen, Rust, Steen and Tidd [12] asked respondents if they would be willing to vote for a proposal requiring each household in their community to pay a certain amount to be used to prevent one in ten crimes in their community. Atkinson, Healey and Mourato [11] similarly asked respondents how much they would be willing to pay to reduce their risks for various types of crimes and their risks of victimization.

Only a few studies have used the CV approach for valuing the benefits of preventing CM. Corso et al. [14] valued the benefits of preventing CM deaths and Shadoin [15] valued how much of $\$ 100$ respondents would be willing to pay for programs to prevent child abuse deaths, sexual abuse and physical abuse. The former study reported a mean WTP per person of \$148 (in 2008 US\$) and a median of \$151 (in 2008 US\$), for a 1 in 100,000 reduction in the mortality risk associated with CM. The latter study reported a significant positive correlation between WTP for prevention of $\mathrm{CM}$ and both knowledge of child $\mathrm{CM}$ and self-reported empathy of the respondent.

The application of the CV methodology as a benefits measure in BCAs is quite limited outside the United States, and virtually non-existent in the field of violence prevention. Perhaps because of this realization, the World Bank [1] and others [16] note the value of being able to transfer benefits obtained from the United States to low- and middle-income countries using the CV method by stating 
that "the simplicity of CV methodology allows for application of the same questionnaire, implying the same set of changes in outcomes, to be applied in different areas, regions, or countries [1]." In contrast, valuing the benefits of violence prevention based on medical costs averted is not as readily transferable across countries because of differences in national health care systems, public health interventions, and criminal justice systems.

To that end, in this study we apply, for the first time ever, the CV methodology to assess the benefits of preventing CM mortality in the middle-income country of Ecuador. Second, we compare the values that respondents in Ecuador place on preventing CM deaths with values previously obtained in the United States [14], to determine if it is possible to transfer the benefits obtained from one country to another for use in BCAs.

\section{Methods and Results}

\subsection{Data Collection}

The initial CV survey to elicit WTP to prevent CM deaths in the United States was conducted by telephone interview in Fall 2008 among a randomly selected sample of adult residents. A full description of the study sample, methods, and results of the US study are published elsewhere [14]. For this study, the original CV survey conducted in English in the United States was translated into Spanish and conducted by in-person interviews between February and June 2012, with a convenience sample of adult residents living in two cities in Ecuador, Quito and Guayaquil. Participants were recruited at utility payment centers in both cities to capture different social demographic gradients. Utility payment centers are located across the cities in different localities including shopping malls, community centers, and small shops. Following consent, participants were taken to a secluded area to conduct the survey. The questions were read to each participant and the research team recorded their answers on a paper version of the survey. Less than $1 \%$ of potential participants declined the survey. Each survey took between 15 and $20 \mathrm{~min}$, and as compensation participants were given a $\$ 15$ phone card.

The CV survey included several separate verbal protocols to establish the "contingent" market. For example, respondents were first presented with a range of questions asking their opinion about maternal and child health issues, before being asked to state their WTP to reduce CM deaths in their community. Respondents were given the following prompt:

"Now imagine there is a program available to your city or town that is proven to be effective in reducing the risk of a child being killed by a parent or caretaker by $50 \%$. This means that the number of children killed on average by child maltreatment in your community is reduced from 2 per 100,000 to 1 per 100,000 per year."

If the respondent was randomized to a question about a payment mechanism through taxes, the following question was asked.

"If this program were available to your city or town, would you be willing to pay [randomly selected dollar amount] in extra taxes per year to sponsor this program given your household income and other expenses?" 
Otherwise, the respondent was asked about a payment mechanism through donations and the following question was asked.

"The prevention program will be paid for by contributions from area residents, and cannot be started unless a minimum amount of money is raised from people like yourself. Would you be willing to donate [randomly selected dollar amount] to sponsor this program given your household income and other expenses?"

We used the double-bounded dichotomous choice CV method [8]. With this approach, we first provided respondents with an initial WTP value, to which they responded "yes" or "no", followed by a second WTP value that was either higher (yes) or lower (no) than the first WTP value, depending on the answer to the first question. To correct for potential starting point bias [8], the initial WTP values of $\$ 10$ to $\$ 300$ (in Ecuador US\$) were randomly selected, and pre-determined in a pilot study. The second WTP values presented were either \$25 higher (if first response was "yes") or \$25 lower (if first response was "no"). By comparison, in the US study [14], the initial WTP values were $\$ 25$ to $\$ 275$ (in US\$) and the second bid value was randomly selected as some amount higher (or lower) than the initial bid value, not constrained by $\$ 25$ more or less.

Because the literature $[9,10]$ suggests that WTP for a risk reduction in mortality caused by violence is influenced by exposure to violence and the perception of the violence in one's own community, the survey also asked respondents to describe their perception of CM prevalence in their community, and to report their exposure to abuse and neglect during childhood. Perception of $\mathrm{CM}$ risk in the neighborhood was coded as a categorical variable and equal to 1 if respondents reported that the risk was "somewhat less" or "much less" than average, equal to 2 if the neighborhood risk was considered "about average", and equal to 3 if the risk was considered either "much greater" or "somewhat greater" than average. History of CM was coded as a dichotomous variable and equal to 1 if the respondent reported any act of physical abuse, sexual abuse, or neglect during childhood, and equal to 0 otherwise.

To test for bias in the amount respondents' were willing to pay for reductions in CM deaths based on the mechanism of payment, we asked respondents in a split sample either WTP in taxes or WTP in donations. We also asked about the appropriateness of the payment vehicle and how confident they were in their responses. In the comparison CV study conducted by Corso, Fang and Mercy [14], the authors found that payment mechanism did make a difference in WTP, with taxes producing significantly higher WTP compared to donations. These results are corroborated by Wiser [17] who found that respondents typically stated a higher WTP when confronted with a collective payment mechanism compared to a voluntary payment mechanism.

Finally, we collected data on several socio-demographic characteristics that have been shown to influence WTP in other studies, including age, gender, race/ethnicity, and income. For example, there is strong evidence that income, which is correlated with age, gender, and race/ethnicity, significantly and positively affects WTP [18]. We added both age and age squared into the regression to account for the possible non-linear relationship between age and WTP [19-21]. 


\subsection{Analysis}

We did not directly observe a respondent's WTP for a reduction in mortality related to CM. However, we assumed a WTP value $Y_{i} *$ that is represented by the model $Y_{i} *=X_{i} \beta+\varepsilon_{i}$, where the $\varepsilon_{i}$ are normally distributed with a mean zero and the $X_{i}$ represent individual respondent characteristics. While $Y_{i}$ * was not directly observed for respondent $i$, it is known to lie in the interval $\left[Y_{i 1}, Y_{i 2}\right]$ based on responses elicited in the $\mathrm{CV}$ survey and the corresponding likelihood contribution is:

$$
\operatorname{Pr}\left(Y_{i 1} \leq Y_{i}^{*} \leq Y_{i 2}\right)=\operatorname{Pr}\left(Y_{i 1} \leq X_{i} \beta+\epsilon_{i} \leq Y_{i 2}\right)
$$

When an upper bound is unknown (right-censored data) the likelihood contribution is:

$$
\operatorname{Pr}\left(Y_{i 1} \leq X_{i} \beta+\epsilon_{i}\right)
$$

and when a lower bound is unknown (left-censored data), we set a lower bound of zero, and the likelihood contribution is:

$$
\operatorname{Pr}\left(0 \leq X_{i} \beta+\epsilon_{i} \leq Y_{i 2}\right)
$$

The maximum likelihood function was estimated with interval regression using the intreg command in Stata version 12 (Stata Corp, College Station, TX, USA).

The 2012 US\$ reported in the Ecuador study were modified to reflect the purchasing power parity (PPP) of Ecuador\$ compared to the PPP of US\$, 0.55 [22]. The PPP is the amount of Ecuador US\$ needed to purchase a similar amount of goods and services that $\$ 1.00$ would buy in the United States. Therefore, a lower bound of \$100 in Ecuador US\$ is divided by 0.55 for a result of $\$ 181.82$ in US\$.

Second, to test for cross-country differences in WTP to prevent CM deaths, we combined the Corso, Fang and Mercy [14] CV survey data from the United States with the survey data collected in Ecuador for this study. To make values elicited from the two populations comparable, the 2008 US\$ from the US respondents were converted to 2012 US\$ using the all-items component of the Consumer Price Index [23]. We used interval regression with the combined datasets to test for a significant difference in the WTP values reported by the two groups. Demographic and covariate values were included in the combined analysis to control for differences in the two study groups. Finally, we estimated the mean WTP value for each country's sample using interval regression without any demographic or covariate variables (referred to herein as "covariate unadjusted"). Bootstrapped standard errors (1,000 replications) were used to calculate bias-corrected 95\% confidence intervals (CIs) on the mean WTP [24]. All results presented herein are in 2012 US\$.

\subsection{Results}

Table 1 provides a summary of the demographic characteristics and other covariates of the Ecuador respondents for the $\mathrm{N}=290$ respondents that completed the CV survey on WTP to prevent $\mathrm{CM}$ deaths within the community. Most of the respondents were of Mestizo ethnicity (84.8\%) and younger than 35 years of age (mean $=32.6)$. The respondents were evenly split by gender $(50.3 \%)$ and $\mathrm{CM}$ history (50.7\%). Household income was reported by the respondents as follows: $51.7 \%$ reported an income of $\$ 5,000$ or less, $26.9 \%$ reported an income greater than $\$ 5,000$ but less than 
$\$ 10,000,10.7 \%$ reported an income greater than $\$ 10,000$ but less than $\$ 15,000$, and $10.3 \%$ reported an income greater than $\$ 15,000$. Respondents reporting a household income of less than $\$ 15,000$ were classified as low income (89.3\%), and the remaining were classified as high income (10.3\%), while only one respondent did not report income. Approximately $65.9 \%$ of the respondents believed the risk of $\mathrm{CM}$ in their community was greater than or equal to the average risk presented (2 per 100,000); $12.1 \%$ of the respondents perceived a lower risk. A little more than half (56.9\%) of the study population felt confident in their ability to pay for a CM program at the values presented; $60.7 \%$ of the respondents stated that the payment mechanism with which they were presented was the appropriate mechanism for funding such a program. The population of Ecuador is $71.9 \%$ mestizo while the mean adult age is around 40 years of age and $51 \%$ female [25]. The CV survey respondents were younger than the general adult population but with a similar ethnic and gender breakdown.

Table 1. Respondent Demographics: Ecuador $(\mathrm{N}=290)$, United States $(\mathrm{N}=199)$ and Combined, Ecuador and United States $(\mathrm{N}=489)$.

\begin{tabular}{|c|c|c|c|c|}
\hline & $\begin{array}{c}\text { Ecuador } \\
\text { Respondents }^{\text {a }} \\
\end{array}$ & $\begin{array}{c}\text { US } \\
\text { Respondents }^{\text {a }} \\
\end{array}$ & $\begin{array}{c}\text { Diff. } \\
p \text {-value } \\
\text { b }^{\mathrm{b}}\end{array}$ & Ecuador + US ${ }^{\text {a }}$ \\
\hline Age, years & $32.6(10.9)$ & $48.9(17.2)$ & $<0.001$ & $39.3(16.0)$ \\
\hline Female & 50.3 & 68.8 & $<0.001$ & 57.9 \\
\hline Race/Ethnicity & & & $<0.001$ & \\
\hline Mestizo & 84.8 & 0.0 & & 50.3 \\
\hline White & 9.3 & 64.3 & & 31.7 \\
\hline Black & 4.5 & 25.6 & & 13.1 \\
\hline Other & 1.3 & 11.1 & & 5.3 \\
\hline Household income, $\$^{c}$ & & & $<0.001$ & \\
\hline Low & 89.3 & 12.1 & & 51.5 \\
\hline High & 10.3 & 65.8 & & 39.3 \\
\hline Missing & 0.03 & 22.1 & & 9.2 \\
\hline CM history & 50.7 & 27.6 & $<0.001$ & 41.3 \\
\hline Neighborhood CM risk & & & $<0.001$ & \\
\hline$<$ Average & 12.1 & 45.7 & & 25.8 \\
\hline About average & 21.1 & 31.7 & & 26.0 \\
\hline$>$ Average & 65.9 & 17.1 & & 46.0 \\
\hline Missing & 0.0 & 5.5 & & 2.2 \\
\hline WTP by increased taxes & 44.8 & 53.8 & 0.052 & 48.5 \\
\hline Confident in ability to pay & 56.9 & 55.8 & 0.807 & 56.4 \\
\hline Appropriate payment mechanism & 60.7 & 70.4 & 0.028 & 64.6 \\
\hline
\end{tabular}

${ }^{\mathrm{a}}$ Mean (standard deviation) reported for age and percentage of respondents for all other variables. ${ }^{\mathrm{b}}$ Based on two-sample $t$-tests for age and chi-square tests for the other variables. ${ }^{c}$ Income levels used in comparing respondents from Ecuador and the United States. The Ecuador respondents reporting non-PPP adjusted income of $\$ 15,000$ (PPP-adjusted $\approx \$ 27,000$ ) or less classified as low and all other non-missing as high. For the United States, respondents reporting income of $\$ 25,000$ or less were classified as low and all other non-missing as high. 
The demographics and other covariates of US respondents $(\mathrm{N}=199)$ and for respondents in the combined (Ecuador and US) analysis are also reported in Table $1(\mathrm{~N}=489)$. The Ecuador and US respondents differed in a number of ways, based on a two-sample $t$-test for age, and chi-square tests for the other variables. The US respondents were significantly different from the Ecuador respondents in most demographic categories. They were, on average, 16 years older $(p<0.001)$, wealthier $(p<0.001)$, and included mostly white $(p<0.001)$ and female respondents $(p<0.001)$. The cutoff for high and low income of $\$ 25,000$ was selected to make the reported incomes comparable. For Ecuador, an income of $\$ 15,000$ when PPP-adjusted is near $\$ 27,000$. Therefore, defining respondents from Ecuador with a household income below $\$ 15,000$ is roughly comparable to respondents in the United States with a household income below $\$ 25,000$.

The US respondents were also much less likely to report any history of abuse $(p<0.001)$ compared to the Ecuadorian respondents. Further, a higher proportion of the US respondents believed that the CM risk in their own neighborhood was less than average $(p<0.001)$, and a higher proportion believed the payment mechanism they were provided was appropriate $(p=0.028)$. However, both groups reported similar confidence in their ability to pay the presented value $(p=0.807)$.

Table 2 presents the results of the interval regression using data from the CV survey conducted in Ecuador. The likelihood ratio chi-square $(30.95, p=0.003)$ indicates that the model is statistically significant compared to the constant-only model.

Table 2. Interval Regression Results of WTP for Reducing the Risk of CM Mortality by 1 in 100,000: Ecuador $(\mathrm{N}=290)$.

\begin{tabular}{lcc}
\hline & Regression & p-value \\
\hline Coefficient & 3.42 & 0.515 \\
Age & -0.05 & 0.472 \\
Non-Mestizo (Ref) & 1.00 & \\
Mestizo & 12.08 & 0.642 \\
Male (Ref) & 1.00 & \\
Female & 11.13 & 0.568 \\
Neighborhood CM risk < average (Ref) & 1.00 & \\
Neighborhood CM risk > average & 26.19 & 0.388 \\
Neighborhood CM risk about average & -0.09 & 0.998 \\
Low household income (Ref) & 1.00 & \\
High household income & 17.86 & 0.490 \\
No history of CM (Ref) & 1.00 & \\
History of CM & -55.96 & 0.018 \\
Pay through donation (Ref) & 1.00 & \\
Pay through taxes & 44.85 & 0.017 \\
Not confident in ability to pay for program (Ref) & 1.00 & \\
Confidence in ability to pay for program & -63.75 & 0.001 \\
Not appropriate payment mechanism (Ref) & 1.00 & \\
Appropriate payment mechanism & 36.17 & 0.064 \\
Constant & 172.41 & \\
Likelihood ratio chi-square (df) & $30.95(13)$ & 0.003 \\
\hline
\end{tabular}


The constant term from the regression, reported in Table 2, corresponds to the estimated WTP value if a respondent was age 0 and reported the reference level for the other demographic covariates. Therefore, the regression coefficients reported in Table 2, estimate the adjustment to the reference WTP value for a respondent reporting demographics other than the reference level. To validate these estimates of WTP, economic theory [8] predicts that the proportion of "yes" responses to the initial bid value should decrease with an increasing bid value. For the Ecuador respondents, $100 \%$ with an initial bid of $\$ 10$ responded "yes" which decreased almost monotonically to a "yes" response rate of $11 \%$ with an initial bid of $\$ 300$. The results of the interval regression using data from the US population are reported elsewhere [14].

There were three significant predictors $(p<0.05)$ of WTP to reduce CM deaths in the Ecuador population: history of $\mathrm{CM}(p=0.018)$, payment through taxes $(p=0.017)$, and confidence in ability to pay $(p=0.001)$. Respondents reporting any history of CM were willing to pay $\$ 56$ (or $24 \%)$ less than those without a history of abuse. A similar (20\% less), but non-significant, result was found with US respondents [13]. Respondents asked to pay taxes were also willing to pay \$36 (or 21\%) more than those asked to make charitable donations. A much larger significant result was found with US respondents [13], where respondents asked to pay taxes were willing to pay twice as much as those asked to pay in donations. Respondents who were confident in their ability to pay the presented value were willing to pay roughly $\$ 64$ (or 27\%) less than respondents lacking confidence. This was not a significant predictor reported for the US respondents [14].

In the interval regression for the combined analysis, the likelihood ratio chi-square (71.73, $p<0.001$ ) indicates that the model is statistically significant compared to the constant-only model. The coefficient specifying country was significant $(p=0.031)$ and equal to -63.87 (see Table 3 ). This result suggests that the US respondents were willing to pay almost $\$ 64$ (or 27\%) less than the Ecuador respondents, for the same reduction in the risk of death associated with $\mathrm{CM}$, after adjusting for demographic and other covariates. Four significant predictors $(p<0.05)$ of WTP were found for the combined analysis, as reported in the interval regression results in Table 3: history of $\mathrm{CM}(p=0.007)$, payment through taxes $(p<0.001)$, confidence in ability to pay $(p=0.014)$, and appropriateness of the payment mechanism $(p<0.001)$.

Table 3. Interval Regression Results of WTP for Reducing the Risk of CM Mortality by 1 in 100,000: Ecuador and the United States $(\mathrm{N}=498)$.

\begin{tabular}{lcc}
\hline & Regression Coefficient & $\boldsymbol{p}$-Value \\
\hline Ecuador (Ref) & 1.00 & \\
US & $-\mathbf{6 3 . 8 7}$ & $\mathbf{0 . 0 3 1}$ \\
Age & -1.53 & 0.524 \\
Age squared & 0.02 & 0.557 \\
Non-White/Non-Mestizo (Ref) & 1.00 & \\
White & 16.66 & 0.418 \\
Mestizo & 27.93 & 0.304 \\
Male (Ref) & 1.00 & \\
Female & -2.82 & 0.842 \\
Neighborhood CM risk $<$ average (Ref) & 1.00 & \\
Neighborhood CM risk $>$ average & 29.08 & 0.129 \\
\hline
\end{tabular}


Table 3. Cont.

\begin{tabular}{lcc}
\hline & Regression Coefficient & $\boldsymbol{p}$-Value \\
\hline Neighborhood CM risk about average & -1.20 & 0.949 \\
Low household income (Ref) & 1.00 & \\
High household income & 16.25 & 0.417 \\
No history of CM (Ref) & 1.00 & \\
History of CM & -43.37 & 0.007 \\
Pay through donation (Ref) & 1.00 & \\
Pay through taxes & 54.52 & $<0.001$ \\
Not confident in ability to pay for program (Ref) & 1.00 & \\
Confidence in ability to pay for program & -33.74 & 0.014 \\
Not appropriate payment mechanism (Ref) & 1.00 & \\
Appropriate payment mechanism & 63.34 & $<0.001$ \\
Constant & 203.12 & \\
Likelihood ratio chi-square (df) & $71.73(16)$ & $<0.001$ \\
\hline
\end{tabular}

Similar interval regression analyses were carried out for respondents asked to consider the donation and taxes payment mechanisms separately (results not shown). The coefficient specifying country for the donation group was significant $(-72.4 ; p=0.050)$, yet was not significant for the taxes group $(-61.4 ; p=0.193)$. Therefore, we considered including in the full regression an interaction term of payment mechanism by country. This interaction term was not significant, but due to the small sample size and the limited power to detect differences in this population, we cannot make any definitive conclusions from this result.

Finally, Table 4 presents the covariate unadjusted mean estimates of WTP for a $50 \%$ reduction in the risk of death associated with CM for the Ecuador and US respondents. For the Ecuador respondents, the mean estimated WTP was $\$ 237$ (95\% CI = \$215, \$259). For the US respondents, the mean estimated WTP was $\$ 175(95 \%$ CI $=\$ 154, \$ 199)$. The difference in mean WTP between Ecuador and US respondents was $\$ 62$, which is similar to the estimated difference from the pooled regression analysis reported in Table 3. Furthermore, the 95\% CIs around the mean WTP values from the combined analysis do not overlap, further evidence of a significant difference in the WTP estimates.

Table 4. Estimated Mean WTP and 95\% CI for Reducing the Risk of CM Mortality by 1 in 100,000: Ecuador and the United States.

\begin{tabular}{lcc}
\hline & Mean WTP $^{\mathbf{a}}$ & $\mathbf{9 5 \%}$ CI $^{\mathbf{b}}$ \\
\hline Ecuador $(\mathrm{N}=290)$ & $\$ 237$ & $\$ 215, \$ 259$ \\
$\mathrm{US}^{\mathrm{c}}(\mathrm{N}=199)$ & $\$ 175$ & $\$ 154, \$ 199$ \\
\hline
\end{tabular}

${ }^{a}$ All WTP values are expressed in 2012 US\$, based on a PPP of 0.55 Ecuador\$ per US\$. ${ }^{b}$ Bias-corrected CIs based on 1000 bootstrap replications. ${ }^{c}$ Mean estimate differs from that reported by [14] as that estimate was covariate-adjusted, in 2008 US\$, and the lower bound treated as missing rather than a zero (see Equation 3).

\section{Discussion}

This article estimates the benefits measure for reductions in CM deaths using CV methods in an Ecuadorian population, as compared to previous estimates obtained from a US population. 
The findings suggest that WTP values are different between the two countries, even when making the necessary PPP adjustments, with the Ecuador population valuing a 1 in 100,000 CM mortality risk reduction of $\$ 237$ and the US population valuing the same risk reduction as $\$ 175$. Our results are similar to those in Alberini et al. [26-28], Carlsson et al. [29], Ready et al. [30], and Rozan [31] who showed that WTP for the same mortality risk reductions differed across countries in ways not related to observable characteristics. For example, Alberini, Hunt and Markandya [27] found that WTP to reduce mortality risks remained significantly different across populations in the United Kingdom, Italy and France, even after WTP bids and household income figures were converted into PPP-adjusted amounts.

In fact, Alberini et al. [32] argue that preferences and WTP may differ across countries for cultural, income and access issues:

"There is no reason why the preferences of people in other countries should be identical to preferences in the United States. Cultural factors, especially those that affect perceptions of illness, may alter people's willingness to trade income for health. Along with income differentials, differences in health and educational status and the availability and cost of health care are some additional reasons to expect differences in such trade-offs."

This suggests that cultural differences and different sensitivities to the "good" being valued may result in systematic differences in WTP, even after controlling for observable characteristics of the populations.

One hint of a cultural difference between the United States and Ecuador in this assessment of $\mathrm{CM}$ mortality is the significant difference in the proportion of respondents indicating abuse or neglect as a child, with nearly $50 \%$ of the Ecuadorian population reporting exposure to $\mathrm{CM}$ and a little more than $25 \%$ of the US population reporting exposure. This self-reported history of child abuse could be a real difference in population-level prevalence of CM that might impact WTP, a difference in the comfort level of reporting abuse, or cultural differences in how CM is defined. Without having actual records of CM available for these respondents or follow-up questions to ask about comfort level with the survey questions, the true prevalence of CM in this population is not known. However, assuming that the reported CM rates are an accurate reflection of the prevalence of CM in the study population, one might expect that WTP to prevent CM would be higher based on the greater knowledge and exposure to the risk under assessment. For example, Leiter and Pruckner [33] and Deshazo and Cameron [34] have reported that exposure to a risk significantly and positively impacts WTP to reduce that risk. In contrast, we report that exposure to CM significantly decreased WTP to prevent CM deaths in the Ecuadorian population. In the other two studies of WTP to prevent CM mortality in the United States [14,15], one found that personal history of abuse decreased WTP to prevent CM deaths [14] and the other [15] found that history of abuse increased WTP to prevent CM deaths, yet neither were significant.

Alternatively, it could be that the Ecuadorian population is willing to pay more to prevent $\mathrm{CM}$ deaths because they believe that the risk is much greater than what is being reported in the "contingent" market described in the survey. For example, Hunter et al. [35] found that for respondents presented with a CV survey who perceived the presented risks as being lower (higher) 
than the actual risks, they consequently reported significantly lower (higher) WTP values. In this study, $66 \%$ of the Ecuadorian respondents stated that they perceived the CM mortality risk to be greater than the average risk ( 2 in 100,000) reported in the survey, whereas only $17 \%$ of the US respondents reported that they perceived the risk to be greater than the reported average. Therefore, following Hunter et al. [35], we might expect for the WTP to prevent CM mortality to be higher in the Ecuadorian population compared to the US population because of the perception of underlying risk in the community. However, as shown in Table 2, perception of risk did not significantly impact WTP to prevent CM deaths in the full regression of the Ecuador data. The same result holds true for the US respondents [14].

Where the WTP estimates from Ecuador and the United States coincide is the impact of payment mechanism on WTP to prevent CM. In both populations, those respondents asked to pay in taxes (versus donations) were willing to pay more to prevent $\mathrm{CM}$ deaths. As corroborated by Wiser [17] and others [36,37], taxes as a payment vehicle are more acceptable when considering goods that affect the whole of society, like violence.

Two important caveats to our study are that the Ecuador sample is not a national, randomly selected sample and the method of data collection differed between the two comparison studies. First, although the comparison sample from the United States [14] was also from a single geographic region, respondents were randomly selected. Thus, these results should be generalized to the broader national populations respectively, with caution. Second, the interview format, which was face-to-face in Ecuador compared to via telephone in the United States, may bias the WTP estimates if respondents are influenced by what they think the interviewer wants to hear, or if respondents experience embarrassment or shame in self-reporting abuse. In either case, it is not clear in which direction the WTP to prevent CM deaths would be biased. Although there are other limitations with the $\mathrm{CV}$ method for estimating WTP to prevent mortality risks in general (like stated preferences being higher than what persons might actually pay out-of-pocket), these biases would be present in both studies because the same CV instrument was used, and therefore not relevant to the cross-country comparison conducted here.

\section{Conclusions}

An important question when performing BCAs of CM interventions in low- to middle-income countries is whether estimates of WTP computed in the United States can be used as a benefits measure. Administering the same CV survey in two countries allowed us to explore the issue whether WTP to prevent CM deaths varies across different populations. We found that the respondents' country did significantly predict WTP even after controlling for individual characteristics likely to be associated with WTP. The results from this study suggest that countries might be better served to design original CV studies to value the benefits of preventing $\mathrm{CM}$ if they want to conduct a BCA of prevention interventions.

The only way to parse out what really lies behind one population's WTP to prevent CM death relative to another population's WTP is to supplement these CV surveys with additional questions about how one defines $\mathrm{CM}$ and questions that begin to explain preferences and factors that influence WTP to prevent CM. At a minimum, the results from this study suggest that payment 
mechanism is one preference that may influence whether and how much one is willing to pay to prevent CM deaths and that this preference may hold across different cultures.

A real strength to this research, as with the study results reported from the comparison sample in the United States [14], is a benefits estimate for preventing a death associated with CM in Ecuador. That is, if each person is willing to pay more than $\$ 200$ to reduce the number of deaths resulting from CM by 1 in 100,000 per year, then the value of one child's life saved in a population of 100,000 is $\$ 20$ million. This represents a significant value that society places on preventing a death from CM. Once this benefits estimate is validated nationally, and coupled with evidence of effective programs, policies and interventions to prevent CM mortality and their costs, these data will prove useful to policy makers considering how to allocate scarce public resources to improve the lives of children.

\section{Acknowledgments}

Funding for the Ecuador data collection was provided through the Compton Foundation International Fellowship and Population Reference Bureau.

\section{Conflicts of Interest}

The authors declare no conflict of interest.

\section{References}

1. Skaperdas, S.; Soares, R.; Willman, A.; Miller, S.C. The Costs of Violence; Social Development Department, The World Bank: Washington, DC, USA, 2009.

2. Waters, H.; Hyder, A.; Rajkotia, Y.; Basu, S.; Rehwinkel, J.A.; Butchart, A. The Economic Dimensions of Interpersonal Violence; Department of Injuries and Violence Prevention, World Health Organization: Geneva, Switzerland, 2004.

3. Fang, X.M.; Brown, D.S.; Florence, C.S.; Mercy, J.A. The economic burden of child maltreatment in the United States and implications for prevention. Child Abuse Neglect 2012, 36, 156-165.

4. Wang, C.-T. Total Estimated Cost of Child Abuse and Neglect in the United States; Prevent Child Abuse America: Chicago, IL, USA, 2007.

5. Fromm, S. Total Estimated Cost of Child Abuse and Neglect in the United States; Prevent Child Abuse America: Chicago, IL, USA, 2001.

6. Corso, P.S.; Fertig, A.R. The economic impact of child maltreatment in the united states: Are the estimates credible? Child Abuse Neglect 2010, 34, 296-304.

7. Prosser, L.A.; Corso, P.S. Measuring health-related quality of life for child maltreatment: A systematic literature review. Health Qual. Life Out. 2007, 5, doi: 10.1186/1477-7525-5-42.

8. Mitchell, R.C.; Carson, R.T. Using Surveys to Value Public Goods: The Contingent Valuation Method; Resources for the Future: Washington, DC, USA, 1989.

9. Ludwig, J.; Cook, P.J. The benefits of reducing gun violence: Evidence from contingent-valuation survey data. J. Risk Uncertainty 2001, 22, 207-226. 
10. Cook, P.J.; Ludwig, J. Gun Violence: The Real Costs; Oxford University Press: New York, NY, USA, 2000.

11. Atkinson, G.; Healey, A.; Mourato, S. Valuing the costs of violent crime: A stated preference approach. Oxford Econ. Pap. 2005, 57, 559-585.

12. Cohen, M.A.; Rust, R.T.; Steen, S.; Tidd, S.T. Willingness-to-pay for crime control programs. Criminology 2004, 42, 89-109.

13. Nagin, D.S.; Piquero, A.R.; Scott, E.S.; Steinberg, L. Public Preferences for Rehabilitation versus Incarceration of Juvenile Offenders: Evidence from a Contingent Valuation Survey; The Berkeley Electronic Press: Berkeley, CA, USA, 2006.

14. Corso, P.S.; Fang, X.M.; Mercy, J.A. Benefits of preventing a death associated with child maltreatment: Evidence from willingness-to-pay survey data. Am. J. Public Health 2011, 101, 487-490.

15. Shadoin, A.L. Demographic and Attitudinal Characteristics Predicting Taxpayer Willingness to Pay for Child Maltreatment Prevention; National Children's Alliance: Washington, DC, USA, 2007.

16. Krupnick, A.J. The Benefits of Ambient Air Quality Improvements in Central and Eastern Europe: A Preliminary Assessment; Energy and Natural Resources Division, Resources for the Future: Washington, DC, USA, 1993.

17. Wiser, R.H. Using contingent valuation to explore willingness to pay for renewable energy: A comparison of collective and voluntary payment vehicles. Ecol. Econ. 2007, 62, 419-432.

18. Carson, R.T.; Mitchell, R.C. The value of clean water-The publics willingness-to-pay for boatable, fishable, and swimmable quality water. Water Resour. Res. 1993, 29, 2445-2454.

19. Johannesson, M.; Johansson, P.O.; Lofgren, K.G. On the value of changes in life expectancy: Blips versus parametric changes. J. Risk Uncertainty 1997, 15, 221-239.

20. Johnson, F.R.; Banzhaf, M.R.; Desvousges, W.H. Willingness to pay for improved respiratory and cardiovascular health: A multiple-format, stated-preference approach. Health Econ. 2000, 9, 295-317.

21. Jones-Lee, M.W.; Hammerton, M.; Philips, P.R. The value of safety-Results of a national sample survey. Econ J. 1985, 95, 49-72.

22. International Comparison Program. Available online: http://data.worldbank.org/data-catalog/ international-comparison-program (accessed on 14 March 2012).

23. Consumer Price Index. Available online: ftp://ftp.bls.gov/pub/special.requests/cpi/cpiai.txt (accessed on 1 December 2012).

24. Efron, B. Better bootstrap confidence-intervals. J. Am. Stat. Assoc. 1987, 82, 171-185.

25. The World Factbook. Available online: www.cia.gov/library/publications/the-world-factbook/ geos/ec.html (accessed on 19 March 2013).

26. Alberini, A.; Cropper, M.; Krupnick, A.; Simon, N.B. Does the value of a statistical life vary with age and health status? Evidence from the US and Canada. J. Environ. Econ. Manag. 2004, 48, 769-792.

27. Alberini, A.; Hunt, A.; Markandya, A. Willingness to pay to reduce mortality risks: Evidence from a three-country contingent valuation study. Environ. Resour. Econ. 2006, 33, 251-264. 
28. Alberini, A.; Krupnick, A.; Cropper, M.; Simon, N.; Cook, J. The Willingness to Pay for Mortality Risk Reductions: A Comparison of the United States and Canada; FEEM Working Paper Series: Milano, Italy, 2001.

29. Carlsson, F.; Kataria, M.; Krupnick, A.; Lampi, E.; Lofgren, A.; Qin, P.; Chung, S.; Sterner, T. Paying for mitigation: A multiple country study. Land Econ. 2012, 88, 326-340.

30. Ready, R.; Navrud, S.; Day, B.; Dubourg, R.; Machado, F.; Mourato, S.; Spanninks, F.; Rodriquez, M.X.V. Benefit transfer in Europe: How reliable are transfers between countries? Environ. Resour. Econ. 2004, 29, 67-82.

31. Rozan, A. Benefit transfer: A comparison of WTP for air quality between France and Germany. Environ. Resour. Econ. 2004, 29, 295-306.

32. Alberini, A.; Cropper, M.; Fu, T.T.; Krupnick, A.; Liu, J.T.; Shaw, D.; Harrington, W. Valuing health effects of air pollution in developing countries: The case of Taiwan. J. Environ. Econ. Manag. 1997, 34, 107-126.

33. Leiter, A.J.; Pruckner, G. Dying in an Avalance: Current Risks and Valuation; University of Adelaide: Adelaide, Australia, 2005.

34. DeShazo, J.R.; Cameron, T.A. The Effect of Health Status on Willingness to Pay for Morbidity and Mortality Risk Reductions; California Center for Population Research, UC Los Angeles: Los Angeles, CA, USA, 2005.

35. Hunter, P.D.; Hanley, N.; Czajkowski, M.; Mearns, K.; Tyler, A.N.; Carvalho, L.; Codd, G.A. The effect of risk perception on public preferences and willingness to pay for reductions in the health risks posed by toxic cyanobacterial blooms. Sci. Total Environ. 2012, 426, 32-44.

36. Kontoleon, A.; Yabe, M.; Darby, L. Alternative Payment Vehicles in Contingent Valuation: The Case of Genetically Modified Foods; Department of Land Economy: Cambridge, UK, 2005.

37. Harris, C.C.; Brown, G. Gain, loss and personal responsibility: The role of motivation in resource valuation decision-making. Ecol. Econ. 1992, 5, 73-92. 
Reprinted from Int. J. Environ. Res. Public Health. Cite as: Simpson, J.; Fougere, G.; McGee, R. Injury and Social Correlates among in-School Adolescents in Four Southeast Asian Countries. Int. J. Environ. Res. Public Health 2013, 10, 1647-1664.

Article

\title{
A Wicked Problem: Early Childhood Safety in the Dynamic, Interactive Environment of Home
}

\section{Jean Simpson $^{1, *}$, Geoff Fougere ${ }^{2}$ and Rob McGee ${ }^{3}$}

1 Injury Prevention Research Unit, Department of Preventive \& Social Medicine, Dunedin School of Medicine, University of Otago, Dunedin 9054, New Zealand

2 Department of Public Health, Wellington School of Medicine, University of Otago, Wellington 6021, New Zealand; E-Mail: geoff.fougere@otago.ac.nz

3 Department of Preventive \& Social Medicine, Dunedin School of Medicine, University of Otago, Dunedin 9054, New Zealand; E-Mail: rob.mcgee@otago.ac.nz

* Author to whom correspondence should be addressed; E-Mail: jean.simpson@otago.ac.nz; Tel.: +64-3-479-8338; Fax: +64-3-479-8337.

Received: 17 March 2013; in revised form: 10 April 2013 / Accepted: / 11 April 2013

Published: 24 April 2013

\begin{abstract}
Young children being injured at home is a perennial problem. When parents of young children and family workers discussed what influenced parents' perceptions and responses to child injury risk at home, both "upstream" and "downstream" causal factors were identified. Among the former, complex and interactive facets of society and contemporary living emerged as potentially critical features. The "wicked problems" model arose from the need to find resolutions for complex problems in multidimensional environments and it proved a useful analogy for child injury. Designing dynamic strategies to provide resolutions to childhood injury, may address our over-dependence on 'tame solutions' that only deal with physical cause-and-effect relationships and which cannot address the complex interactive contexts in which young children are often injured.
\end{abstract}

Keywords: childhood; injury; parents; risk perception; social environment; qualitative research 


\section{Introduction}

Many young children are unintentionally injured in predictable and preventable events occurring at home, a place we think should be safe. Early childhood injury is a major and persistent international public health problem [1] and unintentional childhood injury at home is a significant contributor [2-5]. New Zealand (NZ) ranked a dismal 24th out of 24 rich OECD countries for rates of childhood injury death [6]. A retrospective analysis of injury data has shown that while $23 \%$ of NZ's $0-14$ year olds were aged $0-4$ years, this young group contributed $52 \%$ of the injury deaths and $35 \%$ of the injury hospitalizations for 0-14 years old [2]. Fifty-four percent of injury deaths and $53 \%$ of injury hospitalizations for the $0-4$ years old occurred at home (the majority of which were coded unintentional). In comparison, road traffic crashes contributed $29 \%$ of injury deaths and $4 \%$ of hospitalizations for this age group [2]. Lack of success in limiting childhood injury has continued, possibly due to the gap constantly noted between research and practice, but potentially also because child safety is a more complex problem than we have recognized and requires further analysis to obtain greater insight into how to design, develop and deliver strategies more effectively.

An examination of the descriptions of the circumstances of injuries indicated that around $20 \%$ of NZ early childhood home deaths could, theoretically, be prevented using proven passive interventions. The other $80 \%$ of injuries lie outside the operating range of these interventions. The rationale for prevention strategies used for many of the $80 \%$ is based on descriptive epidemiology, risk analyses, experience and intuition. Strategies are formally enacted through regulation, facilitated through government-funded safety programs, and informally disseminated through the generations, peers and the media. Proving success can be difficult, but potentially unsafe events may be serious for the child and the precautionary principle is invoked: do no harm, but where the child could be seriously harmed, doing nothing is not an option [7].

Passive interventions that do not rely on ongoing human action often operate at the regulatory level. Single causes of injury or a narrow band of circumstances are addressed by product or environmental modification or engineering. Some are not always effective. Proper swimming pool fencing separates the child from the hazard [8], but drownings still occur related to factors other than the physical environment. Events do not occur in isolation and the chains of events leading to children being injured may contain common circumstances regardless of the cause of injury. For example, a lack of active supervision, crowded households, cultural norms, housing conditions and living in deprived neighborhoods have been associated with child injury [9-11].

When examining childhood injury, researchers and practitioners bring different perspectives. For parents, injury prevention is usually a personal, family and peer-based experience while researchers often examine the population experience. The traditional epidemiological paradigm offers one set of research tools, but by using an ecological approach, alternative lenses may identify previously unrecognized factors for further examination. Examining the chains of events leading to a child injury or to protection from injury is likely to contribute to more effective designing and delivery of initiatives.

Katcher et al.'s list of home hazards includes a lack of supervision [4] and two aspects have been noted as being instrumental in reducing young children's exposure to injury risk: supervisors' perception of, and response to, the risk of child injury [12]. Longitudinal studies suggest there are 
"upstream" and "downstream" factors influencing risk perception and response [9,13]. Downstream factors relate to the individual and family social and physical environments, while upstream factors encompass broader societal factors, for example social expectations, income distribution, employment and changes in family forms.

Rittel and Webber's "wicked problems" model recognizes these multiple "messy" dimensions of interactive relationships between factors such as social environments, human interaction and politics $[14,15]$. The origins of the model lie in urban planning where increasingly complex issues were being faced by planners once simpler problems had been addressed. Contemporary expectations, philosophies, goals and values left a set of complex problems to define, set goals for and solve. The origin of the model parallels experiences in environmental health [15] and child safety. The wicked problem approach suggests that it is a mistake to try solving problems as engineers by focusing on a single cause and modifying its characteristics to remove the problem. Such "tame solutions" were not effective in resolving problems involving complex social factors and they considered it "morally objectionable" as well as impractical to not recognize "the inherent wickedness of social problems" (defined as "wicked in a meaning akin to that of "malignant" (in contrast to "benign") or "vicious" (like a circle) or "tricky" (like a leprechaun) or "aggressive" (like a lion, in contrast to the docility of a lamb)" [14]).

In this study, practitioners of child care (parents and those who work closely with young families) were asked - as legitimate and experienced observers and commentators - about the influences on perception of, and responses to, early childhood injury risk at home. This paper reports on a set of upstream themes that emerged from their narratives, and reflects on how these might affect the design and delivery of relevant strategies. While the modified Haddon's matrix offers a cause-specific analysis that encourages identification of upstream factors [16] it does not operate over the wider spectrum of injury events occurring at home. We apply the "wicked problems" framework to help interpret the findings [14].

\section{Methods}

Two closely linked research questions were framed, namely: what influences parents' perceptions of the risk of injury to a young child at home, and what influences parents' ability and willingness to respond appropriately to minimize that risk? The methodology chosen was an interpretive constructivist approach [17] which offered a good fit for focusing on these questions without predetermining content boundaries. This facilitated examining expected, common experiences and meanings, and unexpected or diverse views, beliefs and experiences of people who are actively involved in safety management for young children. An underlying question was the definition of injury and who defines and describes the problem. To date, the definition has predominantly been that of the epidemiologists. Their use of the data is different to that of hospital management wanting to know the "burden of injury" to prioritize resource allocation, which is different to that of clinicians working with the individual child or those in community assessing emergent issues. For example, counting injuries that "nearly happened" is not useful for the epidemiologist, whereas these events provide crucial learning tools for parents and those working with parents. 
The study was conducted in Hawke's Bay, New Zealand. Critical support was provided by people in the health sector and the advisory group (Te Roopu) established with local indigenous iwi (Māori tribe) and health providers. The region has a wide socioeconomic spread and a high Māori population (NZ/Aotearoa's indigenous people).

Two sets of participants were recruited. One comprised of health care professionals, home visitors, nannies, social workers and community educators (collectively referred to as family workers) from each of the local service providers who worked with young children and specifically included injury prevention as part of their practice. The management for each provider was approached, the invitation extended and a time negotiated for holding a focus group discussion with available staff. The second set of participants comprised parents of children $<5$ years old who had sought medical treatment for a home injury. Recruitment was undertaken by staff at the public hospital emergency department and the two urban medical centers where families commonly sought treatment. During the waiting or treatment time, the parent was invited to participate and those willing to do so provided contact details for the interviewers. Ethical approval was granted by the Central Regional Health and Disability Ethics Committee.

Eighteen individual interviews and six focus groups were conducted face-to-face. Interviews, which took about an hour, and focus group discussions, which took approximately two hours, were audio-recorded and transcribed. Parent interviews were held within two weeks of the injury incident to minimize loss of recall [18]. Interviews with Māori parents were conducted by an experienced Māori health worker, and other interviews were conducted by the first author who also facilitated the focus group discussions. A previously-piloted qualitative semi-structured interview with open-ended questions was used with both sets of participants [18]. All but one parent chose to meet at the child's home. Using responsive interviewing, a conversational exchange was created to foster a relationship so in depth information was obtained [19]. One parent interview was excluded from further analysis because it emerged during the interview that it was not a home injury.

The individual parent interviews began with the injury the child had sustained. Participants were encouraged to reflect on their own experience and that of peers and family, with prompts used when necessary to expand participants' explanations or commentary. The focus groups, with between two and eight participants, drew more on their professional experience for their discussion.

The narratives transcribed were independently coded deductively, with codes based on factors in the child injury prevention literature, and inductively, to create new themes, by the first author and a second researcher. The coding was agreed following negotiation of any differences. The themes identified were categorized into "upstream" and "downstream" influences, that is, those that were related to the individual and those that were related to the community or society more broadly [13]. The findings and themes were discussed with the health sector advisors, the service providers and Te Roopu.

With the complexity of the material gathered, possible models were considered for the upstream factors and Rittel and Webber's wicked problems model was chosen to frame the analysis [14]. Wicked problems have ten distinguishing features and these are discussed below. Briefly, wicked problems have no definitive formulation, no stopping rule and solutions are not true-or-false, but good-or-bad. They do not have an immediate or ultimate test for a solution, and their complexity means that solutions are a "one-shot operation" often without the opportunity to learn by trial-and-error. Each 
wicked problem is essentially unique but can be considered a symptom of another problem. The choice of explanation for discrepancies can be explained in numerous ways and will determine the nature of the resolution. Although not all apply equally well to child home safety, the features of model offered a "good fit" for the themes, which were also explored with reference to additional literature, often from outside injury prevention.

\section{Results}

Responses from family workers and parents are incorporated in the following exploration of the influences on parental perception of, and response to, injury risk to young children. Views differed, so while the themes have considerable common ground, where there are differences between the two sets of participants, these are noted. The findings from the narratives are presented in the following themes. The first two, fatigue and learning to parent safely, are ostensibly downstream factors. However, because they are influenced by a range of factors such as neighborhoods, governmental infrastructure, changes in community, social norms and expectations, income, employment, and the value of children in society, they provide a valuable starting point for examining upstream themes.

\subsection{Downstream Influences}

\subsubsection{Fatigue}

Parental fatigue influenced the perception of risk and the response to it. Continually interrupted sleep or lack of sleep, sometimes due to sick children, and often compounded by work or time commitments, resulted in sleep-deprived parents unable to make up for lost sleep. As one mother noted:

"There are times when I've put her on the floor and I lay down on the floor and then I've dozed off, ... [I'm] just so tired"' (mother in paid work).

Lack of sleep was considered likely to lead to poor judgment, including the anticipation of and response to the risk of injury. Experienced family workers suggested that chronic tiredness and stress could also lead to a mother becoming desensitized, and had serious implications for risk perception and response. Family workers also had concerns about fatigue in the context of abusive relationships or disadvantaged households:

"Sleep deprivation: when you've lost an hour's sleep here, you lose two hours' sleep tomorrow night, you lose an hour's sleep the next night-you don't catch up on Friday. If you keep doing that, and you've got to deal with an abusive partner, [and] you've got no money..." (family worker).

Being tired may be "part and parcel" of being a mother, but a number of participants thought contemporary mothers experience greater levels of tiredness than previous generations. While the level of manual labor of previous generations was acknowledged, possible current factors include being older (on average), and the demands generated by external schedules associated with paid work, the changing nature of the family and societal expectations. 
Fatigue was linked to parents working more paid hours than they would like. This affected professionals trying to maintain a career, which can include continuing to prove yourself in the workplace while managing a young family. It equally affected those in low paid employment, commonly with inflexible work hours or uncertain security that meant taking time off threatened their continuing employment but not taking time off was a threat to keeping young children safe.

\subsubsection{Learning to Parent Safely}

“Babies aren't cats or dogs or whatever that you chuck outside and leave for a couple of hours and they'll be OK' (mother with two children).

Parenting is a complex task and participants joked about a paid job being much easier, especially as parenting came "without a manual". A direct relationship was drawn between nurturing and understanding child development and perceiving and responding appropriately to children's injury risk. Safety involved knowing the child and actively supervising them, including anticipating the unexpected: "...you get in the mode of thinking about what could happen: even though sometimes it fails you" ( $\mathrm{A}$ mum). The time parents spent with the child was considered to influence their anticipation of a child's actions and the consequences. Less time with a child could mean that while parents perceived risks and removed them, they may be less experienced in managing risks likely to occur with their child's stage of development or temperament.

Family workers also saw repeated patterns of high risk when parents believed their child to be more capable than (s)he was and the child was expected to do as he was told, remember instructions, and comply with rules (a set of family "regulations" which many adults would find difficulty adhering to).

The quality of parent mentoring similarly influences perception and response to injury risk. Parents frequently identified members of their family particularly mothers, as mentors, also referring to early childhood services. Those working with families in disadvantaged environments identified difficulties upstream with gaps in the infrastructure for providing sufficient professionally trained home-based services negatively affecting parents' supervisory skills. Conversely, negative judgments on parenting skills can affect parents' confidence to make good safety decisions. This was one reason why the overabundance of parenting books on sale providing overwhelming, and sometimes conflicting, advice on parenting was considered unhelpful by so many of the participants. A number of participants opined that literate parents-to-be were a captive market for publishers.

Another conflict emerged between the public message, "injures are predictable and preventable" and medical professionals acceptance that unintentional injury does occur. Although apparently at odds, the pragmatic response of the latter was seen to enable parents, who knew the safety messages, to avoid being paralyzed by their failure to keep their child safe. 


\subsection{Upstream Influences}

\subsubsection{Changes in the Neighborhood}

Almost all participants remarked on the changing face of the community over time and saw the changes as influencing perception and response to injury risk:

"In the past] there were more people in the community. Drive down the street now, there's actually no one at home because everybody's out working... so it's quite different" (a suburban mother)

Childhood memories of ranging the neighborhood without parental constraint (and without harm) were recalled. Freedom and lack of harm may have been an illusion, as observant community members (the "nosy old lady") may have provided covert supervision, influencing some activity. However, communal responsibility has changed and participants perceived effects such as fewer informal minders present in neighborhoods, suspicion of outsiders watching children, less community trust, and more reluctance to be involved in other peoples' lives. A current phenomenon reported was families living in neighborhoods which were not "their" neighborhood because their social and recreational activities occurred elsewhere. Such disconnection was seen as potentially negative by some mothers because it could isolate the primary care-provider at home and did not provide a "yardstick" for normal child behavior or actual risk. The dominant discourse among participants was that protecting young children from serious harm was a community priority. An overt collective responsibility was a positive influence because it indicated that society took child safety seriously and that children being safe was the norm.

\subsubsection{Expectations and Norms}

Parental perception and response to risk is influenced by what constitutes an acceptable injury. It is unclear whether the threshold had changed over time, but family workers suggested that a reduction in family size and fewer children dying from communicable diseases, and increased assisted fertility, means that children may be seen as more precious (and costly), so that for some sectors of the population, greater care is exercised influencing current perceptions of and response to risk. Earlier generations may have been accepting of the long term consequences of injury, but this is not to say that less effort was expended in prevention. Many participants recalled that safety was a high priority for their parents and anything more serious than minor bruises and grazes was unacceptable.

Negative influences were raised, one being an increased tendency to blame someone else when your child is injured. Not negating the collective responsibility, an alternative view was that "blaming" was an example of parents not being actively engaged to anticipate risk for their child and responding appropriately.

Aspects of the changing norms over the last decade were thought to be negatively influential on parents' perceptions of child development and safety. Increasing patterns of unsafe behavior associated with alcohol by teenagers and young women were a major concern to family workers. These seriously impair young mothers' perceptions and responses to risks for their child. The continued marketing of pre-mixed fruity flavored alcoholic beverages and the lowering of the drinking age to 18 years were cited as having a very negative influence on child safety. 
A further negative influence noted was a perceived reduction in personal involvement as a parent with the child. Some participants suggested a lack of time or opportunity to learn to be a parent, or a lack of confidence in taking on the role. Many participants were vocal about society's negative expectations, seen through the media, reinforcing the "supermum" image. There was a sense that mothers especially were being judged and being 'failed' which was counter-productive to managing child safety.

"The bar's too high, you know. You gotta have perfect kids and perfect ... manners and, all those things. It's just constantly trying to strive to get that. And have the perfect family as well you know? The perfect car, to have them in the right school ... It's become such a competitive, stressful thing to have children" (a mother with two children).

\subsubsection{Income and Expenditure}

Two themes were identified in the narratives directly relating to income and expenditure. One was a recurring observation that our materialistic society was a negative influence on parents' managing risk and creating a safe environment for their children while the second was the negative effects of insufficient income.

Many participants feared that parenting was no longer a joy, but more of a "grind" than it had been in the past. This could be a symptom of the "me" generation, less willing to put the child first, having financial commitments, and a sense there are "... high expectations now, people are too greedy, want the big house and both parents work. [It's] not as simple as it used to be" (family worker). The "me" generation attitude, with the philosophy of self-first, was a particular characteristic of materialism that was seen as detrimental to child health and safety and spending time on the children would be in direct competition with personal time and purchasing power. Examples were given of parents at every income level, spending on themselves (clothes and alcohol) and on new "toys" (car, boat, television) but not on improving child safety. While cost might be a problem for some, it is used as an excuse for inaction. It was suggested that contemporary parents wanted to have the best of everything for themselves: jobs, income, and career. Earlier generations, particularly in the 1950s and 1960s were perceived as wanting to have, and do, the best for their children. Having no money did not prevent them from solving problems, and the ability to problem solve was seen as a positive influence for responding appropriately to risk.

Despite this ingenuity, it helps to have "resources [so] that you can buy your way out of problems" (family worker) and insufficient income is a negative influence on parents ability to control their environment, and therefore child safety. Parents and family workers raised the following concerns. Financial security is most unpredictable when a family is young and while home ownership may confer the right to make safety changes; many parents do not have discretionary money. For those in rental accommodation, the ability to control the environment can be much harder. Young families are often in rental accommodation, much of which is older stock. Some landlords are unwilling to make any improvement and some actively avoided making changes because that would require costly compliance with building regulations. Employment for some parents, especially in lower skilled jobs, does not pay sufficiently to support family life. The hours of work required to achieve a living wage, and the lack of flexibility in those hours are 
detrimental to family wellbeing and child safety. Although parents in professional positions are also under pressure, they were considered more likely to be able to negotiate or reorganize their time to be available for their children.

\subsubsection{Work-Life Balance}

Work-life balance was noted as an important influence on parental responses to child safety with positive and negative facets affecting their safety management. There are societal expectations that women will be in the paid workforce and an increasing norm that families need two incomes to make ends meet. Mothers' mental well-being, and therefore the safety of the child, was seen as being closely influenced by work-life balance. A few parents had deliberately opted to spend more time with their children by reducing their paid work hours, or taking leave:

"It's mostly about whether you want the money or whether you want the lifestyle and your kids. And for us it's much more important for us to be around and have the lifestyle with the kids really" (parent of three children).

These participants were more likely to describe the option as a luxury, a "perk" of the job; sometimes with the rider of being fortunate to have the choice, despite peers sometimes finding their choice inexplicable, not least because of the level of hard work being a full time parent demands. For others, however, there was no easy option. One mother needed to be working in her profession for her mental health, but no position was available. Another's partner worked away from home during weekdays leaving her sole parent. For a third, the family needed her income to survive, so it was immaterial that she wanted to be home. This situation was also thought common among lower paid women and was a problem for adequate child supervision and safety. In family workers' experience, women in unskilled positions had limited control over their working hours, the jobs were often casual so did not cover sick leave, and older siblings were left babysitting unsupervised.

\subsubsection{Value of Parents and Children}

The strength of the participants' observations that NZ society does not value its children was surprising. The lack of the following: parenting training, financial recompense for parenting, a living wage, acknowledgement of those who do a good job and adequate parental leave, conveyed the message that parenting was not important. Further undervaluation of children noted was the low pay for early childhood workers. Incentives in NZ policy that actively penalize mothers of young children who do not move into the paid workforce were also seen as potentially negative. Considerable value was seen in being part of the workforce, but requiring young mothers to take up unskilled work in preference to training and work that increased their parenting skills was seen to value the fiscal dollar over investing long term in parenting and greater child safety and another indication that parenting was not considered a legitimate job that contributed to the economy. 


\subsection{Analysis of Child Safety as a Wicked Problem}

The complexities identified in the participants' narratives, and subsequent analyses, are reflected in many of the ten features of the wicked problem which, therefore, offered a framework for exploring themes arising from the influences on parental perception of and response to the risk of child injury at home. These are presented in Table 1, followed by a discussion of key emergent themes for early childhood safety in light of current knowledge of upstream factors.

\section{Discussion}

The participants' narratives around influences on perception of and response to injury risk linked factors that affect early childhood safety with problems requiring solutions at a societal level. The following section draws links between participants' identification of the complex and interactive nature of these influences and factors identified in the literature.

Personal fatigue was a recurrent theme in this study, with participants noting as research has, that lack of sleep affects mental acuity, competence, aggression and the ability to make good judgment, all of which matter for child safety. Further complexity is introduced with fatigue as a symptom of depression [20], which has been linked to child injury [21]. Sleep disturbance among young children is associated with child injury $[22,23]$ and contributes to parental sleep deprivation. In addition, New Zealanders work comparatively long hours [24] so parents may feel "time-poor" and for women, long working hours combined with the "second shift" (unpaid hours of mothering and housework) may result in high levels of ongoing fatigue [25]. Maternal welfare suffers as mothers generally protect time with children at a cost to themselves [26] and mothers are having less sleep than is recommended for maintaining mental and physical health [26].

The child development literature supports participants' insistence that a caring, engaged and constant adult with whom the child can develop a relationship is important [27]. Measuring supervision is difficult [28,29], yet supervision is necessary in a caring relationship, and is beneficial to child safety [30-32]. Active supervision forms the "glue" of caring by a "conscientious parent" [33]. Tacit caring skills identified in other environments are attributes of such supervision: anticipating and defusing potential upsets, ensuring those unable to care for themselves are not left "hungry, angry, lonely or tired", having consistent and fair boundaries, and keeping everyone safe emotionally and physically [34].

The participants' observations on changes in family concurred with findings of a social gradient for child injury in NZ [35], concerns over older siblings' home responsibilities and the lack of mentoring for young supervisors [36,37]. Compared to earlier generations, a greater proportion of NZ marriages now end in divorce, single-parent families are increasing [38] and the median maternal age for the first baby has risen from 26.8 years in 1986 to 30.7 in 2006 for nuptial births. Fewer children are being born, but more children are born to lower compared to higher income households [39]. Families in NZ are relatively mobile and high housing costs contribute as people opt for cheap, poor-quality, rental housing. In the face of poverty, other families combine households which can increase overcrowding, a risk for child injury [40]. 


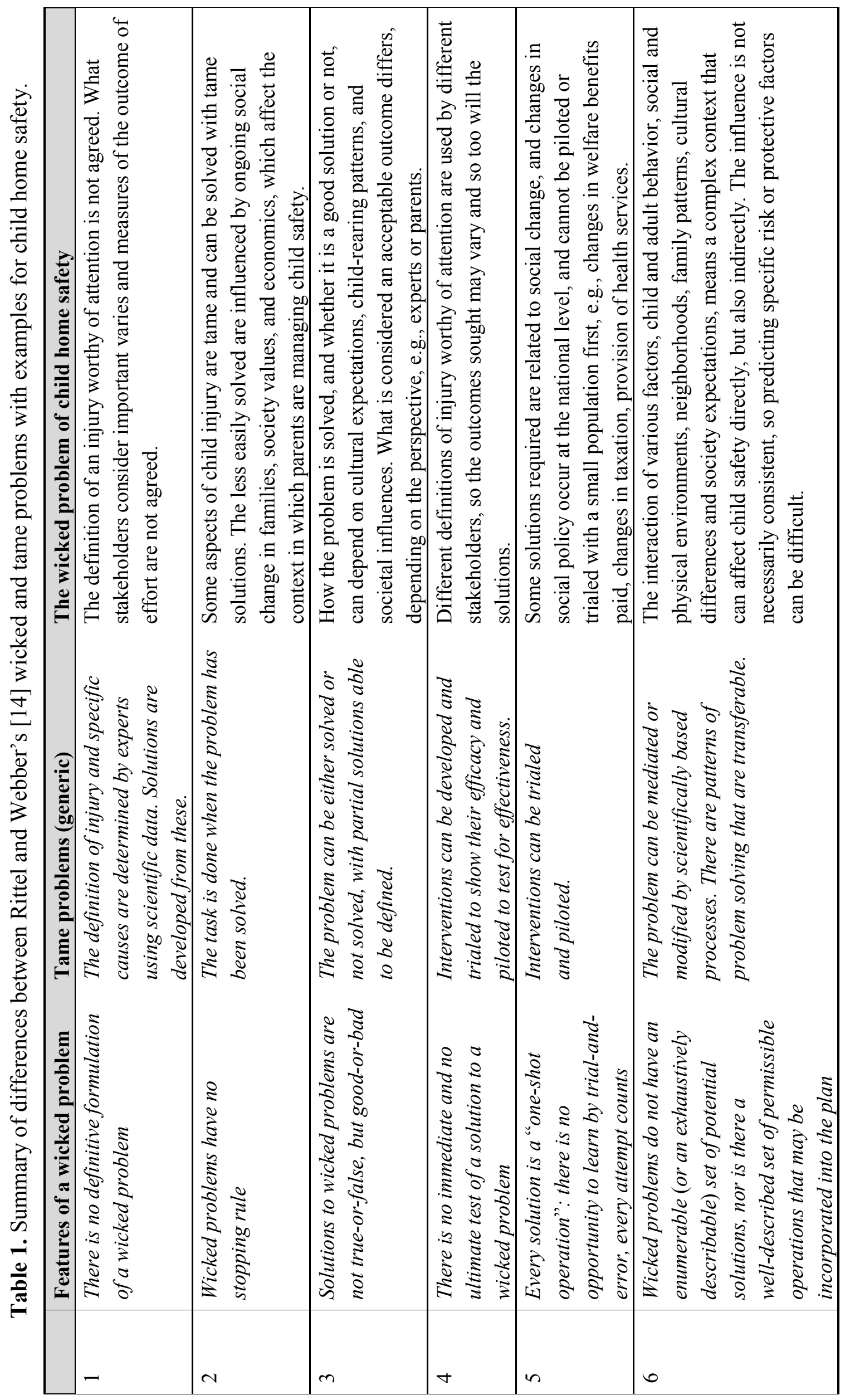




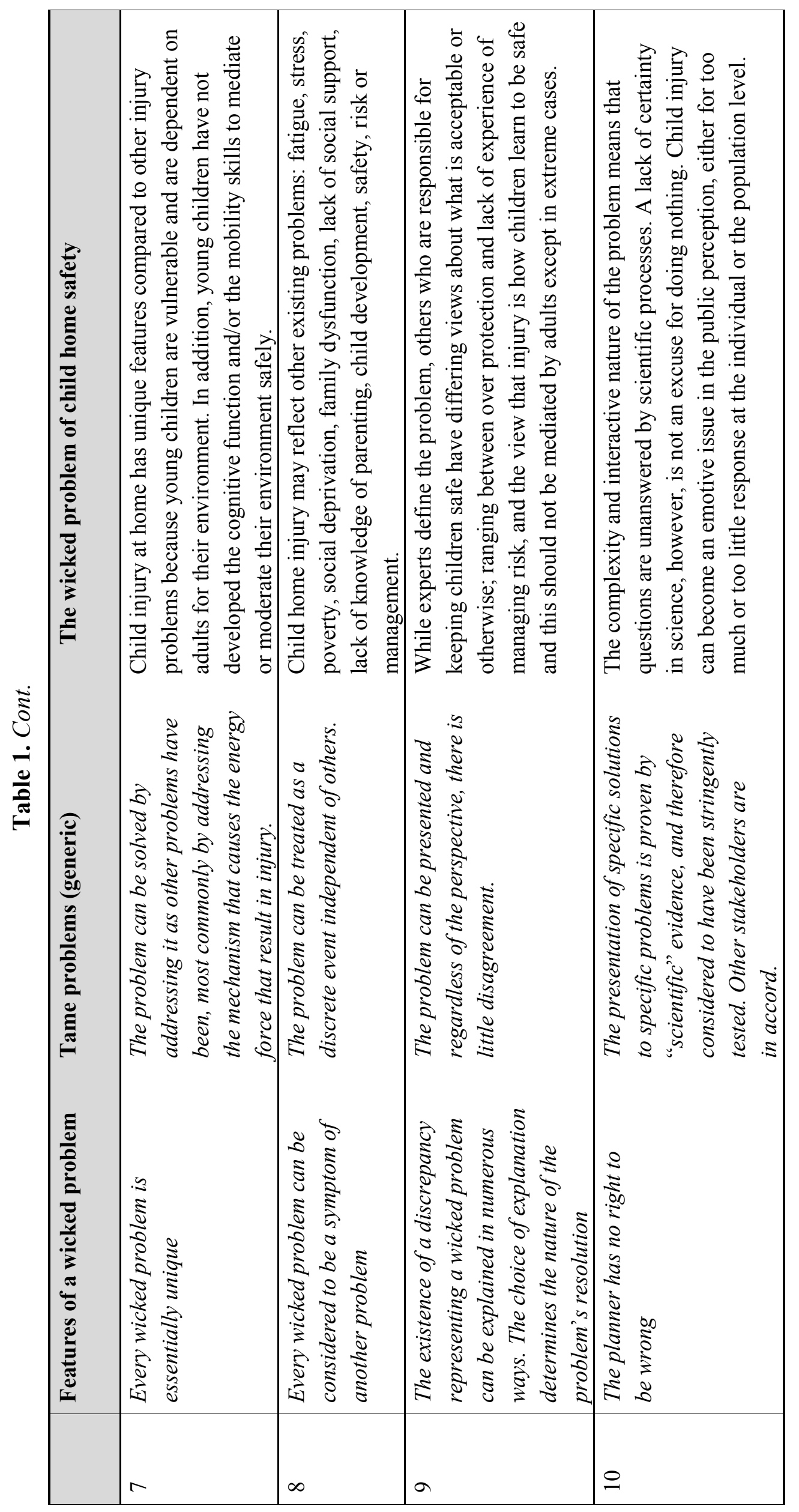


Participant narratives reflected concern about increasing disparity between the overworked and underworked and its implication for child safety, an observation shared by Australian academics:

"We have seen a growth in high-end jobs (mostly with very long hours), in low-end jobs (mostly with not enough hours) and in no jobs at all for a sizeable group of men who don't succeed in the formal education system. Very little of this is good news for children" [41].

Post World War II, NZ was considered an egalitarian society with good child health, and families commonly living on a single wage supplemented by a universal child benefit. Now housing costs are high and household survival often requires more than one income. Some assistance is available for low-paid employed parents and there is direct provision of services and early childcare, however, benefits are means-tested and not pegged to inflation (unlike superannuation for older people). Parental leave in NZ is 14 weeks, much less generous than Sweden (68 weeks) or the UK (39 weeks). The International Social Survey Programme conclusion that inequality rose faster in NZ than in most of the Western world [42], with more emphasis placed on "personal aspiration and responsibility, and less on collective well-being and support from the state" [43] supports participants' concerns about changing values and widening disparities. A large gap between rich and poor is evident in NZ [44] with a "large shift in income from low and middle-income groups to the highest income group" noted prior to 2000 [45]. Recent data show $20 \%$ of dependent children in NZ live in significant or severe hardship compared to $4 \%$ of those aged 65+ years [46] (these reports use international standardized categories for measuring relative poverty). Such inequalities impact on housing and child safety [47].

Traditional economic theory defined unpaid work, undertaken predominantly by women for their own families and households (providing food, maintaining the household, bringing up and keeping children safe, and caring for others) as "unproductive", and the role of parents, especially for women, is devalued [33,48]. Although seriously criticized for the inequity it supports [49], it appears to continue as an underlying assumption behind policy decisions, despite the estimated value of this unpaid work to NZ being of the order of $39 \%$ of gross domestic product [50].

Work-life balance has changed in recent decades [51] and Hakim's suggestion that most women prefer an adaptive lifestyle, combining work and home [52] fitted many of the participants' narratives. Women have increased control over fertility, paid work may be more flexible and employment is increasing, for example, in service industries where women are more likely to be employed [52]. However, the employment environment makes it harder for workers, both fathers and mothers, to be good parents [26,41,48]. Reduced job security and conditions do not support family life, and include casual contracts, longer hours and expectations that paid work will always come before family. NZ lacks recognition of young children's needs for health and safety: "Returning to work sooner than desired after having a baby, and working full-time rather than part-time, are consistent with women accommodating a job rather than the workplace accommodating mothers" [53]. "Institutional and structural factors" such as a reduction in the hours required to work, and recognition that career paths may be different for women than for men would be helpful [53]. 
Where to from Here?

Injury prevention moved away from "blaming the victim" prior to the 1970s, recognizing that victims were often unable to modify the unsafe features of their physical environment. The focus was on developing "tame solutions" which have generated successes. Human behavior still contributes to injury occurring and its prevention, and the value of employing behavioural sciences has been increasingly recognized [54]. Such approaches have been particularly useful in investigating the parent/child relationship associated with child injury [55]. What is in little evidence is the investigation of societal and systemic factors in the context of injury. One of the few is Hanson et al.'s [56] injury iceberg, which contributes to the recognition of social context [57].

Exploring the influences on child safety through the eyes of practitioners identified societal values and systemic issues. Typical of wicked problems, they do not operate independently, but do overlap with other dimensions of children's health. There would be considerable benefit in developing and utilizing collaborative strength to engage national decision makers on child safety.

Strengths of this study included the insights two critical sets of child safety informants provided and their accord with conclusions in other literature. Society influences how parents parent, and necessary change does not occur in isolation. Making the environment supportive for those caring for young children will be crucial. This study recognises the legitimacy of practitioners' voices and their ability to identify the complexities of influences that influence the exposure to risk of early childhood injury. Methodologically, the semi-structured schedule ensured the focus remained on child safety, while the open-ended, responsive data collection method meant informants were not restricted by accepted knowledge. There were limitations. Participation was voluntary which may have reduced the variety of voices. Few of the mothers were in full time employment and few were single parenting. Family workers' observations provided insights into their clients' lives, but these were not their clients' views. Participants' narratives did not have the benefit of a "kaupapa Māori" analysis so an important world view was not included.

While further thought is required to determine how to address these broader issues, this investigation must not be an excuse for doing nothing. Trialling a specific intervention to change how society perceives and values children will not be possible because, as a wicked problem "every solution is a "one-shot" operation there is no opportunity to learn by trial-and-error, every attempt counts". Complex action will be required to shift the focus in public policy and economic thinking to a position that actively seeks to foster child safety and wellbeing in all areas of government.

Positive actions would be to:

(a) Undertake child impact assessments for all proposed NZ legislation and policy development, and retrospectively for existing legislation and policy, specifically addressing child safety.

(b) Reorient underlying perceptions from children as a social cost, to children as an asset for society's future.

(c) Develop policy to increase job security for primary carers and institute a living wage to contribute to improving child safety by addressing low-paid employment, poverty and potentially the social gradient of child injury. 
(d) Adequately resource parenting programs proven to be effective cross-culturally to be accessible to parents and families. Additional resources may be needed to develop, deliver and evaluate effective programs to meet the needs of families for whom current systems do not work.

(e) Develop programs to train community health professionals to mentor and support parents and their extended families so they are competent care-providers.

\section{Conclusions}

New Zealand once prided itself on being an international leader in child health, but now lags behind in providing a safe place for children to live. Examining the problem through the eyes of those whose work involves keeping young children safe on a daily basis, has identified dimensions of the problem that have been missed and reprioritised aspects that have been accepted as norms. Reframing child safety as a wicked problem recognizes the potential relationships with other problems, as well as upstream factors including employment and income distribution, the changing nature of neighborhoods and families, work-life balance and the value of children in society. This is not to say that solutions such as swimming pool fencing or child resistant closures have not reduced child injury. However, unless the upstream influences on parents managing child safety are addressed, parents will continue to be victims of societal and systemic factors over which they have no control. Injury prevention has made considerable efforts to address the physical environment, but it is unlikely that resolutions will be achieved without challenging the societal factors that have been misdiagnosed, ignored or put in the "too hard basket".

\section{Acknowledgments}

The authors are indebted to the parents and family workers who shared their experience and observations so willingly. Thanks to Chrystal Jaye, Megan Morton, and Nandika Currey for their advice, hard work and assistance, to the University of Otago, and to the NZ Accident Compensation Corporation for funding the initial research undertaken in this study.

\section{References}

1. Peden, M.; Oyegbite, K.; Ozanne-Smith, J.; Hyder, A.A.; Branche, C.; Rahman, A.F.; Rivaram, F.; Bartolomeos, K. World Report on Child Injury Prevention; World Health Organization: Geneva, Switzerland, 2008.

2. Gulliver, P.; Dow, N.A.; Simpson, J.C. The epidemiology of home injuries to children under five years in New Zealand. Aust. New Zeal. J. Public Health 2005, 29, 29-34.

3. Sengoelge, M.; Bauer, R.; Laflamme, L. Unintentional child home injury incidence and patterns in six countries in Europe. Int. J. Inj. Contr. Saf. Promot. 2008, 15, 129-139.

4. Katcher, M.L.; Meister, A.N.; Sorkness, C.A.; Staresinic, A.G.; Pierce, S.E.; Goodman, B.M.; Peterson, N.M.; Hatfield, P.M.; Schirmer, J.A. Use of the modified Delphi technique to identify and rate home injury hazard risk and prevention methods for young children. Inj. Prev. 2006, 12, 189-194. 
5. Ramsay, L.J.; Moreton, G.; Gorman, D.R.; Blake, E.; Goh, D.; Elton, R.A.; Beattie, T.F. Unintentional home injury in preschool-aged children: Looking for the key-An exploration of the inter-relationship and relative importance of potential risk factors. Public Health 2003, 117, 404-411.

6. Child Poverty in Perspective: An Overview of Child Well-Being in Rich Countries; Unicef Innocenti Research Centre: Florence, Italy, 2007.

7. Pless, I.B. Expanding the precautionary principle. Inj. Prev. 2003, 9, 1-2.

8. National Committee for Injury Prevention and Control. Injury Prevention: Meeting the Challenge; Oxford University Press: New York, NY, USA, 1989.

9. Blakemore, T. Examining Potential Risk Factors, Pathways and Processes Associated with Childhood Injury in the Longitudinal Study of Australian children. Available online: http://www.fahcsia.gov.au/about/publicationsarticles/research/austsocialpolicy/Documents/a ustsocpolicy_2006/article2.htm (accessed on 17 March 2013).

10. Mulvaney, C.; Kendrick, D. Depressive symptoms in mothers of pre-school children: Effects of deprivation, social support, stress and neighbourhood social capital. Soc. Psychiatry Psychiatr. Epidemiol. 2005, 40, 202-208.

11. Haynes, R.; Reading, R.; Gale, S. Household and neighbourhood risks for injury to 5-14 years old children. Soc. Sci. Med. 2003, 57, 625-636.

12. Saluja, G.; Brenner, R.; Morrongiello, B.A.; Haynie, D.; Rivera, M.; Cheng, T.L. The role of supervision in child injury risk: Definition, conceptual and measurement issues. Inj. Control Saf. Promot. 2004, 11, 17-22.

13. McKinlay, J. A case for refocusing upstream: The political economy of illness. In Patients, Physicians and Illness: A Sourcebook in Behavioral Science and Health; Gartley, J., Ed.; Free Press: New York, NY, USA, 1979; pp. 9-25.

14. Rittel, H.W.J.; Webber, M.M. Dilemmas in a general theory of planning. Policy Sci. 1973, 4, 155-169.

15. Kreuter, M.W.; De Rosa, C.; Howze, E.H.; Baldwin, G.T. Understanding wicked problems: A key to advancing environmental health promotion. Health Educ. Behav. 2004, 31, 441-454.

16. Runyan, C.W. Introduction: Back to the future-Revisiting Haddon's conceptualization of injury epidemiology and prevention. Epidemiol. Rev. 2003, 25, 60-64.

17. Davidson, C.; Tolich, M. Social Science Research in New Zealand, 2nd ed.; Pearson Prentice Hall: Auckland, New Zealand, 2003.

18. Simpson, J.C.; Turnbull, B.L.; Ardagh, M.; Richardson, S. Child home injury prevention: Understanding the context of unintentional injuries to preschool children. Int. J. Inj. Contr. Saf. Promot. 2009, 16, 159-167.

19. Rubin, H.J.; Rubin, I.S. Qualitative Interviewing: The Art of Hearing Data, 2nd ed.; Sage Publications; Thousand Oaks, CA, USA, 2005.

20. Dennis, C.L.; Ross, L. Relationships among infant sleep patterns, maternal fatigue, and development of depressive symptomatology. Birth 2005, 32, 187-193.

21. Schwebel, D.C.; Brezausek, C.M. Chronic maternal depression and children's injury risk. J. Pediatr. Psychol. 2008, 33, 1108-1116. 
22. Owens, J.A.; Fernando, S.; McGuinn, M. Sleep disturbance and injury risk in young children. Behav. Sleep Med. 2005, 3, 18-31.

23. Schwebel, D.C.; Brezausek, C.M. Nocturnal awakenings and pediatric injury risk. J. Pediatr. Psychol. 2008, 33, 323-332.

24. Fursman, L. Finding Time: Parents' Long Working Hours and time Impact on Family Life. Available online: http://www.familiescommission.org.nz/publications/research-reports/findingtime (accessed on 17 March 2013).

25. Hochschild, A. The Second Shift: Working Parents and the Revolution at Home; Viking: New York, NY, USA, 1989.

26. Craig, L. Contemporary Motherhood: The Impact of Children on Adult Time; Ashgate: Hampshire, England, UK, 2007.

27. Leach, P.; Barnes, J.; Malmberg, L.; Sylva, K.; Stein, A. The quality of different types of child care at 10 and 18 months: A comparison between types and factors related to quality. Early Child Dev. Care 2008, 178, 177-209.

28. Petrass, L.A.; Finch, C.F.; Blitvich, J.D. Methodological approaches used to assess the relationship between parental supervision and child injury risk. Inj. Prev. 2009, 15, 132-138.

29. Morrongiello, B.A.; Corbett, M. The parent supervision attributes profile questionnaire: A measure of supervision relevant to children's risk of unintentional injury. Inj. Prev. 2006, $12,19-23$.

30. Morrongiello, B.A.; Corbett, M.; Brison, R.J. Identifying predictors of medically-attended injuries to young children: Do child or parent behavioural attributes matter? Inj. Prev. 2009, $15,220-225$.

31. Schwebel, D.C.; Kendrick, D. Caregiver supervision and injury risk for young children: Time to re-examine the issue. Inj. Prev. 2009, 15, 217-219.

32. Schwebel, D.C.; Klemencic, N.; Corbett, M. Interactions between child behavior patterns and parenting: Implications for children's unintentional injury risk. J. Pediatr. Psychol. 2004, 29, 93-104.

33. Crittenden, A. The Price of Motherhood; Metropolitan Books: New York, NY, USA, 2001.

34. Baines, D. Losing the "eyes in the back of our heads": Social service skills, lean caring, and violence. J. Soc. Soc. Welf. 2004, 31, 31-50.

35. Shaw, C. The Contribution of Causes of Death to Socioeconomic Inequalities in Child Mortality: New Zealand 1981-1999. Available online: http://journal.nzma.org.nz/journal/1181227/1779/ (accessed on 17 March 2013).

36. Harre, N.; Coveney, A. School-based scalds prevention: Reaching children and their families. Health Educ. Res. 2000, 15, 191-202.

37. Willis, K.E.; Tanz, R.R.; Christoffel, K.; Schofer, J.L.; Lavigne, J.V.; Donovan, M.; Kalangis, K. Supervision in childhood injury cases: A reliable taxonomy. Accid. Anal. Prev. 1997, 29, 133-137.

38. Ministry of Social Development. New Zealand Families Today: A Briefing for the Families Commission. Available online: http://www.msd.govt.nz/about-msd-and-our-work/publications -resources/research/nz-families-today/index.html (accessed on 17 March 2013).

39. Zealand, S.N. NZ Statistics. 2010. Available online: http://www.stats.govt.nz (accessed on 17 March 2013). 
40. Moore, A. Changing patterns of childhood mortality in Wolverhampton. Arch. Dis. Child. 2005, 90, 687-691.

41. Stanley, F.; Richardson, S.; Prior, M. Children of the Lucky Country? MacMillan: Sydney, Australia, 2005.

42. Gendall, P.; Murray, N. Social inequality in New Zealand: International Social Survey Programme. Te Kunenga ki Pürehuroa, 2010. Available online: http://www.massey.ac.nz/massey/ $\mathrm{fms} / /$ Massey\%20News/2010/03/docs/Social-Inequality-2009.pdf (accessed on 17 March 2013).

43. Gendall, P. All things being equal. New Zeal. Listener 2010, 223, 3651.

44. Wilkinson, R.; Pickett, K. The Spirit Level: Why More Equal Societies Almost Always do Better; Allen Lane: London, UK, 2009.

45. Child Poverty Action Group, Our children: The Priority for Policy 2001. Available online: http://www.cpag.org.nz/assets/Publications/OC.2003.pdf (accessed on 17 March 2013).

46. Perry, B. Non-Income Measures of Material Wellbeing and Hardship: First Results from the 2008 New Zealand Living Standards Survey, with International Comparisons. 2009. Available online: http://www.msd.govt.nz/about-msd-and-our-work/publications-resources/ monitoring/living-standards/living-standards-2008.html (accessed on 17 March 2013).

47. Keall, M.D.; Baker, M.; Howden-Chapman, P.; Cunningham, M. Association between the number of home injury hazards and home injury. Accid. Anal. Prev. 2008, 40, 887-893.

48. Manne, A. Motherhood: How Should We Care for Our Children? Allen \& Unwin: Sydney, Australia, 2005.

49. Waring, M. Counting for Nothing: What Men Value and What Women are Worth; Allen \& Unwin: Wellington, New Zealand, 1988.

50. Statistics, N.Z. Around the Clock: Findings from the New Zealand Time Use Survey 1998-99; Social Policy Division of Statistics New Zealand: Wellington, New Zealand, 2001. Available online: http://www.stats.govt.nz/browse_for_stats/people_and_communities/time_use/aroundthe-clock-from-nz-time-use-survey.aspx (accessed on 17 March 2013).

51. Crompton, R. Employment, flexible working and the family. Br. J. Sociol. 2002, 53, 537-558.

52. Hakim, C. Lifestyle preferences as determinants of women's differentiated labor market careers. Work Occup. 2002, 29, 428-459.

53. McPherson, M. New Zealand Cultural Norms of Parenting and Childcare and How These Relate to Labour Force Participation Decision and Requirements; Families Commission: Wellington, New Zealand, 2006. Available online: http://www.familiescommission. org.nz/publications/research-reports/new-zealand-cultural-norms-of-parenting-and-childcare (accessed on 17 March 2013).

54. Trifiletti, L.B.; Gielen, A.C.; Sleet, D.A.; Hopkins, K. Behavioral and social sciences theories and models: Are they used in unintentional injury prevention research? Health Educ. Res. 2005, 20, 298-307.

55. Schwebel, D.C.; Gaines, J. Pediatric unintentional injury: Behavioral risk factors and implications for prevention. J. Dev. Beh. Peds. 2007, 28, 245-254.

56. Hanson, D.; Hanson, J.; Vardon, P.; McFarlane, K.; Lloyd, J.; Muller, R.; Durrheim, D. The injury iceberg: An ecological approach to planning community safety interventions. Health Promot. J. Aust. 2005, 16, 5-10. 
57. Green, L.W.; Kreuter, M.W. Health Program Planning: An Educational and Ecological Approach, 4th ed.; Green, L.W., Kreuter, M.W., Eds.; McGraw-Hill: New York, NY, USA, 2005; pp. 1-458. 
MDPI AG

Klybeckstrasse 64

4057 Basel, Switzerland

Tel. +41616837734

Fax +41613028918

http://www.mdpi.com/

IJERPH Editorial Office

E-Mail: ijerph@mdpi.com

http://www.mdpi.com/journal/ijerph 


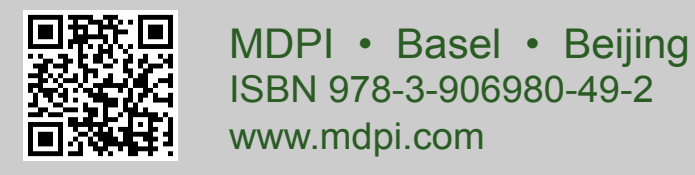

